\title{
Left Bundle Branch Block
}

Controversies in Aortic Valve Interventions and Cardiac Resynchronization Therapy

Patrick Houthuizen 


\title{
Stellingen behorende bij het proefschrift
}

\author{
Left Bundle Branch Block \\ Controversies in Aortic Valve Interventions \\ and Cardiac Resynchronization Therapy
}

1. Het linker bundeltak blok (LBBB) dat ontstaat na een transcatheter aortaklep implantatie (TAVI) is een frequent voorkomende en ernstige postoperatieve complicatie (dit proefschrift).

2. Het TAVI-geïnduceerd LBBB ontstaat vrijwel altijd vóór ontslag uit het ziekenhuis en verdwijnt spontaan in een derde van de gevallen. (dit proefschrift).

3. Het optreden van LBBB na aortaklep interventies wordt sterk bepaald door de toegepaste techniek, de gebruikte klepprothese en de ervaring van de implanterend arts. Deze factoren dienen voor elke patiënt in overweging genomen te worden bij de keuze van het type interventie (dit proefschrift).

4. Cardiale resynchronisatie therapie dient overwogen te worden bij patiënten met een persisterend linker bundeltak blok na aortaklep interventies (dit proefschrift).

5. Alhoewel zwart-wit, voegt de echocardiografie kleur toe aan de dagelijkse cardiologische praktijk.

6. Het gebruik van spreadsheet programma's als database voor wetenschappelijke doeleinden dient ten stelligste ontraden te worden.

7. Bij het rapporteren van kwaliteit van zorg, worden te weinig eisen gesteld aan de kwaliteit van de verzamelde data. Echter, ook hier geldt "Rubbish in, rubbish out".

8. Les in bescheidenheid zou deel moeten uitmaken van de kerncompetentie "Communicatie" in de opleiding tot cardioloog.

9. Ons huidig economisch model en onze gebrekkige lange-termijn visie vormen een rechtstreekse bedreiging voor ons voortbestaan.

10. Hoe veel te meer ge er van weet, hoe veel te meer ge weet dat ge te weinig weet (Steve Stevaert).

11. Je kinderen zijn je carrière (Paula Houthuizen). 


\section{Left Bundle Branch Block}

Controversies in Aortic Valve Interventions and Cardiac Resynchronization Therapy 
(c) Patrick Houthuizen, Maastricht 2014

ISBN 9789461593283

Productie: P. Houthuizen \& Datawyse | Universitaire Pers Maastricht 


\title{
Left Bundle Branch Block
}

\section{Controversies in Aortic Valve Interventions and Cardiac Resynchronization Therapy}

\author{
PROEFSCHRIFT
}

ter verkrijging van de graad van doctor aan de Universiteit Maastricht, op gezag van de Rector Magnificus, Prof. dr. L.L.G. Soete volgens het besluit van het College van Decanen, in het openbaar te verdedigen

op woensdag 11 juni 2014 om 14:00 uur

door

Patrick Houthuizen 


\section{Promotoren}

Prof. dr. F.W. Prinzen

Prof. dr. P. de Jaegere (Erasmus Universiteit Rotterdam)

\section{Copromotor}

Dr. L.M. van Gelder (Catharina ziekenhuis Eindhoven)

\section{Beoordelingscommissie}

Prof. dr. T. Delhaas (voorzitter)

Prof. dr. H.J.G.M. Crijns

Prof. dr. B. Mochtar

Prof. dr. J.W.M.G. Widdershoven (Tilburg University)

Prof. dr. F. Zijlstra (Erasmus Universiteit Rotterdam)
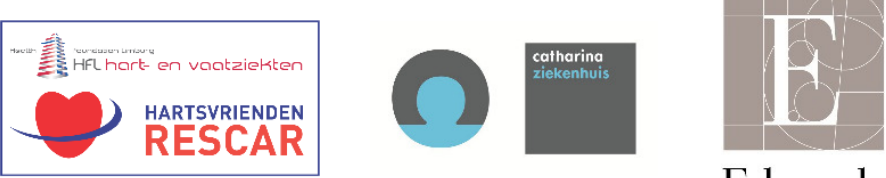

\section{Edwards}

\section{\# St.Jude Medicac $[$ medecs]}

Deze publicatie werd mede mogelijk gemaakt dankzij de financiële steun van:

Stichting Hartsvrienden RESCAR, Catharina ziekenhuis Eindhoven, Edwards Lifesciences B.V., St-Jude Medical Nederland B.V. en Medecs B.V. 
Niets blijft meer heel Als van binnen alles breekt

Frank Boeijen Jazz in Barcelona 



\section{Table of Contents}

1. Introduction

Part 1: Controversies in aortic valve interventions

2. Left Bundle-Branch Block Induced by Transcatheter Aortic Valve Implantation Increases Risk of Death

3. Occurrence, Fate and Consequences of Ventricular Conduction Abnormalities after Transcatheter Aortic Valve Implantation

4. Trends in the Occurrence of New Left Bundle Branch Block after Transcatheter Aortic Valve Implantation

5. Frequency and Long-Term Prognosis of New Left Bundle Branch Block Induced by Surgical Aortic Valve Replacement

6. Postoperative Conduction Disorders after Implantation of the Self99 Expandable Sutureless Perceval S Bioprosthesis

\section{Part 2: Controversies in cardiac resynchronization therapy}

7. Atrioventricular and Interventricular Delay Optimization in Cardiac Resynchronization: Physiological Principles and Overview of Available Methods

8. Baseline Left Ventricular $\mathrm{dP} / \mathrm{dt}_{\max }$ rather than the Acute Improvement in $\mathrm{dP} / \mathrm{dt}_{\max }$ Predicts Clinical Outcome in Patients with Cardiac Resynchronization Therapy

9. General Discussion

Addendum

Summary 185

Samenvatting

Dankwoord

Curriculum Vitae

List of Publications

Abbrevations 



\section{CHAPTER 1 \\ Introduction}





\section{Introduction}

The heart, as a complex organ, is capable to maintain blood supply to the body under varying physiological circumstances. To do so, a coordinated contraction sequence of the ventricles is required, which is facilitated by rapid activation via a specialized conduction system of which the right and left bundle branches are the main constituents. An important disorder of the ventricular conduction system is left bundle branch block (LBBB). In a heart with LBBB, activation of the left ventricle (LV) is no longer achieved through the conduction system, but by much slower myocyte-to-myocyte conduction. As a consequence, this type of activation results in a delayed activation of the LV. This thesis investigates the importance of LBBB in relation to different aortic valve repair procedures and in relation to cardiac resynchronization therapy (CRT).

\section{Historical controversies of left bundle branch block}

Although LBBB is an important conduction disorder, there has been a major controversy about its diagnosis from the electrocardiogram (ECG). The early concepts of its pathophysiology date back to the beginning of the twentieth century along with Einthoven's development of the string galvanometer. ${ }^{1}$ In 1910, Eppinger and Rothberger were the first to induce left and right bundle branch block in a canine heart model by division of the respective bundle branches (Figure 1). Based on a single ano-oesophageal lead ECG, they described the changes to morphology and duration of the QRScomplex. ${ }^{2}$ By comparison of the ECG of patients, these results were extrapolated to the human heart thereby neglecting the effects of differences in chest anatomy and position of the heart as well as the specific properties of the distinctive ano-oesophagal lead. ${ }^{3}$ This resulted in a persistent and erroneous transposition of LBBB and right bundle branch block (RBBB). This confusion has been maintained not the least by Lewis, even despite growing criticism of his contemporaries. ${ }^{1}$ Although Fahr was the first to draw attention to the transposition, 4 it was not until the early 1930s that the misinterpretation was finally acknowledged by Barker, Macleod and Alexander. ${ }^{5}$

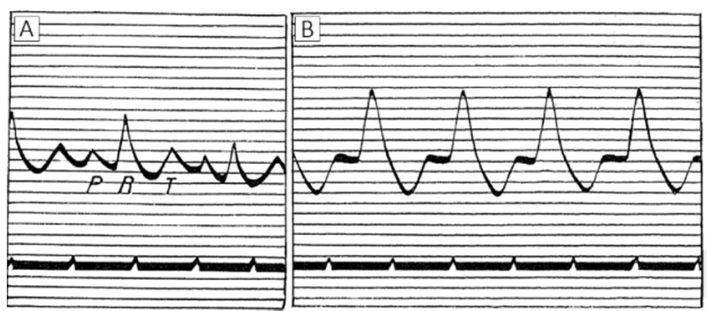

Figure 1. Single ano-esophagal lead electrocardiogram recordings of the first experimental left bundle branch block.

After mechanical division of the left bundle branch, the QRS complex of the baseline electrocardiogram (panel A) abruptly changes in duration and voltage (panel B). From Eppinger and Rothberger. Klin Med; 1910: 70: 1-20. 


\section{Functional anatomy of the conduction system}

The ventricular conduction system starts in the atrioventricular (AV) node. This node is located deep within the interatrial septum in proximity of the septal tricuspidal valve leaflet, coronary sinus and Eustachian valve. It penetrates the membraneous interventricular septum to continue as the His bundle which in turn give rise to the fascicles of the left bundle branch at the crest of the muscular ventricular septum. The bundle is in close proximity of the interleaflet triangle of non- and right-coronary cusp of the aortic valve (Figure 2).6,7 The left bundle branch first runs as a ribbonlike structure under the septal endocardium in order to separate into a narrow anterior fascicle, a broader and earlier branching posterior fascicle and often septal radiations which can have heterogeneous patterns. ${ }^{8-11}$

In the healthy heart, rapid conduction of the electrical impulse from the AV node through the His bundle, bundle branches and the Purkinje system activates the whole left ventricle $\mathrm{LV}$ within 60-80 milliseconds (msec). Ventricular activation proceeds from subendocardially located exit points of the bundle branches to the epicardium in a centrifugal and tangential direction..$^{12,13}$

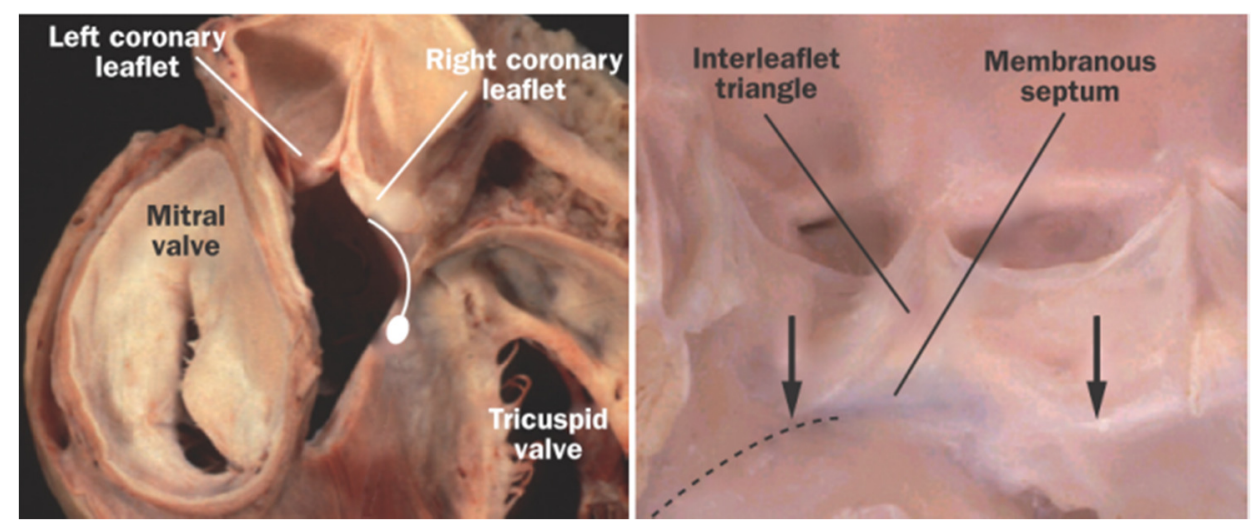

Figure 2. Anatomy of the atrioventricular conduction system.

The left panel shows a superior view of the heart after removal of both atria and the aortic non-coronary cusp. It shows the atrioventricular node that gives rise to the His bundle. In an opened aortic root view from the left ventricle (right panel) the close relationship of the His bundle and left bundle branch (broken black line) is visible. Adapted from van der Boon et al. Nat Rev Cardiol 2012; 9(8) :1-10, with permission.

\section{Electrocardiographic diagnosis of left bundle branch block}

Historically, a QRS-duration $\geq 120$ msec is required for the diagnosis of LBBB, however this threshold has been achieved as a result of extrapolation from experimental canine data. It further is merely a pragmatic choice, as it is easy to read from the conventional ECG where it equals $3 \mathrm{~mm}$ at a recording speed of $25 \mathrm{~mm} / \mathrm{s}$. Already in 
1965, Grant and Dodge published a study of 128 patients with a QRS-duration $\geq 120$ msec and a previously normal QRS complex. By comparison of both ECG's they concluded that, in LBBB, the average QRS-prolongation was 50 to $60 \mathrm{msec}$. In up to one third of the cases, the prolongation was even 70 msec. $^{14}$ This assessment is logically sound, as right-to-left septal activation in LBBB requires $40 \mathrm{msec}$ after which it takes $50 \mathrm{msec}$ to reach the posterolateral wall and another $50 \mathrm{msec}$ to completely activate the posterolateral wall (Figure 3). In the paper of the Ad Hoc Working Group of the World Health Organization and International Society and Federation of Cardiology in 1985, Willems et al. already acknowledged the former by stating that "the QRSduration usually exceeds $140 \mathrm{msec}$ in most patients with complete bundle branch block". Surprisingly, in their criteria for diagnosing LBBB, the threshold value of 120 msec was persevered. ${ }^{9}$

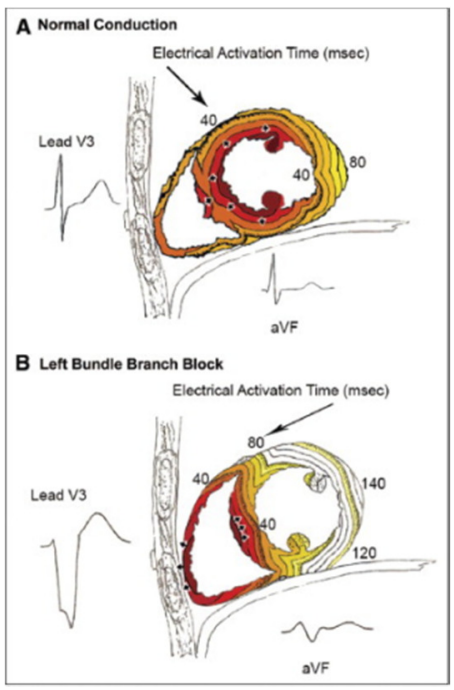

Figure 3. Total activation time of the left ventricle. In the left pane, it can be appreciated that total electrical activation time of the left ventricle is $80 \mathrm{msec}$ with a leftto-right septal activation. In left bundle branch block on contrary (right pane), the right ventricle is activated first and it takes approximately 40-50 msec before the left ventricular endocardium is activated (right-to-left septal activation). Subsequently, the activation front progresses in another $50 \mathrm{msec}$ to re-entry into the Purkinje network followed by $40 \mathrm{msec}$ time to activate the posterolateral wall. Each color line represents successive $10 \mathrm{msec}$. Adapted from Strauss et al. Am J Cardiol 2012; 107 (6): 927-934, with permission.

In more recent years, the importance of differentiating true LBBB from more diffuse intravascular conduction delays has gained importance due to the application of cardiac resynchronization therapy (CRT). Several studies have demonstrated that the likelihood of CRT-response is dependent on QRS morphology and duration. In fact, the highest response rates have been described in patients with LBBB morphology and/or QRS-duration $\geq 150$ msec. The Comparison of Medical Therapy, Pacing and Defibrillation in Heart Failure (COMPANION) trial randomized patients with advanced heart failure (New York Heart Association (NYHA) class III or IV) to optimal medical therapy alone or combined with CRT-P(acemaker) or CRT-D(efibrillator). Patients with a QRS-duration $\leq 147$ msec did not benefit from CRT compared with optimal medical therapy alone. In the Multicenter Automatic Defibrillation Implantation Trial - Cardiac Resynchronization Therapy (MADIT-CRT), heart failure patients with NYHA class I or II were randomized to CRT-D or intracardiac defibrillator 
(ICD) therapy. A subgroup analysis categorized patients into LBBB or non-LBBB based on QRS-morphology and -duration with a cut-off value of $\geq 130 \mathrm{msec}$. It was found that only LBBB patients demonstrated a significant reduction in the primary endpoint of heart failure events or death when comparing CRT-D with ICD therapy. ${ }^{15}$ Based on these results and in conjunction with the previous arguments, Strauss et al. proposed a contemporary definition of LBBB using a threshold in QRS-duration of $130 \mathrm{msec}$ for women and $140 \mathrm{msec}$ for men. ${ }^{16}$ Nevertheless, the most recent guidelines of both the European Society of Cardiology (ESC) and American Heart Association (AHA) stick to a QRS-duration $\geq 120 \mathrm{msec}$ for the diagnosis of LBBB (Table 1). ${ }^{17}$ Some large clinical trials investigating LBBB as a predictor of effective CRT even used more simplified criteria and defined LBBB as a V1-negative QRS-complex of more than $120-130$ msec in the absence of Q-waves in the lateral leads. ${ }^{15,18}$

Table 1. Criteria for the diagnosis of left bundle branch block.

Current LBBB criteria of the European Society of Cardiology (ESC) and American Heart Association (AHA) are summarized in the two left columns. Contemporary criteria, as proposed by Strauss et al, are viewed in the right column. Adapted from van Deursen et al. J Electrocardiol 2014; 47 (2): 202-211, with permission.

\begin{tabular}{lccc}
\hline & ESC guidelines $^{19}$ & AHA guidelines $^{17}$ & Strauss criteria $^{16}$ \\
\hline QRS-duration & $\geq 120 \mathrm{msec}$ & $\geq 120 \mathrm{msec}$ & $\begin{array}{c}\geq 130 \mathrm{msec} \text { (female) } \\
\geq 140 \mathrm{msec} \text { (male) }\end{array}$ \\
QS or rS & $\mathrm{V}_{1}$ & $\mathrm{~V}_{1}$ & $\mathrm{~V}_{1}, \mathrm{~V}_{2}$ \\
positive T-wave & $\mathrm{V}_{1}$ & - & - \\
normal intrinsicoid deflection $(<60 \mathrm{msec})$ & - & $\mathrm{V}_{1}-\mathrm{V}_{3}$ & - \\
delayed intrinsicoid deflection $(\geq 60 \mathrm{msec})$ & $\mathrm{I}, \mathrm{V}_{6}$ & $\mathrm{~V}_{5}, \mathrm{~V}_{6}$ & - \\
notched or slurred R & - & $\mathrm{I}_{6}, \mathrm{aV}_{\mathrm{L}}, \mathrm{V}_{5}$ and $\mathrm{V}_{6}$ & - \\
mid-QRS notching/slurring $(\geq 2$ leads $)$ & - & - & $\mathrm{V}_{1}, \mathrm{~V}_{2}, \mathrm{I}, \mathrm{aV} \mathrm{L}, \mathrm{V}_{5}, \mathrm{~V}_{6}$, \\
RS pattern in $\mathrm{V}_{5}, \mathrm{~V}_{6}$ allowed & no & yes & yes \\
Q-waves I, $\mathrm{V}_{5}, \mathrm{~V}_{6}$ & - & not allowed & allowed \\
QS with positive T-wave & aV & - & - \\
usually discordant T-wave & all leads & all leads & - \\
\hline
\end{tabular}

\section{Pathophysiology of left bundle branch block}

In the clinical setting it is not clear whether LBBB is an epiphenomenon rather than a causal factor in heart failure. In contrast, there is ample evidence in experimental literature that the electrical dyssynchrony caused by LBBB results in left ventricular remodeling and worsening of pump function. The induction of a proximal LBBB by radiofrequent ablation of the basal septum in a canine heart model, results in immediate and persistent changes in both septal and lateral LV wall. Acutely after induction of LBBB, a decreased septal strain is observed in combination with an increased lateral strain with corresponding changes in external work and myocardial blood 
flow. These changes result in LV remodeling in the long run with progressive left ventricular dilation and decreasing ejection fraction (Figure 4). ${ }^{20,21}$ The mechanical dyssynchrony induced by LBBB can be visualized by both conventional M-mode echocardiography as well as by advanced imaging techniques like speckle tracking echocardiography. Figure 5 demonstrates the typical ultrasound image of a LBBB contraction pattern. In time, the septal wall is the first to contract, even before the actual aortic valve opening; this contraction therefore hardly contributes to the ejection of blood. The septal contraction stretches the still passive LV lateral wall. Around the time of aortic valve opening, the lateral wall starts to contract rather forcefully because of the earlier stretching (Frank-Starling mechanism). As a result of this contraction, shortening of the septal muscle fibers is interrupted and turned into the socalled septal-rebound stretch. ${ }^{22}$ To recapitulate, the LBBB strain pattern is characterized by a dyssynchronous LV activation causing the septal and lateral wall to pull at each other resulting in waste of energy.
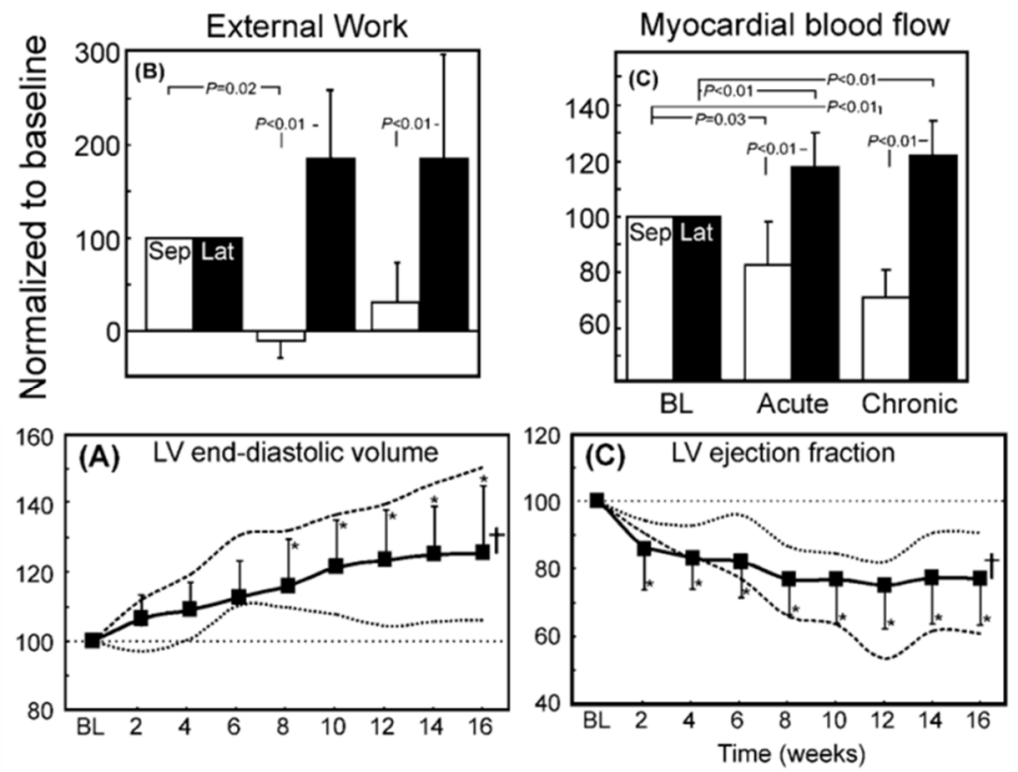

Figure 4. Physiological effects of a proximal left bundle branch block in a canine heart model.

Immediately after the induction of a proximal left bundle branch block in a canine heart model, there is a significant decrease in external work and myocardial bloodflow in the septal wall, compared to an increase in the lateral wall. As a results of the electrical and mechanical dyssynchrony, the left ventricular enddiastolic volume increases progressively with a decrease in ejection fraction. Adapted from Vernooy et al. Eur Heart J 2005; 26 (1) :91-98, with permission.

In humans, these progressive pathophysiological effects of LBBB are more difficult to examine as the onset of LBBB is often a silent event. Still, by comparing 18 patients with LBBB in absence of cardiac disease with 10 healthy controls, Grines et al. were able to describe the electrical and hemodynamic characteristics of LBBB and its effect 
on interventricular synchrony. They demonstrated that LBBB patients exhibited larger LV systolic dimensions and reduced fractional shortening. ${ }^{23}$ More recently, Lee et al. performed a retrospective analysis of 51 patients with prolonged QRS-duration (of whom 41\% with LBBB) in which they demonstrated a progressive reduction in $L V$ ejection fraction (LVEF) in patients with LBBB. ${ }^{24}$ Although these studies provide some insight in the effects of LBBB, prospective studies evaluating the pathophysiological changes of newly acquired LBBB are obviously lacking. However, the activation sequence of right ventricular (RV) pacing is very similar to that of LBBB and can therefore serve as a valuable surrogate. ${ }^{25}$ From this perspective, the Dual Chamber and VVI Implantable Defibrillator (DAVID) trial showed highly important data. In this study, patients with a LVEF $\leq 40 \%$ and indication for ICD therapy who were randomized to dual-chamber rate responsive pacing at 70 beats per minute (bpm) had significantly more heart failure hospitalizations than patients randomized to ventricular backup pacing at $40 \mathrm{bpm}^{26}$ Similarly, in patients with sinus node disease and preserved ejection fraction, the risk of heart failure hospitalization was proportional to the percentage of cumulative right ventricular pacing as has been demonstrated in a subanalysis of the Mode Selection Trial (MOST). ${ }^{27}$

Finally, data from CRT-related research support the hypothesis that LBBB is the causal factor of LV dysfunction. Indeed, by treating the electrical dyssynchrony alone, CRT is able to induce LV reverse remodeling with improvement in LV function, reduction in heart failure symptoms and ultimately mortality. ${ }^{28-31}$ This is also supported by experimental research, showing that biventricular pacing reverses global and regional functional and structural abnormalities in a canine LBBB heart model. ${ }^{32}$ 


\section{Left bundle branch block as a risk factor for cardiovascular morbidity and mortality}

In the second half of the past century, a wealth of literature has been published on the prognostic significance of LBBB. In those times, the interest in LBBB was mainly the result of the emerging application of the ECG as a screening tool in a varying study population. This was especially the case for LBBB in an apparently healthy population (e.g. airforce crew members ${ }^{33-35}$ and people applying for a life insurance ${ }^{36}$ ). Not surprisingly, the clinical significance of LBBB became subject of debate. In general, the majority of studies do find a strong association between LBBB and cardiovascular disease, more specific hypertension, cardiomegaly, coronary artery disease and heart failure. ${ }^{34,37-43}$ The prevalence of LBBB is far below $0.5 \%$ in healthy, young individuals and increases up to $25 \%$ in patients with chronic heart failure. $33-35,44$ In terms of mortality, outcome is obviously dependent on the population studied with apparent conflicting results (Table 2). Most of these studies, however, did not distinguish newly acquired from pre-existing LBBB nor did they have adequate control groups. The first population-based prospective study to overcome these flaws, was the Framingham Study. In that study, during a follow-up of 18 years, 55 people developed a new LBBB of whom only $11 \%$ remained free from cardiovascular disease. Also, within 10 years after onset of LBBB, $50 \%$ of these patients had died from cardiovascular abnormalities compared to only $12 \%$ of an age- and gender-matched control population. ${ }^{38}$ Also, in patients with acute or chronic coronary artery disease and in patients with chronic heart failure, LBBB is an independent predictor of all-cause and/or cardiovascular mortality. ${ }^{44-47}$ Stenestrand et al. found a significant increase in all-cause mortality for patients with LBBB in univariate analysis. However, after adjustment for LVEF, LBBB did no longer predict one-year mortality. This observation could be consistent with the hypothesis that LBBB induces LV remodeling with deterioration of cardiac function. Therefore, the fact that LVEF is LBBB-dependent, might explain Stenestrand's results in multivariate analysis. ${ }^{25,48}$ Yet, although these studies found an association between LBBB and adverse cardiovascular outcome, LBBB could still be cause or consequence of heart failure. 


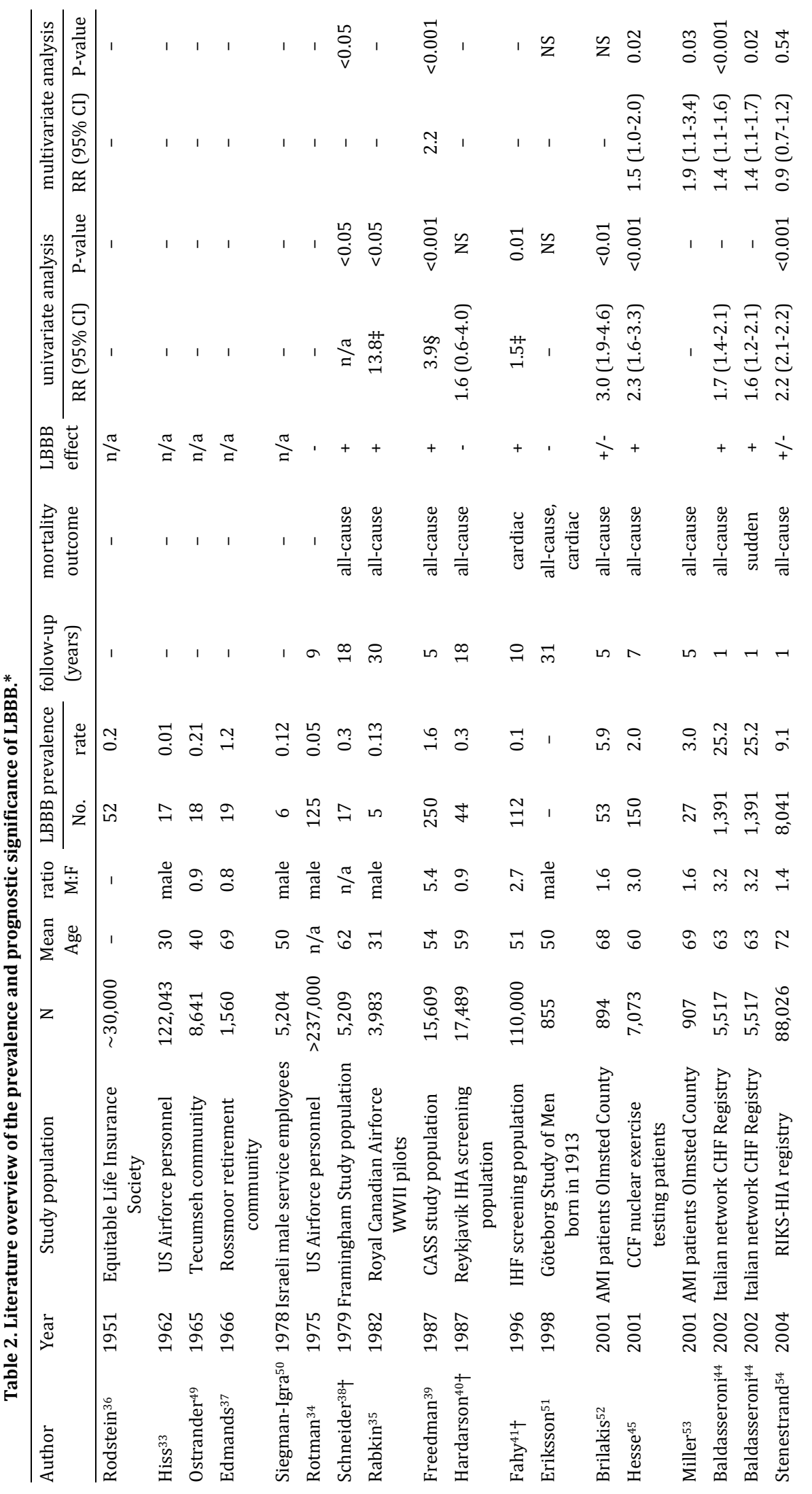




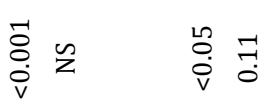

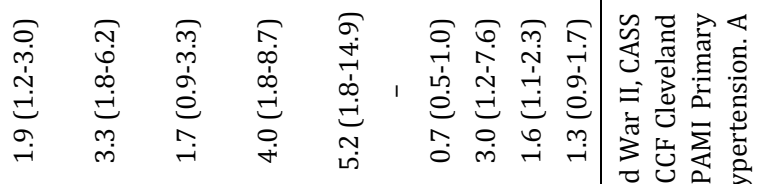

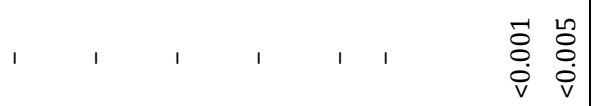

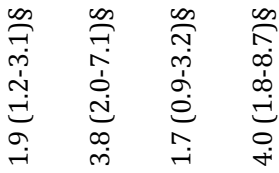

๘) ำ

둔

ปี

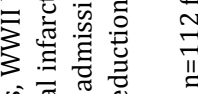

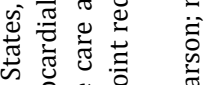

ت

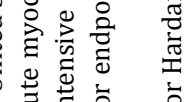

$+\quad+\quad+1 \frac{1}{+}++\frac{1}{+}$

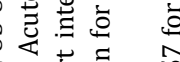

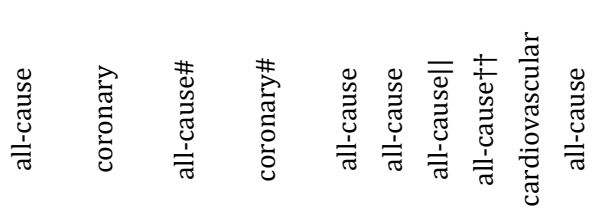

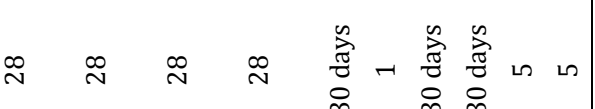

工舫

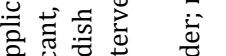

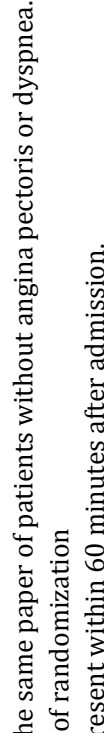

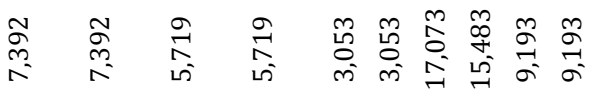

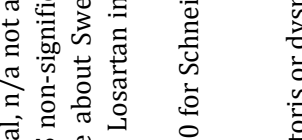

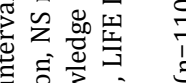

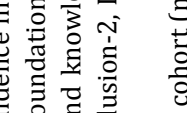

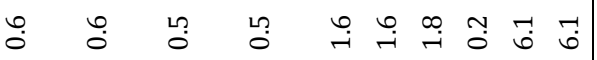

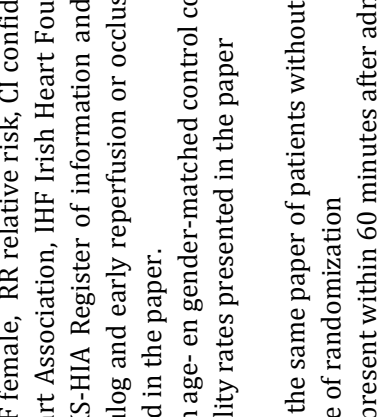

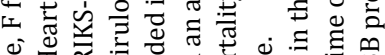

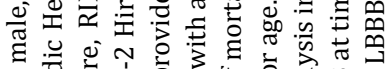

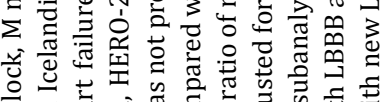

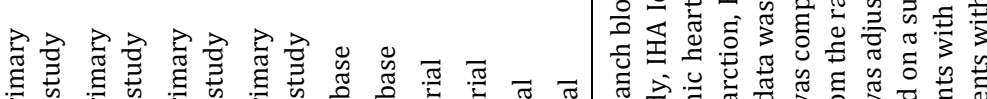

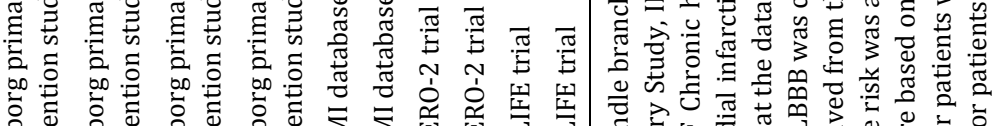

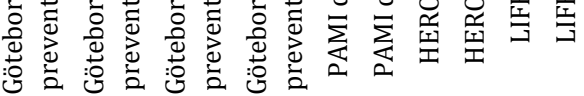

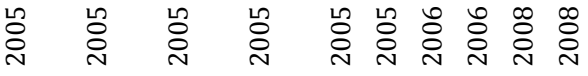

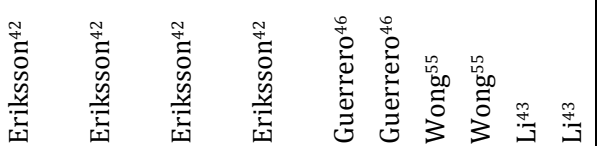

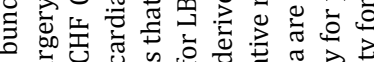

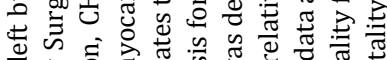

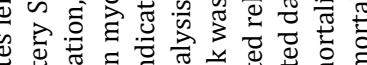

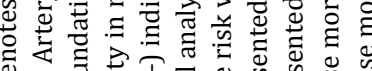

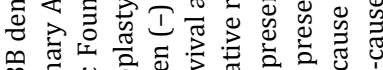

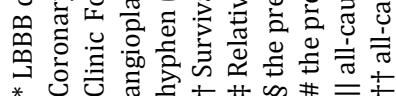




\section{Left bundle branch block and aortic valve interventions}

As can be seen from figure 2, the left bundle branch is located in close proximity to the aortic valve. As a consequence, interventions for repairing this valve contain a risk for induction of LBBB. Early experiments with surgical aortic valve replacement (SAVR) suggested that LBBB was a relatively frequent surgical complication, with an incidence as high as $32 \%$, whereas a more recent study by El-Khally et al. demonstrated a much lower rate of $6 \% .56,57$ The recently introduced transcatheter aortic valve implantation (TAVI) is complicated by LBBB in up to $60 \%$ of the patients. Considering that TAVI is a rapidly emerging intervention and that LBBB has been recognized as a serious condition in other settings, the prognostic relevance of TAVI-induced LBBB is questioned. This is the first main research question of this thesis. Complementary, this thesis also focuses on the fate of TAVI-induced LBBB over time in order to elucidate whether the conduction disorder is temporary or persistent.

A second main research question is what the prevalence and clinical significance of LBBB following conventional SAVR are. After all, patients selected for TAVI are often considered as having a too high risk for postoperative morbidity and mortality when undergoing SAVR. However, in this consideration the frequent development of LBBB after TAVI is not taken into account. Most of the studies addressing LBBB after SAVR date back to 1970-1980 where different surgical techniques and materials were used. ${ }^{56,58,59}$ Moreover, the only contemporary paper on significance of SAVRinduced LBBB was flawed by a small sample size and limited number of mortality events. ${ }^{57}$

Several factors are presumed to be responsible for the occurrence of LBBB after TAVI. As described above, there is an intimate connection between the native aortic valve and the left bundle branch which is located in the membranous septum. The majority of implanted TAVI devices until now are either the self-expanding Medtronic CoreValve System (MCS; Medtronic Inc, Minneapolis, MN, USA) or the balloonexpandable Edwards SAPIEN valve (ES; Edwards Lifesciences LLC, Irvine, CA, USA). As the frequency of TAVI-induced LBBB is considerably higher with the MCS, there are also important device related factors influencing the development of LBBB. Indeed, the distal skirt of the MCS protrudes relatively deep into the LVOT. Its frame is made of self-expanding nitinol exerting continuous and increasing pressure on the membranous septum. This in contrast with the ES device, which consists of a stainless steel or cobalt-chromium frame which is expanded by a balloon. Furthermore, the presence of calcium of the native aortic valve compressing the membranous septum is thought to be another causal factor. ${ }^{7}$

A novel device, the self-expandable Perceval S bioprosthesis (Sorin Biomedica Cardio Srl, Sallugia, Italy), claims to combine the advantages of TAVI (sutureless; ease of implantation) with those of conventional SAVR (possibility of native valve excision; visual access of the aorta). However, this prosthesis has comparable properties as the MCS device as it is also composed of self-expanding nitinol. This constituted a 
third research question focussing on the frequency of LBBB occurrence after implantation of the Perceval S valve.

\section{Controversies in cardiac resynchronization therapy}

During the last 15 years, CRT has emerged as an effective therapy in patients with symptomatic heart failure and conduction disorders, especially LBBB. As a considerable number of patients do not exhibit a response to CRT 60 the question is whether the therapy should be tailored to the individual patient. To this purpose, a possible target is optimization of the AV- and ventriculo-ventricular (VV) timing of the CRT device. ${ }^{61}$ The spectrum of available methods is however broad and (patho)physiological and/or scientific evidence is often absent.

To this purpose, several hemodynamic measurements are proposed to guide CRT optimization. As the effects of CRT exhibit an "on-off" phenomenon and result in acute and immediate electrical, hemodynamic and mechanical changes; they can be measured by for example maximum rate of rise in $\mathrm{LV}$ pressure ( $\mathrm{LV} \mathrm{dP} / \mathrm{dt}_{\max }$ ), pressure-volume loops, stroke volume and bloodpressure.28,62-65 To evaluate hemodynamics, $\mathrm{LV} \mathrm{dP} / \mathrm{dt}_{\max }$ has proven to be a valuable surrogate for $\mathrm{LV}$ contractility. ${ }^{66} \mathrm{Alt}-$ hough influenced to some extent by heart rate, preload and afterload, ${ }^{67}$ this is of minor importance in the setting of measuring the acute hemodynamic effect of CRT. After all, CRT improves regional and global contractility while preload and afterload remain fairly constant. $\mathrm{LV} \mathrm{dP} / \mathrm{dt}_{\max }$ has been used to measure the acute hemodynamic effects of CRT in for example the Pacing Therapies for Congestive Heart Failure (PATH-CHF) study, ${ }^{28}$ Whether an positive acute hemodynamic effect also translates into a favourable long-term clinical outcome is still unclear. In the PATH-CHF study no correlation was found between acute hemodynamic response (measured by LV $\left.\mathrm{dP} / \mathrm{dt}_{\max }\right)$ and long-term response, however the sample size was low $(\mathrm{n}=25) .{ }^{68}$ Therefore we finally questioned whether the acute increase in $\mathrm{LV} \mathrm{dP} / \mathrm{dt}_{\max }$ would predict long-term outcome.

\section{Outline of the thesis}

In chapter 2 we describe the prognostic significance of TAVI-induced LBBB by comparing mortality during long-term follow-up between TAVI patients who did and did not develop a new LBBB. This was done in a retrospective study among 679 TAVI patients collected from 8 implanting centers in the Netherlands. Subsequently, we studied the behaviour of TAVI-induced LBBB after hospital discharge to see whether LBBB (dis)appears within 24 hours after implantation, before hospital discharge and during long-term follow-up (chapter 3). The relation between persistent LBBB and mortality was also investigated. To this purpose, data were combined from 3 centers 
in the Netherlands and 1 center in Canada. In chapter 4 we focus on the effect of increasing experience together with newer implantation techniques on the occurrence of TAVI-induced LBBB in the same patient population.

The occurrence of LBBB as complication of SAVR (chapter 5) was studied in a patient cohort of 1,764 patients who underwent SAVR from 2002 to 2010 in a single center (Catharina Hospital, Eindhoven, the Netherlands).

In chapter 6, we report the early results of the self-expandable sutureless Perceval $S$ bioprosthesis, more specifically by addressing the issue of new LBBB. Insight from the performance of this valve could help to clarify the mechanism of LBBB after aortic valve interventions. Although the self-expanding design is comparable to MCS, there is a different delivery system and the possibility to surgically remove the native valve and its calcium.

In chapter 7 and chapter $\boldsymbol{8}$ we focus on the treatment of LBBB by CRT. We discuss the physiological rationale of AV/VV-optimization followed by a review of available invasive and non-invasive optimization methods with a critical appraisal of the literature. While the recognition of LBBB morphology on the ECG predicts outcome of CRT, a possibly complementary approach is to test the acute hemodynamic response to CRT. To this purpose, we assessed whether the absolute level of contractility, assessed by measuring $\mathrm{LV} \mathrm{dP} / \mathrm{dt}_{\max }$ or its acute increase upon initiation of CRT, predicts long-term clinical outcome in terms of mortality after initiation of CRT.

Finally, a general discussion is presented together with future perspectives with respect to aortic intervention-related $\mathrm{LBBB}$ and $\mathrm{LV} \mathrm{dP} / \mathrm{dt}_{\max }$-guided optimization of CRT (chapter 9). 


\section{References}

1. Hollman A. The history of bundle branch block. Med Hist Suppl 1985; 82-102.

2. Eppinger H, Rothberger C. Über die Folgen der Durchschneidung der Tawarschen Schenkel des Reizleitungssystems. Klin Med 1910; 70: 1-20.

3. Eppinger H, Störk O. Zur Klinik des Elektrokardiogramms. Klin Med 1910; 71: 157-164.

4. Fahr GE. An analysis of the spread of the excitation wave in the human ventricle. Arch Intern Med 1920; 25: 146-173.

5. Barker PS, Maclead A, Alexander J. The excitatory process observed in the exposed human heart. Am Heart J 1930; 5: 720-742.

6. James TN. The tendons of Todaro and the "triangle of Koch": lessons from eponymous hagiolatry. $J$ Cardiovasc Electrophysiol 1999; 10: 1478-1496.

7. van der Boon RM, Nuis R-J, Van Mieghem NM, Jordaens L, Rodés-Cabau J, van Domburg RT, Serruys PW, Anderson RH, de Jaegere PPT. New conduction abnormalities after TAVI-frequency and causes. Nat Rev Cardiol 2012; 9: 1-10.

8. Massing GK, James TN. Anatomical configuration of the His bundle and bundle branches in the human heart. Circulation 1976; 53: 609-621.

9. Willems JL, Robles de Medina EO, Bernard R, Coumel P, Fisch C, Krikler D, Mazur N, Meijler FL, Mogensen L, Moret P, Pisa Z, Rautaharju PM, Surawicz B, Watanabe Y, Wellens HJJ. Criteria for intraventricular conduction disturbances and pre-excitation. J Am Coll Cardiol 1985; 5: 1261-1275.

10. Flowers NC. Left bundle branch block: a continuously evolving concept. J Am Coll Cardiol 1987; 9: 684-697.

11. Strik M, Regoli F, Auricchio A, Prinzen F. Electrical and mechanical ventricular activation during left bundle branch block and resynchronization. J Cardiovasc Transl Res 2012; 5: 117-126.

12. Durrer D, Dam RT van, Freud GE, Janse MJ, Meijler FL, Arzbaecher RC. Total excitation of the isolated human heart. Circulation 1970; 41: 899-912.

13. Houthuizen P, Bracke FALE, van Gelder BM. Atrioventricular and interventricular delay optimization in cardiac resynchronization therapy: physiological principles and overview of available methods. Heart Fail Rev 2011; 16: 263-276.

14. Grant RP, Dodge HT. Mechanisms of QRS complex prolongation in man; left ventricular conduction disturbances. Am J Med 1956; 20: 834-852.

15. Zareba W, Klein H, Cygankiewicz I, Hall WJ, McNitt S, Brown M, Cannom D, Daubert JP, Eldar M, Gold MR, Goldberger JJ, Goldenberg I, Lichstein E, Pitschner H, Rashtian M, Solomon S, Viskin S, Wang P, Moss AJ. Effectiveness of Cardiac Resynchronization Therapy by QRS Morphology in the Multicenter Automatic Defibrillator Implantation Trial-Cardiac Resynchronization Therapy (MADIT-CRT). Circulation 2011; 123: 1061-1072.

16. Strauss DG, Selvester RH, Wagner GS. Defining left bundle branch block in the era of cardiac resynchronization therapy. Am J Cardiol 2011; 107: 927-934.

17. Surawicz B, Childers R, Deal BJ, Gettes LS, Bailey JJ, Gorgels A, Hancock EW, Josephson M, Kligfield P, Kors J, Macfarlane P, Mason JW, Mirvis DM, Okin P, Pahlm O, Rautaharju PM, van Herpen G, Wagner GS, Wellens H. AHA/ACCF/HRS recommendations for the standardization and interpretation of the electrocardiogram. Part III: intraventricular conduction disturbances. Circulation 2009; 119: e235e240.

18. Gold MR, Thébault C, Linde C, Abraham WT, Gerritse B, Ghio S, St John Sutton M, Daubert J-C. Effect of QRS duration and morphology on cardiac resynchronization therapy outcomes in mild heart failure: results from the Resynchronization Reverses Remodeling in Systolic Left Ventricular Dysfunction (REVERSE) study. Circulation 2012; 126: 822-829.

19. Luna AB. The morphology of the electrocardiogram. In: Camm AJ, Lüscher TF, Serruys PW. ESC Textbook of Cardiovascular Medicine. 1st edition UK Blackwell Publishing Ltd; 2006. p.10.

20. Prinzen FW, Augustijn CH, Arts T, Allessie M, Reneman RS. Redistribution of myocardial fiber strain and blood flow by asynchronous activation. Am J Physiol 1990; 259: H300-H308. 
21. Vernooy K, Verbeek X, Peschar M, Crijns HJGM, Arts T, Cornelussen RNM, Prinzen FW. Left bundle branch block induces ventricular remodeling and functional septal hypoperfusion. Eur Heart J 2005; 26: 91-98.

22. De Boeck BWL, Teske AJ, Meine M, Leenders GE, Cramer MJ, Prinzen FW, Doevendans P. Septal rebound stretch reflects the functional substrate to cardiac resynchronization therapy and predicts volumetric and neurohormonal response. Eur J Heart Fail 2009; 11: 863-871.

23. Grines CL, Bashore TM, Boudoulas H, Olson S, Shafer P, Wooley CF. Functional abnormalities in isolated left bundle branch block. The effect of interventricular asynchrony. Circulation 1989; 79: 845853.

24. Lee S-J, McCulloch C, Mangat I, Foster E, De Marco T, Saxon L. Isolated bundle branch block and left ventricular dysfunction. J Card Fail 2003; 9: 87-92.

25. Zannad F, Huvelle E, Dickstein K, van Veldhuisen DJ, Stellbrink C, Køber L, Cazeau S, Ritter P, Maggioni A, Ferrari R, Lechat P. Left bundle branch block as a risk factor for progression to heart failure. Eur J Heart Fail 2007; 9: 7-14.

26. Wilkoff BL, Cook JR, Epstein AE, Greene HL, Hallstrom AP, Hsia H, Kutalek SP, Sharma A. Dual-chamber pacing or ventricular backup pacing in patients with an implantable defibrillator: the Dual Chamber and VVI Implantable Defibrillator (DAVID) Trial. JAMA 2002; 288: 3115-3123.

27. Sweeney MO, Hellkamp AS, Ellenbogen K, Greenspon AJ, Freedman R, Lee KL, Lamas G. Adverse effect of ventricular pacing on heart failure and atrial fibrillation among patients with normal baseline QRS duration in a clinical trial of pacemaker therapy for sinus node dysfunction. Circulation 2003; 107: 2932-2937.

28. Auricchio A, Stellbrink C, Block M, Sack S, Vogt J, Bakker P, Klein H, Kramer A, Ding J, Salo R, Tockman B, Pochet T, Spinelli J. Effect of pacing chamber and atrioventricular delay on acute systolic function of paced patients with congestive heart failure. Circulation 1999; 99: 2993-3001.

29. Bristow MR, Saxon L, Boehmer J, Krueger S, Kass D, de Marco T, Carson P, DiCarlo L, DeMets D, White BG, DeVries DW, Feldman AM. Cardiac-resynchronization therapy with or without an implantable defibrillator in advanced chronic heart failure. N Engl J Med 2004; 350: 2140-2150.

30. Abraham WT, Young JB, León AR, Adler S, Bank AJ, Hall S, Lieberman R, Liem LB, O’Connell JB, Schroeder JS, Wheelan KR. Effects of cardiac resynchronization on disease progression in patients with left ventricular systolic dysfunction, an indication for an implantable cardioverter-defibrillator, and mildly symptomatic chronic heart failure. Circulation 2004; 110: 2864-2868.

31. Cleland JGF, Daubert J-C, Erdmann E, Freemantle N, Gras D, Kappenberger L, Tavazzi L. The effect of cardiac resynchronization on morbidity and mortality in heart failure. N Engl J Med 2005; 352: 15391549.

32. Vernooy K, Cornelussen RNM, Verbeek XAAM, Vanagt WYR, van Hunnik A, Kuiper M, Arts T, Crijns HJGM, Prinzen FW. Cardiac resynchronization therapy cures dyssynchronopathy in canine left bundle-branch block hearts. Eur Heart J 2007; 28: 2148-2155.

33. Hiss RG, Lamb LE. Electrocardiographic Findings in 122,043 Individuals. Circulation 1962; 25: $947-$ 961.

34. Rotman M, Triebwasser JH. A clinical and follow-up study of right and left bundle branch block. Circulation 1975; 51: 477-484.

35. Rabkin SW, Mathewson FL, Tate RB. The electrocardiogram in apparently healthy men and the risk of sudden death. Br Heart J 1982; 47: 546-552.

36. Rodstein M, Gubner R, Mills J, Lovell J, Ungerleider HE. A mortality study in bundle branch block. Arch Intern Med 1951; 87: 663-668.

37. Edmands RE. An Epidemiological Assessment of Bundle-Branch Block. Circulation 1966; 34: 10811087.

38. Schneider JF, Thomas HE, Kreger BE, McNamara PM, Kannel WB. Newly acquired left bundle-branch block: the Framingham study. Ann Intern Med 1979; 90: 303-310.

39. Freedman R, Alderman EL, Thomas Sheffield L, Saporito M, Fisher LD. Bundle branch block in patients with chronic coronary artery disease: Angiographic correlates and prognostic significance. $J$ Am Coll Cardiol 1987; 10: 73-80. 
40. Hardarson T, Arnason, Elíasson GJ, Pálsson K, Eyjólfsson K, Sigfússon N. Left bundle branch block: prevalence, incidence, follow-up and outcome. Eur Heart J 1987; 8: 1075-1079.

41. Fahy GJ, Pinski SL, Miller DP, McCabe N, Pye C, Walsh MJ, Robinson K. Natural history of isolated bundle branch block. Am J Cardiol 1996; 77: 1185-1190.

42. Eriksson P, Wilhelmsen L, Rosengren A. Bundle-branch block in middle-aged men: risk of complications and death over 28 years. The Primary Prevention Study in Göteborg, Sweden. Eur Heart J 2005; 26: $2300-2306$.

43. Li Z, Dahlöf B, Okin PM, Kjeldsen SE, Wachtell K, Ibsen H, Nieminen MS, Jern S, Devereux RB. Left bundle branch block and cardiovascular morbidity and mortality in hypertensive patients with left ventricular hypertrophy: the Losartan Intervention For Endpoint Reduction in Hypertension study. J Hypertens 2008; 26: 1244-1249.

44. Baldasseroni S. Left bundle-branch block is associated with increased 1-year sudden and total mortality rate in 5517 outpatients with congestive heart failure: A report from the Italian network on congestive heart failure. Am Heart J 2002; 143: 398-405.

45. Hesse B, Diaz L, Snader CE, Blackstone EH, Lauer MS. Complete bundle branch block as an independent predictor of all-cause mortality: report of 7,073 patients referred for nuclear exercise testing. $\mathrm{Am}$ J Med 2001; 110: 253-259.

46. Guerrero M, Harjai K, Stone GW, Brodie B, Cox D, Boura J, Grines L, O'Neill W, Grines C. Comparison of the prognostic effect of left versus right versus no bundle branch block on presenting electrocardiogram in acute myocardial infarction patients treated with primary angioplasty in the primary angioplasty in myocardial infarction trials. Am J Cardiol 2005; 96: 482-488.

47. Wong TY. Retinal Arteriolar Narrowing and Risk of Coronary Heart Disease in Men and Women: The Atherosclerosis Risk in Communities Study. JAMA J Am Med Assoc 2002; 287: 1153-1159.

48. Francia P, Balla C, Paneni F, Volpe M. Left bundle-branch block - pathophysiology, prognosis, and clinical management. Clin Cardiol 2007; 30: 110-115.

49. Ostrander LD, Brandt RL, Kjelsberg MO, Epstein FH. Electrocardiographic Findings Among the Adult Population of a Total Natural Community, Tecumseh, Michigan. Circulation 1965; 31: 888-898.

50. Siegman-Igra Y, Yahini JH, Goldbourt U, Neufeld HN. Intraventricular conduction disturbances: A review of prevalence, etiology, and progression for ten years within a stable population of Israeli adult males. Am Heart J 1978; 96: 669-679.

51. Eriksson P, Hansson P-O, Eriksson H, Dellborg M. Bundle-Branch Block in a General Male Population : The Study of Men Born 1913. Circulation 1998; 98: 2494-2500.

52. Brilakis ES, Wright RS, Kopecky SL, Reeder GS, Williams B, Miller WL. Bundle branch block as a predictor of long-term survival after acute myocardial infarction. Am J Cardiol 2001; 88: 205-209.

53. Miller WL, Sgura F, Kopecky SL, Asirvatham SJ, Williams B, Wright RS, Reeder GS. Characteristics of presenting electrocardiograms of acute myocardial infarction from a community-based population predict short- and long-term mortality. Am J Cardiol 2001; 87: 1045-1050.

54. Stenestrand U, Tabrizi F, Lindbäck J, Englund A, Rosenqvist M, Wallentin L. Comorbidity and myocardial dysfunction are the main explanations for the higher 1-year mortality in acute myocardial infarction with left bundle-branch block. Circulation 2004; 110: 1896-1902.

55. Wong C-K, Stewart RH, Gao W, French JK, Raffel C, White HD. Prognostic differences between different types of bundle branch block during the early phase of acute myocardial infarction: insights from the Hirulog and Early Reperfusion or Occlusion (HERO)-2 trial. Eur Heart J 2006; 27: 21-28.

56. Thomas JL, Dickstein RA, Parker FB, Potts JL, Poirier RA, Fruehan CT, Eich RH. Prognostic significance of the development of left bundle conduction defects following aortic valve replacement. J Thorac Cardiovasc Surg 1982; 84: 382-386.

57. El-Khally Z, Thibault B, Staniloae C, Theroux P, Dubuc M, Roy D, Guerra P, Macle L, Talajic M. Prognostic significance of newly acquired bundle branch block after aortic valve replacement. Am J Cardiol 2004; 94: 1008-1011.

58. Thompson R, Mitchell A, Ahmed M, Towers M, Yacoub M. Conduction defects in aortic valve disease. Am Heart J 1979; 98: 3-10.

59. Habicht JM, Scherr P, Zerkowski HR, Hoffmann A. Late conduction defects following aortic valve replacement. J Heart Valve Dis 2000; 9: 629-632. 
60. Daubert JC, Saxon L, Adamson PB, Auricchio A, Berger RD, Beshai JF, Breithard O, Brignole M, Cleland J, DeLurgio DB, Dickstein K, Exner DV, Gold M, Grimm RA, Hayes DL, Israel C, Leclercq C, Linde C, Lindenfeld J, Merkely B, Mont L, Murgatroyd F, Prinzen F, Saba SF, Shinbane JS, Singh J, Tang AS, Vardas PE, Wilkoff BL, Zamorano JL, Anand I, Blomström-Lundqvist C, Boehmer JP, Calkins H, Cazeau S, Delgado V, Estes NA, Haines D, Kusumoto F, Leyva P, Ruschitzka F, Stevenson LW, Torp-Pedersen CT. 2012 EHRA/HRS expert consensus statement on cardiac resynchronization therapy in heart failure: implant and follow-up recommendations and management. Europace 2012; 14; 1236-1286.

61. Mullens W, Kepa J, Vusser P De, Vercammen J, Rivero-Ayerza M, Wagner P, Dens J, Vrolix M, Vandervoort P, Tang WHW. Importance of adjunctive heart failure optimization immediately after implantation to improve long-term outcomes with cardiac resynchronization therapy. Am J Cardiol 2011; 108: 409-415.

62. Verbeek XAAM, Vernooy K, Peschar M, van der Nagel T, van Hunnik A, Prinzen FW. Quantification of interventricular asynchrony during LBBB and ventricular pacing. Am J Physiol Heart Circ Physiol 2002; 283: H1370-8.

63. Verbeek XAAM, Vernooy K, Peschar M, Cornelussen RN., Prinzen FW. Intra-ventricular resynchronization for optimal left ventricular function during pacing in experimental left bundle branch block. $J$ Am Coll Cardiol 2003; 42: 558-567.

64. van Gelder BM, Bracke FALE, Meijer A, Lakerveld LJM, Pijls NHJ. Effect of optimizing the VV interval on left ventricular contractility in cardiac resynchronization therapy. Am J Cardiol 2004; 93: 15001503.

65. van Geldorp IE, Delhaas T, Hermans B, Vernooy K, Broers B, Klimusina J, Regoli F, Faletra FF, Moccetti T, Gerritse B, Cornelussen R, Settels JJ, Crijns HJGM, Auricchio A, Prinzen FW. Comparison of a noninvasive arterial pulse contour technique and echo Doppler aorta velocity-time integral on stroke volume changes in optimization of cardiac resynchronization therapy. Europace 2011; 13: 87-95.

66. Mason DT. Usefulness and limitations of the rate of rise of intraventricular pressure $(\mathrm{dp} / \mathrm{dt})$ in the evaluation of myocardial contractility in Man. Am J Cardiol 1969; 23: 516-527.

67. Kass DA, Maughan WL, Guo ZM, Kono A, Sunagawa K, Sagawa K. Comparative influence of load versus inotropic states on indexes of ventricular contractility: experimental and theoretical analysis based on pressure-volume relationships. Circulation 1987; 76: 1422-1436.

68. Stellbrink C, Breithardt OA, Franke A, Sack S, Bakker P, Auricchio a, Pochet T, Salo R, Kramer A, Spinelli J. Impact of cardiac resynchronization therapy using hemodynamically optimized pacing on left ventricular remodeling in patients with congestive heart failure and ventricular conduction disturbances. J Am Coll Cardiol 2001; 38: 1957-1965. 
PART 1

Controversies in

Aortic Valve Interventions 



\section{CHAPTER 2}

\section{Left Bundle-Branch Block Induced by Transcatheter Aortic Valve Implantation Increases Risk of Death}

Patrick Houthuizen, Leen A.F.M. Van Garsse, Thomas T. Poels, Peter de Jaegere, Robert M. van der Boon, Ben M. Swinkels, Jurrien M. ten Berg, Frank van der Kley, Martin J. Schalij, Riccardo Cocchieri, Guus R.G. Brueren, Albert H.M. van Straten, Peter den Heijer, Mohamed Bentala, Vincent van Ommen, Jolanda Kluin, Pieter R. Stella, Martin H. Prins, Jos G. Maessen, Frits W. Prinzen

Published in Circulation 2012; 126: 720-708 


\section{Abstract}

\section{Background}

Transcatheter aortic valve implantation (TAVI) is a novel therapy for treatment of severe aortic stenosis. Although $30 \%$ to $50 \%$ of patients develop new left bundlebranch block (LBBB), its effect on clinical outcome is unclear.

\section{Methods and Results}

Data were collected in a multicenter registry encompassing TAVI patients from 2005 until 2010. The all-cause mortality rate at follow-up was compared between patients who did and did not develop new LBBB. Of 679 patients analyzed, 387 (57.0\%) underwent TAVI with the Medtronic CoreValve System and 292 (43.0\%) with the Edwards SAPIEN valve. A total of 233 patients (34.3\%) developed new LBBB. Median follow-up was 449.5 (interquartile range [IQR], 174-834) days in patients with and 450 (IQR, 253-725) days in patients without LBBB ( $P=0.90)$. All-cause mortality was $37.8 \%(\mathrm{n}=88)$ in patients with LBBB and $24.0 \%(\mathrm{n}=107)$ in patients without LBBB $(\mathrm{P}=0.002)$. By multivariate regression analysis, independent predictors of all-cause mortality were TAVI-induced LBBB (hazard ratio [HR], 1.54; confidence interval [CI], 1.12-2.10), chronic obstructive lung disease (HR, 1.56; CI, 1.15-2.10), female sex (HR, 1.39; CI, 1.04-1.85), left ventricular ejection fraction 50\% (HR, 1.38; CI, 1.021.86), and baseline creatinine (HR, 1.32; CI, 1.19-1.43). LBBB was more frequent after implantation of the Medtronic CoreValve System than after Edwards SAPIEN implantation $(51.1 \%$ and $12.0 \%$, respectively; $\mathrm{P}=0.001)$, but device type did not influence the mortality risk of TAVI-induced LBBB.

\section{Conclusions}

All-cause mortality after TAVI is higher in patients who develop LBBB than in patients who do not. TAVI-induced LBBB is an independent predictor of mortality. 


\section{Introduction}

Transcatheter aortic valve implantation (TAVI) is a relatively new, less invasive treatment for severe, symptomatic aortic stenosis and is advocated as an alternative to conventional surgical aortic valve replacement in patients who do not qualify for surgery. In the latter patient category, the PARTNER trial (Placement of Aortic Transcatheter Valve trial) has demonstrated that TAVI significantly reduces allcause mortality, repeat hospitalization and cardiac symptoms compared with standard therapy including balloon valvuloplasty. ${ }^{1}$ For patients at high risk for surgery, survival after TAVI was comparable to that of surgical replacement, albeit with different periprocedural risks. ${ }^{2}$

Recent studies describe that TAVI can induce cardiac conduction abnormalities; the most frequent one being left bundle branch block (LBBB). The incidence of TAVIinduced LBBB has been reported to vary between $7 \%$ and $83 \%$ and seems to depend on the device being used. ${ }^{3-6}$

Although, in the light of valve implantation, LBBB may seem a fairly harmless side effect, LBBB leads to abnormal ventricular contraction and compromised cardiac pump function. ${ }^{7-9}$ Clinical studies have shown that LBBB is associated with increased morbidity and mortality in a broad population, varying from healthy individuals to patients after myocardial infarction to patients with established heart failure. ${ }^{10}$

The aim of the present study was to investigate the impact of a new LBBB after TAVI on all-cause mortality in a series of 679 patients who underwent TAVI between November 2005 and December 2010 in 8 centers in the Netherlands.

\section{Methods}

\section{Study population}

All patients who underwent TAVI with either the self-expandable Medtronic CoreValve System (MCS; Medtronic Inc, Minneapolis, MN, USA) or the balloon-expandable Edwards SAPIEN valve (ES; Edwards Lifesciences LLC, Irvine, CA, USA) between November 2005 up to December 2010 in any of the 8 participating centers were reviewed. The study population was defined by using prospectively collected clinical and procedural data that were entered into the dedicated TAVI database of each center. If necessary, additional information was collected retrospectively by analysis of medical records and/or telephone review. 


\section{Study design}

We compared patients who developed new LBBB within 7 days after TAVI with patients who did not. For this purpose, all electrocardiograms (ECG) before and within 7 days after implantation were collected and reviewed by the first and third author (P.H. and T.P.) to extract heart rhythm, PR- and QRS-interval and QRS-axis. Newly developed LBBB was defined as a postprocedural V1-negative QRS-complex with a duration of more than $120 \mathrm{msec}$ and a notched or slurred R-wave in at least one of the lateral leads $\left(\mathrm{I}, \mathrm{a} \mathrm{V}_{\mathrm{L}}, \mathrm{V}_{5}, \mathrm{~V}_{6}\right)$, according to the established guidelines. ${ }^{11}$ As a surrogate for the extent of left ventricular hypertrophy, we measured the amplitude of the $\mathrm{R}$-wave in $\mathrm{aV}$ and $\mathrm{V}_{5} / \mathrm{V}_{6}$ as well as the amplitude of the $\mathrm{S}$-wave in $\mathrm{V}_{1}$, based on the Sokolow-Lyon criteria. ${ }^{12} \mathrm{An}$ absent $\mathrm{Q}$-wave in $\mathrm{V}_{6}$ was regarded as indicator for septal fibrosis. ${ }^{13,14}$

Exclusion criteria for the study were an aborted procedure without valve implantation, pre-existing permanent pacemaker (PPM) and/or pre-existing LBBB. All patients requiring postprocedural PPM implantation were excluded from analysis (regardless of whether they developed LBBB or not), because a pacemaker intervention protects from bradyarrhythmic cardiac death, thereby influencing mortality. Moreover, it is known that intrinsic atrioventricular conduction apparently recovers within time, as some patients who have been implanted a permanent pacemaker do not require ventricular pacing at long-term follow-up. ${ }^{15}$ As a result, these patients have intrinsic ventricular activation and do not exhibit the dyssynchronous activation of right ventricular pacing. Cause of death was classified into three categories: cardiovascular, non-cardiovascular and sudden. Death was defined as cardiovascular if it was caused by pump failure (acute or chronic), coronary artery disease or cerebrovascular disease. The cause of death was categorized as sudden if a patient died suddenly.

\section{Primary endpoint}

The primary endpoint was all-cause mortality at follow-up and was collected by consulting the Dutch civil registry. This governmental controlled registry contains vital records of the entire population, including date of death.

\section{Statistical Analysis}

Primary hypothesis of this study was that TAVI-induced LBBB affects all-cause mortality of TAVI patients. This idea arose from studies that showed a reduced mortality due to cardiac resynchronization therapy (CRT) in LBBB patients. For patients with New York Heart Association (NYHA) class I or II, the MADIT-CRT trial demonstrated a $31 \%$ reduction in ventricular tachyarrhythmias or death due to CRT.16 Overall 1year mortality after TAVI in previous reports ranges from 24 to $31 \% .1,17$ Assuming a $30 \%$ incidence of LBBB and a 1 -year mortality of $30 \%$ and $20 \%$ in patients with and 
without TAVI-induced LBBB, respectively, we estimated that a minimum sample size of 231 patients with new LBBB and 462 patients without would be needed (twosided alpha of 0.05 and a power of 0.8 ).

Baseline variables were compared between both groups. Categorical variables are presented as numbers and proportions and were compared using the Fisher's exact test. For continuous variables, normality of distribution was assessed with the Kolmogorov-Smirnov test. Normal and skewed continuous variables are presented as means with standard deviation (SD) and medians with interquartile range (IQR), respectively, and were compared accordingly, using either an unpaired t-test or the Mann-Whitney U test. A two-sided p-value less than 0.05 was considered to be statistically significant. Survival was estimated using the Kaplan-Meier method. The logrank test was used to compare mortality between patients with and without TAVIinduced LBBB. All variables with a p-value $\leq 0.20$ in univariate Cox regression analysis, were entered into a multivariate Cox regression analysis using the enter method to determine the effect of TAVI-induced LBBB, adjusted for other potential predictors of the primary endpoint. To evaluate if TAVI-induced LBBB was subject to a learning curve, consecutive patients of each center were ranked according to their entry time into the local TAVI program. Next, patients were grouped into strata of 20 patients according to their ranking number. The $6^{\text {th }}$ and last stratum consisted of case number 100 and higher. Subsequently, data from all centers were combined. The aforementioned ranking and stratification was performed separately for both the MCS and the ES device. For descriptive purposes, we performed analysis of subsets with and without LBBB with use of the Breslow-Day test for heterogeneity testing. All statistical analyses were performed using Statistical Package for Social Sciences (SPSS), version 17 (IBM SPSS, Chicago, IL, USA).

\section{Results}

\section{Study population}

Between November 15, 2005 and December 23, 2010, 1,013 patients underwent TAVI in the 8 participating centers in the Netherlands. Not eligible were 197 patients because of an aborted procedure without valve implantation $(n=11)$ and pre-existing LBBB and/or pre-existing PPM $(n=186)$. In addition, another 118 patients were excluded because of postprocedural PPM implantation (Figure 1). There were 19 patients who died shortly after implantation so that no follow-up ECG was available. As a consequence, it was not possible to categorize these patients. Therefore, a total of 679 patients were eligible for analysis. Baseline characteristics of the total study population and patients with and without TAVI-induced LBBB are outlined in table 1. Patients were septua- and octogenerians with an almost even gender distribution. Baseline QRS duration was slightly, but significantly, shorter in patient with TAVI- 
induced LBBB. Based on electrocardiographic indices, there was no significant difference in left ventricular hypertrophy or septal fibrosis. All other baseline variables did not differ significantly between both groups.

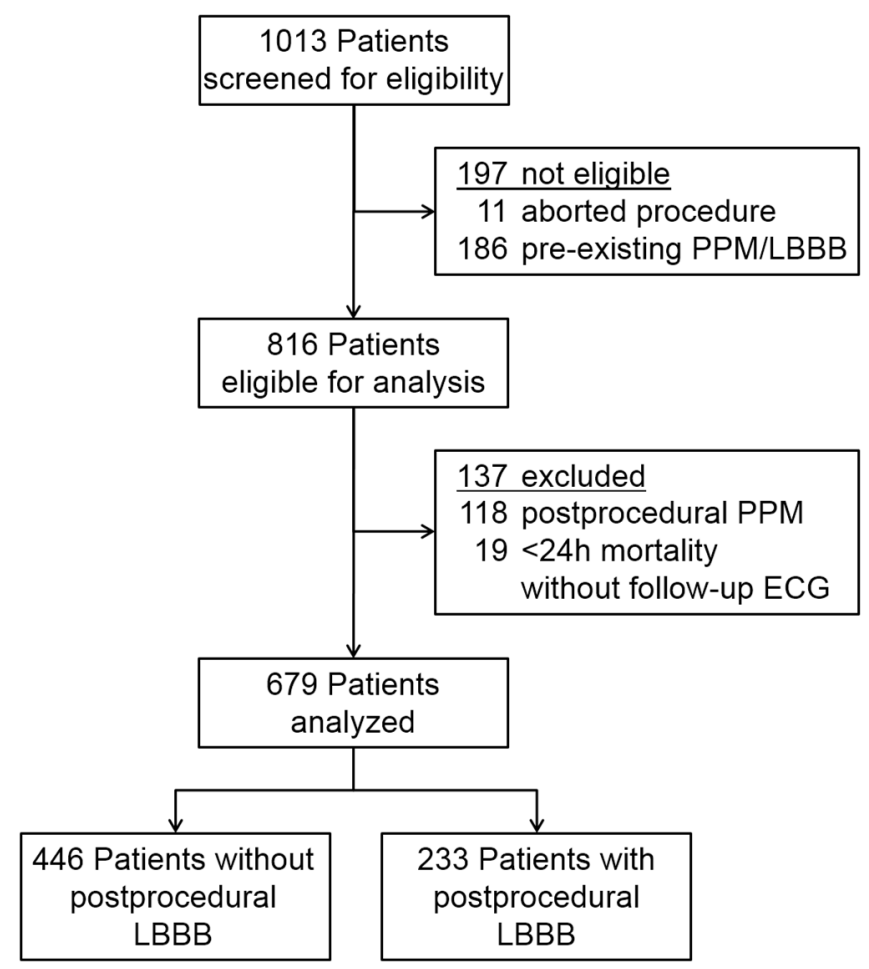

Figure 1. Study population.

PPM denotes permanent pacemaker, LBBB left bundle branch block. Categorization in either group was made based on comparison of the preprocedural and $\leq 7$ days postprocedural electrocardiogram.

\section{Procedural outcomes}

In 387 patients (57.0\%) a MCS device was implanted (valve size $26 \mathrm{~mm}$ [n=192] and $29 \mathrm{~mm}$ [ $\mathrm{n}=195]$ ]) and in 292 patients (43.0\%) an ES device (valve size $23 \mathrm{~mm}$ [ $\mathrm{n}=109$ ] and $26 \mathrm{~mm}$ [n=183]). Access was transfemoral in 463 (68.2\%) patients, subclavial in $10(1.5 \%)$ and transapical (ES devices only) in 206 (30.3\%). From the 8 participating centers, 2 centers implanted both ES and MCS, 3 centers used predominantly MCS and 3 centers implanted ES devices. All procedures were performed by experienced and skilled physicians who underwent extensive training of the procedure. 
Table 1. Baseline and procedural characteristics of the patients.*

\begin{tabular}{|c|c|c|c|c|}
\hline Characteristic & $\begin{array}{l}\text { Study population } \\
(\mathrm{N}=679)\end{array}$ & $\begin{array}{l}\text { no LBBB } \\
(\mathrm{N}=446)\end{array}$ & $\begin{array}{l}\text { new LBBB } \\
(\mathrm{N}=233)\end{array}$ & $P$ value \\
\hline \multicolumn{5}{|l|}{ Demographics } \\
\hline Age - yr & $81(77-85)$ & $82(77-85)$ & $81(78-85)$ & 0.86 \\
\hline Male gender - no. (\%) & $319(47.0)$ & $216(48.4)$ & $103(44.4)$ & 0.33 \\
\hline \multicolumn{5}{|l|}{ Clinical } \\
\hline Coronary artery disease - no. (\%) & $319(47.0)$ & $207(46.4)$ & $112(48.1)$ & 0.70 \\
\hline Previous MI - no. (\%) & $127(18.7)$ & $91(20.4)$ & $36(15.5)$ & 0.12 \\
\hline Previous PCI - no. (\%) & $193(28.4)$ & 119 (26.7) & $74(31.8)$ & 0.18 \\
\hline Previous CABG - no. (\%) & $164(24.2)$ & $114(25.6)$ & $50(21.5)$ & 0.26 \\
\hline Cerebral vascular disease - no. (\%) & $120(17.7)$ & $75(16.8)$ & $45(19.3)$ & 0.46 \\
\hline Peripheral vascular disease - no. (\%) & $141(20.8)$ & $100(22.4)$ & $41(17.6)$ & 0.16 \\
\hline Diabetes mellitus - no. (\%) & $160(23.6)$ & $9421.1)$ & $66(28.3)$ & 0.04 \\
\hline COPD - no. (\%) & $178(26.2)$ & $118(26.5)$ & $60(25.8)$ & 0.86 \\
\hline Creatinine $-\mathrm{mg} / \mathrm{dl}$ & $1.07(0.85-1.38)$ & $1.07(0.86-1.40)$ & $1.05(0.81-1.37)$ & 0.60 \\
\hline Logistic EuroSCORE† & $16.0(10.0-25.0)$ & $16.0(10.0-25.0)$ & $16.0(10.0-24.5)$ & 0.64 \\
\hline \multicolumn{5}{|l|}{ Electrocardiography } \\
\hline sinus rhythm - no. (\%) & $535(78.8)$ & $355(80.0)$ & $180(77.3)$ & 0.48 \\
\hline baseline PR-duration - msec & $180(160-202)$ & $180(160-202)$ & $180(160-202)$ & 0.83 \\
\hline baseline QRS-duration - msec & $98(89-110)$ & $100(90-110)$ & $96(88-106)$ & 0.003 \\
\hline baseline QRS-axis - degreesł & $14.6 \pm 41.6$ & $15.2 \pm 43.3$ & $13.4 \pm 38.1$ & 0.55 \\
\hline R-wave $\mathrm{aV}_{\mathrm{L}}-\mathrm{mm}$ & $7(3-11)$ & $7(3-11)$ & $7(4-11)$ & 0.55 \\
\hline $\mathrm{S}$-wave $\mathrm{V}_{1}+\mathrm{R}$-wave $\mathrm{V}_{5 / 6}-\mathrm{mm}$ & $27(20-35)$ & $27(19-35)$ & $29(22-35)$ & 0.14 \\
\hline absence of Q-wave $V_{6}(\%)$ & 61.8 & 62.7 & 61.8 & 0.84 \\
\hline \multicolumn{5}{|l|}{ Echocardiography } \\
\hline Maximal aortic valve gradient $-\mathrm{mmHg}$ & $74(60-90)$ & $74(61-90)$ & $74(60-93)$ & 0.86 \\
\hline Mean aortic valve gradient $-\mathrm{mmHg}$ & $45(36-57)$ & $44(35-56)$ & $45(36-58)$ & 0.54 \\
\hline Aortic valve area $-\mathrm{cm}^{2}$ & $0.7(0.6-0.8)$ & $0.7(0.6-0.8)$ & $0.7(0.5-0.8)$ & 0.35 \\
\hline LVEF < $50 \%-$ no. (\%) & $190(28.0)$ & $122(27.4)$ & $68(29.3)$ & 0.65 \\
\hline \multicolumn{5}{|l|}{ Procedural } \\
\hline Medtronic CoreValve System - no. (\%) & $387(57.0)$ & $189(42.4)$ & $198(85.0)$ & $<0.001$ \\
\hline Transapical access - no. (\%) & $206(30.3)$ & $180(40.4)$ & $26(11.2)$ & $<0.001$ \\
\hline
\end{tabular}

* Results are presented as median (interquartile range) or absolute number (percentage), unless stated otherwise. MI denotes myocardial infarction, PCI percutaneous coronary intervention, CABG coronaryartery bypass grafting, COPD chronic obstructive lung disease, LVEF left ventricular ejection fraction † The logistic European System for Cardiac Operative Risk Evaluation (EuroSCORE) is a score system ranging from 0 to $100 \%$ used to predict 30-day mortality of cardiovascular surgery. $\ddagger$ Baseline QRS axis is presented as mean \pm SD (standard deviation).

In all 679 patients an ECG at baseline and before discharge was available for analysis. A new LBBB after TAVI occurred in 233 (34.3\%) patients. In these patients, QRSduration increased from 96 (88-106) msec before to 150 (140-162) msec after TAVI 
$(\mathrm{P}<0.001)$. Compared to patients without LBBB, those who developed a new LBBB also had a significantly larger increase in PR-interval (18 [-2-40] msec versus 0 [16-16] msec, respectively; $\mathrm{P}<0.001$ ).

\section{Primary endpoint}

Median follow-up was 449.5 (IQR, 174-834) days in patients with and 450 (IQR, 253-725) days in patients without new LBBB ( $\mathrm{P}=0.90)$. At 30 days, all-cause mortality rate was $12.9 \%(n=30)$ in patients who developed new LBBB compared with $8.7 \%$ $(\mathrm{n}=39)$ in patients who did not (log-rank $\mathrm{P}=0.09)$. At 1 year after implantation the

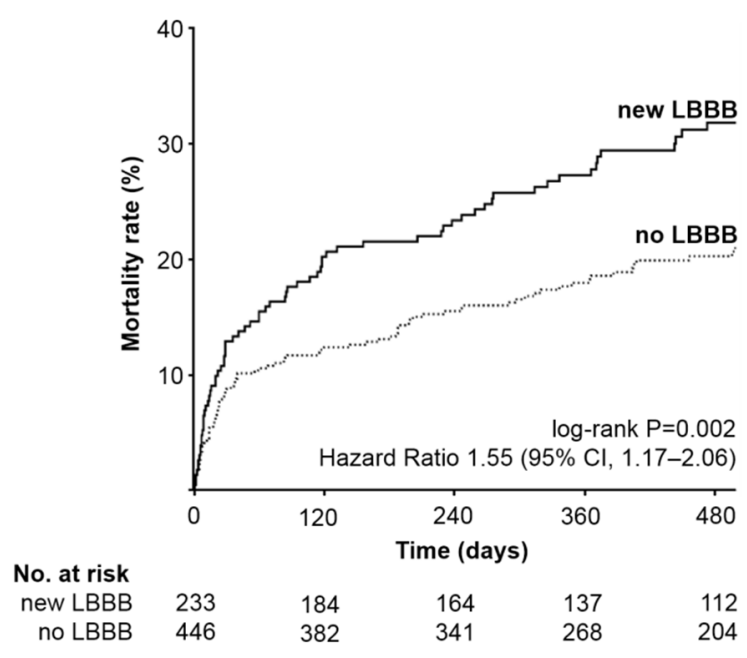

Figure 2. Kaplan-Meier survival curves for the primary endpoint.

"New LBBB" denotes patients who developed left bundle branch block (LBBB) upon the transcatheter aortic valve implantation (TAVI) procedure, whereas "no LBBB" denotes the patients who did not. Event-rates were compared using the log-rank test. endpoint had occurred in $62(26.6 \%)$ patients with and in $78(17.5 \%)$ of patients without new LBBB (log-rank $\mathrm{P}=0.006$ ), indicating an increment in absolute and relative mortality risk for new LBBB of $9.1 \%$ and $52.0 \%$, respectively. During total followup, the primary endpoint of all-cause mortality was reached in $37.8 \%(n=88)$ of patients with and $24.0 \%$ $(n=107)$ of patients without new LBBB (log-rank $\mathrm{P}=0.002$ ). Kaplan-Meier estimates of survival indicate a continuous worsening of outcome in patients with TAVI-induced LBBB (Figure 2). For the subset of 118 patients excluded from analysis because of PPM implantation, mortality rate was $4.2 \%(n=5), 16.9 \%(n=20)$ and $28.8 \%(n=34)$ at 30 days, 1 year and total follow-up, respectively.

Determinants of all-cause mortality at total follow-up are shown in Table 2. By univariate analysis following variables significantly predicted the endpoint in descending order of hazard ratio (HR): chronic obstructive lung disease (HR, 1.56, CI, 1.15-2.10), TAVI-induced LBBB (HR, 1.55, CI, 1.17-2.06), female gender (HR, 1.52, CI, 1.15-2.03), left ventricular ejection fraction (LVEF) $\leq 50 \%$ (HR, 1.46, CI, 1.09-1.96), use of MCS prosthesis (HR, 1.41, CI, 1.05-1.90) and baseline creatinine (HR, 1.29, CI, 1.18-1.42). 
Table 2. Univariate and multivariate Cox regression analysis of the primary endpoint of all-cause mortality.*

\begin{tabular}{|c|c|c|c|c|c|c|}
\hline \multirow[b]{2}{*}{ Variable } & \multicolumn{3}{|c|}{ Univariate Analysis } & \multicolumn{3}{|c|}{ Multivariate Analysis } \\
\hline & HR & $\mathrm{CI}$ & $P$ value & HR & $\mathrm{CI}$ & $P$ value \\
\hline Age & 0.99 & $0.97-1.01$ & 0.20 & & & \\
\hline Female gender & 1.52 & $1.15-2.03$ & 0.003 & 1.39 & $1.04-1.85$ & 0.03 \\
\hline Baseline creatinine & 1.29 & $1.18-1.42$ & $<0.001$ & 1.32 & $1.19-1.43$ & $<0.001$ \\
\hline Previous MI & 1.24 & $0.88-1.74$ & 0.23 & & & \\
\hline Previous CABG & 0.95 & $0.68-1.32$ & 0.75 & & & \\
\hline Cerebrovascular disease & 0.98 & $0.68-1.41$ & 0.92 & & & \\
\hline Peripheral vascular disease & 1.09 & $0.77-1.55$ & 0.61 & & & \\
\hline Diabetes mellitus & 1.25 & $0.91-1.71$ & 0.17 & 1.21 & $0.88-1.66$ & 0.25 \\
\hline COPD & 1.52 & $1.13-2.05$ & 0.006 & 1.56 & $1.15-2.10$ & 0.004 \\
\hline LVEF $\leq 50 \%$ & 1.46 & $1.09-1.96$ & 0.01 & 1.38 & $1.02-1.86$ & 0.03 \\
\hline MCS prosthesis $†$ & 1.41 & $1.05-1.90$ & 0.02 & 1.13 & $0.81-1.56$ & 0.48 \\
\hline Transfemoral access & 1.03 & $0.75-1.41$ & 0.86 & & & \\
\hline TAVI-induced LBBB & 1.55 & $1.17-2.06$ & 0.002 & 1.54 & $1.12-2.10$ & 0.007 \\
\hline
\end{tabular}

* HR denotes hazard ratio, CI 95\% confidence interval, MI myocardial infarction, CABG coronary-artery bypass grafting, COPD chronic obstructive pulmonary disease, LVEF left ventricular ejection fraction, TAVI-induced LBBB new left bundle branch block induced by transcatheter aortic valve implantation † For calculation of the hazard ratio, the Medtronic CoreValve System (MCS) prosthesis was compared to the Edwards SAPIEN (ES) prosthesis.

By multivariate analysis, TAVI-induced LBBB was one of the strongest independent predictors of all-cause mortality (HR, 1.54, CI, 1.12-2.10), together with chronic obstructive lung disease (HR, 1.54, CI, 1.13-2.09), followed by female gender (HR, 1.38, $\mathrm{CI}, 1.04-1.85$ ), left ventricular ejection fraction $\leq 50 \%$ (HR, 1.38, CI, 1.02-1.86) and baseline creatinine (HR, 1.32, CI, 1.19-1.43).

Descriptive subset analysis showed that the effect of TAVI-induced LBBB on mortality was constant throughout different subgroups, except for chronic obstructive lung disease. The mortality risk of new LBBB was similar in patients who received an MCS or ES device (Figure 3).

The cause of death was cardiovascular in 42 (39.3\%) patients without and in 42 (47.7\%) patients with TAVI-induced LBBB. Death was non-cardiovascular in 47 (43.9\%) and 31 (35.2\%) patients without and with TAVI-induced LBBB, respectively, whereas the cause of death was sudden in $18(16.8 \%)$ patients without and in 15 (17.0\%) patient with new LBBB. In other words, cardiovascular mortality rate was 9.4\% for patients without and $18.0 \%$ for patients with TAVI-induced LBBB (log-rank $\mathrm{P}<0.001$ ), whereas non-cardiac mortality rate was $10.5 \%$ and $13.3 \%$, respectively ( $\log$-rank $\mathrm{P}=0.20$ ). The mortality rate for sudden death was $4.0 \%$ for patients without and $6.4 \%$ for patients with TAVI-induced LBBB (log-rank $\mathrm{P}=0.13$ ). 


\begin{tabular}{|c|c|c|c|c|c|c|}
\hline \multirow[b]{2}{*}{ Overall } & \multicolumn{2}{|c|}{$\begin{array}{cc}\text { no LBBB } & \text { new LBBB } \\
\text { number events/total number (\%) }\end{array}$} & \multicolumn{2}{|r|}{ Relative Risk } & $(95 \% \mathrm{Cl})$ & \multirow[t]{2}{*}{ P-value } \\
\hline & $107 / 446(23.4 \%)$ & $88 / 233(37.8 \%)$ & $\rightarrow-$ & 1.92 & $(1.37-2.71)$ & \\
\hline Female gender & & & & & & 0.44 \\
\hline Male & $47 / 230(20.4 \%)$ & $40 / 130(30.7 \%)$ & & 1.73 & $(1.06-2.83)$ & \\
\hline Female & $60 / 216(27.8 \%)$ & $48 / 103(46.6 \%)$ & & 2.27 & $(1.39-3.70)$ & \\
\hline Previous MI & & & & & & 0.51 \\
\hline Yes & $24 / 91(26.4 \%)$ & $17 / 36(47.2 \%)$ & & 2.50 & $(1.12-5.58)$ & \\
\hline No & $83 / 355(23.4 \%)$ & $71 / 197(36.0 \%)$ & $\rightarrow$ & 1.85 & $(1.26-2.70)$ & \\
\hline Previous CABG & & & & & & 0.93 \\
\hline Yes & $27 / 114(23.7 \%)$ & $19 / 50(38.0 \%)$ & & 1.98 & $(0.97-4.04)$ & \\
\hline No & $80 / 332(24.1 \%)$ & $69 / 183(37.7 \%)$ & & 1.91 & $(1.29-2.82)$ & \\
\hline Cerebrovascular disease & & & & & & 0.65 \\
\hline Yes & $19 / 75(25.3 \%)$ & $16 / 45(35.6 \%)$ & & 1.63 & $(0.73-3.63)$ & \\
\hline No & $88 / 371(23.7 \%)$ & $72 / 188(38.3 \%)$ & & 2.00 & $(1.37-2.92)$ & \\
\hline Peripheral vascular disease & & & & & & 0.46 \\
\hline Yes & $26 / 100(0.26 \%)$ & $14 / 41(34.1 \%)$ & & 1.48 & $(0.67-3.24)$ & \\
\hline No & $81 / 346(23.4 \%)$ & $74 / 192(38.5 \%)$ & 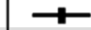 & 2.05 & $(1.40-3.01)$ & \\
\hline Diabetes mellitus & & & & & & 0.30 \\
\hline Yes & $23 / 94(24.5 \%)$ & $30 / 66(45.5 \%)$ & & 2.57 & $(1.31-5.05)$ & \\
\hline No & $84 / 352(23.9 \%)$ & $58 / 167(34.7 \%)$ & & 1.70 & $(1.14-2.54)$ & \\
\hline COPD & & & & & & 0.002 \\
\hline Yes & $45 / 118(38.1 \%)$ & $20 / 60(33.3 \%)$ & - & 0.81 & $(0.42-1.56)$ & \\
\hline No & $62 / 328(18.9 \%)$ & $68 / 173(39.3 \%)$ & $\longrightarrow$ & 2.78 & $(1.84-4.19)$ & \\
\hline LVEF $\leq 50 \%$ & & & & & & 0.17 \\
\hline Yes & $33 / 122(27.0 \%)$ & $34 / 68(50.0 \%)$ & -1 & 2.70 & $(1.45-5.02)$ & \\
\hline No & $74 / 323(22.9 \%)$ & $53 / 164(32.3 \%)$ & $\longrightarrow$ & 1.61 & $(1.06-2.44)$ & \\
\hline Creatinine & & & & & & 0.17 \\
\hline$\leq 1.07 \mathrm{mg} / \mathrm{dl}$ & $44 / 221(19.9 \%)$ & $32 / 118(27.1 \%)$ & -1 & 1.50 & $(0.89-2.53)$ & \\
\hline$>1.07 \mathrm{mg} / \mathrm{dl}$ & $63 / 225(28.0 \%)$ & $56 / 115$ (48.7\%) & $\longrightarrow$ & 2.44 & $(1.53-3.90)$ & \\
\hline Device type & & & & & & 0.73 \\
\hline MCS & $52 / 189(27.5 \%)$ & 76/198 (38.3\%) & 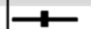 & 1.64 & $(1.07-2.52)$ & \\
\hline ES & $55 / 257(21.4 \%)$ & $12 / 35(34.3 \%)$ & & 1.92 & $(0.90-4.09)$ & \\
\hline & & 0.1 & 0 & 10 & & \\
\hline & & $\begin{array}{l}\text { Highe } \\
\text { in patients with }\end{array}$ & $\begin{array}{l}\mathrm{Hig} \\
\text { in } \mathrm{p}\end{array}$ & $\begin{array}{l}\text { ality } \\
\text { vith LBBB }\end{array}$ & & \\
\hline
\end{tabular}

Figure 3. Subset analysis of all-cause mortality.

Hazard ratio and $95 \%$ confidence interval (CI) are plotted for the primary endpoint of all-cause mortality at follow-up comparing patients without (no LBBB) and with (new LBBB) TAVI-induced left bundle branch block (LBBB). MI denotes myocardial infarction, CABG coronary artery bypass grafting, CVA cerebrovascular accident, PAD peripheral artery disease, COPD chronic obstructive lung disease, LVEF left ventricular ejection fraction, MCS Medtronic CoreValve System, ES Edwards SAPIEN.

\section{Determinants of TAVI-induced LBBB}

A binary logistic regression analysis was performed to identify baseline variables associated with the development of TAVI-induced LBBB. The use of the MCS prosthesis contributed significantly to the occurrence of LBBB in univariate analysis (HR, 7.69, CI, 5.13-11.54). By multivariate analysis, this interaction persisted (HR, 8.51, CI, 5.5313.11) (Table 3).

\section{Comparison of devices}

After MCS implantation, a new LBBB occurred in 198 out of 387 patients (51.1\%), as opposed to 35 out of 292 patients (12.0\%) who have been implanted an ES valve $(\mathrm{P}<0.001)$. Implantation of 26 and $29 \mathrm{~mm}$ MCS devices resulted in new LBBB in 95 out of 192 (49.5\%) and 103 out of 195 (52.8\%) patients, respectively ( $\mathrm{P}=0.54)$. 
Table 3. Univariate and multivariate binary logistic regression analysis of TAVI-induced left bundle branch block.*

\begin{tabular}{lllllll}
\hline & \multicolumn{3}{l}{ Univariate Analysis } & \multicolumn{3}{l}{ Multivariate Analysis } \\
Variable & HR & CI & P value & HR & CI & P value \\
\hline Age & 0.87 & $0.98-1.03$ & 0.87 & & & \\
Female gender & 0.84 & $0.61-1.16$ & 0.30 & & & \\
Baseline creatinine & 0.85 & $0.68-1.05$ & 0.14 & 0.83 & $0.66-1.05$ & 0.12 \\
Previous MI & 0.71 & $0.47-1.09$ & 0.12 & 0.78 & $0.49-1.24$ & 0.29 \\
Previous CABG & 0.80 & $0.55-1.16$ & 0.24 & & & \\
Cerebrovascular disease & 1.18 & $0.79-1.78$ & 0.42 & & & \\
Peripheral vascular disease & 0.74 & $0.49-1.11$ & 0.14 & 1.57 & $0.97-2.55$ & 0.07 \\
Diabetes mellitus & 1.48 & $1.03-2.13$ & 0.04 & 1.52 & $1.01-2.29$ & 0.04 \\
COPD & 0.96 & $0.67-1.38$ & 0.84 & & & \\
LVEF $\leq 50 \%$ & 1.10 & $0.77-1.56$ & 0.60 & & & \\
R $\left(\mathrm{aV} \mathrm{V}_{\mathrm{L}}\right)>11$ mm & 0.87 & $0.56-1.36$ & 0.55 & & & \\
$\mathrm{~S}\left(\mathrm{~V}_{1}\right)+\mathrm{R}\left(\mathrm{V}_{5 / 6}\right)>35 \mathrm{~mm}$ & 1.01 & $0.97-1.04$ & 0.72 & & & \\
absent $\mathrm{Q}$ in $\mathrm{V}_{6}$ & 1.05 & $0.72-1.54$ & 0.79 & & & \\
$\mathrm{MCS}$ prosthesis $\dagger$ & 7.69 & $5.13-11.54$ & $<0.001$ & 8.51 & $5.53-13.11$ & $<0.001$ \\
\hline
\end{tabular}

* HR denotes hazard ratio, CI 95\% confidence interval, MI myocardial infarction, CABG coronary-artery bypass grafting, COPD chronic obstructive pulmonary disease, LVEF left ventricular ejection fraction. † For calculation of the hazard ratio, the Medtronic CoreValve System (MCS) prosthesis was compared to the Edwards SAPIEN prosthesis.

For the ES device, new LBBB occurred less frequently with $23 \mathrm{~mm}$ valves (7 out of 109 [6.4\%]) than with $26 \mathrm{~mm}$ valves (28 out of 183 [15.3\%]) (P=0.03). Table 4 shows the difference in mortality rate between patients with and without LBBB for the entire study population and for subpopulations receiving the MCS and ES device. Mortality rate did not differ significantly between MCS and ES for patients with or for patients without TAVI-induced LBBB (log-rank P-value $=0.85$ and 0.23 , respectively). The frequency of LBBB development after MCS implantation decreased with increasing entry time, from $\sim 60 \%$ to $\sim 40 \%$. Entry time did not affect frequency of LBBB development after ES implantation (Figure 4). In the 2 centers implanting both MCS and ES, the frequency of new LBBB was significantly higher in MCS compared to ES implants (46.7\% and 15.9\%, respectively; $\mathrm{P}<0.001$ ). Also, LBBB occurred in $53.7 \%$ of cases in the MCS implanting centers compared to $10.3 \%$ of cases in the ES implanting centers $(\mathrm{P}<0.001)$. Of the 118 patients requiring postprocedural PPM implantation, $86.4 \%(n=102)$ was after MCS and 13.6\% (n=16) after ES implantation. In this patient category, the distribution of the different valve types was $5.9 \%(n=7), 7.6 \%$ $(n=9), 42.4 \%(n=50)$ and 44.1\% $(n=52)$ for the ES $23 \mathrm{~mm}$, ES $26 \mathrm{~mm}$, MCS $26 \mathrm{~mm}$ and MCS $29 \mathrm{~mm}$ valve, respectively. 


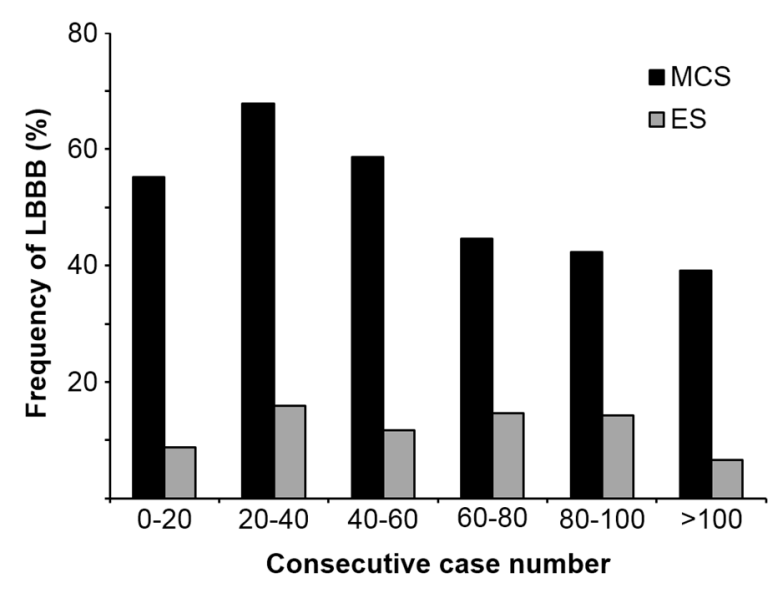

Figure 4. Incidence of TAVI-induced LBBB according to valve type.

The percentage of patients that develop a TAVI-induced LBBB for both the Medtronic CoreValve System (MCS) and the Edwards SAPIEN (ES) device. Patients were ranked into six different categories, according to their entry time into the local TAVI program.

Table 4. Mortality of patients without and with new left bundle branch block for the total study population and for subpopulations receiving each device type.*

\begin{tabular}{lllllll}
\hline \multicolumn{2}{l}{ all } & \multicolumn{3}{l}{ no LBBB } & \multicolumn{3}{c}{ new LBBB } \\
& no./total no. (\%) & & & & \\
\hline total study population & $195 / 679$ & $(28.7 \%)$ & $107 / 446$ & $(23.4 \%)$ & $88 / 233$ & $(37.8 \%)$ \\
MCS & $128 / 387$ & $(33.1 \%)$ & $52 / 189$ & $(27.5 \%)$ & $76 / 198$ & $(38.4 \%)$ \\
ES & $67 / 292$ & $(22.9 \%)$ & $55 / 257$ & $(21.4 \%)$ & $12 / 35$ & $(34.3 \%)$ \\
\hline
\end{tabular}

* LBBB denotes left bundle branch block, MCS Medtronic CoreValve System, ES Edwards SAPIEN.

\section{Discussion}

The present study shows that all-cause mortality is significantly higher in TAVI patients who develop LBBB as compared with TAVI patients who do not. The higher allcause mortality is largely determined by a significantly higher rate of cardiovascular deaths in patients with LBBB. TAVI-induced LBBB is the one of the strongest predictors of all-cause mortality in TAVI patients and this effect remains after adjustment for all potential confounders. Since the PARTNER trial showed that TAVI reduced allcause mortality at 1 year by $38 \%$ as compared with standard therapy. ${ }^{1}$, the $\sim 60 \%$ increase in 1-year mortality due to new-onset LBBB in present study suggests that the benefit of valve replacement by TAVI is largely neutralized when LBBB develops. In wider perspective, the strong influence of abnormal conduction on clinical outcome in patients with valvular heart disease, indicates that proper impulse conduction and valvular function are both, approximately equally, important for normal cardiac function. 


\section{TAVI-induced LBBB as risk factor for mortality}

Previous TAVI-related studies have registered LBBB as a complication, but did not mention its possible clinical relevance, ${ }^{15,18}$ because little is known about the impact of LBBB in the setting of valvular heart disease. However, multivariate analysis of our data indicate that TAVI-induced LBBB is an independent and important risk factor for all-cause mortality after TAVI. Although it is not possible to completely exclude that LBBB is a surrogate for another baseline or procedural characteristic, we think that our data strongly indicate that TAVI-induced LBBB itself is a risk factor for mortality. After all, most baseline characteristics of patient without and with TAVI-induced LBBB were comparable. Notably, in the TAVI-induced LBBB group, there was no higher incidence of left ventricular hypertrophy or septal fibrosis, both known to be associated with a poorer prognosis. There was also no coincidental association of TAVI-induced LBBB with non-cardiovascular cause of death. In logistic binary regression analysis, the use of the MCS prosthesis was a potent predictor of new-onset LBBB, however in multivariate Cox regression analysis for survival the device type being used did not predict mortality. This paradox can be explained by the fact that TAVI-induced LBBB is the predominant cause of mortality.

\section{Possible mechanism of increased mortality}

There are two possible explanations for the deleterious effect of TAVI-induced LBBB: the risk of progression to high degree atrioventricular conduction disorders and the adverse effects of dyssynchrony induced by LBBB. With regard to the latter, this possible effect of LBBB is in concordance with literature on electrocardiology and heart failure management, where LBBB is increasingly recognized as an important disorder, especially since the introduction of CRT.10,16 Moreover, the Dual Chamber and VVI Implantable Defibrillator (DAVID) trial demonstrated that continuous right ventricular pacing (resulting in a left ventricular activation pattern comparable to that of LBBB) increases the combined endpoint of heart failure hospitalization and death compared to backup pacing only. In that trial with 250 patients in each study arm, HR for all-cause 1-year mortality was 1.61.19

Both experimental LBBB and clinical right ventricular pacing lead to an early reduction in cardiac pump function followed by worsening over time, at least partly caused by left ventricular remodeling.9,20 Recently, a reduction in left ventricular function has also been observed in TAVI patients shortly after development of LBBB. ${ }^{21}$ Timewise similar, but directionally opposite changes are known after application of CRT in heart failure patients, where a rapid improvement in left ventricular function is seen followed by reverse remodeling and ultimately, reduction in mortality. ${ }^{22-24}$ Therefore, a likely cause for the higher mortality after TAVI-induced LBBB is progression of heart failure as a consequence of left ventricular remodeling induced by the abnormal contraction pattern. This hypothesis is supported by the observed larger percentage of cardiovascular deaths in patients with TAVI-induced LBBB. This 
is congruent with observations that in chronic right ventricular pacing, heart failure hospitalization occurs more frequently in patients with depressed than in patients with normal cardiac function. ${ }^{25}$ Except for pump failure, patients who develop dyssynchrony induced left ventricular dysfunction, are also susceptible to ventricular tachyarrhythmias, which could be another possible explanation for the higher mortality in the TAVI-induced LBBB group.

In our study, we were not able to differentiate between different (cardiac) causes of death. However, it is reasonable to presume that in our setting the significantly higher rate of cardiovascular death after TAVI-induced LBBB, is in a majority of cases caused by (dyssynchrony-induced) heart failure. As there is no significant difference in sudden death, it seems less likely that TAVI-induced LBBB is associated with brady-arrhythmias. Future studies are needed to confirm our hypotheses on mechanisms of increased mortality by TAVI-induced LBBB. In this way, we will be able to choose a cost-effective treatment strategy that will improve quality of life and/or life expectancy (e.g. pacemaker or CRT implantation) in this patient population composed of septua- and octogenerians.

\section{Possible mechanism of TAVI-induced LBBB}

The development of atrioventricular conduction disorders and LBBB observed with aortic valve disease ${ }^{26}$ as well as after TAVI ${ }^{4,27-29}$ or surgical aortic valve replacement ${ }^{30-32}$, has been explained by the proximity of the atrioventricular node and left bundle branch to the aortic valve. ${ }^{33}$ During the TAVI procedure, pressure of the prosthesis skirt on the membranous septum and the nearby atrioventricular node and left bundle branch, may cause conduction disorders. ${ }^{4}$ Indeed, it has been demonstrated that LBBB development was predicted by deeper MCS prosthesis implantation. ${ }^{34}$

Therefore, another possible cause of death for TAVI-induced LBBB is progression to high degree atrioventricular block, although a postprocedural new LBBB has not been identified as a risk factor for permanent pacemaker implantation, in contrast to pre-procedural LBBB. ${ }^{15}$

\section{Comparison of devices}

The present study corroborates data from other studies, demonstrating that the incidence of TAVI-induced LBBB is higher for the MCS device than for the ES prosthesis $^{5,35}$. A similar difference was observed for requirement of PPM implantation due to high-degree atrioventricular block, which is also in agreement with earlier studies ${ }^{4,5}$. The higher chance of inducing conduction disorders by the MCS device has been attributed to the longer prosthesis skirt of the former. ${ }^{28}$ However, recently it has been shown that during MCS implantation procedures LBBB develops before actual insertion of the valve device in more than $50 \%$ of the cases and that contact of guidewire and/or compression of the left ventricular outflow orifice by the dilatory 
balloon may be responsible for part of the damage to the conduction system. ${ }^{3,6}$ For the ES prosthesis, these data is not available. However, there are important differences between the delivery systems (catheters, balloon sizes and shapes) and vascular access route (i.e. transapical access where there is no need for a curved stiff guidewire in the left ventricle) that may explain the lower incidence of LBBB in ES implants. Our data further indicate that the incidence of LBBB in MCS implants decreases to some extent with increasing experience. Still, even with increasing experience the frequency of LBBB is $40 \%$ for MCS as opposed to less than $10 \%$ for the ES prosthesis. Therefore, education on TAVI should not only be directed to optimal valve repair, but also to preventing LBBB. Clearly, there is a large urge for better understanding the origin of TAVI-induced LBBB in order to develop better tools to prevent this conduction disorder. Our observation that TAVI-induced LBBB increases risk of mortality combined with a more than 4 times higher incidence of LBBB and PPM implantation in MCS implants, should be taken into consideration in making the choice between currently available devices and obtaining informed consent of the patient.

\section{Study limitations}

The present study is based on a multicenter Dutch registry, with the inherent limitations of such a design. However, this study is composed of consecutive cases over a 5 -year period from 8 out of 11 TAVI implanting centers in the Netherlands. To warrant data quality and validity, we have chosen a hard endpoint (all-cause mortality). No monitoring board or core lab was available for ECG analysis, but we strictly adhered to published guidelines for the diagnosis of $\mathrm{LBBB}^{11}$ and scored the presence of LBBB without knowledge of the actual outcome of the patient. The mean 30-day allcause mortality rate of our study is higher and the 1-year all-cause mortality rate is lower than compared to that of earlier reports, including the PARTNER trial, ${ }^{1,2,17}$ probably as a result of differences in logistic EuroSCORE, patient characteristics, inclusion and exclusion criteria.

\section{Conclusion}

In patients who develop LBBB after TAVI all-cause mortality is significantly higher compared with patients who do not develop LBBB. The excess in mortality is largely determined by a significantly higher rate of cardiovascular deaths in patients with LBBB. The frequency of LBBB is strongly dependent on prosthesis type, however the mortality risk when LBBB occurs, is equal for both devices. These data indicate that LBBB is a serious complication of TAVI that may strongly attenuate the benefit of this procedure. Further research is warranted to clarify cause of death as well as causal factors of the TAVI-induced LBBB. 


\section{References}

1. Leon MB, Smith CR, Mack M, Miller DC, Moses JW, Svensson LG, Tuzcu EM, Webb JG, Fontana GP, Makkar RR, Brown DL, Block PC, Guyton RA, Pichard AD, Bavaria JE, Herrmann HC, Douglas PS, Peterson JL, Ajkin JJ, Anderson WA, Wang D, Pocock S. Transcatheter aortic-valve implantation for aortic stenosis in patients who cannot undergo surgery. N Engl J Med 2010; 363: 1597-1607.

2. Smith CR, Leon MB, Mack MJ, Miller DC, Moses JW, Svensson LG, Tuzcu EM, Webb JG, Fontana GP, Makkar RR, Williams M, Dewey T, Kapadia S, Babaliaros V, Thourani VH, Corso P, Pichard AD, Bavaria JE,Herrmann HC, Akin JJ, Anderson WA, Wang D, Pocock SJ. Transcatheter versus surgical aorticvalve replacement in high-risk patients. N Engl J Med 2011; 364: 2187-2198.

3. Piazza N, Onuma Y, Jesserun E, Kint PP, Maugenest AM, Anderson RH, de Jaegere PP, Serruys PW. Early and persistent intraventricular conduction abnormalities and requirements for pacemaking after percutaneous replacement of the aortic valve. JACC Cardiovasc Interv 2008; 1: 310-316.

4. Sinhal A, Altwegg L, Pasupati S, Humphries KH, Allard M, Martin P, Cheung A, Ye J, Kerr C, Lichtenstein SV, Webb JG. Atrioventricular block after transcatheter balloon expandable aortic valve implantation. JACC Cardiovasc Interv 2008; 1: 305-309.

5. Roten L, Wenaweser P, Delacretaz E, Hellige G, Stortecky S, Tanner H, Pilgrim T, Kadner A, Eberle B, Zwahlen M, Carrel T, Meier B, Windecker S. Incidence and predictors of atrioventricular conduction impairment after transcatheter aortic valve implantation. Am J Cardiol 2010; 106: 1473-1480.

6. Nuis R-J, Van Mieghem NM, Schultz CJ, Tzikas A, van der Boon RM, Maugenest AM, Cheng J, Piazza N, van Domburg RT, Serruys PW, de Jaegere PP. Timing and potential mechanisms of new conduction abnormalities during the implantation of the Medtronic CoreValve System in patients with aortic stenosis. Eur Heart J 2011; 32: 2067-2074.

7. Grines CL, Bashore TM, Boudoulas H, Olson S, Shafer P, Wooley CF. Functional abnormalities in isolated left bundle branch block. The effect of interventricular asynchrony. Circulation 1989; 79: 845853.

8. Lee SJ, McCulloch C, Mangat I, Foster E, De Marco T, Saxon LA. Isolated bundle branch block and left ventricular dysfunction. J Card Fail 2003; 9: 87-92.

9. Vernooy K, Verbeek XA, Peschar M, Crijns HJ, Arts T, Cornelussen RN, Prinzen FW. Left bundle branch block induces ventricular remodeling and functional septal hypoperfusion. Eur Heart J 2005; 26: 9198.

10. Zannad F, Huvelle E, Dickstein K, van Veldhuisen DJ, Stellbrink C, Kober L, Cazeau S, Ritter P, Maggioni AP, Ferrari R, Lechat P. Left bundle branch block as a risk factor for progression to heart failure. Eur J Heart Fail 2007; 9: 7-14.

11. Willems JL, Robles de Medina E, Bernard R, Coumel P, Fisch C, Krikler D, Mazur NA, Meijler FL, Mogensen L, Moret P, Pisa Z, Rautaharju, PM, Surawicz, B, Watanabe, Y, Wellens, HJJ. Criteria for intraventricular conduction disturbances and pre-excitation. J Am Coll Cardiol 1985; 5: 1261-1275.

12. Sokolow M, Lyon TP. The ventricular complex in left ventricular hypertrophy as obtained by unipolar precordial and limb leads. Am Heart J 1949; 37: 161-186.

13. Burch GE, Depasquale N. A study at autopsy of the relation of absence of the $Q$ wave in leads $\mathrm{I}, \mathrm{aVL}$, V5, and V6 to septal fibrosis. Am Heart J 1960; 60: 336-340.

14. Xiao HB, Gibson DG. Absent septal q wave on electrocardiogram: a forgotten marker of myocardial disease. Int J Cardiol 1996; 53: 1-4.

15. Jilaihawi H, Chin D, Vasa-Nicotera M, Jeilan M, Spyt T, Ng GA, Bence J, Logtens E, Kovac J. Predictors for permanent pacemaker requirement after transcatheter aortic valve implantation with the CoreValve bioprosthesis. Am Heart J 2009; 157: 860-866.

16. Zareba W, Klein H, Cygankiewicz I, Hall WJ, McNitt S, Brown M, Cannon D, Daubert JP, Eldar M, Gold MR, Goldberger JJ, Goldenberg I, Lichstein E, Pitschner H, Rashtian M, Solomon S, Viskin S, Wang P, Moss A. Effectiveness of Cardiac Resynchronization Therapy by QRS Morphology in the Multicenter Automatic Defibrillator Implantation Trial-Cardiac Resynchronization Therapy (MADIT-CRT). Circulation 2011; 123: 1061-1072. 
17. Webb JG, Altwegg L, Boone RH, Cheung A, Ye J, Lichtenstein S, Lee M, Masson JB, Thompson C, Moss R, Carere R, Munt B, Nietlispach F, Humphries K. Transcatheter aortic valve implantation: impact on clinical and valve-related outcomes. Circulation 2009; 119: 3009-3016.

18. Calvi V, Puzzangara E, Pruiti GP, Conti S, Di Grazia A, Ussia GP, Capodanno D, Tamburino C. Early conduction disorders following percutaneous aortic valve replacement. Pacing Clin Electrophysiol 2009; 32 Suppl 1: S126-30.

19. Wilkoff BL, Cook JR, Epstein AE, Greene HL, Hallstrom AP, Hsia H, Kutalek SP, Sharma A. Dual-chamber pacing or ventricular backup pacing in patients with an implantable defibrillator: the Dual Chamber and VVI Implantable Defibrillator (DAVID) Trial. JAMA 2002; 288: 3115-3123.

20. Yu CM, Chan JY, Zhang Q, Omar R, Yip GW, Hussin A, Fang F, Lam KH, Chan HC, Fung JW. Biventricular Pacing in Patients with Bradycardia and Normal Ejection Fraction. N Engl J Med 2009; 361: 21232134.

21. Tzikas A, van Dalen BM, Van Mieghem NM, Gutierrez-Chico JL, Nuis R-J, Kauer F, Schultz C, Serruys PW, de Jaegere PP, Geleijnse ML. Frequency of conduction abnormalities after transcatheter aortic valve implantation with the Medtronic-CoreValve and the effect on left ventricular ejection fraction. Am J Cardiol 2011; 107: 285-289.

22. Yu CM, Chau E, Sanderson JE, Fan K, Tang MO, Fung WH, Lin H, Kong SL, Lam YM, Hill MR, Lau CP. Tissue Doppler echocardiographic evidence of reverse remodeling and improved synchronicity by simultaneously delaying regional contraction after biventricular pacing therapy in heart failure. Circulation 2002; 105: 438-445.

23. Bristow MR, Saxon LA, Boehmer J, Krueger S, Kass DA, De Marco T, Carson P, DiCarlo L, DeMets D, White BG, DeVries DW, Feldman AM. Cardiac resynchronization therapy with or without an implantable defibrillator in advanced chronic heart failure. N Engl J Med 2004; 350: 2140-2150.

24. Cleland JG, Daubert JC, Erdmann E, Freemantle N, Gras D, Kappenberger L, Tavazzi L. The effect of cardiac resynchronization on morbidity and mortality in heart failure. N Engl J Med 2005; 352: 15391549.

25. Sweeney MO, Prinzen FW. A new paradigm for physiologic ventricular pacing. J Am Coll Cardiol 2006; 47: 282-288.

26. Schwartz LS, Goldfischer J, Sprague GJ, Schwartz SP. Syncope and sudden death in aortic stenosis. Am J Cardiol 1969; 23: 647-658.

27. Rodés-Cabau J, Webb JG, Cheung A, Ye J, Dumont E, Feindel CM, Osten M, Natarajan MK, Velianou JL, Martucci G, DeVarennes B, Chisholm R, Peterson MD, Lichtenstein SV, Nietlispach F, Doyle D, DeLarochelliere R, Teoh K, Chu V, Dancea A, Lachapelle K, Cheema A, Latter D, Horlick E. Transcatheter aortic valve implantation for the treatment of severe symptomatic aortic stenosis in patients at very high or prohibitive surgical risk: acute and late outcomes of the multicenter Canadian experience. $J$ Am Coll Cardiol 2010; 55: 1080-1090.

28. Khawaja MZ, Rajani R, Cook A, Khavandi A, Moynagh A, Chowdhary S, Spence MS, Brown S, Khan SQ, Walker N, Trivedi U, Hutchinson N, De Belder AJ, Moat N, Blackman DJ, Levy RD, Manoharan G, Roberts D, Khogali, Crean P, Brecker SJ, Baumbach A, Mullen M, Laborde J-C, Hildick-Smith D. Permanent pacemaker insertion after CoreValve transcatheter aortic valve implantation: incidence and contributing factors (the UK CoreValve Collaborative). Circulation 2011; 123: 951-960.

29. Tamburino C, Capodanno D, Ramondo A, Petronio AS, Ettori F, Santoro G, Klugmann S, Bedogni F, Maisano F, Marzocchi A, Poli A, Antoniucci D, Napodano M, De Carlo M, Fiorina C, Ussia GP. Incidence and predictors of early and late mortality after transcatheter aortic valve implantation in 663 patients with severe aortic stenosis. Circulation 2011; 123: 299-308.

30. Limongelli G, Ducceschi V, D'Andrea A, Renzulli A, Sarubbi B, De Feo M, Cerasuolo F, Calabro R, Cotrufo M. Risk factors for pacemaker implantation following aortic valve replacement: a single centre experience. Heart 2003; 89: 901-904.

31. Erdogan HB, Kayalar N, Ardal H, Omeroglu SN, Kirali K, Guler M, Akinci E, Yakut C. Risk factors for requirement of permanent pacemaker implantation after aortic valve replacement. J Card Surg 2006; 21: 211-215. 
32. Dawkins S, Hobson AR, Kalra PR, Tang AT, Monro JL, Dawkins KD. Permanent pacemaker implantation after isolated aortic valve replacement: incidence, indications, and predictors. Ann Thorac Surg 2008; 85: 108-112.

33. Piazza N, de Jaegere P, Schultz C, Becker AE, Serruys PW, Anderson RH. Anatomy of the aortic valvar complex and its implications for transcatheter implantation of the aortic valve. Circ Cardiovasc Interv 2008; 1: 74-81.

34. Baan J Jr., Yong ZY, Koch KT, Henriques JP, Bouma BJ, Vis MM, Cocchieri R, Piek JJ, de Mol BA. Factors associated with cardiac conduction disorders and permanent pacemaker implantation after percutaneous aortic valve implantation with the CoreValve prosthesis. Am Heart J 2010; 159: 497-503.

35. Erkapic D, Kim WK, Weber M, Mollmann H, Berkowitsch A, Zaltsberg S, Pajitnev DJ, Rixe J, Neumann T, Kuniss M, Sperzel J, Hamm CW, Pitschner HF. Electrocardiographic and further predictors for permanent pacemaker requirement after transcatheter aortic valve implantation. Europace 2010; 12: 1188-1190. 


\section{CHAPTER 3}

\section{Occurrence, Fate and Consequences of Ventricular Conduction Abnormalities after Transcatheter Aortic Valve Implantation}

Patrick Houthuizen, Robert M.A. van der Boon, Marina Urena, Nicolas van Mieghem, Guus R.G. Brueren, Thomas T. Poels, Leen A.F.M. Van Garsse, Josep Rodés-Cabau, Frits W. Prinzen, Peter de Jaegere

Published in EuroIntervention 2014; 9: 1142-1150 


\section{Abstract}

\section{Introduction}

Transcatheter aortic valve implantation (TAVI) is frequently complicated by new left bundle branch block (new LBBB). We investigated the development and persistence of LBBB during follow-up and its clinical consequence.

\section{Methods and Results}

ECGs at baseline, within 24 hours, before discharge and at 12 months after TAVI were assessed in 476 patients without pre-existing LBBB and/or pacemaker before or after TAVI. TAVI-induced new LBBB was categorized based on timing of occurrence; within 24 hours (acute), after 24 hours but before discharge (subacute), and after discharge (late) in addition to persistence (transient or persistent). A total of 175 patients (36.8\%) developed new LBBB of which $85.7 \%$ occurred within 24 hours after TAVI, $12.0 \%$ before and $2.3 \%$ after hospital discharge and was persistent in 111 patients (63.4\%). Implantation of the Medtronic CoreValve System (MCS) led more frequently to new LBBB than the balloon-expandable Edwards SAPIEN valve (ES) (53.8\% versus $21.7 \%$ ) with less recovery during follow-up (39.0\% versus $9.5 \%)$. Late new LBBB was only seen in 4 patients $(0.8 \%)$. During a median followup of 915 (interquartile range [IQR], 578-1,234) days, persistent LBBB was associated with a significant increase in mortality as compared to no LBBB and temporary LBBB combined (hazard ratio, 1.49, 95\% confidence interval, 1.10-2.03; $\mathrm{P}=0.01$ ).

\section{Conclusion}

TAVI-induced new LBBB occurs in almost $40 \%$ of patients of which almost all before hospital discharge. It occurs 3 times more frequent after MCS than after ES valve implantation and has a twofold lower tendency to resolve during follow-up. Persistent LBBB is associated with a higher mortality. 


\section{Introduction}

Since the first successful implantation in $2002,{ }^{1}$ transcatheter aortic valve implantation (TAVI) has become an accepted and evidence-based alternative to surgical aortic valve replacement in selected patients with aortic valve stenosis. ${ }^{2,3}$ Despite its clinical benefits, periprocedural conduction disorders, in particular new left bundle branch block (new LBBB), frequently occur after TAVI. ${ }^{4-6}$ New LBBB affects left ventricular function, increases the risk for postoperative permanent pacemaker implantation and has been associated with an increased mortality. 4,5,7,8

New LBBB occurs more frequently after implantation of the self-expanding Medtronic CoreValve System (MCS; reported frequency 30-60\%) than after the balloonexpandable Edwards SAPIEN valve (ES; reported frequency 6-12\%) (6,9-13. $^{6}$.

There are, however, scant detailed electrocardiographic data assessing the changes of QRS duration and morphology not only shortly after TAVI but also during follow-up. Recovery of TAVI-induced new LBBB may occur but is less frequent after MCS than ES valve implantation. Also, little is known about the development of intraventricular conduction disorders after hospital discharge ${ }^{5,14-16}$.

This was subject of the present study in which a series of 476 patients who underwent TAVI with the MCS or ES device without pre-existing LBBB, permanent pacemaker (PPM) or postprocedural PPM implantation were subjected to a detailed and prospective electrocardiographic assessment.

\section{Methods}

\section{Patient population}

The patient population consists of 701 patients who underwent TAVI between January 2006 and July 2011 with the Medtronic CoreValve System (MCS; Medtronic Inc, Minneapolis, MN, USA) $(\mathrm{n}=339)$ or the balloon-expandable Edwards SAPIEN valve (ES; Edwards Lifesciences LLC, Irvine, CA, USA) $(n=350)$ in any of following institutions: Quebec Heart \& Lung Institute $(n=212 ; E S: n=206)$, Erasmus Medical Center Rotterdam ( $n=202$; MCS: $n=200)$, Catharina Hospital Eindhoven $(n=173$; MCS: $n=139$; ES: $n=30$ ), Maastricht University Medical Center ( $n=114$; ES: $n=114)$. In 12 patients the procedure was aborted without implantation of any valve.

For the purpose of the study, only patients with a minimum follow-up of 1 year after TAVI were eligible. Also, patients with pre-existing LBBB and/or permanent pacemaker (PPM) before TAVI were excluded from analysis, as well as patients who did not undergo valve implantation (aborted procedure). Patients who received a new PPM within 30 days after TAVI were also excluded, since it precludes accurate assessment of eventual LBBB or other conduction disorders. Therefore, the study 
population consisted of 484 patients (Figure 1), of whom 6 patients $(1.2 \%)$ died during or shortly after the procedure resulting in the absence of any postprocedural electrocardiogram (ECG). From another 2 patients $(0.4 \%)$ there were no ECGs available after the implantation.

All clinical and procedural data were prospectively collected and entered into a dedicated central database. If necessary, additional information was collected by analysis of medical records. The use of anonymous clinical, procedural and follow-up data for research were in accordance with the institutional policies.
701 patients

screened for eligibility
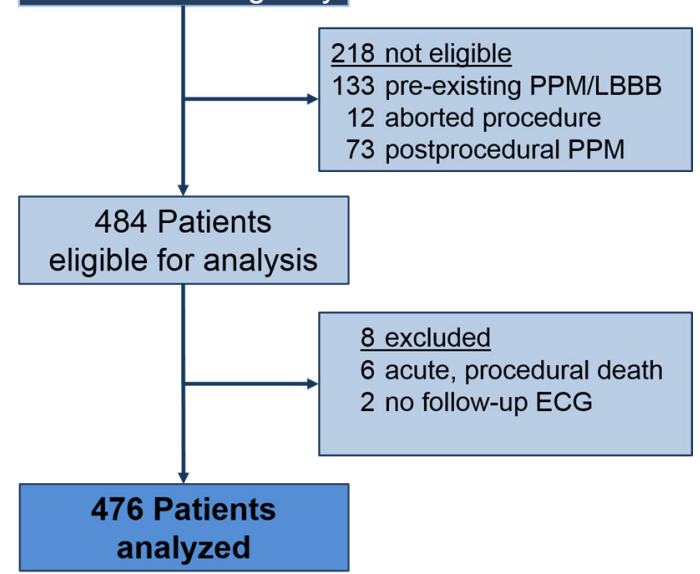

Figure 1. Study population.

PPM denotes permanent pacemaker, LBBB left bundle branch block.

\section{Objectives \& data collection}

The primary objective was to assess the changes in intraventricular conduction by comparing the 12-lead ECGs at baseline, within 24 hours, before discharge and 12 months after TAVI. ECG tracings were stored digitally in either the portable document (PDF) or Joint Photographic Experts Group (JPEG) format, depending on availability per patient and center. All tracings were analyzed by an experienced cardiologist $(\mathrm{PH})$ to record heart rhythm, PR interval, QRS duration, QRS morphology and QRS axis in exact degrees. Digital files were zoomed to $800 \%$ to measure intervals and duration. Presence of first, second or third degree atrioventricular block, right bundle branch block (RBBB), LBBB, left anterior hemiblock (LAHB) and left posterior hemiblock (LPHB) were recorded according to the established criteria ${ }^{17}$. Accordingly, LBBB was defined as a V1-negative QRS-complex of $\geq 0.12$ seconds in duration with absent Q-waves and a notched or slurred R in leads I, aVL, V5 and/or V6. A LAHB was defined as a QRS-duration $\geq 0.10$ seconds with a frontal plane QRS-axis between -45 and -90 degrees in the presence of a qR in leads I and aVL. In the presence of RBBB, LAHB was defined as a frontal plane QRS-axis between -45 and -90 degrees. Finally, a significant change in QRS duration was defined as an absolute change of more than 30 milliseconds (msec), based on reported interobserver variability of measured QRS duration. ${ }^{18}$ Examples of the ECG interpretation are shown in figure 2. 
Type 1

QRS-widening without other conduction defect
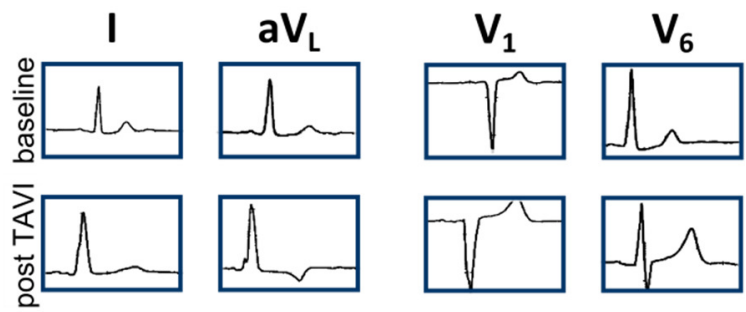

Type 2
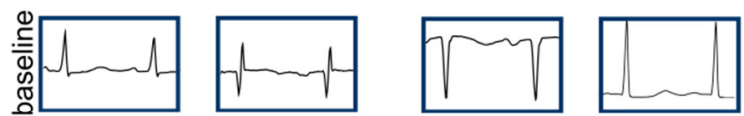

Development of new left anterior hemiblock
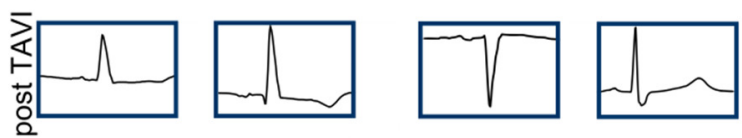

Type 3
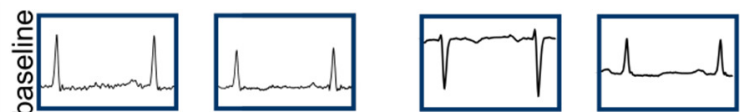

Development of new
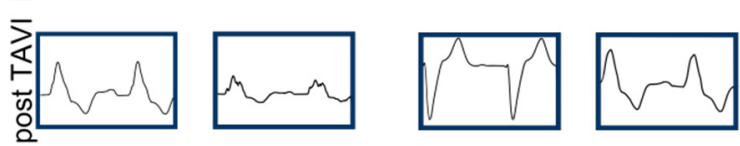

Figure 2. Examples of changes in QRS-duration and/or morphology.

Illustration of different patterns of change in QRS-duration and/or morphology after TAVI. Type 1 indicates QRS-widening $>120$ msec without distinct conduction defect and type 2 and 3 are an example of new LAHB en new LBBB, respectively. Although there is a significant widening ( $>30 \mathrm{msec}$ ) of the QRS complex in type 1 , this should not be considered a new LBBB.

The occurrence of and recovery from LBBB was studied by comparing ECGs between the different time points. Distinction was made between acute $L B B B$ (onset within 24 hours after TAVI), subacute $\angle B B B$ (onset after 24 hours but before discharge) and late $\angle B B B$ (onset after discharge). In addition, persistent $\angle B B B$ was defined by any LBBB that is present 12 months after TAVI and transient $\angle B B B$ in case a new LBBB resolved within 12 months. In patients who died before 1 year follow-up ( $n=50$; $10.5 \%)$ and in those without an ECG at 1 year after TAVI $(n=34 ; 7.1 \%)$, the last available ECG was used for classification of transient or persistent LBBB.

The secondary objective was to compare mortality between patients with temporary, persistent and no LBBB. Mortality was checked by contacting the Civil Registry in the Netherlands which continuously collects all deaths and cause of all Dutch citizens and inhabitants of the Netherlands. For the Canadian study population, mortality was checked by contacting the referring physician or general practitioner. 


\section{Statistical analysis}

Categorical variables are presented as numbers and proportions. For continuous variables, normality of distribution was assessed with the Kolmogorov-Smirnov test. Normal and skewed continuous variables are presented as means with standard deviation (SD) and medians with interquartile range (IQR), respectively.

Baseline variables between patients without a new LBBB, and patients with transient LBBB or persistent LBBB after TAVI were compared using repeated measures analysis of variance (ANOVA) in case of a continuous measurement. Binary logistic regression analysis was used to compare categorical variables. Where applicable, variables were compared using the unpaired t-test or Mann-Whitney $U$ test for normal and skewed continuous variables, respectively. Categorical variables were compared using the Pearson Chi-Square test. Survival was estimated using the KaplanMeier method. Log-rank testing was used to compare differences in survival between patients without, with transient and with persistent LBBB. Survival was also compared between patients with persistent and patients without persistent LBBB (i.e. patients with transient or no LBBB) using both log-rank testing and Cox regression analysis. In addition, Kaplan Meier estimates of survival were also constructed for patients who received a PPM after TAVI.

A two-sided p-value less than 0.05 was considered to be statistically significant. All statistical analyses were performed using Statistical Package for Social Sciences (SPSS), version 20 (IBM SPSS, Chicago, IL, USA).

\section{Results}

Baseline characteristics and procedural details of the study population of 476 patients eligible for analysis (Figure 1) and of those with a transient and persistent LBBB (Figure 3) are shown in Table 1. Overall, there was an almost even distribution of both devices (MCS in 223 patients or 46.8\%; ES in 253 patients or $53.2 \%$ ). The majority of patients (301 or 63.2\%) underwent transfemoral TAVI and 168 (35.3\%) underwent transapical TAVI.

There were 175 patients (36.8\%) who developed a new LBBB that occurred within 24 hours after TAVI (acute LBBB) in 150 patients (31.5\%), >24 hours but before hospital discharge (subacute LBBB) in 21 (4.4\%) and after discharge (late LBBB) in 4 patients $(0.8 \%)$ (Figure 2$)$. At 12 months, TAVI-induced new LBBB was persistent in 111 out of 175 patients (63.4\%) and transient in 64 (36.6\%).

ECG details are shown in Table 2. A new LAHB was the second most frequent ventricular conduction disorder and occurred in $17.2 \%(n=76)$ out of the 442 patients without LAHB at baseline and was persistent in 57 (75\%). A new RBBB occurred in 12 patients $(2.7 \%)$ without baseline RBBB $(n=446)$. Most conduction disorders occurred before discharge. A new LBBB, LAHB and RBBB occurred during follow-up in 4, 7 and 1 patient(s), respectively. 


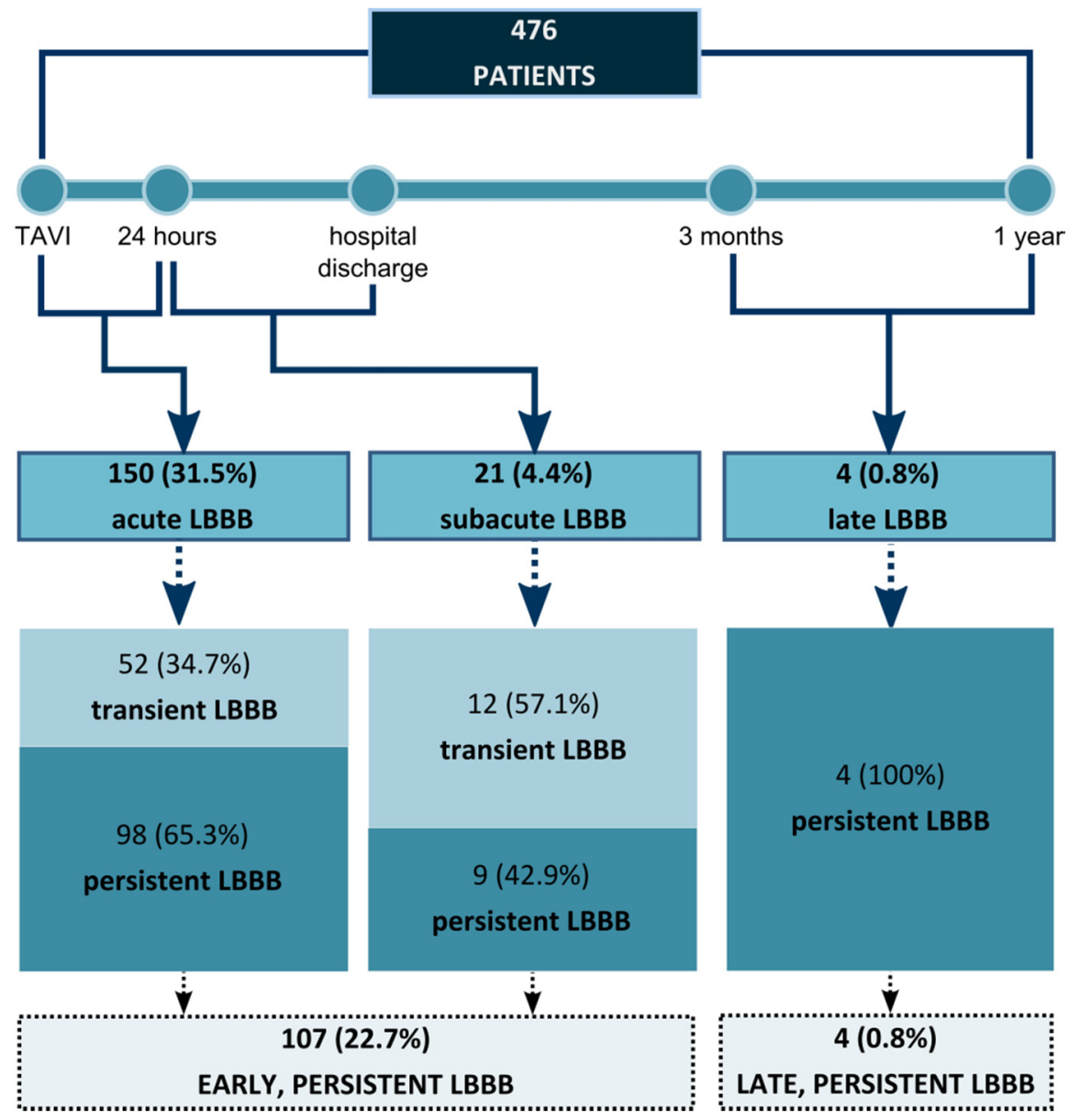

Figure 3. Frequency, timing and persistence of TAVI-induced, new LBBB.

LBBB denotes left bundle branch block.

By univariate analysis, a new LBBB occurred more frequently after MCS than after ES valve implantation and was also more often persistent (53.8\% and 39.0\% for MCS versus $21.7 \%$ and $9.5 \%$ for ES, respectively; $\mathrm{p}<0.001$ ) (Table 1 and 3 ). As the transfemoral route is associated with MCS implantation, this access route was also more frequent in patients who developed new LBBB. Yet, a new LAHB was more frequent after ES valve implantation $(27.5 \%$ versus $5.3 \%$; $\mathrm{p}<0.001)$ that was also more often persistent $(20.3 \%$ versus $4.4 \%$; $\mathrm{P}<0.001)$. 
Table 1. Clinical characteristics of the study population.*

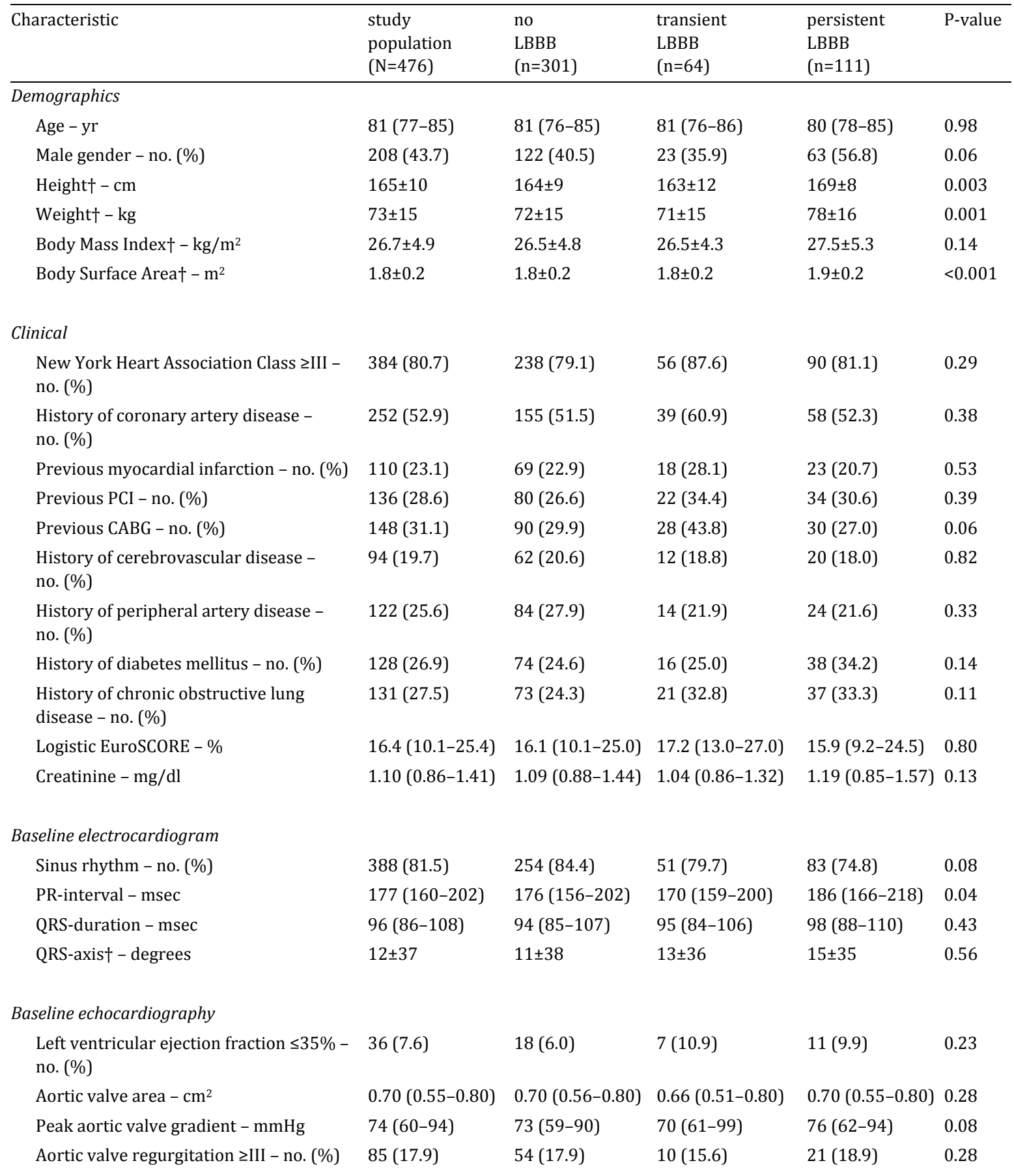




\begin{tabular}{|c|c|c|c|c|c|}
\hline Characteristic & $\begin{array}{l}\text { study } \\
\text { population } \\
(\mathrm{N}=476)\end{array}$ & $\begin{array}{l}\text { no } \\
\text { LBBB } \\
(n=301)\end{array}$ & $\begin{array}{l}\text { transient } \\
\text { LBBB } \\
(\mathrm{n}=64)\end{array}$ & $\begin{array}{l}\text { persistent } \\
\text { LBBB } \\
(\mathrm{n}=111)\end{array}$ & P-value \\
\hline \multicolumn{6}{|l|}{ Procedural characteristics } \\
\hline Type of access- no. (\%) & & & & & $<0.001$ \\
\hline transfemoral & $301(63.2)$ & $166(55.1)$ & $44(68.8)$ & $91(82.0)$ & \\
\hline Transapical & $168(35.3)$ & $131(43.5)$ & $20(31.3)$ & $17(15.3)$ & \\
\hline transsubclavian & $5(1.1)$ & $2(0.7)$ & $0(0)$ & $3(2.7)$ & \\
\hline Prosthesis type and size - no. (\%) & & & & & $<0.001$ \\
\hline Medtronic CoreValve System & $223(46.8)$ & $103(34.2)$ & $33(51.6)$ & $87(78.4)$ & \\
\hline $26 \mathrm{~mm}$ & $76(16.0)$ & $39(13.0)$ & $12(18.8)$ & $25(22.5)$ & \\
\hline $29 \mathrm{~mm}$ & $147(30.1)$ & $64(21.3)$ & $21(32.8)$ & $62(55.9)$ & \\
\hline Edwards SAPIEN & $253(53.2)$ & $198(65.8)$ & $31(48.4)$ & $24(21.6)$ & \\
\hline $20 \mathrm{~mm}$ & $1(0.2)$ & $1(0.3)$ & $0(0)$ & $0(0)$ & \\
\hline $23 \mathrm{~mm}$ & $153(32.1)$ & $121(40.1)$ & $21(32.8)$ & $11(9.9)$ & \\
\hline $26 \mathrm{~mm}$ & $94(19.5)$ & $72(23.9)$ & $10(15.6)$ & $12(10.8)$ & \\
\hline $29 \mathrm{~mm}$ & $5(1.1)$ & $4(1.3)$ & $0(0)$ & $1(0.9)$ & \\
\hline
\end{tabular}

* Results are presented as median (interquartile range) or absolute number (percentage), unless stated otherwise. PCI denotes percutaneous coronary intervention, CABG coronary-artery bypass grafting. † Height, weight, body mass index, body surface area and baseline QRS axis are presented as mean \pm SD.

Table 2. Comparison of electrocardiographic characteristics at baseline, within 24 hours after procedure, before discharge and at long-term follow-up.*

\begin{tabular}{lcccc}
\hline Characteristic & baseline & $\begin{array}{c}\text { post } \\
\text { procedure }\end{array}$ & $\begin{array}{c}\text { at } \\
\text { discharge }\end{array}$ & $\begin{array}{c}12 \\
\text { months }\end{array}$ \\
\hline time postprocedure - days (IQR) & - & $0(0-0)$ & $4(3-8)$ & $366(304-378)$ \\
ECG's analyzed - no. & 476 & 468 & 467 & 392 \\
missing ECG - no. (\%) & $0(0)$ & $8(1.7)$ & $9(1.9)$ & $84(17.6)$ \\
no comparison ECG available - no. (\%) & $0(0)$ & $8(1.7)$ & $15(3.2)$ & $89(18.7)$ \\
& & & & \\
Rhythm - no. (\%) & & & & \\
$\quad$ Sinus rhythm & $388(81.5)$ & $362(77.4)$ & $355(76.0)$ & $307(78.3)$ \\
$\quad$ Atrial fibrillation/flutter & $87(18.3)$ & $91(19.4)$ & $107(22.9)$ & $78(19.9)$ \\
$\quad$ Ventricular pace & $0(0)$ & $6(1.3)$ & $2(0.4)$ & $7(0.1 .7)$ \\
$\quad$ Other & $1(0.2)$ & $9(1.9)$ & $3(0.6)$ & $0(0)$ \\
PR-interval - msec & & & & $184(160-210)$ \\
QRS-duration - msec & $177(160-202)$ & $182(160-210)$ & $187(160-220)$ & $110(95-136)$ \\
QRS-axis - degrees & $96(86-108)$ & $120(100-145)$ & $115(100-144)$ & $-2 \pm 45$ \\
Conduction disorders - no. (\%) & $12 \pm 37$ & $-2 \pm 46$ & $0 \pm 43$ & \\
$\quad$ First-degree AV block & $81(17.0)$ & $97(20.8)$ & $120(25.9)$ & $91(23.3)$
\end{tabular}




$\begin{array}{lcccc}\text { Second-degree AV block } & 0(0) & 1(0.2) & 1(0.2) & 0(0) \\ \text { Third-degree AV block } & 0(0) & 8(1.7) & 4(0.9) & 4(1.0) \\ \text { RBBB } & 17(3.6) & 14(3.0) & 17(3.6) & 7(1.5) \\ \text { LAHB } & 21(4.4) & 68(14.5) & 57(12.2) & 50(12.8) \\ \text { RBBB \& LAHB } & 13(2.7) & 21(4.5) & 18(3.9) & 18(4.6) \\ \text { LBBB } & 0(0) & 150(31.5) & 134(28.7) & 89(22.7) \\ \text { Unspecified } & 2(0.4) & 9(1.9) & 4(0.9) & 6(1.5)\end{array}$

Change in conduction disorders - no. (\%)

$\begin{array}{lcccc}\text { New RBBB } & - & 8(1.7) & 3(0.6) & 1(0.2) \\ \text { New LAHB } & - & 64(13.4) & 5(1.1) & 7(1.5) \\ \text { New LBBB } & - & 150(31.5) & 21(4.4) & 4(1.0) \\ \text { Recovery from RBBB } & - & - & 3(0.6) & 5(1.1) \\ \text { Recovery from LAHB } & - & - & 19(4.0) & 0(0) \\ \text { Recovery from LBBB } & - & - & 34(7.1) & 30(7.7)\end{array}$

* IQR denotes interquartile range, ECG electrocardiogram, AV atrioventricular, RBBB right bundle branch block, LAHB left anterior hemiblock, LBBB left bundle branch block.

Table 3. Comparison of devices.*

\begin{tabular}{|c|c|c|c|c|c|c|c|}
\hline \multirow{2}{*}{$\begin{array}{l}\text { Characteristic } \\
\text { New } L B B B\end{array}$} & \multicolumn{2}{|c|}{$\begin{array}{l}\text { total } \\
\text { population } \\
(\mathrm{N}=476)\end{array}$} & \multicolumn{2}{|c|}{$\begin{array}{l}\text { MCS } \\
(n=223)\end{array}$} & \multicolumn{2}{|c|}{$\begin{array}{l}\text { ES } \\
(n=253)\end{array}$} & \multirow{2}{*}{$\begin{array}{c}\text { P-value } \\
<0.001\end{array}$} \\
\hline & 175 & $36.8 \%$ & 120 & $53.8 \%$ & 55 & $21.7 \%$ & \\
\hline transient & 58 & $12.2 \%$ & 30 & $13.5 \%$ & 28 & $11.1 \%$ & \\
\hline transient, evolving to persistent LAHB & 6 & $1.3 \%$ & 3 & $1.3 \%$ & 3 & $1.2 \%$ & \\
\hline persistent & 111 & $23.3 \%$ & 87 & $39.0 \%$ & 24 & $9.5 \%$ & \\
\hline New $L A H B$ & 76 & $17.2 \%$ & 11 & $5.3 \%$ & 65 & $27.5 \%$ & $<0.001$ \\
\hline transient & 18 & $4.1 \%$ & 1 & $0.5 \%$ & 17 & $7.2 \%$ & \\
\hline transient, evolving to persistent LBBB & 1 & $0.2 \%$ & 1 & $0.5 \%$ & 0 & $0 \%$ & \\
\hline persistent & 57 & $12.9 \%$ & 9 & $4.4 \%$ & 48 & $20.3 \%$ & \\
\hline New RBBB & 12 & $2.7 \%$ & 7 & $3.3 \%$ & 5 & $2.1 \%$ & $\mathrm{n} / \mathrm{a}$ \\
\hline transient & 8 & $1.8 \%$ & 5 & $2.4 \%$ & 3 & $1.3 \%$ & \\
\hline persistent & 4 & $0.9 \%$ & 2 & $0.9 \%$ & 2 & $0.8 \%$ & \\
\hline
\end{tabular}

* MCS denotes Medtronic CoreValve System, ES Edwards SAPIEN, LAHB Left anterior hemiblock, LBBB Left bundle branch block, RBBB right bundle branch block. 


\section{Outcome (mortality at follow-up)}

Median follow-up was 898 (IQR, 592-1,183), 944 (IQR, 691-1,321) and 914 (IQR, 268-1,333) days in patients without, with temporary and with persistent LBBB, respectively $(\mathrm{P}=0.08)$. Mortality at 1 year was $17.3 \%(\mathrm{n}=52), 6.2 \%(\mathrm{n}=4)$ and $27.0 \%$ $(\mathrm{n}=30)$ in patients without LBBB, with temporary LBBB and with persistent LBBB, respectively and was $38.2 \%(n=115), 31.2 \%(n=20)$ and $53.2 \%(n=59)$ at total follow-up (Figure 4 - panel A). When comparing patients with persistent LBBB and patients without persistent LBBB (i.e. combining patients without LBBB and patients with temporary LBBB), mortality at total follow-up was $37.0 \%(n=135)$ and $53.2 \%$ $(n=59)$ for patients without and with persistent LBBB, respectively (Figure 4 - panel B). By univariate regression model, the hazard of mortality was 1.49 (95\% confidence interval, 1.10-2.03; $\mathrm{P}=0.01$ ). In total 73 patients received a PPM within 30 days after TAVI in whom the mortality at total follow-up was $47.9 \%(n=35)$ (Figure 4 panel B). The indication of PPM after TAVI was total atrioventricular block in the majority of patients $(75.3 \%$; $n=55)$ and $19.2 \%(n=14)$ had LBBB in the postprocedural period before PPM implantation.
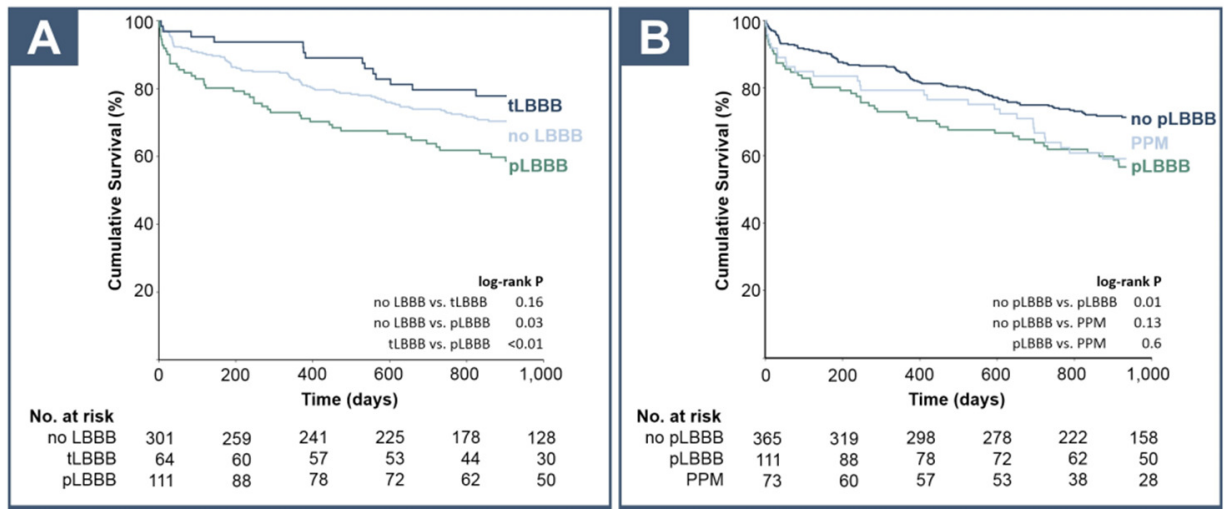

Figure 4. Kaplan-Meier survival estimate of patient without, with temporary and with persistent LBBB.

Panel A compares survival between patients without, with temporary and with persistent LBBB. Panel B compares survival between patients with persistent and without persistent LBBB. The survival curve of patients who received a permanent pacemaker within 30 days is also shown (dashed line). Comparison was made using the log-rank test. "No LBBB" denotes patients without left bundle branch block (LBBB) induced by transcatheter aortic valve implantation (TAVI), "tLBBB" patients with temporary LBBB and "pLBBB" patients with persistent LBBB.

\section{Discussion}

This study demonstrates that approximately $40 \%$ of patients develop a new LBBB after TAVI of which most persists at follow-up. A new LBBB occurs 2.5 times more 
often after MCS than after ES valve implantation and is also associated with less recovery. Persistent LBBB is associated with a worse prognosis (i.e. higher mortality during follow-up). These findings contribute to better insight into the occurrence, persistence and consequence of TAVI-induced LBBB.

Acknowledging the absence of direct comparisons between different valves, a consistently higher frequency of new LBBB has been reported after MCS (29$65 \%)^{11,19}$ than after ES valve implantation (4-18\%). ${ }^{20,21}$ Given the differences in design, mode of implantation and action, the difference between both valves is plausible but does not explain the variation in LBBB frequency of each valve separately. ${ }^{6}$ This variation may be in part due intrinsic features of observational research ${ }^{22}$ and variations and difficulties in the application of diagnostic criteria of LBBB as illustrated in Figure 3. We also believe that -in addition to the morphologic ECG criteriathe timing of occurrence (within 24 hours, before and after hospital discharge) and recovery of new LBBB should be considered as demonstrated by Urena et al. and by the present study ${ }^{5}$. The present study does not allow to elucidate whether the prognosis in case of a persistent LBBB differs between MCS and ES implantation. A difference in mortality is conceivable, given the lesser recovery of the conduction abnormality after MCS implantation but remains to be proven. The sample size of present study, however, does not allow a valid analysis of an eventual different prognostic effect between both valves.

At variance with observations in smaller series -in which a lower frequency and degree of persistence of new LAHB was reported- we found that new LAHB occurred more often and persisted more after ES valve than after MCS valve implantation..$^{21,23}$ The difference in new LAHB between both valves may be explained by the fact that a much higher number of patients have a new (complete) LBBB after MCS valve implantation. While new LBBB is known to be associated with a decrease in left ventricular function, a higher risk of complete AV block and impaired survival, the prognostic effects of a new LAHB after TAVI remains to be established. ${ }^{24,25}$

In concordance with a previous observation revealing a higher mortality in patients with a LBBB after TAVI at discharge, ${ }^{4}$ we presently found a higher mortality during follow-up in patients with a persistent new LBBB. These results are supported by a recent study, showing that mortality after TAVI increases with increasing QRSduration. ${ }^{26}$ In conflict with these studies, however, a recent Italian multicentre registry showed no difference in mortality between patients without and with new LBBB on the ECG before hospital discharge. ${ }^{27}$ This discrepancy between studies may be explained by differences in baseline risk of the study population, the application of diagnostic ECG criteria and differences in the degree of persistence of new LBBB. Therefore, prognostic factors other than LBBB may have played a more dominant role in the outcome of these patients. Furthermore, it is conceivable that an adverse prognostic effect is only seen in patients with a persistent LBBB. We found that up to $35 \%$ of LBBB recovers at follow-up. A difference in the degree of persistence between present and the Italian study population may also explain the discrepancy. Registries comparing both the MCS and the ES prosthesis in large patient populations (U.K. 
TAVI, FRANCE 2, PRAGMATIC) ${ }^{28-30}$ did not find a difference in 1-year mortality. Rate of postprocedural PPM implantation, however, was approximately 3 times higher for the MCS valve. These patients are protected from brady-arrhythmias thus influencing outcome.

The nature of the present study does not allow to establish the cause of death or reason why patients with a persistent LBBB after TAVI suffer from an increased mortality. The increased risk of death in these patients may be explained by dyssynchrony-induced heart failure which may in particularly have negative effects in elderly and hypertrophic hearts.

TAVI-induced LBBB has been reported to be associated with decrease in LV ejection fraction (LVEF) similar to the adverse effects of LBBB in patients or individuals with and without cardiovascular disease.5,7,8,31 Of note, a recent study reported a substantial increase in hospitalization of patients with a moderate increase in QRS-duration indicating that decreased cardiac performance was the cause of clinical deterioration. ${ }^{26}$ The prognostic effects of LBBB is further underscored by observations in a wide spectrum of patients with and without cardiovascular disease and the fact that after cardiac resynchronization therapy a reduction of $53 \%$ in both mortality and heart failure is seen in LBBB patients. ${ }^{32,33}$ Another potential cause of death may be progression to complete heart block as has been demonstrated in patients with LBBB after surgical aortic valve implantation. ${ }^{34}$ Survival of patients with new PPM is intermediary between survival of patients with and without persistent LBBB. This may be explained by the fact that these patients are protected from brady-arrhythmic death, but not from dyssynchrony-induced heart failure.

\section{Limitations}

The main limitation of the study is its observational nature and does therefore not provide full insight into the pathophysiology of the observations. For instance, depth of implantation was not included, which is known to play an important role in LBBB development.5,19,20 This, in addition to the number of patients precluded a multivariate analysis for assessment of predictors of both transient and persistent new LBBB. Echocardiographic data were not systematically available which precluded to assess the influence of LBBB on left ventricular function. Although the ECG's were analysed by an experienced cardiologist (PH) using established criteria of conduction disorders, independent CoreLab analysis was not performed. Median follow-up of present study was approximately 2.5 years. The cause of mortality is manifold. Therefore, analysis of mortality in larger populations with longer follow-up may help to increase understanding of the prognostic effects of new persistent LBBB after TAVI. 


\section{Conclusion}

TAVI-induced new LBBB occurs in almost $40 \%$ of patients of which most occur before hospital discharge. It occurs 2.5 times more frequent after MCS than after ES valve implantation and has a twofold lower tendency to resolve. Late new LBBB occurs rarely. Persistent LBBB is associated with a higher mortality. 


\section{References}

1. Cribier A. Percutaneous Transcatheter implantation of an aortic valve prosthesis for calcific aortic stenosis: first human case description. Circulation 2002; 106: 3006-3008.

2. Leon MB, Smith CR, Mack M, Miller DC, Moses JW, Svensson LG, Tuzcu EM, Webb JG, Fontana GP, Makkar RR, Brown DL, Block PC, Guyton RA, Pichard AD, Bavaria JE, Herrmann HC, Douglas PS, Petersen JL, Akin JJ, Anderson WN, Wang D, Pocock S. Transcatheter aortic valve implantation for aortic stenosis in patients who cannot undergo surgery. N Engl J Med 2010; 363: 1597-1607.

3. Smith CR, Leon MB, Mack MJ, Miller DC, Moses JW, Svensson LG, Tuzcu EM, Webb JG, Fontana GP, Makkar RR, Williams M, Dewey T, Kapadia S, Babaliaros V, Thourani VH, Corso P, Pichard AD, Bavaria JE, Herrmann HC, Akin JJ, Anderson WN, Wang D, Pocock SJ. Transcatheter versus surgical aorticvalve replacement in high-risk patients. N Engl J Med 2011; 364: 2187-2198.

4. Houthuizen P, Garsse LAFM Van, Poels TT, J, de Jaegere P, van der Boon RM, Swinkels BM, Berg JM, Kley F van der, Schalij MJ, Cocchieri R, Brueren GRG, van Straten AHM, den Heijer P, Bentala M, van Ommen V, Kluin J, Stella PR, Prins MH, Maessen JG, Prinzen FW. Left bundle branch block induced by transcatheter aortic valve implantation increases risk of death. Circulation 2012; 126: 720-728.

5. Urena M, Mok M, Serra V, Dumont E, Nombela-Franco L, Delarochellière R, Doyle D, Igual A, Larose E, Amat-Santos I, Côté M, Cuéllar H, Pibarot P, Jaegere P de, Philippon F, Garcia Del Blanco B, RodésCabau J. Predictive factors and long-term clinical consequences of persistent left bundle branch block following transcatheter aortic valve implantation with a balloon-expandable valve. J Am Coll Cardiol 2012; 60: 1743-1752.

6. van der Boon RM, Nuis R-J, Van Mieghem NM, Jordaens L, Rodés-Cabau J, van Domburg RT, Serruys PW, Anderson RH, de Jaegere PPT. New conduction abnormalities after TAVI-frequency and causes. Nature reviews Cardiology 2012; 9: 1-10.

7. Tzikas A, van Dalen BM, Van Mieghem NM, Gutierrez-Chico J-L, Nuis R-J, Kauer F, Schultz C, Serruys PW, de Jaegere PPT, Geleijnse ML. Frequency of conduction abnormalities after transcatheter aortic valve implantation with the Medtronic-CoreValve and the effect on left ventricular ejection fraction. Am J Cardiol 2011; 107: 285-289.

8. Hoffmann R, Herpertz R, Lotfipour S, Aktug O, Brehmer K, Lehmacher W, Autschbach R, Marx N, Lotfi S. Impact of a new conduction defect after transcatheter aortic valve implantation on left ventricular function. JACC Cardiovascular interventions 2012; 5: 1257-1263.

9. Sinhal A, Altwegg L, Pasupati S, Humphries KH, Allard M, Martin P, Cheung A, Ye J, Kerr C, Lichtenstein $\mathrm{S} \mathrm{V}, \mathrm{Webb} J \mathrm{G}$. Atrioventricular block after transcatheter balloon expandable aortic valve implantation. JACC Cardiovascular interventions 2008; 1: 305-309.

10. Bleiziffer S, Ruge H, Hörer J, Hutter A, Geisbüsch S, Brockmann G, Mazzitelli D, Bauernschmitt R, Lange R. Predictors for new-onset complete heart block after transcatheter aortic valve implantation. JACC Cardiovascular interventions 2010; 3: 524-530.

11. Roten L, Wenaweser P, Delacrétaz E, Hellige G, Stortecky S, Tanner H, Pilgrim T, Kadner A, Eberle B, Zwahlen M, Carrel T, Meier B, Windecker S. Incidence and predictors of atrioventricular conduction impairment after transcatheter aortic valve implantation. Am J Cardiol 2010; 106: 1473-1480.

12. Khawaja M, Rajani R, Cook A, Khavandi A, Moynagh A, Chowdhary S, Spence MS, Brown S, Khan SQ, Walker N, Trivedi U, Hutchinson N, Belder a J De, Moat N, Blackman DJ, Levy RD, Manoharan G, Roberts D, Khogali SS, Crean P, Brecker SJ, Baumbach A, Mullen M, Laborde J-C, Hildick-Smith D. Permanent pacemaker insertion after CoreValve transcatheter aortic valve implantation: incidence and contributing factors (the UK CoreValve Collaborative). Circulation 2011; 123: 951-960.

13. Nuis R-J, Van Mieghem NM, Schultz CJ, Tzikas A, van der Boon RM, Maugenest A-M, Cheng J, Piazza N, van Domburg RT, Serruys PW, de Jaegere PP. Timing and potential mechanisms of new conduction abnormalities during the implantation of the Medtronic CoreValve System in patients with aortic stenosis. Eur Heart J 2011; 32: 2067-2074.

14. Piazza N, Onuma Y, Jesserun E, Kint PP, Maugenest A-M, Anderson RH, de Jaegere PPT, Serruys PW. Early and persistent intraventricular conduction abnormalities and requirements for pacemaking after percutaneous replacement of the aortic valve. JACC Cardiovascular interventions 2008; 1: 310316. 
15. Jilaihawi H, Chin D, Vasa-Nicotera M, Jeilan M, Spyt T, Ng GA, Bence J, Logtens E, Kovac J. Predictors for permanent pacemaker requirement after transcatheter aortic valve implantation with the CoreValve bioprosthesis. Am Heart J 2009; 157: 860-866.

16. Fraccaro C, Buja G, Tarantini G, Gasparetto V, Leoni L, Razzolini R, Corrado D, Bonato R, Basso C, Thiene G, Gerosa G, Isabella G, Iliceto S, Napodano M. Incidence, predictors, and outcome of conduction disorders after transcatheter self-expandable aortic valve implantation. Am J Cardiol 2011; 107: 747-754.

17. Surawicz B, Childers R, Deal BJ, Gettes LS, Bailey JJ, Gorgels A, Hancock EW, Josephson M, Kligfield P, Kors J a, Macfarlane P, Mason JW, Mirvis DM, Okin P, Pahlm 0, Rautaharju PM, van Herpen G, Wagner GS, Wellens H. AHA/ACCF/HRS recommendations for the standardization and interpretation of the electrocardiogram. Part III: intraventricular conduction disturbances. Circulation 2009; 119: e23540.

18. De Guillebon M, Thambo J-B, Ploux S, Deplagne A, Sacher F, Jais P, Haissaguerre M, Ritter P, Clementy J, Bordachar P. Reliability and reproducibility of QRS duration in the selection of candidates for cardiac resynchronization therapy. J Cardiovasc Electrophsyiol 2010; 21: 890-892.

19. Baan J, Yong ZY, Koch KT, Henriques JPS, Bouma BJ, Vis MM, Cocchieri R, Piek JJ, de Mol BAJM. Factors associated with cardiac conduction disorders and permanent pacemaker implantation after percutaneous aortic valve implantation with the CoreValve prosthesis. Am Heart J 2010; 159: 497-503.

20. Aktug O, Dohmen G, Brehmer K, Koos R, Altiok E, Deserno V, Herpertz R, Autschbach R, Marx N, Hoffmann R. Incidence and predictors of left bundle branch block after transcatheter aortic valve implantation. Int J Cardiol 2012; 160: 26-30.

21. Gutiérrez M, Rodés-Cabau J, Bagur R, Doyle D, DeLarochellière R, Bergeron S, Lemieux J, Villeneuve J, Côté M, Bertrand OF, Poirier P, Clavel M-A, Pibarot P, Dumont E. Electrocardiographic changes and clinical outcomes after transapical aortic valve implantation. Am Heart J 2009; 158: 302-308.

22. Grimes DA, Schulz KF. Epidemiology series. Bias and causal associations in observational research. Lancet 2002; 359: 248-252.

23. Godin M, Eltchaninoff H, Furuta A, Tron C, Anselme F, Bejar K, Sanchez-Giron C, Bauer F, Litzler P-Y, Bessou J-P, Cribier A. Frequency of conduction disturbances after transcatheter implantation of an Edwards Sapien aortic valve prosthesis. Am J Cardiol 2010; 106: 707-712.

24. Corne RA, Beamish RE, Rollwagen RL. Significance of left anterior hemiblock. Br Heart J 1978; 40: 552-557.

25. Rowlands DJ. Left and right bundle branch block, left anterior and left posterior hemiblock. Eur Heart J 1984; 5 Suppl A: 99-105.

26. Meguro K, Lellouche N, Yamamoto M, Fougeres E, Monin J-L, Lim P, Mouillet G, Dubois-Rande J-L, Teiger E. Prognostic value of QRS duration after transcatheter aortic valve implantation for aortic stenosis using the CoreValve. Am J Cardiol 2013; 111: 1778-1783.

27. Testa L, Latib A, Marco F De, Carlo M De, Agnifili M, Latini RA, Petronio AS, Ettori F, Poli A, Servi S De, Ramondo A, Napodano M, Klugmann S, Ussia GP, Tamburino C, Brambilla N, Colombo A, Bedogni F. Clinical impact of persistent left bundle branch block after transcatheter aortic valve implantation with CoreValve Revalving System. Circulation 2013; 112: 554-559.

28. Moat NE, Ludman P, de Belder MA, Bridgewater B, Cunningham AD, Young CP, Thomas M, Kovac J, Spyt T, MacCarthy PA, Wendler O, Hildick-Smith D, Davies SW, Trivedi U, Blackman DJ, Levy RD, Brecker SJD, Baumbach A, Daniel T, Gray H, Mullen MJ. Long-term outcomes after transcatheter aortic valve implantation in high-risk patients with severe aortic stenosis: the U.K. TAVI (United Kingdom Transcatheter Aortic Valve Implantation) Registry. J Am Coll Cardiol 2011; 58: 2130-2138.

29. Gilard M, Eltchaninoff H, Iung B, Donzeau-Gouge P, Chevreul K, Fajadet J, Leprince P, Leguerrier A, Lievre M, Prat A, Teiger E, Lefevre T, Himbert D, Tchetche D, Carrié D, Albat B, Cribier A, Rioufol G, Sudre A, Blanchard D, Collet F, Santos P Dos, Meneveau N, Tirouvanziam A, Caussin C, Guyon P, Boschat J, Breton H Le, Collart F, Houel R, et al. Registry of transcatheter aortic-valve implantation in high-risk patients. $N$ Engl J Med 2012; 366: 1705-1715. 
30. Chieffo A, Buchanan GL, Van Mieghem NM, Tchetche D, Dumonteil N, Latib A, van der Boon RM, Vahdat O, Marcheix B, Farah B, Serruys PW, Fajadet J, Carrié D, de Jaegere PPT, Colombo A. Transcatheter aortic valve implantation with the Edwards SAPIEN versus the Medtronic CoreValve Revalving system devices: a multicenter collaborative study: the PRAGMATIC Plus Initiative (Pooled-RotterdAm-Milano-Toulouse In Collaboration). J Am Coll Cardiol 2013; 61: 830-836.

31. Grines CL, Bashore TM, Boudoulas H, Olson S, Shafer P, Wooley CF. Functional abnormalities in isolated left bundle branch block. The effect of interventricular asynchrony. Circulation 1989; 79: 845853.

32. Zannad F, Huvelle E, Dickstein K, Veldhuisen DJ van, Stellbrink C, Køber L, Cazeau S, Ritter P, Maggioni A Pietro, Ferrari R, Lechat P. Left bundle branch block as a risk factor for progression to heart failure. Eur J Heart Fail 2007; 9: 7-14.

33. Zareba W, Klein H, Cygankiewicz I, Hall WJ, McNitt S, Brown M, Cannom D, Daubert JP, Eldar M, Gold MR, Goldberger JJ, Goldenberg I, Lichstein E, Pitschner H, Rashtian M, Solomon S, Viskin S, Wang P, Moss AJ. Effectiveness of cardiac resynchronization therapy by QRS morphology in the Multicenter Automatic Defibrillator Implantation Trial-Cardiac Resynchronization Therapy (MADIT-CRT). Circulation 2011; 123: 1061-1072.

34. Mieghem NM Van, Head SJ, Jong W de, Domburg RT van, Serruys PW, Jaegere PP de, Jordaens L, Takkenberg JJM, Bogers AJJC, Kappetein A-P. Persistent annual permanent pacemaker implantation rate after surgical aortic valve replacement in patients with severe aortic stenosis. Ann Thorac Surg 2012; 94: 1143-1149. 



\section{CHAPTER 4}

\section{Trends in the Occurrence of New Left Bundle Branch Block after Transcatheter Aortic Valve Implantation}

Robert M.A. van der Boon, Patrick Houthuizen, Marina Urena, Thomas T. Poels, Nicolas M. van Mieghem, Guus R.G. Brueren, Sibel Altintas, Leen A.F.M. van Garsse, Ron T. van Domburg, Rutger-Jan Nuis, Josep Rodés-Cabau, Peter de Jaegere, Frits W. Prinzen

Submitted for publication 


\section{Abstract}

\section{Background}

TAVI-induced new-onset left bundle branch block (TAVI-induced LBBB) is a frequent postoperative complication. New techniques are focused on the reduction of this conduction abnormality. The aim of the study was to investigate the changes in occurrence of new LBBB after TAVI in both the Medtronic CoreValve System (MCS) and Edwards Sapien valve (ES) over time.

\section{Methods and Results}

ECGs at multiple time points in 476 patients without baseline LBBB and/or pre- or postprocedural pacemaker were assessed to determine frequency of new LBBB and whether it was transient or permanent. To study the effect of experience, patients were subdivided per participating center into equal tertiles based on the number of procedures. Univariate and multivariate logistic regression was used to study the independent predictors of permanent LBBB after TAVI.

TAVI-induced LBBB occurred in 175 patients (36.8\%) and was transient in 111 (63.4\%) and persistent in 64 (36.6\%) patients. The frequency of TAVI-induced LBBB significantly decreased over time from $47.2 \%$ in cohort 1 to $28.5 \%$ in cohort 3 $(\mathrm{p}=0.002)$. This effect was dependent on the valve type implanted and was only significant after MCS implantation $(68.3 \%, 53.2 \%$ and $35.5 \%$, respectively; $\mathrm{P}<0.001)$ and not after ES implantation $(24.7 \%, 16.2 \%$ and $24.0 \%$, respectively; $\mathrm{P}=0.73)$. This did also hold for depth of implantation $(\mathrm{P}<0.001$ and $\mathrm{P}=0.21$ for MCS and ES, respectively). Multivariate analysis stratified for valve type revealed that cohort was the only significant predictor of permanent TAVI-induced LBBB in patients undergoing TAVI with the MCS (Cohort 3 odds ratio [OR], 0.12; 95\% confidence interval [95\% CI], 0.02-0.58) and not with the ES (Cohort 3 OR, 0.51; 95\% CI 0.05-5.50).

\section{Conclusions}

Over time the frequency of transient and persistent LBBB after TAVI decreased significantly. This effect was mainly seen in patients undergoing TAVI with the MCS in parallel to a reduction in the depth of implantation. Patients with ES valve had significantly less LBBB of which persistent LBBB showed a trend to further reduction over time. 


\section{Introduction}

Transcatheter Aortic Valve Implantation (TAVI) is increasingly used to treat patients with aortic stenosis, who are ineligible or poor candidates for surgical aortic valve replacement (SAVR). In patients who are ineligible for SAVR, TAVI is superior to medical therapy in terms of mortality reduction and for those at high risk for SAVR, TAVI is equally effective. ${ }^{1-4}$ Yet, the perioperative occurrence of new conduction disorders remains a vexing issue. TAVI-induced new-onset left bundle branch block (TAVI-induced LBBB) is reported in 29-65\% of patients undergoing TAVI with the self-expanding Medtronic CoreValve System (MCS, Medtronic Inc, Minneapolis, MN, USA) and in $4-18 \%$ of the patients receiving the balloon-expendable Edwards SAPIEN valve (ES, Edwards Lifesciences LLC, Irvine, CA, USA). ${ }^{5}$

The occurrence of TAVI-induced LBBB has been reported to be associated with worse long-term outcome, including higher risk of complete atrioventrioventricular block (AVB), new permanent pacemaker implantation (PPI) and mortality. ${ }^{6-11} \mathrm{As}$ a consequence LBBB has been included as a complication in the Valve Academic Research Consortium Guidelines (VARC-2). ${ }^{12}$

It is conceivable that increased awareness and insight in the relationship between depth of implantation and new LBBB is in conjunction with new delivery systems incorporating more stable deployment of the valve. This may have led or will lead to a decreased incidence of new LBBB and permanent pacemaker (PPM) implantation. 13,14

The aim of the present study was to investigate the changes in occurrence of new LBBB after TAVI in a series of 476 patients undergoing TAVI with the MCS or ES valve incorporating a detailed and prospective electrocardiographic assessment.

\section{Methods}

\section{Study population}

The study population consisted of 701 patients who underwent TAVI between January 2006 and July 2011 with the MCS or the balloon-expandable ES valve in any of following institutions: Quebec Heart \& Lung Institute ( $\mathrm{n}=212)$; Erasmus Medical Center Rotterdam $(\mathrm{n}=202)$, Catharina Hospital Eindhoven $(\mathrm{n}=173)$, Maastricht University Medical Center $(\mathrm{n}=114) .{ }^{11}$ Patients with pre-existing LBBB and/or permanent pacemaker (PPM) before TAVI were excluded from analysis, as well as patients who did not undergo valve implantation (aborted procedure). Patients who received a new PPM within 30 days $(n=76)$ after TAVI were also excluded, since it precluded accurate assessment of eventual LBBB and other conduction disorders. There were 8 patients $(1.7 \%)$ who died during or shortly after valve implantation resulting in the 
absence of a post-procedural ECG. From another 2 patients (0.4\%) there was no follow-up ECG available. After exclusion of these patients, the final population consisted of 476 patients.

All clinical and procedural data were prospectively collected and entered into a dedicated central database. If necessary, additional information was collected by analysis of medical records. The use of anonymous clinical, procedural and followup data for research were in accordance with the institutional policies.

\section{Measurement of depth of implantation}

To assess the depth of implantation, quantitative angiographic analysis (depth of implantation) was performed using CAAS 5.9 software (Pie Medical, Maastricht, The Netherlands) in 3 of the 4 participating centers. Calibration was achieved using a graduated pigtail with radiopaque markers. The depth of implantation of the frame was defined as mean of the distance from the lower edge of the non-coronary and left coronary sinus to the ventricular edge of the frame. In one center only using the ES device, depth of implantation was assessed using postprocedural transthoracic echocardiography. Depth was defined as the distance between the hinge point of the anterior mitral leaflet and the ventricular end of the stent valve in the parasternal long axis view.

\section{Study Endpoints}

The primary endpoint was the occurrence of TAVI-induced LBBB before hospital discharge and at 12-months follow-up. To study the effect of experience, patients were subdivided into equal tertiles per participating center which were pooled into 3 "consecutive" cohorts. All standard 12-lead ECGs at baseline, post-procedure, before discharge and at 12-months follow-up were collected and were analyzed by an experienced cardiologist (PH) to record heart rhythm, PR interval, QRS duration, QRS morphology and QRS axis in exact degrees, as described earlier. ${ }^{11}$ LBBB was defined as a V1-negative QRS-complex of $\geq 0.12$ seconds in duration with absent Q-waves and a notched or slurred R in leads I, aVL, V5 and/or V6 according to established guidelines. TAVI-induced LBBB was defined as the occurrence of any new LBBB, either transient or persistent. ${ }^{11}$

\section{Statistical Analysis}

Categorical variables are presented as frequencies and percentages and, compared with the use of the Pearson Chi Square Test or the Fisher's exact test, as appropriate. Continuous variables are presented as means $( \pm S D$ ) (in case of a normal distribution) or medians (IQR) (in case of a skewed distribution) and compared with the use of analysis of variance. Normality of the distributions was assessed using the ShapiroWilk test. To study the independent predictors of permanent LBBB after TAVI logistic 
regression was performed. All characteristics with a p-value $\leq 0.10$ on univariate analysis and those judged to be clinically relevant were included in the multivariate logistic regression model, taking into account the restricted number of variables. Separate models were constructed to stratify for valve type. A two-sided alpha level of 0.05 was used for all superiority testing. The statistical analyses were performed using SPSS software version 17.0 (SPSS Inc., Chicago, Illinois, USA).

\section{Results}

\section{Baseline characteristics and procedural details}

The overall and cohort-based (Cohort 1 to 3 ) patient demographics and procedural characteristics are summarized in Table 1. Except for a decrease in the number of patients with severe symptoms of heart failure (New York Heart Association class III or IV; $89.8 \%$ vs. $80.9 \%$ vs. $73.9 \%, p=0.001$ ), there were no differences in the baseline clinical, electro- and echocardiographic characteristics between the three cohorts. The ES valve was used in 253 (53.2\%) patients and the MCS in 223 (46.8\%). Transfemoral TAVI was the most frequent modality $(n=301,63.2 \%)$ followed by transapical $(n=168,35.3 \%)$ and subclavian TAVI ( $n=5,1.1 \%)$. Access strategy did not change over time in the three different cohorts. During the study period there was a significant decrease in median depth of implantation for the total cohort (6.3 (IQR, 3.0-9.6), 5.4 (IQR, 2.5-8.3) and 4.0 (IQR, 1.3-6.7) respectively; $\mathrm{P}<0.001)$. When stratified for valve type this trend was only significant in patients undergoing TAVI with the MCS (10.6 (IQR, 3.4-17.8), 8.1 (IQR, 5.1-11.0) and 6.9 (IQR, 4.4-9.5), respectively; $\mathrm{P}<0.001$ ) (Figure 1).

\section{Postprocedural ECG}

Electrocardiographic details before discharge and at 12-months follow-up (366 days; [IQR, 304-378]) are depicted in Table 2. No significant changes were found between the three cohorts on the last ECG before discharge. Follow-up ECG revealed a trend towards a higher frequency of variable heart rhythms ( $0 \%$ vs. $0 \%$ vs. $2.4 \%$, $\mathrm{p}=0.04$ ). There were no differences in PR-interval, QRS-duration or QRS-axis. The occurrence of any or permanent LBBB over time are shown in Figure 2 and 3. A total of 175 patients $(36.8 \%)$ developed a new LBBB after TAVI. At 12-months follow-up TAVI-induced LBBB was persistent in 111 of 175 patients (63.4\%) and transient in $64(36.6 \%)$. The frequency of any TAVI-induced LBBB significantly decreased over time from $47.2 \%$ in cohort 1 to $28.5 \%$ in cohort 3 ( $\mathrm{p}=0.002$ ). After stratification for valve type this effect was driven by patients undergoing TAVI with the MCS (68.3\%, $53.2 \%$ and $35.5 \%$, respectively; $\mathrm{P}<0.001)$ and not with the ES valve $(24.7 \%, 16.2 \%$ and $24.0 \%$, respectively; $\mathrm{P}=0.73$ ). The same effect was found for the occurrence of 
permanent TAVI-induced LBBB in the total population $(30.8 \%, 24.5 \%$ and $14.6 \%$, respectively; $\mathrm{P}=0.003)$ and in the MCS population $(48.8 \%$ vs. $40.5 \%$ vs. $24.2 \%$, $\mathrm{p}=0.011)$ and not in the ES population $(11.7 \%, 9.8 \%$ and $8.3 \%$, respectively; $\mathrm{P}=0.35)$.

A

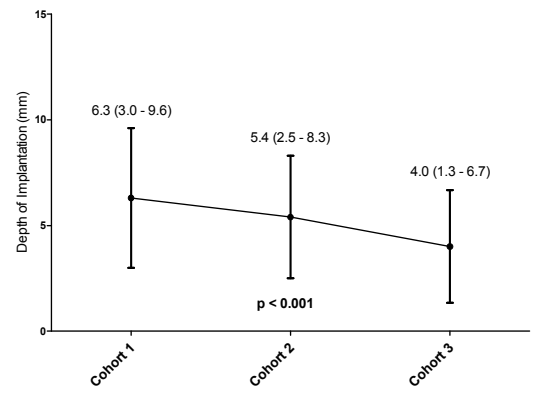

B

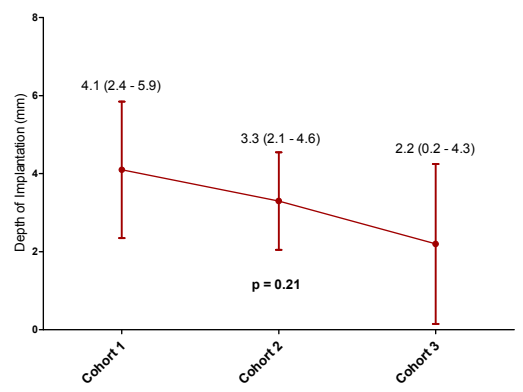

C

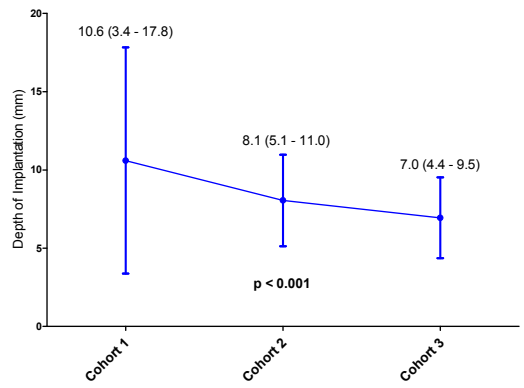

Figure 1. Depth of implantation for different cohorts and/or device.

The depth of implantation for the 3 different cohorts are shown for the total study population (panel A), the Medtronic CoreValve System (MCS) population (panel B) and the Edwards SAPIEN (ES) population (panel C).

\section{Univariate and multivariate analysis}

Univariate analysis revealed that age, male gender, body surface area, history of diabetes mellitus, baseline rhythm other than sinus rhythm, PR-interval, QRS-interval, earlier procedure and cohort were associated with an increased risk of permanent TAVI-induced LBBB $(p<0.10)$. The crude and adjusted odds ratios stratified for the different devices are shown in Table 3. In patients undergoing TAVI with the MCS, cohort was the only significant predictor of permanent TAVI-induced LBBB (Cohort 3; OR, 0.12; 95\% CI 0.02 - 0.58; $p=0.009$ ). In patients undergoing TAVI with ES valve there was no significant difference from cohort 1 to cohort 3 (Cohort 3; OR, 0.51; 95\% CI, 0.05-5.50; $\mathrm{p}=0.58$ ). 


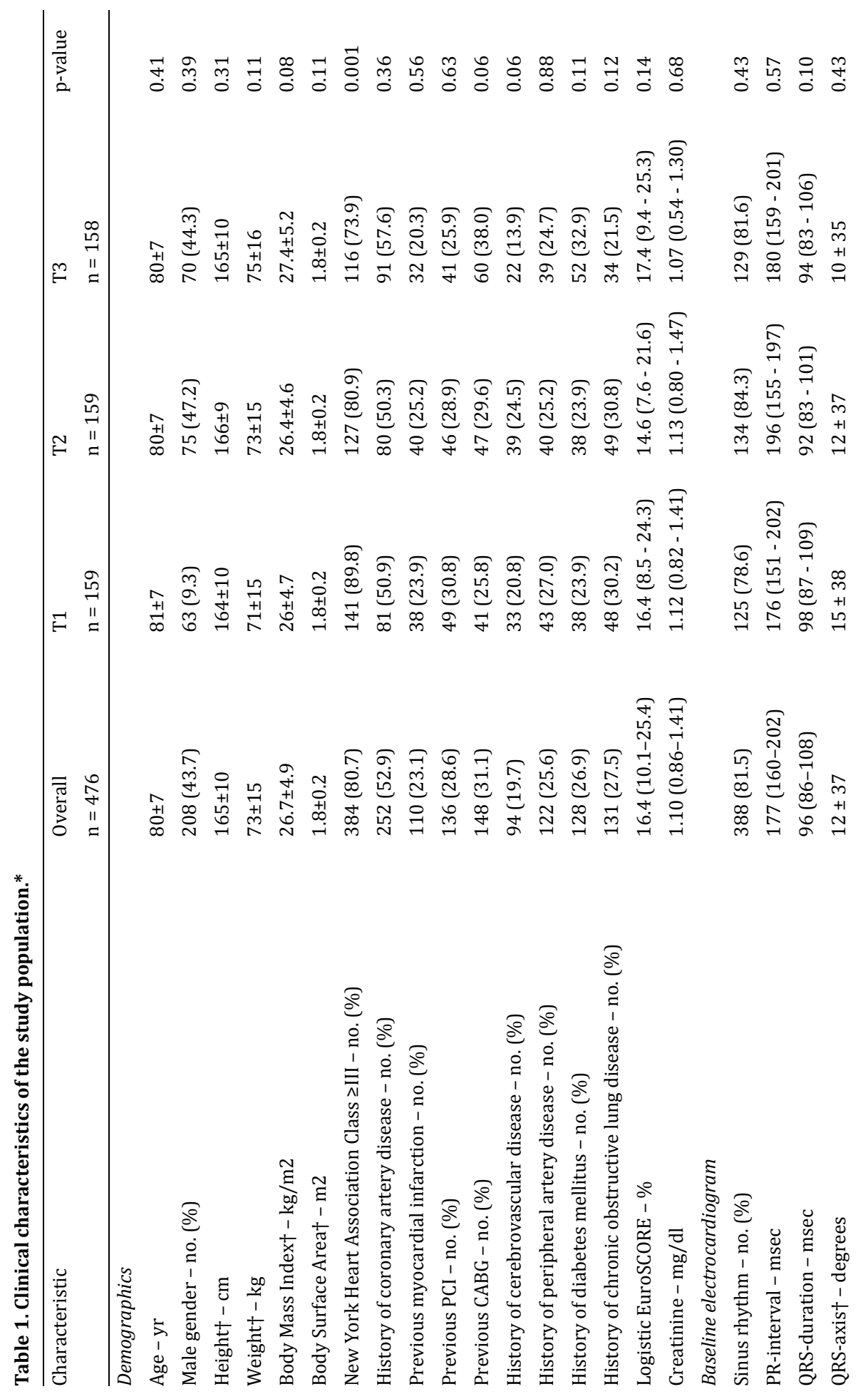




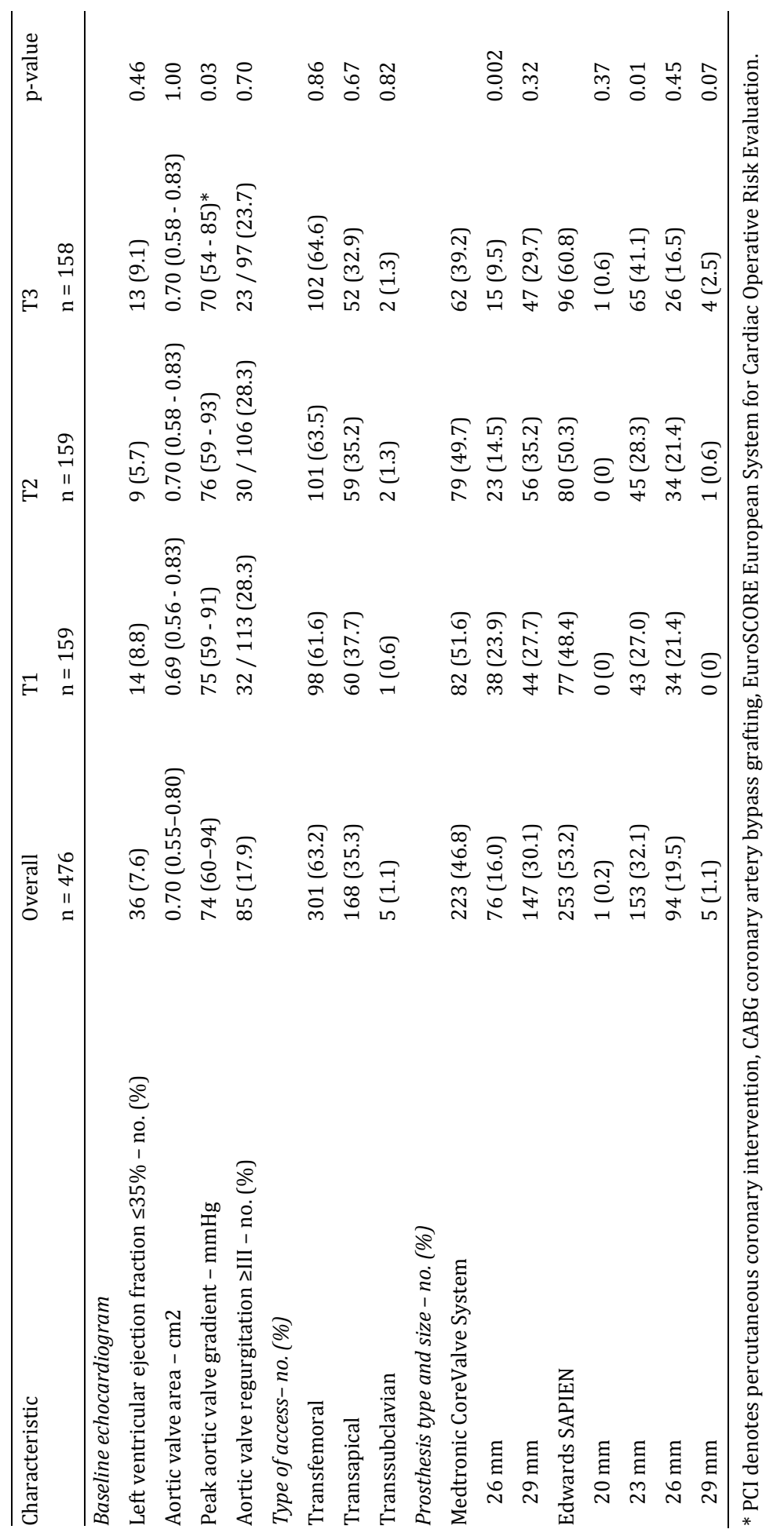


Table 2. Electrocardiographic characteristics before discharge and at long-term follow-up.*

\begin{tabular}{|c|c|c|c|c|c|}
\hline Characteristic & Overall & T1 & $\mathrm{T} 2$ & T3 & P value \\
\hline \multicolumn{6}{|l|}{ Before Discharge } \\
\hline ECG's analyzed - no. & 467 & 158 & 156 & 153 & \\
\hline \multicolumn{6}{|l|}{ Rhythm - no. (\%) } \\
\hline Sinus rhythm & $355(76.0)$ & $115(72.8)$ & $128(82.1)$ & $112(73.2)$ & 0.10 \\
\hline Atrial fibrillation/flutter & 107 (22.9) & $40(25.3)$ & $26(16.7)$ & $41(26.8)$ & 0.07 \\
\hline Ventricular pace & $2(0.4)$ & $0(0)$ & $2(1.3)$ & $0(0)$ & 0.14 \\
\hline Other & $3(0.6)$ & $3(1.9)$ & $0(0)$ & $0(0)$ & 0.05 \\
\hline PR-interval - msec & \multicolumn{5}{|c|}{$188(158-218) 184(154-214) 186(161-211) 188(162-214) 0.89$} \\
\hline QRS-duration - msec & $115(95-136)$ & $120(99-141)$ & $110(88-132)$ & $110(90-130)$ & 0.07 \\
\hline QRS-axis - degrees & $0 \pm 43$ & $0 \pm 47$ & $-3 \pm 41$ & $4 \pm 41$ & 186 \\
\hline \multicolumn{6}{|l|}{ Long-term follow-up } \\
\hline ECG's analyzed - no. & 392 & 138 & 131 & 123 & \\
\hline \multicolumn{6}{|l|}{ Rhythm - no. (\%) } \\
\hline Sinus rhythm & 307 (78.3) & $108(78.3)$ & $110(84.0)$ & $89(72.4)$ & 0.08 \\
\hline Atrial fibrillation/flutter & $78(19.9)$ & $28(20.3)$ & $20(15.3)$ & $30(24.4)$ & 0.19 \\
\hline Ventricular pace & $4(1.0)$ & $2(1.4)$ & $1(0.8)$ & $1(0.8)$ & 0.82 \\
\hline Other & $3(0.8)$ & $0(0)$ & $0(0)$ & $3(2.4)$ & 0.04 \\
\hline PR-interval - msec & $184(159-209)$ & $186(90-130)$ & $184(164-204)$ & )183 (158-208) & 0.77 \\
\hline QRS-duration - msec & $110(91-130)$ & $110(90-130)$ & $110(90-131)$ & $105(86-125)$ & 0.11 \\
\hline QRS-axis - degrees & $-2 \pm 45$ & $-2 \pm 49$ & $-5 \pm 40$ & $1 \pm 45$ & 0.55 \\
\hline
\end{tabular}

* ECG denotes electrocardiogram. 


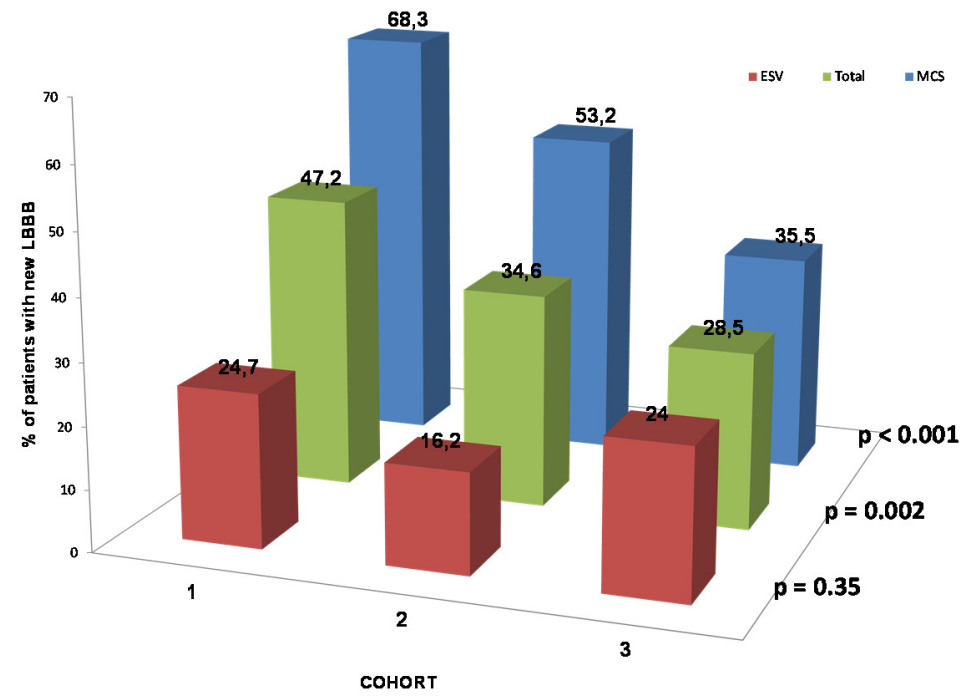

Figure 2. Incidence of any LBBB depending on cohort and/or device.

The incidence of any left bundle branch block (LBBB) for the 3 different cohorts are shown for the total study population, the Medtronic CoreValve System (MCS) population and the Edwards SAPIEN (ES) population.

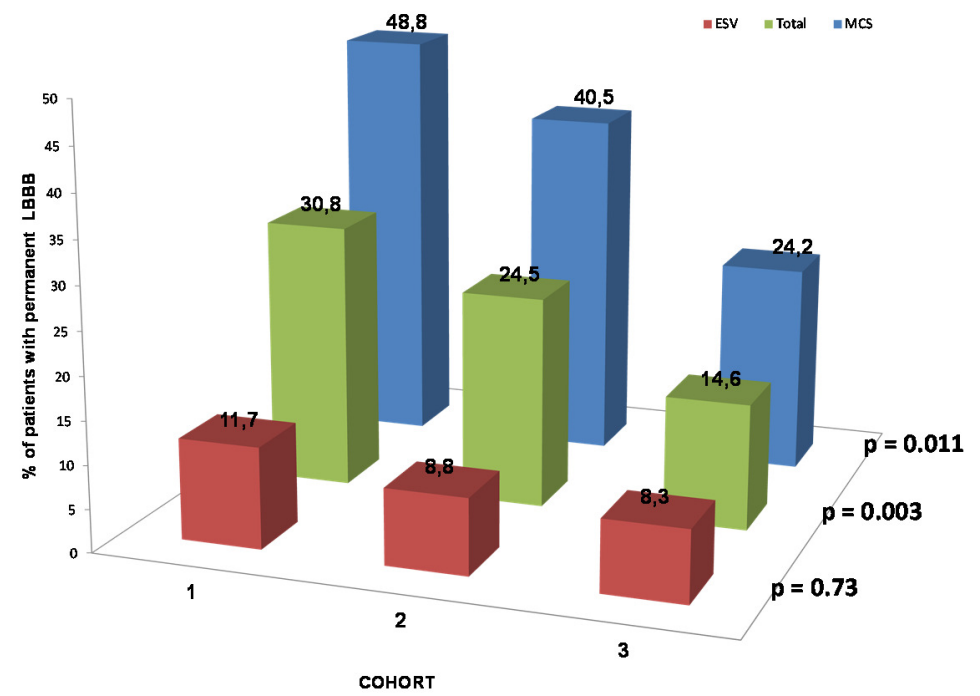

Figure 3. Incidence of persistent LBBB depending on cohort and/or device.

The incidence of persistent left bundle branch block (LBBB) for the 3 different cohorts are shown for the total study population, the Medtronic CoreValve System (MCS) population and the Edwards SAPIEN (ES) population. 
Table 3a. Independent predictors of permanent LBBB in MCS patients.*

\begin{tabular}{lll}
\hline Characteristic & $\begin{array}{l}\text { Crude OR } \\
(95 \% \text { C.I. })\end{array}$ & $\begin{array}{l}\text { Adjusted OR } \\
\text { (95\% C.I. })\end{array}$ \\
\hline Cohort 1 & reference & reference \\
Cohort 2 & $0.72(0.38-1.33)$ & $0.40(0.13-1.28)$ \\
Cohort 3 & $0.34(0.16-0.69)$ & $0.12(0.02-0.58)$ \\
Age - yr & $1.00(0.96-1.04)$ & $1.04(0.98-1.10)$ \\
Male gender & $1.36(0.79-2.34)$ & $1.03(0.46-2.35)$ \\
Body Surface Area - m² & $2.70(0.73-0.01)$ & $2.57(0.37-18.15)$ \\
History of diabetes mellitus & $1.49(0.80-2.77)$ & $1.50(0.63-3.58)$ \\
Sinus rhythm & & - \\
PR-interval - msec & $0.71(0.39-1.33)$ & $1.00(0.99-1.01)$ \\
QRS-duration - msec & $1.00(0.99-1.02)$ & $0.98(0.95-1.00)$ \\
Year of procedure & $0.98(0.97-1.00)$ & $1.44(0.83-2.50)$ \\
\hline
\end{tabular}

* LBBB denotes left bundle branch block, MCS Medtronic CoreValve System, OR odds ratio, CI confidence interval.

Table 3b. Independent predictors of permanent LBBB in ES valve patients.

\begin{tabular}{lll}
\hline Characteristic & $\begin{array}{l}\text { Crude OR } \\
(95 \% \text { C.I. })\end{array}$ & $\begin{array}{l}\text { Adjusted OR } \\
\text { (95\% C.I.) }\end{array}$ \\
\hline Cohort 1 & reference & reference \\
Cohort 2 & $0.73(0.26-2.05)$ & $0.56(0.10-2.88)$ \\
Cohort 3 & $0.69(0.25-1.87)$ & $0.51(0.05-5.50)$ \\
Age - yr & $0.99(0.94-1.05)$ & $1.04(0.96-1.31)$ \\
Male gender & $3.59(1.47-8.74)$ & $2.07(0.65-6.53)$ \\
Body Surface Area - m ${ }^{2}$ & $11.55(1.70-78.32)$ & $3.41(0.22-53.59)$ \\
History of diabetes mellitus & $3.26(1.38-7.65)$ & $4.53(1.42-14.38)$ \\
Sinus rhythm & & \\
PR-interval - msec & $0.78(0.25-2.44)$ & - \\
QRS-duration - msec & $1.01(1.00-1.02)$ & $1.00(1.00-1.02)$ \\
Transfemoral access & $1.01(0.99-1.03)$ & $1.00(0.97-1.03)$ \\
Year of procedure & & $0.64(0.20-2.03)$ \\
\hline
\end{tabular}

* LBBB denotes left bundle branch block, ES Edwards SAPIEN, OR odds ratio, CI confidence interval 


\section{Discussion}

The main finding of present study is the reduction of TAVI-induced LBBB over time after both MCS and ES valve implantation. This was predominantly seen in patients receiving the MCS valve, which is associated by a much higher frequency of new LBBB. Multivariate analysis revealed that cohort was the only independent predictor of a decrease in LBBB over time in parallel to a significant decrease in the depth of implantation. These findings underscore that both device- and procedure-related factors play a role in the occurrence of LBBB after TAVI. Patient- and device stratification, continued training and eventually advanced guidance during valve positioning and release, may help to further reduce TAVI-induced LBBB. This is not trivial since LBBB is associated with interventricular dyssynchrony that in turn may affect cardiac performance, thereby, affecting quality of life and eventually also prognosis.

With respect to treatment stratification, it reasonable to avoid the MCS valve in patients who have an increased perioperative risk to develop new LBBB or high-degree atrioventricular block. For that purpose, determinants of perioperative LBBB and the interplay between patient-, procedure-, and device- related factors need to be more clearly established. ${ }^{15}$ For instance, one may decide not to use the MCS valve in a patient with a pre-existing RBBB (patient related factor). Yet, the contribution of the procedure/operator related factors (e.g. sizing, depth of implantation, experience) on top of the contribution of the device itself remains to be elucidated.

The observations of present study in both valves and the findings of the valve specific multivariate analysis suggests that experience was the overriding factor in the reduction of TAVI-induced LBBB. Yet, refinements in valve technology and delivery catheter (e.g. Accutrack system) may have played a role as well and preclude firm conclusions. ${ }^{12,13}$ The reduction of the depth of implantation over time in both valves, however, is supporting the role of experience. In previous reports, depth of implantation has been reported to be associated with LBBB. ${ }^{8,12,16-21}$ Although we were not able to study this effect in a multivariate fashion due to multicolinearity (between depth of implantation and cohort), a relation between reduced depth of implantation and reduction in TAVI-induced LBBB is most likely present. Moreover, we observed that for depth of implantation, the interquartile range became smaller. However, in contrast with Binder et al. who found that depth of implantation was a predictor of TAVI-induced LBBB and PPI in ES valve patients, ${ }^{21}$ we did not find the same trend for our patients undergoing ES valve implantation. These differences might be explained by differences in measurement of depth of implantation or in ECG criteria for LBBB.

\section{Clinical Implications}

In subjects without and with cardiovascular disease, LBBB is associated with an increased cardiovascular morbidity and mortality. ${ }^{22}$ In patients who underwent SAVR, postoperative LBBB is associated with syncope, permanent pacemaker implantation 
and sudden death during follow-up. ${ }^{23-25}$ The effects of TAVI-LBBB on mortality is subject of debate. ${ }^{6-11}$ Yet, TAVI-induced LBBB may progress to complete atrioventricular block, syncope and PPI. ${ }^{7-9}$ LBBB and PPM implantation are associated with interventricular dyssynchrony which in turn may lead to impaired cardiac performance that has been shown to predict adverse long-term outcome. ${ }^{8,9,26,27}$ Also, LBBB may be associated with impared left ventricular recovery after TAVI.8, 27 It is therefore plausible that TAVI-induced LBBB is also associated with increased morbidity and mortality during follow-up similar to the findings in patients and apparently healthy individuals. Several studies have proposed a role for cardiac resynchronization therapy in patients with heart failure and atrioventricular dyssynchrony, however, data on patients after TAVI is scarce. ${ }^{32-35}$

The gradual shift towards younger and less-sick patients highlights the need to further reduce perioperative complications that may not have an immediate but long-term effect on cardiac function and well-being. ${ }^{36}$ As mentioned above, measures such as tailored valve selection, continued training, guidance of valve positioning and refinements in catheter and valve technology may serve this objective. ${ }^{37,38}$

\section{Study limitations}

This study is observational and thus subject to limitations of such a study design. Data were analyzed by an expert cardiologist using established criteria for conduction abnormalties, However, independent Corelab analysis was not performed. Although, this analysis included both clinical, electrocardiographical and procedural predictors of LBBB, we cannot preclude the role of hidden bias due to uncollected data.

\section{Conclusion}

Over time the frequency of LBBB after TAVI decreased significantly. This effect was mainly seen in patients undergoing TAVI with the MCS in parallel to a reduction in the depth of implantation. Patients with ES valve had significantly less LBBB of which persistent LBBB frequency showed a trend of further reduction over time. 


\section{References}

1. Leon MB, Smith CR, Mack M, Miller DC, Moses JW, Svensson LG, Tuzcu EM, Webb JG, Fontana GP, Makkar RR, Brown DL, Block PC, Guyton RA, Pichard AD, Bavaria JE, Herrmann HC, Douglas PS, Petersen JL, Akin JJ, Anderson WN, Wang D, Pocock S. Transcatheter aortic-valve implantation for aortic stenosis in patients who cannot undergo surgery. N Engl J Med 2010; 363: 1597-1607.

2. Smith CR, Leon MB, Mack MJ, Miller DC, Moses JW, Svensson LG, Tuzcu EM, Webb JG, Fontana GP, Makkar RR, Williams M, Dewey T, Kapadia S, Babaliaros V, Thourani VH, Corso P, Pichard AD, Bavaria JE, Herrmann HC, Akin JJ, Anderson WN, Wang D, Pocock SJ. Transcatheter versus surgical aorticvalve replacement in high-risk patients. N Engl J Med 2011; 364: 2187-2198.

3. Kodali SK, Williams MR, Smith CR, Svensson LG, Webb JG, Makkar RR, Fontana GP, Dewey TM, Thourani VH, Pichard AD, Fischbein M, Szeto WY, Lim S, Greason KL, Teirstein PS, Malaisrie SC, Douglas PS, Hahn RT, Whisenant B, Zajarias A, Wang D, Akin JJ, Anderson WN, Leon MB. Two-year outcomes after transcatheter or surgical aortic-valve replacement. N Engl J Med 2012; 366: 1686-1695.

4. Makkar RR, Fontana GP, Jilaihawi H, Kapadia S, Pichard AD, Douglas PS, Thourani VH, Babaliaros VC, Webb JG, Herrmann HC, Bavaria JE, Kodali S, Brown DL, Bowers B, Dewey TM, Svensson LG, Tuzcu M, Moses JW, Williams MR, Siegel RJ, Akin JJ, Anderson WN, Pocock S, Smith CR, Leon MB. Transcatheter aortic-valve replacement for inoperable severe aortic stenosis. $N$ Engl J Med 2012; 366: 16961704.

5. Van der Boon RM, Nuis R-J, Van Mieghem NM, Schultz C, van Geuns RJ, Serruys PW, Kappetein AP, van Domburg RT, de Jaegere PP. New conduction abnormalities after TAVI - frequency and causes. Nat Rev Cardiol 2012; 9: 454-463.

6. Houthuizen P, Van Garsse LAFM, Poels TT, de Jaegere P, van der Boon RM, Swinkels BM, Ten Berg JM, van der Kley F, Schalij MJ, Baan J Jr, Cocchieri R, Brueren GR, van Straten AH, den Heijer P, Bentala M, van Ommen V, Kluin J, Stella PR, Prins MH, Maessen JG, Prinzen FW Left bundle-branch block induced by transcatheter aortic valve implantation increases risk of death. Circulation 2012; 126: 720-728.

7. Testa L, Latib A, De Marco F, De Carlo M, Agnifili M, Latini RA, Petronio AS, Ettori F, Poli A, De Servi S, Ramondo A, Napodano M, Klugmann S, Ussia GP, Tamburino C, Brambilla N, Colombo A, Bedogni F. Clinical impact of persistent left bundle-branch block after transcatheter aortic valve implantation with CoreValve Revalving System. Circulation 2013; 127: 1300-1307.

8. Urena M, Mok M, Serra V, Dumont E, Nombela-Franco L, DeLarochellière R, Doyle D, Igual A, Larose E, Amat-Santos I, Côté M, Cuéllar H, Pibarot P, de Jaegere P, Philippon F, Garcia del Blanco B, RodésCabau J. Predictive factors and long-term clinical consequences of persistent left bundle branch block following transcatheter aortic valve implantation with a balloon-expandable valve. J Am Coll Cardiol 2012; 60: 1743-1752.

9. Nazif TM, Williams MR, Hahn RT, Kapadia S, Babaliaros V, Rodés-Cabau J, Szeto WY, Jilaihawi H, Fearon WF, Dvir D, Dewey TM, Makkar RR, Xu K, Dizon JM, Smith CR, Leon MB, Kodali SK. Clinical implications of new-onset left bundle branch block after transcatheter aortic valve replacement: analysis of the PARTNER experience. Eur Heart J 2013; in press.

10. Franzoni I, Latib A, Maisano F, Costopoulos C, Testa L, Figini F, Giannini F, Basavarajaiah S, Mussardo M, Slavich M, Taramasso M, Cioni M, Longoni M, Ferrarello S, Radinovic A, Sala S, Ajello S, Sticchi A, Giglio M, Agricola E, Chieffo A, Montorfano M, Alfieri O, Colombo A. Comparison of incidence and predictors of left bundle branch block after transcatheter aortic valve implantation using the CoreValve versus the Edwards valve. Am J Cardiol 2013; 112: 554-559.

11. Houthuizen P, van der Boon RMA, Urena M, Van Mieghem N, Brueren GB, T Poels T, Van Garsse LA, Rodés-Cabau J, Prinzen FW, de Jaegere P. Occurrence, fate and consequences of Ventricular Conduction Abnormalities after Transcatheter Aortic Valve Implantation. Eurointervention 2014; 9: 11421150.

12. Kappetein AP, Head SJ, Généreux P, Piazza N, van Mieghem NM, Blackstone EH, Brott TG, Cohen DJ, Cutlip DE, van Es GA, Hahn RT, Kirtane AJ, Krucoff MW, Kodali S, Mack MJ, Mehran R, Rodés-Cabau J, Vranckx P, Webb JG, Windecker S, Serruys PW, Leon MB. Updated standardized endpoint definitions for transcatheter aortic valve implantation: the Valve Academic Research Consortium-2 consensus document. J Am Coll Cardiol 2012; 60: 1438-1454. 
13. Muñoz-García AJ, Hernández-García JM, Jiménez-Navarro MF, Alonso-Briales JH, Domínguez-Franco AJ, Fernández-Pastor J, Peña Hernández J, Barrera Cordero A, Alzueta Rodríguez J, de Teresa-Galván E. Factors predicting and having an impact on the need for a permanent pacemaker after CoreValve prosthesis implantation using the new Accutrak delivery catheter system. JACC Cardiovasc Interv 2012; 5: 533-539.

14. Tchetche D, Modine T, Farah B, Vahdat O, Sudre A, Koussa M, Lereun C, Nejjari M, Choby M, Rosencher J, Sorbets E, Fajadet J. Update on the need for a permanent pacemaker after transcatheter aortic valve implantation using the CoreValve Accutrak system. EuroIntervention 2012; 8: 556-562.

15. Piazza N, de Jaegere P, Schultz C, Becker AE, Serruys PW, Anderson RH. Anatomy of the aortic valvar complex and its implications for transcatheter implantation of the aortic valve. Circ Cardiovasc Interv 2008; 1: 74-81.

16. Piazza N, Onuma Y, Jesserun E, Kint PP, Maugenest AM, Anderson RH, de Jaegere PP, Serruys PW. Early and persistent intraventricular conduction abnormalities and requirements for pacemaking after percutaneous replacement of the aortic valve. JACC Cardiovasc Interv 2008; 1: 310-316.

17. Piazza N, Nuis R-J, Tzikas A, Otten A, Onuma Y, García-García H, Schultz C, van Domburg R, van Es GA, van Geuns R, de Jaegere P, Serruys PW. Persistent conduction abnormalities and requirements for pacemaking six months after transcatheter aortic valve implantation. Eurointervention 2010; 6: 475484.

18. Baan J Jr, Yong ZY, Koch KT, Henriques JP, Bouma BJ, Vis MM, Cocchieri R, Piek JJ, de Mol BA. Factors associated with cardiac conduction disorders and permanent pacemaker implantation after percutaneous aortic valve implantation with the CoreValve prosthesis. Am Heart J 2010; 159: 497-503.

19. Fraccaro C, Buja G, Tarantini G, Gasparetto V, Leoni L, Razzolini R, Corrado D, Bonato R, Basso C, Thiene G, Gerosa G, Isabella G, Iliceto S, Napodano M. Incidence, predictors, and outcome of conduction disorders after transcatheter self-expandable aortic valve implantation. Am J Cardiol 2011; 107: 747-754.

20. Aktug Ö, Dohmen G, Brehmer K, Koos R, Altiok E, Deserno V, Herpertz R, Autschbach R, Marx N, Hoffmann R. Incidence and predictors of left bundle branch block after transcatheter aortic valve implantation. Int J Cardiol 2012; 160: 26-30.

21. Binder RK, Webb JG, Toggweiler S, Freeman M, Barbanti M, Willson AB, Alhassan D, Hague CJ, Wood DA, Leipsic J. Impact of post-implant SAPIEN XT geometry and position on conduction disturbances, hemodynamic performance, and paravalvular regurgitation. JACC Cardiovasc Interv 2013; 6: 462468.

22. Zannad F, Huvelle E, Dickstein K, van Veldhuisen DJ, Stellbrink C, Køber L, Cazeau S, Ritter P, Maggioni AP, Ferrari R. Left bundle branch block as a risk factor for progression to heart failure. Eur J Heart Fail 2007; 9: 7-14.

23. Thomas JL, Dickstein RA, Parker FB Jr, Potts JL, Poirier RA, Fruehan CT, Eich RH. Prognostic significance of the development of left bundle conduction defects following aortic valve replacement. $J$ Thorac Cardiovasc Surg 1982; 84: 382-386.

24. El-Khally Z, Thibault B, Staniloae C, Theroux P, Dubuc M, Roy D, Guerra P, Macle L, Talajic M. Prognostic significance of newly acquired bundle branch block after aortic valve replacement. Am J Cardiol 2004; 94: 1008-1011.

25. Van Mieghem NM, Head SJ, de Jong W, van Domburg RT, Serruys PW, de Jaegere PP, Jordaens L, Takkenberg JJ, Bogers AJ, Kappetein AP. Persistent annual permanent pacemaker implantation rate after surgical aortic valve replacement in patients with severe aortic stenosis. Ann Thorac Surg 2012; 94: 1143-1149.

26. Hoffmann R, Herpertz R, Lotfipour S, Aktug Ö, Brehmer K, Lehmacher W, Autschbach R, Marx N, Lotfi $\mathrm{S}$. Impact of a new conduction defect after transcatheter aortic valve implantation on left ventricular function. JACC Cardiovasc Interv 2012; 5: 1257-1263.

27. Tzikas A, van Dalen BM, Van Mieghem NM, Gutierrez-Chico JL, Nuis RJ, Kauer F, Schultz C, Serruys PW, de Jaegere PP, Geleijnse ML. Frequency of conduction abnormalities after transcatheter aortic valve implantation with the Medtronic-CoreValve and the effect on left ventricular ejection fraction. Am J Cardiol 2011; 107: 285-289. 
28. Singh JP, Fan D, Heist EK, Alabiad CR, Taub C, Reddy V, Mansour M, Picard MH, Ruskin JN, Mela T. Left ventricular lead electrical delay predicts response to cardiac resynchronization therapy. Heart Rhythm 2006; 3: 1285-1292.

29. Sweeney MO, van Bommel RJ, Schalij MJ, Borleffs CJW, Hellkamp AS, Bax JJ. Analysis of ventricular activation using surface electrocardiography to predict left ventricular reverse volumetric remodeling during cardiac resynchronization therapy. Circulation 2010; 121: 626-634.

30. Reynolds MR, Magnuson EA, Lei Y, Wang K, Vilain K, Li H, Walczak J, Pinto DS, Thourani VH, Svensson LG, Mack MJ, Miller DC, Satler LE, Bavaria J, Smith CR, Leon MB, Cohen DJ. Cost-effectiveness of transcatheter aortic valve replacement compared with surgical aortic valve replacement in high-risk patients with severe aortic stenosis: results of the PARTNER (Placement of Aortic Transcatheter Valves) trial (Cohort A). J Am Coll Cardiol 2012; 60: 2683-2692.

31. Osnabrugge RLJ, Head SJ, Genders TSS, Van Mieghem NM, De Jaegere PP, van der Boon RM, Kerkvliet JM, Kalesan B, Bogers AJ, Kappetein AP, Hunink MG. Costs of transcatheter versus surgical aortic valve replacement in intermediate-risk patients. Ann Thorac Surg 2012; 94: 1954-1960.

32. Abraham WT, Fisher WG, Smith AL, Delurgio DB, Leon AR, Loh E, Kocovic DZ, Packer M, Clavell AL, Hayes DL, Ellestad M, Trupp RJ, Underwood J, Pickering F, Truex C, McAtee P, Messenger J. Cardiac resynchronization in chronic heart failure. $N$ Engl J Med 2002; 346: 1845-1853.

33. Tang ASL, Wells GA, Talajic M, Arnold MO, Sheldon R, Connolly S, Hohnloser SH, Nichol G, Birnie DH, Sapp JL, Yee R, Healey JS, Rouleau JL. Cardiac-resynchronization therapy for mild-to-moderate heart failure. N Engl J Med 2010; 363: 2385-2395.

34. Meguro K, Lellouche N, Teiger E. Cardiac resynchronization therapy improved heart failure after left bundle branch block during transcatheter aortic valve implantation. J Invasive Cardiol 2012; 24: 132133.

35. Osmancik P, Stros P, Herman D, Kocka V, Paskova E. Cardiac resynchronization therapy implantation following transcatheter aortic valve implantation. Europace 2011; 13: 290-291.

36. Lange R, Bleiziffer S, Mazzitelli D, Elhmidi Y, Opitz A, Krane M, Deutsch MA, Ruge H, Brockmann G, Voss B, Schreiber C, Tassani P, Piazza N. Improvements in transcatheter aortic valve implantation outcomes in lower surgical risk patients: a glimpse into the future. J Am Coll Cardiol 2012; 59: 280 287.

37. Meredith IT, Worthley SG, Whitbourn RJ, Antonis P, Montarello JK, Newcomb AE, Lockwood S, Haratani N, Allocco DJ, Dawkins KD. Transfemoral aortic valve replacement with the repositionable Lotus Valve System in high surgical risk patients: the REPRISE I study. Eurointervention 2013; in press.

38. Schofer J, Colombo A, Klugmann S, Fajadet J, Demarco F, Tchétché D, Maisano F, Bruschi G, Latib A, Bijuklic K, Weissman N, Low R, Thomas M, Young C, Redwood S, Mullen M, Yap J, Grube E, Nickenig G, Sinning JM, Hauptmann KE, Friedrich I, Lauterbach M, Schmoeckel M, Davidson C, Lefevre T. Prospective Multicenter Evaluation of the Direct Flow Medical Transcatheter Aortic Valve. J Am Coll Cardiol 2013; in press. 


\section{CHAPTER 5}

\section{Frequency and Long-Term Prognosis of New Left Bundle Branch Block Induced by Surgical Aortic Valve Replacement}

Thomas T. Poels, Patrick Houthuizen, Leen A.F.M. Van Garsse, Jos G. Maessen, Frits W. Prinzen, Albert H.M. van Straten

Submitted for publication 


\section{Abstract}

\section{Introduction}

The frequent occurrence of left bundle branch block (LBBB) induced by transcatheter aortic valve implantation (TAVI) has led to renewed interest in its prognostic significance after aortic valve intervention. There is little contemporary data on frequency and prognosis of new bundle branch block (BBB) after surgical aortic valve replacement (AVR).

\section{Methods and Results}

All-cause mortality was compared between patients who did and did not develop persistent new BBB within 7 days after AVR with or without concomitant bypass surgery in an observational cohort of patients who underwent AVR from 2002 up to 2010 in a single center. Prospectively collected data from a central registry were extracted into a dedicated database. Electrocardiographic (ECG) data were retrospectively collected by reviewing medical records. Patients were not eligible if they had a baseline ECG with BBB and/or pacemaker activity on baseline or postoperative ECG. A postoperative time frame of 3 to 12 months was used to collect follow-up ECGs.

Of the 2,279 patients who underwent AVR 2,033 patients were eligible for analysis. In 269 patients (11.8\%) no baseline and/or follow-up ECG were available, resulting in 1,764 patients qualifying for analysis. Early LBBB and RBBB occurred in 71 (4.0\%) and $92(5.2 \%)$ respectively. At follow-up, the bundle branch block was persistent in 28 (1.6\%) for LBBB, and 73 (4.2\%) for RBBB, respectively.

During a median follow-up of 4.5 (interquartile range [IQR], 2.4-6.5) years mortality rate was $16.3 \%(\mathrm{n}=271)$ in patients without, $24.1 \%(\mathrm{n}=7)$ patients with persistent LBBB and $18.9 \%(n=14)$ patients with persistent RBBB (log-rank $\mathrm{P}=0.49)$. Also in multivariate analysis, neither AVR-induced LBBB nor AVR-induced RBBB was identified as a predictor of mortality.

\section{Conclusion}

AVR-induced LBBB and RBBB occur infrequently in $4.0 \%$ and $5.2 \%$ of patients, respectively and at follow-up most of these conduction disorders resolve. Neither LBBB or RBBB are associated with a significant increase in all-cause mortality during long-term follow-up, partly due to the low number of these conduction abnormalities. 


\section{Introduction}

Surgical aortic valve replacement (SAVR) is the evidence based treatment of choice for patients with severe aortic valve stenosis. Nevertheless, in recent years transcatheter aortic valve implantation (TAVI) has emerged as an attractive alternative for selected patients with a high operative risk.1,2 TAVI is however complicated by new left bundle branch block (LBBB) in up to $65 \%$ of patients. ${ }^{3}$ It is generally appreciated that $\angle B B B$ is an independent predictor of cardiovascular morbidity and mortality. ${ }^{4}$ Not surprisingly, TAVI-induced LBBB leads to a decrease in left ventricular function ${ }^{5-7}$ and to an increased risk of conduction disorders necessitating pacemaker implantation. ${ }^{6}$ Moreover, during long-term follow-up a TAVI-induced LBBB may be associated with an increase in total and cardiovascular mortality. ${ }^{8}$

Despite these recent insights, there is little contemporary data on frequency or prognostic impact of bundle branch block (BBB) after SAVR. Still, it is asserted that SAVR is complicated by new LBBB in $16-32 \%^{9-11}$ and by new right bundle branch block (RBBB) in $11-13 \%,{ }^{12,13}$ thereby often referring to reports from the eighties. ${ }^{14}$, 15 These data need to be interpreted with caution as knowledge, materials and techniques have changed over time. Data on the relationship between SAVR-induced bundle branch block (BBB) and mortality in the past decade has been limited.12,16

The primary purpose of present study was to investigate the frequency and persistence of SAVR-induced bundle branch block (LBBB and RBBB) and its impact on all-cause mortality in a series of 1,764 patients who underwent SAVR from 2002 up to 2010 in a single center in the Netherlands. Secondly, we analyzed predictors of SAVR-induced bundle branch block.

\section{Methods}

\section{Study Population}

All patients who underwent SAVR with or without concomitant bypass surgery in the Catharina Hospital Eindhoven (the Netherlands) from 2002 up to 2010 were reviewed. Data were collected prospectively in a central registry and relevant data to the purpose of this study were extracted into a dedicated database. In the central registry, mortality was collected by consulting the Dutch civil register. This governmental controlled register contains vital records of the entire population, including date of death. Electrocardiographic data were retrospectively collected by reviewing medical records. The medical ethics committee of the hospital waived the need for informed consent. 


\section{Study objectives}

The primary objective of this study was to assess frequency, persistence and prognosis of SAVR-induced bundle branch block. For this purpose, electrocardiograms (ECG) before and within 7 days after implantation and were assessed by the first author (T.P.) to extract heart rhythm, PR- and QRS interval, QRS axis in exact degrees and intra-ventricular conduction delay (IVCD). Afterwards, all ECGs with a QRS $>120$ msec were reviewed by the second author (P.H.). Subsequently, follow-up ECGs of all patients with new bundle branch block on the postoperative ECG were collected and reviewed. A postoperative time frame of 3 to 12 months was used to collect these ECGs. At the time of ECG analysis, both reviewers were blinded to the outcome of the patients.

Patients were not eligible if they had a baseline ECG with LBBB, RBBB or presence of pacemaker activity. If the postprocedural ECG demonstrated pacemaker rhythm, patients were also excluded as it was not possible to assess the intrinsic conduction of these patients.

According to the established guidelines, LBBB was defined as a postprocedural V1-negative QRS-complex $\geq 120 \mathrm{msec}$ with absent Q-waves and a notched or slurred $\mathrm{R}$-wave in the left lateral leads $\left(\mathrm{I}, \mathrm{a} \mathrm{V}_{\mathrm{L}}, \mathrm{V}_{5}, \mathrm{~V}_{6}\right)$. RBBB was defined as a postprocedural QRS-complex $\geq 120$ msec with a triphasic QRS-complex in V1 together with a dominant $S$ wave in leads I and V6.(17)

Any new bundle branch block on the postoperative ECG was defined as early LBBB or early RBBB, respectively. If the bundle branch block was still present on the follow-up ECG, it was considered a persistent LBBB or persistent RBBB, respectively. In case of a missing follow-up ECG or ventricular pacing, the patient was classified according to the postoperative ECG.

Prostheses size was defined by ranking the prostheses size in tertiles.

\section{Statistical Analysis}

Categorical variables are presented as numbers and proportions. For continuous variables, normality of distribution was assessed with the Kolmogorov-Smirnov test. Normal and skewed continuous variables are presented as means with standard deviation (SD) and medians with interquartile range (IQR), respectively.

Baseline variables between different patients categories were compared using repeated measures analysis of variance (ANOVA) in case of a continuous measurement. Binary logistic regression analysis was used to compare categorical variables.

Survival was estimated using the Kaplan-Meier method. Cox regression analysis test was used to compare mortality between patients with and without SAVR-induced bundle branch block. All characteristics in the univariate analysis with a pvalue less than 0.10 were included in a multivariate analysis. This analysis was also used to plot adjusted survival curves for patients with and without SAVR-induced bundle branch block. A binary logistic regression analysis test was used to analyze 
predictors of the occurrence of SAVR-induced bundle branch block. All characteristics in the univariate analysis with a p-value less than 0.10 were included in a multivariate analysis. All statistical analyses were performed using Statistical Package for Social Sciences (SPSS), version 19 (IBM SPSS, Chicago, IL, USA).

\section{Results}

\section{Study population}

Between January 2002 up to December 2010, a total of 2,279 patients underwent SAVR with or without concomitant bypass surgery in our center. As per protocol 246 patients were not eligible, either because of pre-existing LBBB $(n=81)$, pre-existing RBBB $(n=104)$ or baseline pacemaker rhythm ( $n=38)$. Another 23 patients demonstrated pacemaker rhythm on the postprocedural ECG and were therefore excluded. In the remaining 2,033 patients eligible for analysis, we were not able to retrieve a baseline and/or follow-up ECG in 269 patients (11.8\%). Subsequently these patients

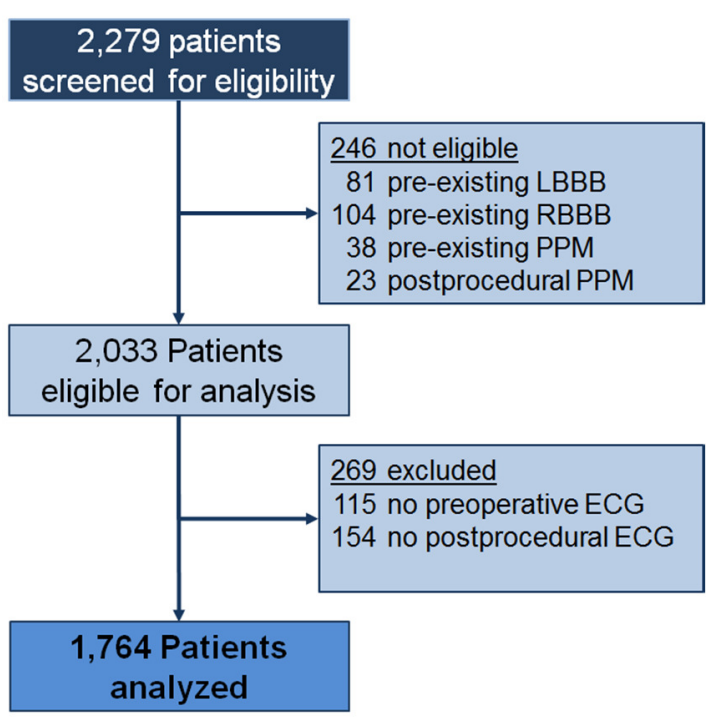

Figure 1. Study Population.

LBBB indicates left bundle branch block; RBBB, right bundle branch block; PPM, permanent pacemaker and ECG, electrocardiogram. were excluded, resulting in 1,764 patients who were analyzed in this study (Figure 1).

\section{Procedural outcome; early versus persistent bundle branch block}

All patients underwent successful implantation of the aortic valve prosthesis and $40.6 \%$ $(n=717)$ also had concomitant bypass surgery. A total of 71 (4.0\%) patients developed an early LBBB which was persistent in 28 (1.6\%) patients; in other words 43 (60.6\%) patients showed resolution of the conduction disorder. Another 2 (2.8\%) patients with early LBBB showed ventricular pacing on the follow-up ECG. Early RBBB developed in 92 (5.2\%) patients. On follow-up, there was resolution of RBBB in 19 (20.7\%) and ventricular pacing in 11 (12.0\%) patients (Figure 2). In 2 patients with RBBB, there was no follow-up ECG available; they were therefore classified as persistent RBBB according to their postoperative ECG. Baseline and procedural characteristics of patients with and 
without persistent bundle branch block were comparable between all groups (Table 1).

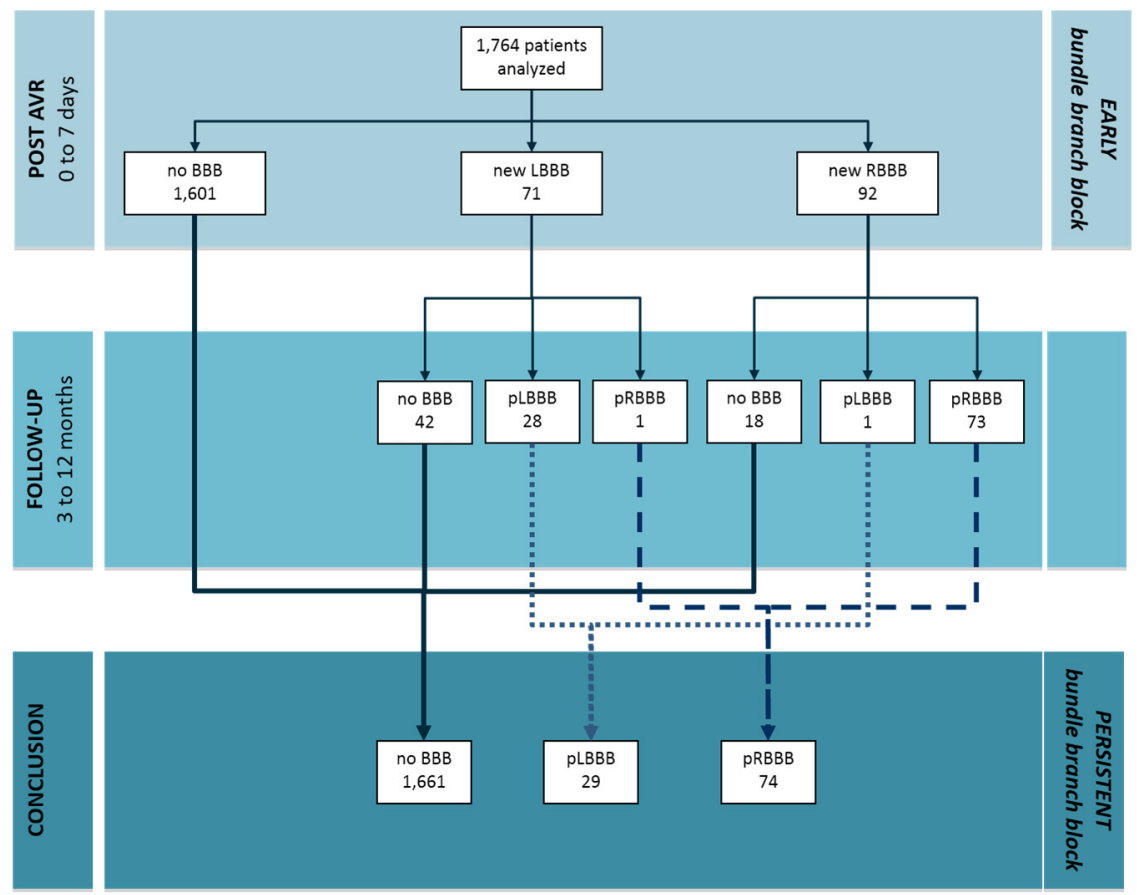

Figure 2. Frequency, timing and persistence of SAVR-induced Bundle Branch Block.

SAVR indicates aortic valve replacement. Early bundle branch block is defined as bundle branch block within 7 days postoperatively. Persistent bundle branch block is defined as bundle branch block existing at 3-12 months follow-up. 
Table 1. Clinical characteristics of the study population.

\begin{tabular}{|c|c|c|c|c|c|}
\hline Characteristic & $\begin{array}{l}\text { Study Population } \\
(n=1,764)\end{array}$ & $\begin{array}{l}\text { No bundle } \\
\text { branch block } \\
(n=1,661)\end{array}$ & $\begin{array}{l}\text { Persistent LBBB } \\
(n=29)\end{array}$ & $\begin{array}{l}\text { Persistent RBBB } \\
(\mathrm{n}=74)\end{array}$ & $\begin{array}{l}\text { Pvalue } \\
\text { Value }\end{array}$ \\
\hline \multicolumn{6}{|l|}{ Demographics } \\
\hline Age - years & $70(62-76)$ & $70(62-76)$ & $71(63-76)$ & $69(58-76)$ & 0.54 \\
\hline Male gender - no.(\%) & $1064(60.3)$ & 995 (59.9) & $21(72.4)$ & $48(64.9)$ & 0.29 \\
\hline \multicolumn{6}{|l|}{ Clinical } \\
\hline Previous MI - no.(\%) & 235 (13.3) & $218(13.1)$ & $3(10.3)$ & $14(18.9)$ & 0.32 \\
\hline Previous PCI - no.(\%) & $156(8.8)$ & $145(8.7)$ & $2(6.9)$ & $9(12.2)$ & 0.56 \\
\hline Previous CABG - no.(\%) & $73(4.1)$ & $66(4.0)$ & $0(0.0)$ & $7(9.5)$ & 0.08 \\
\hline Reoperation - no.(\%) & $146(8.3)$ & $132(7.9)$ & $2(6.9)$ & $12(16.2)$ & $<0.05$ \\
\hline Cerebral vascular disease - no.(\%) & $80(4.5)$ & $68(4.1)$ & $4(13.8)$ & $8(10.8)$ & $<0.05$ \\
\hline Peripheral vascular disease - no.(\%) & $171(9.7)$ & $163(9.8)$ & $4(13.8)$ & $4(5.4)$ & 0.35 \\
\hline Diabetes mellitus - no.(\%) & $289(16.4)$ & $274(16.5)$ & $6(20.7)$ & $9(12.2)$ & 0.51 \\
\hline COPD - no.(\%) & 308 (17.5) & $290(17.5)$ & $5(17.2)$ & $13(17.6)$ & 1.00 \\
\hline Renal disease $†$ - no.(\%) & $64(3.6)$ & $59(3.6)$ & $1(3.4)$ & $4(5.4)$ & 0.71 \\
\hline Dialysis - no.(\%) & $12(0.7)$ & $12(0.7)$ & $0(0.0)$ & $0(0.0)$ & 1.00 \\
\hline Hypertension - no.(\%) & $768(43.5)$ & $722(43.5)$ & $13(44.8)$ & $33(44.6)$ & 0.97 \\
\hline \multicolumn{6}{|l|}{ Electrocardiography } \\
\hline Baseline QRS duration - msec & $96(88-102)$ & $96(88-102)$ & $100(91-108)$ & $96(88-104)$ & 0.11 \\
\hline \multicolumn{6}{|l|}{ Echocardiography } \\
\hline LVEF< $<50 \%$ - no. $(\%)$ & $246(13.9)$ & 230 (13.8) & $3(10.3)$ & $13(17.6)$ & 0.57 \\
\hline \multicolumn{6}{|l|}{ Procedural } \\
\hline Calcification - no.(\%) & $1454(82.4)$ & $1365(82.2)$ & $26(89.7)$ & $63(85.1)$ & 0.48 \\
\hline Endocarditis - no.(\%) & $66(3.7)$ & $59(3.6)$ & $1(3.4)$ & $6(8.1)$ & 0.15 \\
\hline Cristalloid cardioplegia - no.(\%) & $1417(80.3)$ & $1334(80.3)$ & $20(69.0)$ & $63(85.1)$ & 0.19 \\
\hline Intra-aortic balloon pump - no.(\%) & $20(1.1)$ & $17(1.0)$ & $0(0.0)$ & $3(4.1)$ & 0.09 \\
\hline Aortic occlusion time - minutes & $63(50-80)$ & $63(50-80)$ & $73(56-97)$ & $71(54-94)$ & $<0.05$ \\
\hline Concomitant CABG - no.(\%) & $717(40.6)$ & $676(40.7)$ & $12(41.4)$ & $29(39.2)$ & 0.96 \\
\hline Duration ECC - minutes & $85.5(67-110)$ & $85(67-110)$ & $96(78-125)$ & $95(70-120)$ & $<0.05$ \\
\hline Rethoracotomy - no.(\%) & $134(7.6)$ & $127(7.6)$ & $2(6.9)$ & $5(6.8)$ & 0.95 \\
\hline Follow-up - days & $1642(867-2364)$ & 1639 (872-2349) & $1393(399-2525)$ & $1800(809-2562)$ & 0.59 \\
\hline Biological prostheses - no.(\%) & $978(55.4)$ & $928(55.9)$ & $15(51.7)$ & $35(47.3)$ & 0.32 \\
\hline Prostheses size' & & & & & $<0.05$ \\
\hline Small - no.(\%) & $463(26.2)$ & $433(26.1)$ & $9(31.0)$ & $21(28.4)$ & \\
\hline Medium - no.(\%) & $641(36.3)$ & $601(36.2)$ & $10(34.5)$ & $30(40.5)$ & \\
\hline Large - no.(\%) & $660(37.4)$ & $627(37.3)$ & $10(34.5)$ & $23(31.1)$ & \\
\hline
\end{tabular}

* LBBB indicates left bundle branch block; RBBB, right bundle branch block; bundle branch block, bundle branch block; MI, myocardial infarction; PCI, percutaneous coronary intervention; CABG, coronary artery bypass grafting; COPD, chronic obstructive lung disease; and LVEF, left ventricular ejection fraction. Results are presented as median (interquartile range) or absolute No. (percentage).

$\dagger$ Renal disease was defined as creatinine $>1.14$

Prostheses size was defined by ranking the prostheses size in tertiles. 


\section{Prognosis of SAVR-induced persistent bundle branch block}

Median follow-up was 3.8 (interquartile range [IQR], 0.0-8.9), 4.9 (IQR, 0.0-9.4) and 4.5 (IQR, 0.0-9.4) years in patients with persistent LBBB, persistent RBBB and without new bundle branch block, respectively $(\mathrm{P}=0.59)$.

At 30 days, mortality rate was $3.1 \%(n=51)$ in patients without, $6.9 \%(n=2)$ in patients with persistent LBBB and 6.8\% $(\mathrm{n}=5)$ in patients with persistent RBBB (logrank $\mathrm{P}=0.11)$. At 1 year, these numbers were $6.9 \%(\mathrm{n}=115), 6.9 \%(\mathrm{n}=2)$ and $10.8 \%$ $(\mathrm{n}=8)$, respectively (log-rank $\mathrm{P}=0.43)$. During total follow-up, the primary endpoint of all-cause mortality was reached in $271(16.3 \%)$ of patients without, in 7 (24.1\%) patients with persistent LBBB and in $14(18.9 \%)$ patients with persistent RBBB and (log-rank $\mathrm{P}=0.49$ ) (Figure 3).

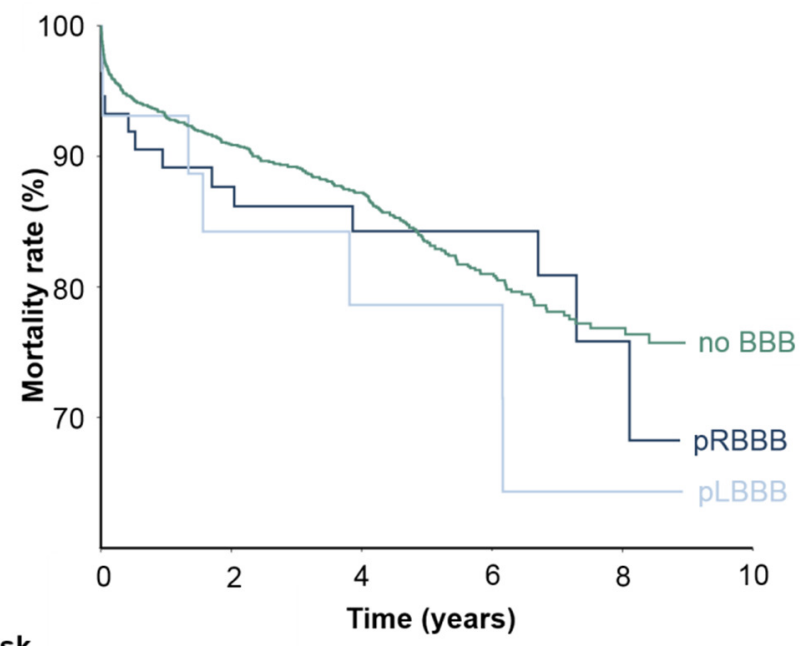

No. at risk

$\begin{array}{rccccc}\text { no BBB } & 1,661 & 1,319 & 950 & 511 & 171 \\ \text { pLBBB } & 74 & 59 & 44 & 30 & 10 \\ \text { pRBBB } & 29 & 19 & 14 & 11 & 5\end{array}$

Figure 3. Kaplan Meier survival curve of patients with SAVR-induced LBBB, SAVR-induced RBBB and without SAVR-induced bundle branch block.

"Persistent LBBB" indicates patients who developed a persistent left bundle branch block (LBBB) induced by aortic valve replacement. "Persistent RBBB" indicates patients who developed persistent right bundle branch block (RBBB) induced by aortic valve replacement, whereas "no bundle branch block (no BBB)" indicates patients who did not. Event rates were compared by log-rank test.

\section{Predictors of mortality}

In univariate analysis, SAVR-induced persistent LBBB (hazard ratio, HR, 1.54; 95\% confidence interval, CI, 0.56-3.27, $\mathrm{P}=0.51$ ) nor SAVR-induced persistent RBBB (HR, $1.10,95 \% \mathrm{CI} 0.66-2.19, \mathrm{P}=0.55$ ) was a predictor of mortality. In multivariate Cox regression analysis, following variables emerged as independent predictors of all- 
cause mortality in descending order of their hazard ratio: dialysis, intra-aortic balloon pump (IABP), rethoracotomy, cerebral vascular disease (CVA), chronic obstructive pulmonary disease (COPD), renal disease, peripheral vascular disease, small valve size, left ventricular ejection fraction (LVEF) $<50 \%$, age and duration of the extra corporeal circulation (ECC). Again, SAVR-induced permanent LBBB (HR, 1.08, 95\% CI, 0.50-2.38, P=0.84) and SAVR-induced permanent RBBB (HR, 1.00, 95\% CI, 0.58-1.73, $\mathrm{P}=0.99$ ) did not predict the endpoint (Table 2).

Predictors of SAVR-induced persistent bundle branch block

Binary logistic regression analysis was performed to identify baseline and procedural factors associated with the development of a persistent LBBB and persistent RBBB. In multivariate analysis the duration of QRS on the preoperative ECG was associated with risk of development of SAVR-induced permanent LBBB. (Table 3). Endocarditis was the only factor associated with the risk of development of persistent RBBB (Table 4). 
Table 2. Univariate and multivariate Cox regression analysis of the primary endpoint of all-cause mortality.

\begin{tabular}{|c|c|c|c|c|c|c|}
\hline \multirow[b]{2}{*}{ Variable } & \multicolumn{3}{|c|}{ Univariate analysis } & \multicolumn{3}{|c|}{ Multivariate analysis } \\
\hline & HR & $\mathrm{CI}$ & $P$ value & HR & $\mathrm{CI}$ & P Value \\
\hline \multicolumn{7}{|l|}{ Demographics } \\
\hline Age - per year & 1.05 & $1.03-1.06$ & $<0.05$ & 1.04 & $1.02-1.05$ & $<0.05$ \\
\hline Male gender & 0.87 & $0.69-1.10$ & 0.23 & & & \\
\hline \multicolumn{7}{|l|}{ Clinical } \\
\hline Previous MI & 1.49 & $1.10-2.02$ & $<0.05$ & 1.05 & $0.76-1.45$ & 0.79 \\
\hline Previous PCI & 1.22 & $0.83-1.81$ & 0.31 & & & \\
\hline Previous CABG & 2.34 & $1.54-3.55$ & $<0.05$ & 1.04 & $0.51-2.10$ & 0.92 \\
\hline Reoperation & 1.77 & $1.25-2.50$ & $<0.05$ & 1.17 & $0.65-2.10$ & 0.60 \\
\hline Cerebral vascular disease & 1.99 & $1.31-3.02$ & $<0.05$ & 1.69 & $1.10-2.59$ & $<0.05$ \\
\hline Peripheral vascular disease & 2.10 & $1.53-2.89$ & $<0.05$ & 1.59 & $1.13-2.23$ & $<0.05$ \\
\hline Diabetes mellitus & 1.51 & $1.14-1.99$ & $<0.05$ & 1.26 & $0.94-1.67$ & 0.12 \\
\hline COPD & 1.71 & $1.32-2.21$ & $<0.05$ & 1.63 & $1.25-2.12$ & $<0.05$ \\
\hline Renal disease $^{\dagger}$ & 2.87 & $1.86-4.43$ & $<0.05$ & 1.62 & $1.01-2.59$ & $<0.05$ \\
\hline Dialysis & 5.65 & $2.66-11.97$ & $<0.05$ & 4.15 & $1.89-9.13$ & $<0.05$ \\
\hline Hypertension & 1.11 & $0.88-1.40$ & 0.37 & & & \\
\hline \multicolumn{7}{|l|}{ Electrocardiography } \\
\hline Baseline QRS duration - per msec & 1.00 & $0.99-1.01$ & 0.60 & & & \\
\hline \multicolumn{7}{|l|}{ Echocardiography } \\
\hline $\mathrm{LVEF}<50 \%$ & 1.74 & $1.32-2.30$ & $<0.05$ & 1.51 & $1.12-2.04$ & $<0.05$ \\
\hline \multicolumn{7}{|l|}{ Procedural } \\
\hline Calcification & 0.98 & $0.72-1.33$ & 0.89 & & & \\
\hline Endocarditis & 1.49 & $0.88-2.50$ & 0.14 & & & \\
\hline Blood cardioplegia & 1.04 & $0.79-1.38$ & 0.77 & & & \\
\hline Intra-aortic balloon pump - per minute & 6.30 & $3.44-11.51$ & $<0.05$ & 3.40 & $1.69-6.85$ & $<0.05$ \\
\hline Aortic occlusion time - per minute & 1.01 & $1.01-1.01$ & $<0.05$ & 1.00 & $0.99-1.01$ & 0.79 \\
\hline Concomitant CABG & 1.45 & $1.15-1.83$ & $<0.05$ & 0.97 & $0.72-1.30$ & 0.83 \\
\hline Duration ECC - per minute & 1.00 & $1.00-1.01$ & $<0.05$ & 1.00 & $1.00-1.01$ & $<0.05$ \\
\hline Rethoracotomy & 2.34 & $1.68-3.27$ & $<0.05$ & 1.94 & $1.37-2.76$ & $<0.05$ \\
\hline SAVR-induced LBBB & 1.54 & $0.56-3.27$ & 0.51 & 1.08 & $0.50-2.38$ & 0.84 \\
\hline SAVR-induced RBBB & 1.10 & $0.66-2.19$ & 0.55 & 1.00 & $0.58-1.73$ & 0.99 \\
\hline Biological prostheses & 1.65 & $1.30-2.09$ & $<0.05$ & 1.19 & $0.88-1.62$ & 0.26 \\
\hline Prostheses size! & 0.76 & $0.66-0.88$ & $<0.05$ & 0.80 & $0.68-0.93$ & $<0.05$ \\
\hline Small & 1.73 & $1.30-2.30$ & $<0.05$ & 1.56 & $1.15-2.12$ & $<0.05$ \\
\hline Medium & 1.15 & $0.87-1.54$ & 0.32 & 1.03 & $0.77-1.39$ & 0.83 \\
\hline Large & 0.58 & $0.44-0.77$ & $<0.05$ & 0.64 & $0.47-0.87$ & $<0.05$ \\
\hline
\end{tabular}

* HR indicates hazard ratio; CI, 95\% confidence interval; LBBB, left bundle branch block; bundle branch block, bundle branch block; MI, myocardial infarction; PCI, percutaneous coronary intervention; CABG, coronary artery bypass grafting; COPD, chronic obstructive lung disease; and LVEF, left ventricular ejection fraction, SAVR surgical aortic valve replacement, LBBB left bundle branch block, RBBB right bundle branch block.

† Renal disease was defined as creatinine $>1.14 \mathrm{mg} / \mathrm{dl}$

| Prostheses size was defined by ranking the prostheses size in tertiles. 
Table 3. Univariate and multivariate binary regression analysis of SAVR-induced permanent left bundle branch block.

\begin{tabular}{|c|c|c|c|c|c|c|}
\hline \multirow[b]{2}{*}{ Variable } & \multicolumn{3}{|c|}{ Univariate analysis } & \multicolumn{3}{|c|}{ Multivariate analysis } \\
\hline & HR & $\mathrm{CI}$ & P value & HR & $\mathrm{CI}$ & P Value \\
\hline \multicolumn{7}{|l|}{ Demographics } \\
\hline Age - per year & 1.01 & $0.98-1.05$ & 0.47 & & & \\
\hline Male gender & 1.74 & $0.77-3.95$ & 0.19 & & & \\
\hline \multicolumn{7}{|l|}{ Clinical } \\
\hline Previous MI & 0.75 & $0.22-2.49$ & 0.64 & & & \\
\hline Previous PCI & 0.76 & $0.18-3.23$ & 0.71 & & & \\
\hline Previous CABG & 0.00 & $0.00-0.00$ & 1.00 & & & \\
\hline Reoperation & 0.82 & $0.19-3.48$ & 0.79 & & & \\
\hline Peripheral vascular disease & 1.50 & $0.52-4.37$ & 0.46 & & & \\
\hline Diabetes Mellitus & 1.34 & $0.54-3.32$ & 0.53 & & & \\
\hline COPD & 0.99 & $0.37-2.60$ & 0.98 & & & \\
\hline Renal disease $^{\dagger}$ & 0.95 & $0.13-7.08$ & 0.96 & & & \\
\hline Dialysis & 0.00 & $0.00-0.00$ & 1.00 & & & \\
\hline Hypertension & 1.06 & $0.50-2.21$ & 0.89 & & & \\
\hline \multicolumn{7}{|l|}{ Electrocardiography } \\
\hline Baseline QRS duration - per msec & 1.03 & $1.00-1.07$ & $<0.05$ & 1.03 & $1.00-1.06$ & $<0.05$ \\
\hline \multicolumn{7}{|l|}{ Echocardiography } \\
\hline $\mathrm{LVEF}<50 \%$ & 0.71 & $0.21-2.36$ & 0.57 & & & \\
\hline \multicolumn{7}{|l|}{ Procedural } \\
\hline Calcification & 1.86 & $0.56-6.20$ & 0.31 & & & \\
\hline Endocarditis & 0.92 & $0.12-6.85$ & 0.93 & & & \\
\hline Blood cardioplegia & 0.54 & $0.24-1.19$ & 0.13 & & & \\
\hline Intra-aortic balloon pump - per minute & 0.00 & $0.00-0.00$ & 1.00 & & & \\
\hline Aortic occlusion time - per minute & 1.02 & $1.01-1.03$ & $<0.05$ & 1.03 & $1.00-1.06$ & 0.08 \\
\hline Concomitant CABG & 1.03 & $0.49-2.17$ & 0.94 & & & \\
\hline Duration ECC - per minute & 1.00 & $1.00-1.01$ & $<0.05$ & 0.99 & 0.97-1.02 & 0.51 \\
\hline Rethoracotomy & 0.90 & $0.21-3.82$ & 0.89 & & & \\
\hline Biological prostheses & 0.86 & $0.41-1.79$ & 0.69 & & & \\
\hline Prostheses size! & 0.88 & $0.56-1.40$ & 0.60 & & & \\
\hline
\end{tabular}

* HR indicates hazard ratio; CI, 95\% confidence interval; LBBB, left bundle branch block; bundle branch block, bundle branch block; MI, myocardial infarction; PCI, percutaneous coronary intervention; CABG, coronary artery bypass grafting; COPD, chronic obstructive lung disease; and LVEF, left ventricular ejection fraction.

$\dagger$ Renal disease was defined as creatinine $>1.14 \mathrm{mg} / \mathrm{dl}$

| Prostheses size was defined by ranking the prostheses size in tertiles. 
Table 4. Univariate and multivariate binary regression analysis of SAVR-induced permanent right bundle branch block.

\begin{tabular}{|c|c|c|c|c|c|c|}
\hline \multirow[b]{2}{*}{ Variable } & \multicolumn{3}{|c|}{ Univariate analysis } & \multicolumn{3}{|c|}{ Multivariate analysis } \\
\hline & HR & $\mathrm{CI}$ & $P$ value & HR & $\mathrm{CI}$ & P Value \\
\hline \multicolumn{7}{|l|}{ Demographics } \\
\hline Age - per year & 0.99 & $0.97-1.01$ & 0.38 & & & \\
\hline Male gender & 1.23 & $0.75-1.99$ & 0.42 & & & \\
\hline \multicolumn{7}{|l|}{ Clinical } \\
\hline Previous MI & 1.55 & $0.85-2.82$ & 0.15 & & & \\
\hline Previous PCI & 1.45 & $0.71-2.98$ & 0.31 & & & \\
\hline Previous CABG & 2.57 & $1.14-5.82$ & $<0.05$ & 1.54 & $0.45-5.27$ & 0.50 \\
\hline Reoperation & 2.25 & $1.18-4.27$ & $<0.05$ & 1.50 & $0.56-3.99$ & 0.46 \\
\hline Peripheral vascular disease & 0.52 & $0.19-1.45$ & 0.21 & & & \\
\hline Diabetes Mellitus & 0.70 & $0.34-1.42$ & 0.32 & & & \\
\hline COPD & 1.01 & $0.55-1.86$ & 0.98 & & & \\
\hline Renal disease $^{\dagger}$ & 1.55 & $0.55-4.39$ & 0.41 & & & \\
\hline Dialysis & 0.00 & 0.00 & 1.00 & & & \\
\hline Hypertension & 1.05 & $0.66-1.67$ & 0.85 & & & \\
\hline \multicolumn{7}{|l|}{ Electrocardiography } \\
\hline Baseline QRS duration - per msec & 1.00 & $0.98-1.03$ & 0.69 & & & \\
\hline \multicolumn{7}{|l|}{ Echocardiography } \\
\hline $\mathrm{LVEF}<50 \%$ & 1.33 & $0.72-2.46$ & 0.36 & & & \\
\hline \multicolumn{7}{|l|}{ Procedural } \\
\hline Calcification & 1.23 & $0.64-2.36$ & 0.53 & & & \\
\hline Endocarditis & 2.40 & $1.00-5.74$ & 0.05 & 2.50 & $1.02-6.13$ & $<0.05$ \\
\hline Blood cardioplegia & 0.70 & $0.37-1.35$ & 0.29 & & & \\
\hline Intra-aortic balloon pump - per minute & 4.16 & $1.19-14.52$ & $<0.05$ & 3.01 & $0.70-12.96$ & 0.14 \\
\hline Aortic occlusion time - per minute & 1.01 & $1.00-1.02$ & $<0.05$ & 1.01 & $0.99-1.03$ & 0.24 \\
\hline Concomitant CABG & 0.94 & $0.58-1.51$ & 0.79 & & & \\
\hline Duration ECC - per minute & 1.00 & $1.00-1.01$ & 0.09 & 1.00 & 0.98-1.01 & 0.60 \\
\hline Rethoracotomy & 0.88 & $0.35-2.21$ & 0.78 & & & \\
\hline Biological prostheses & 0.71 & $0.45-1.13$ & 0.15 & & & \\
\hline Prostheses size! & 0.87 & $0.65-1.17$ & 0.35 & & & \\
\hline
\end{tabular}

* HR indicates hazard ratio; CI, 95\% confidence interval; LBBB, left bundle branch block; bundle branch block, bundle branch block; MI, myocardial infarction; PCI, percutaneous coronary intervention; CABG, coronary artery bypass grafting; COPD, chronic obstructive lung disease; and LVEF, left ventricular ejection fraction.

$\dagger$ Renal disease was defined as creatinine $>1.14 \mathrm{mg} / \mathrm{dl}$

| Prostheses size was defined by ranking the prostheses size in tertiles. 


\section{Discussion}

In this observational study of a large patient cohort who underwent SAVR, we have demonstrated that new LBBB and new RBBB occurred in $4.0 \%$ and $5.2 \%$, respectively. After 3 to 12 months follow-up, LBBB was persistent in $1.6 \%$ and RBBB in $4.2 \%$ of the patients.

Neither persistent LBBB nor persistent RBBB was associated with an increased risk in mortality during long-term follow-up. After correction for potential confounders, we found preoperative QRS duration to be associated with development of a persistent LBBB and endocarditis with development a persistent RBBB.

\section{Frequency and persistence of SAVR-induced bundle branch block}

In parallel with progressive insight in the anatomy of the conduction system, ${ }^{18}$ the occurrence of intraventricular conduction defects after SAVR was already appreciated in the early ' $70 \mathrm{~s} .{ }^{14}$ In subsequent decennia, a frequency up to $25 \%$ of new left bundle branch conduction disorders after SAVR has been reported,13,15,19 and some authors noted an increased rate of sudden and/or cardiac death during long-term follow-up in patients who developed LBBB. ${ }^{15}$ In a more recent study of El-Khally et al., it was demonstrated that LBBB occurred in $6.4 \%$ and RBBB occurred in $11.2 \%$ in a series of 262 SAVR patients. ${ }^{12}$

In the light of these results, we found (early) LBBB and RBBB to be less than reported by El-Khally's study. The former study reports on earlier procedures $(1995$ to 1997) and improvement in operation techniques possible have led to a decrease in incidence of bundle branch block. For example, extracorporeal circulation time was longer than in our study. Also, El-Khally's study used other criteria for the diagnosis of LBBB and there is growing evidence that these classic criteria may lead to over-interpretation of LBBB. ${ }^{20,21}$

A recent study by Houthuizen et al. ${ }^{22}$ showed that in 476 patients, $36.8 \%$ developed a TAVI-induced new LBBB which was persistent in $63.4 \%$ of these patients at one-year follow-up. Acknowledging the absence of head-to-head comparison between TAVI and SAVR, the frequency of new LBBB after SAVR in present study is considerably lower.

\section{Prognosis of persistent SAVR-induced bundle branch block}

\section{SAVR-induced $L B B B$}

In the aforementioned study of El-Khally, patients with postoperative conduction disorders (defined as both RBBB and LBBB) had significantly more adverse events defined as syncope, total atrioventricular block and/or sudden cardiac death. ${ }^{12}$ In our study, no significant difference in mortality was found between patients with and without bundle branch block. Explanations for these discrepancies may be that El 
Khally used a combined endpoint, in addition to only implementing early and not persistent bundle branch block. Given the low sample size and low rate of sudden cardiac death, the significant difference in outcome in their study was possibly driven by a higher frequency of atrioventricular block and/or syncope.

Although subject of debate, there is evidence that TAVI-induced LBBB is associated with an increased risk of cardiovascular mortality. ${ }^{8,23-25}$ Such higher mortality may, at least partly, be the result of dyssynchrony-induced heart failure. Of note, LBBB is a well-known independent predictor of cardiovascular morbidity and mortality in a broad patient population. ${ }^{4}$

We expected to find the same results in the SAVR population, however this was not the case in present study. Still, the majority of patients undergoing SAVR are of younger age, have less comorbidities, preserved ejection fraction and considerably lower mortality rate. As a result, the effect of LBBB is less profound and a longer follow-up might be needed to develop overt heart failure. This idea is reminiscent of the effect of right ventricular pacing which causes dyssynchronous activation and a consistent decrease in left ventricular ejection fraction, but only affects mortality in patients with already depressed cardiac function. ${ }^{26}$ Also, the number of patients with SAVR-induced LBBB in our study is relatively low, which could results in a too low sample size to detect statistically significant differences. Indeed, there seems a tendency to higher mortality in patients with SAVR-induced LBBB, however, present study is inadequately powered to detect a statistical significant difference.

From this perspective, SAVR offers an important advantage over TAVI, given the very low frequency of persistent LBBB, especially in the light of possible detrimental effects of this conduction disorder.

\section{SAVR-induced RBBB}

SAVR-induced RBBB occurred more frequently than LBBB and was also more persistent. It is not associated with an increase in all-cause mortality, in concordance with the general belief that RBBB is a benign finding in asymptomatic healthy individuals. ${ }^{27-31}$ Still, more recently it has been postulated that that RBBB in healthy individuals is associated with increased cardiovascular mortality. ${ }^{28}$ Also, among patients with heart failure, the presence of RBBB has been associated with an adverse prognosis. ${ }^{28,} 32,33$ At follow-up a large proportion (12.0\%) of patients with early RBBB were ventricular paced. This may indicate that patients with an SAVR-induced RBBB are prone to develop high-degree atrioventricular conduction disorders as has been described by El-Khally et al. ${ }^{12}$

\section{Predictors of SAVR-induced bundle branch block}

Except for preoperative QRS duration, we were not able to identify other baseline or procedural characteristics to be associated with the development of SAVR-induced LBBB, which is in line with a previous report by Habicht et al. ${ }^{13}$ Still, there are several other factors that may contribute to operative damage to the conduction system, 
namely trauma by sutures, injury as a result of valve decalcification, local edema/hematoma and/or micro-infarction of the bundle branch due to micro-thrombi. ${ }^{13,15}$ Based on autopsy reports, microscopical traumatic lesions have been found in the atrioventricular conduction tissue and left bundle. ${ }^{34}$

SAVR was more frequently complicated by (early and persistent) RBBB than by LBBB, although the right bundle is not in such close proximity to the aortic valve complex than the left bundle., 35 Moreover, traumatic lesions to the right bundle branch block are seldom seen on autopsy specimens of the heart after SAVR. ${ }^{34}$ Although speculative, it is more likely that the right bundle is affected by ischemic damage rather than by direct trauma. This could be explained by the fact that the right bundle is solely perfused by the septal branches of the left anterior descending artery

\section{Study Limitations}

As a result of the observational design, our study could be hampered by the intrinsic risk of information and selection bias. Still, all data were collected prospectively in a central database with established definitions. To ensure data quality and validity, we further chose a hard end-point (all-cause mortality). No monitoring board or core laboratory was available for ECG analysis, but we strictly adhered to published guidelines for the diagnosis of LBBB and RBBB and scored the presence of conduction disorders without knowledge of the actual outcome of the patient.

\section{Conclusions}

SAVR-induced LBBB and RBBB occur infrequently in $4.0 \%$ and $5.2 \%$ of patients, respectively and at follow-up most of these conduction disorders resolve. Neither LBBB or RBBB are associated with an increase in all-cause mortality during longterm follow-up, although present study is inadequately powered to detect a statistical significant difference. 


\section{References}

1. Leon MB, Mack M, Miller DC, Moses JW, Svensson LG, Tuzcu EM, Webb JG, Fontana GP, Makkar RR, Brown DL, Block PC, Guyton RA, Pichard AD, Bavaria JE, Herrmann HC, Douglas PS, Petersen JL, Akin JJ, Anderson WN, Wang D, Pocock S. Transcatheter aortic-valve implantation for aortic stenosis in patients who cannot undergo surgery. The $N$ Engl J Med 2010; 363: 1597-1607.

2. Smith CR, Leon MB, Mack MJ, Miller DC, Moses JW, Svensson LG, Tuzcu EM, Webb JG, Fontana GP, Makkar RR, Williams M, Dewey T, Kapadia S, Babaliaros V, Thourani VH, Corso P, Pichard AD, Bavaria JE, Herrmann HC, Akin JJ, Anderson WN, Wang D, Pocock SJ. Transcatheter versus surgical aortic valve replacement in high-risk patients. N Engl J Med 2011; 364: 2187-2198.

3. van der Boon RM, Nuis R-J, Van Mieghem NM, Jordaens L, Rodes-Cabau J, van Domburg RT, Serruys PW, Anderson RH, de Jaegere PP. New conduction abnormalities after TAVI - frequency and causes. Nat Rev Cardiol 2012; 9: 454-463.

4. Zannad F, Huvelle E, Dickstein K, van Veldhuisen DJ, Stellbrink C, Køber L, Cazeau S, Ritter P, Maggioni AP, Ferrari R, Lechat P. Left bundle branch block as a risk factor for progression to heart failure. Eur J Heart Fail 2007; 9: 7-14.

5. Tzikas A, van Dalen BM, Van Mieghem NM, Gutierrez-Chico JL, Nuis RJ, Kauer F, Schultz C, Serruys PW, de Jaegere PP, Geleijnse ML. Frequency of conduction abnormalities after transcatheter aortic valve implantation with the Medtronic-CoreValve and the effect on left ventricular ejection fraction. Am J Cardiol 2011; 107: 285-289.

6. Urena M, Mok M, Serra V, Dumont E, Nombela-Franco L, DeLarochelliere R, Doyle D, Igual A, Larose E, Amat-Santos I, Côté M, Cuéllar H, Pibarot P, de Jaegere P, Philippon F, Garcia del Blanco B, RodésCabau J. Predictive factors and long-term clinical consequences of persistent left bundle branch block following transcatheter aortic valve implantation with a balloon-expandable valve. J Am Coll Cardiol 2012; 60: 1743-1752.

7. Hoffmann R, Herpertz R, Lotfipour S, Aktug O, Brehmer K, Lehmacher W, Autschbach R, Marx N, Lotfi Sl. Impact of a new conduction defect after transcatheter aortic valve implantation on left ventricular function. JACC Cardiovasc Interv 2012; 5: 1257-1263.

8. Houthuizen P, Van Garsse LA, Poels TT, de Jaegere P, van der Boon RM, Swinkels BM, Ten Berg JM, van der Kley F, Schalij MJ, Baan J Jr, Cocchieri R, Brueren GR, van Straten AH, den Heijer P, Bentala M, van Ommen V, Kluin J, Stella PR, Prins MH, Maessen JG, Prinzen FW. Left bundle-branch block induced by transcatheter aortic valve implantation increases risk of death. Circulation 2012; 126: 720-728.

9. Baan J Jr., Yong ZY, Koch KT, Henriques JP, Bouma BJ, Vis MM, Cocchieri R, Piek JJ, de Mol BA. Factors associated with cardiac conduction disorders and permanent pacemaker implantation after percutaneous aortic valve implantation with the CoreValve prosthesis. Am Heart J 2010; 159: 497-503.

10. Nuis RJ, de Jaegere P. Electrocardiographic and further predictors for permanent pacemaker requirements after transcatheter aortic valve implantation. Europace 2010; 12: 1061-1062.

11. Haworth P, Behan M, Khawaja M, Hutchinson N, de Belder A, Trivedi U, Trivedi U, Laborde JC, HildickSmith D. Predictors for permanent pacing after transcatheter aortic valve implantation. Cath Cardiovasc Interv 2010; 76: 751-756.

12. El-Khally Z, Thibault B, Staniloae C, Theroux P, Dubuc M, Roy D, Guerra P, Macle L, Talajic M. Prognostic significance of newly acquired bundle branch block after aortic valve replacement. Am J Cardiol 2004; 94: 1008-1011.

13. Habicht JM, Scherr P, Zerkowski HR, Hoffmann A. Late conduction defects following aortic valve replacement. J Heart Valve Dis 2000; 9: 629-632.

14. Follath F, Ginks WR. Changes in the QRS complex after aortic valve replacement. Br HeartJ 1972; 34: 553-560.

15. Thomas JL, Dickstein RA, Parker FB, Jr., Potts JL, Poirier RA, Fruehan CT, Eich RH. Prognostic significance of the development of left bundle conduction defects following aortic valve replacement.J Thor Cardiovasc Surg 1982; 84: 382-386. 
16. Van Mieghem NM, Head SJ, de Jong W, van Domburg RT, Serruys PW, de Jaegere PP, Jordaens L, Takkenberg JJ, Bogers AJ, Kappetein AP. Persistent annual permanent pacemaker implantation rate after surgical aortic valve replacement in patients with severe aortic stenosis. Ann Thor Surg 2012; 94: 1143-1149.

17. Surawicz B, Childers R, Deal BJ, Gettes LS, Bailey JJ, Gorgels A, Hancock EW, Josephson M, Kligfield P, Kors JA, Macfarlane P, Mason JW, Mirvis DM, Okin P, Pahlm O, Rautaharju PM, van Herpen G, Wagner GS, Wellens H. AHA/ACCF/HRS recommendations for the standardization and interpretation of the electrocardiogram: part III: intraventricular conduction disturbances: a scientific statement from the American Heart Association Electrocardiography and Arrhythmias Committee, Council on Clinical Cardiology; the American College of Cardiology Foundation; and the Heart Rhythm Society. Endorsed by the International Society for Computerized Electrocardiology. J Am Coll Cardiol 2009; 53: 976981.

18. Rosenbaum MB, Elizari MV, Lazzari J, Nau GJ, Levi RJ, Halpern MS. Intraventricular trifascicular blocks. Review of the literature and classification. Am Heart J 1969; 78: 450-459.

19. Thompson R, Mitchell A, Ahmed M, Towers M, Yacoub M. Conduction defects in aortic valve disease. Am Heart J 1979; 98: 3-10.

20. Strauss DG, Selvester RH, Wagner GS. Defining left bundle branch block in the era of cardiac resynchronization therapy. Am J Cardiol 2011; 107: 927-934.

21. Strauss DG. Importance of defining left bundle branch block. J Electrocardiol 2012; 45: 505-507.

22. Houthuizen P, van der Boon RM, Urena M, van Mieghem N, Brueren GB, Poels TT, Van Garsse LA, Rodés-Cabau J, Prinzen FW, de Jaegere P. Occurrence, fate and consequences of ventricular conduction abnormalities after transcatheter aortic valve implantation. EuroIntervention 2014; 9: 11421150.

23. Testa L, Latib A, De Marco F, De Carlo M, Agnifili M, Latini RA, Petronio AS, Ettori F, Poli A, De Servi S, Ramondo A, Napodano M, Klugmann S, Ussia GP, Tamburino C, Brambilla N, Colombo A, Bedogni F. Clinical impact of persistent left bundle-branch block after transcatheter aortic valve implantation with CoreValve Revalving System. Circulation 2013; 127: 1300-1307.

24. Meguro K, Lellouche N, Yamamoto M, Fougeres E, Monin JL, Lim P, et al. Prognostic value of QRS duration after transcatheter aortic valve implantation for aortic stenosis using the CoreValve. $\mathrm{Am} J$ Cardiol 2013; 111: 1778-1783.

25. Nazif TM, Williams MR, Hahn RT, Kapadia S, Babaliaros V, Rodes-Cabau J, Szeto WY, Jilaihawi H, Fearon WF, Dvir D, Dewey TM, Makkar RR, Xu K, Dizon JM, Smith CR, Leon MB, Kodali SK. Clinical implications of new-onset left bundle branch block after transcatheter aortic valve replacement: analysis of the PARTNER experience. Eur Heart J 2013; in press.

26. Sweeney MO, Hellkamp AS, Ellenbogen KA, Greenspon AJ, Freedman RA, Lee KL, Lamas GA. Adverse effect of ventricular pacing on heart failure and atrial fibrillation among patients with normal baseline QRS duration in a clinical trial of pacemaker therapy for sinus node dysfunction. Circulation 2003; 107: 2932-2937.

27. Zhang ZM, Rautaharju PM, Soliman EZ, Manson JE, Cain ME, Martin LW, Bavry AA, Mehta L, Vitolins M, Prineas RJ. Mortality risk associated with bundle branch blocks and related repolarization abnormalities. Am J Cardiol 2012; 110: 1489-1495.

28. Bussink BE, Holst AG, Jespersen L, Deckers JW, Jensen GB, Prescott E. Right bundle branch block: prevalence, risk factors, and outcome in the general population: results from the Copenhagen City Heart Study. Eur Heart J 2013; 34: 138-146.

29. Fahy GJ, Pinski SL, Miller DP, McCabe N, Pye C, Walsh MJ, Robinson K. Natural history of isolated bundle branch block. Am J Cardiol 1996; 77: 1185-1190.

30. Eriksson P, Hansson PO, Eriksson H, Dellborg M. Bundle-branch block in a general male population: the study of men born 1913. Circulation 1998; 98: 2494-2500.

31. Fleg JL, Das DN, Lakatta EG. Right bundle branch block: long-term prognosis in apparently healthy men. J Am Coll Cardiol 1983; 1: 887-892. Abdel-Qadir HM, Tu JV,

32. Austin PC, Wang JT, Lee DS. Bundle branch block patterns and long-term outcomes in heart failure. Int J Cardiol 2011; 146: 213-218. 
33. Barsheshet A, Goldenberg I, Garty M, Gottlieb S, Sandach A, Laish-Farkash A, et al. Relation of bundle branch block to long-term (four-year) mortality in hospitalized patients with systolic heart failure. Am J cardiol 2011; 107: 540-544.

34. Fukuda T, Hawley RL, Edwards JE. Lesions of conduction tissue complicating aortic valvular replacement. Chest 1976; 69: 605-614.

35. Jilaihawi H, Chin D, Vasa-Nicotera M, Jeilan M, Spyt T, Ng GA, Bence J, Logtens E, Kovac J. Predictors for permanent pacemaker requirement after transcatheter aortic valve implantation with the CoreValve bioprosthesis. Am Heart J 2009; 157: 860-866. 


\section{CHAPTER 6}

\section{Postoperative Conduction Disorders after Implantation of the Self-Expandable Sutureless Perceval S Bioprosthesis}

Astrid G.M. van Boxtel, Patrick Houthuizen, Mohamed A. Soliman Hamad, Jelena Sjatskig, Erwin Tan, Frits W. Prinzen, Albert H.M. van Straten

Accepted for publication in The Journal of Heart Valve Disease 


\begin{abstract}

\section{Background}

Minimally invasive techniques for aortic valve replacement (AVR) have been developed as an alternative to conventional AVR for patients with high operative risk. Still, these techniques are associated with an increased risk of postoperative conduction disorders. This study aims to identify the incidence and fate of postoperative conduction disorders in patients undergoing sutureless (SU) AVR with the Perceval S bioprosthesis.
\end{abstract}

\title{
Methods and Results
}

In this observational study, patients who underwent SU AVR with the Perceval S prosthesis in the Catharina Hospital (the Netherlands) were analysed. Electrocardiograms (ECGs) at baseline, within 24 hours postoperatively, before hospital discharge and at follow-up were collected by reviewing patients' records. The ECGs were analysed by two independent investigators to record QRS-duration and conduction disorders.

All patients $(\mathrm{n}=31)$ who underwent implantation of the Perceval $\mathrm{S}$ bioprosthesis between September 2010 and September 2012 were included. At baseline, 2 patients (6.5\%) had pre-existing left bundle branch block (LBBB) and one patient (3.2\%) had a permanent pacemaker (PPM). New-onset LBBB developed in 12 patients (41.4\%); being transient in three patients (10.3\%). Postoperatively, four patients $(13.3 \%)$ required PPM implantation because of total atrioventricular block; all of these patients had either pre-existing LBBB $(n=1)$ or new LBBB $(n=3)$.

\section{Conclusions}

SU AVR with the Perceval S bioprosthesis is frequently complicated by new LBBB, which was persistent in the majority of patients. A relatively high incidence of postoperative PPM implantation was also observed. 


\section{Introduction}

The number of patients in need for aortic valve replacement (AVR) is increasing. Conventional surgical aortic valve replacement (SAVR) is the treatment of choice for patients with severe aortic stenosis. However, the operative risk for the elderly population with comorbidities is often too high, which stimulated the development of less invasive techniques. Recently, the transcatheter aortic valve implantation (TAVI) proved to be a valuable alternative to SAVR in patients with high operative risk. . $^{1-3}$ Despite its success, TAVI has a relatively high incidence of paravalvular aortic regurgitation, ventricular conduction disorders and postoperative permanent pacemaker implantation. ${ }^{4,5}$ These complications have been attributed to the inability to remove the native aortic valve resulting in presence of the calcified native leaflets around the percutaneous valve and near the atrioventricular conduction system.5,6

From this perspective, the recently developed sutureless aortic valve replacement (SU AVR) combines the advantages of a less invasive technique with the possibility of surgical removal of the native valve. ${ }^{7}$ One of the available prostheses for SU AVR is the stent-mounted Perceval S aortic valve (Sorin Biomedica Cardio Srl, Sallugia, Italy). This prosthesis is mounted in a nitinol stent, which presumably has comparable mechanical properties as the self-expandable Medtronic CoreValve prosthesis (MCS) used for TAVI. For the latter, it is well known to be associated with a high incidence of postoperative left bundle branch block (LBBB) and atrioventricular conduction disorders necessitating implantation of a permanent pacemaker (PPM).5,8

In present study, we aimed to identify the incidence and fate of postoperative conduction disorders in patients undergoing AVR with the sutureless Perceval S bioprosthesis in our center.

\section{Methods}

\section{Patient population}

We analyzed all patients in whom a Perceval S bioprosthesis was implanted since September 2010 through September 2012 in the Catharina Hospital (the Netherlands). The indication for surgical aortic valve replacement was made by consensus agreement of both the cardiologist and cardiothoracic surgeon adhering to the European guidelines for aortic valve replacement. ${ }^{9,10}$ The choice for the Perceval S bioprosthesis was made depending on patient's age, comorbidity and clinical frailty. The local medical ethical committee approved the study and waived the need for an informed consent. 


\section{Surgical procedure}

Partial upper sternotomy (J-sternotomy) in the third intercostal space ( $\mathrm{n}=10)$ or full sternotomy $(\mathrm{n}=21)$ was performed to get access to the aorta. The choice for partial sternotomy was made according to the preference of the surgeon. Standard cardiopulmonary bypass was used, cannulating the aorta and right atrium with venting via the right superior pulmonary vein. After intermittent warm blood cardioplegia was administered, a transverse aortotomy just above the sinotubular junction was done. The native valve was removed and the annulus was decalcified.

\section{Device and implantation}

The Perceval S bioprosthesis consists of a trileaflet bovine pericardial valve mounted in a self-expandable nitinol stent (Figure 1) and is available in 3 sizes $(21,23$ and 25 $\mathrm{mm}$ ). To implant the valve, it is first compressed using a crimping tool and loaded into a dedicated delivery system. The valve is guided to its correct position by three sutures stitched to the native annulus, in the lowest part of each valve sinus. After posi-

Figure 1. Photographic example of the selfexpandable Perceval bioprosthesis. tioning, the valve is deployed and delivery system and sutures are removed. Finally, the valve is further expanded by balloon inflation of 4 atmosphere during 30 seconds. ${ }^{7}$ Valve position was visually checked and afterwards aortotomy is closed, cross clamp is removed and the heart is weaned off from cardiopulmonary bypass.

\section{Data and ECG collection}

All baseline and procedural data were collected prospectively in a central registry and relevant data were transferred to a dedicated database. Patients were interrogated by telephone interview to inform if a permanent pacemaker had been implanted after hospital discharge. After treatment, electrocardiograms (ECGs) were recorded at least daily until discharge from the intensive care unit; thereafter ECGs were obtained on indication and during every outpatient visit. For the purpose of this study, ECG's at baseline, 24 hours after surgery, before hospital discharge and at follow-up were retrospectively collected by reviewing patient records.

All tracings were analyzed by an independent investigator and an experienced cardiologist (PH) to record heart rhythm, PR interval, QRS duration, QRS morphology and QRS axis in exact degrees. Presence of first, second or third degree atrioventricular block, right bundle branch block (RBBB), LBBB, left anterior hemiblock (LAHB) 
and left posterior hemiblock (LPHB) were recorded according to the established criteria. ${ }^{11}$ Accordingly, LBBB was defined as a V1-negative QRS-complex of $\geq 0.12$ seconds in duration with absent Q-waves and a notched or slurred R in leads I, aVL, V5 and/or V6. A LAHB was defined as a QRS-duration $\geq 0.10$ seconds with a frontal plane QRS-axis between -45 and -90 degrees in the presence of a qR in leads I and aVL. In the presence of RBBB, LAHB was defined as a frontal plane QRS-axis between -45 and -90 degrees. A conduction disorder was considered transient if it disappeared after hospital discharge; a persistent conduction disorder was present during followup. LBBB resulting in postoperative PPM implantation was also considered persistent.

\section{Statistical analysis}

Categorical variables are presented as numbers and proportions. For continuous variables, normality of distribution was assessed with the Kolmogorov-Smirnov test. Normal and skewed continuous variables are presented as means with standard deviation (SD) and medians with interquartile range (IQR), respectively. A two-sided p-value less than 0.05 was considered to be statistically significant. All statistical analyses were performed using Statistical Package for Social Sciences (SPSS), version 19 or higher (IBM SPSS, Chicago, IL, USA).

\section{Results}

From September 2010 through September 2012, 31 patients underwent surgical implantation of the Perceval S bioprosthesis. Baseline characteristics of the study population are outlined in table 1. Implantation was successful in all patients but one, who required surgical valve replacement (day 23) because of prosthesis dysfunction with severe aortic regurgitation. This patient was not excluded from analysis in order to analyse the immediate postoperative ECG's (until day 23). One patient required pericardiocentesis (day 21) because of pericardial tamponade and another patient suffered from a non-fatal ischemic stroke (day 4). There was one patient (3.2\%) with pre-existing PPM who however exhibited intrinsic conduction on all ECG's (i.e. was not pacemaker dependent). Another two patients (6.5\%) had a pre-existing LBBB. All patients were alive during a median follow-up period of 282 (198-548) days. 
Table 1. Clinical characteristics of the study population.*

\begin{tabular}{|c|c|}
\hline Characteristic & $\begin{array}{l}\text { Total population } \\
(\mathrm{N}=31)\end{array}$ \\
\hline \multicolumn{2}{|l|}{$\overline{\text { Demographics }}$} \\
\hline Age - yr & $76.4 \pm 5,2$ \\
\hline Male gender - no. (\%) & $13(41.9)$ \\
\hline Height $-\mathrm{cm}$ & $166 \pm 8$ \\
\hline Weight - kg & $73 \pm 12$ \\
\hline Body Mass Index - kg/m² & $26.4 \pm 4.0$ \\
\hline Body Surface Area - m² & $1.8 \pm 0.2$ \\
\hline \multicolumn{2}{|l|}{ Clinical } \\
\hline New York Heart Association Class $\geq$ III - no. (\%) & $5(16.1)$ \\
\hline History of coronary artery disease - no. (\%) & $9(29.0)$ \\
\hline Previous myocardial infarction - no. (\%) & $3(9.7)$ \\
\hline Previous PCI - no. (\%) & $2(6.5)$ \\
\hline Previous $\mathrm{CABG}-$ no. $(\%)$ & $0(0)$ \\
\hline History of cerebrovascular disease - no. (\%) & $5(16.1)$ \\
\hline History of peripheral artery disease - no. (\%) & $5(16.1)$ \\
\hline History of diabetes mellitus - no. (\%) & $11(35.5)$ \\
\hline History of chronic obstructive lung disease - no. (\%) & $4(12.9)$ \\
\hline Logistic EuroSCORE - \% & $1.7 \pm 1.0$ \\
\hline Pre-existing permanent pacemaker - no. (\%) & $1(3.2)$ \\
\hline \multicolumn{2}{|l|}{ Baseline electrocardiogram } \\
\hline Sinus rhythm - no. (\%) & $30(96.8)$ \\
\hline PR-interval - msec & $178 \pm 41$ \\
\hline QRS-duration - msec & $96 \pm 17$ \\
\hline QRS-axis - degrees & $11 \pm 31$ \\
\hline Pre-existing left bundle branch block - no. (\%) & $3(9.7)$ \\
\hline \multicolumn{2}{|l|}{ Baseline echocardiography } \\
\hline \multicolumn{2}{|l|}{ Left ventricular function - no. (\%) } \\
\hline normal $(L V E F \geq 50 \%)$ & $30(96.8)$ \\
\hline moderately reduced (LVEF 35-50\%) & $1(3.2)$ \\
\hline severely reduced $(\mathrm{LVEF} \leq 35 \%)$ & $0(0)$ \\
\hline Aortic valve area $-\mathrm{cm}^{2}$ & $0.69 \pm 0.13$ \\
\hline Peak aortic valve gradient - mmHg & $88 \pm 32$ \\
\hline Aortic valve regurgitation $\geq$ III - no. (\%) & $7(22.6)$ \\
\hline \multicolumn{2}{|l|}{ Procedural characteristics } \\
\hline Aortic occlusion time - min & $48 \pm 24$ \\
\hline Extracorporal circulation time - min & $68 \pm 29$ \\
\hline Concomitant CABG - no. (\%) & $6(19.4)$ \\
\hline
\end{tabular}

\footnotetext{
${ }^{*}$ Results are presented as mean ( \pm standard deviation) or absolute number (percentage), unless stated otherwise. PCI percutaneous coronary intervention, CABG coronary-artery bypass grafting, msec milliseconds, LVEF left ventricular ejection fraction, min minutes.

† The logistic EUROpean System for Cardiac Operative Risk Evaluation (EuroSCORE-II) is a score system ranging from 0 to $100 \%$ used to predict 30 -day mortality of cardiovascular surgery.
} 


\section{Postoperative conduction disorders}

The results of ECG comparison at the different time points are shown in table 2. In patients without pre-existing LBBB $(n=29), 12$ patients $(41.4 \%)$ developed new LBBB which was transient in $33.3 \%$ of these patients $(n=4)$. In patients without preexisting PPM ( $n=30)$, there were four patients $(13.3 \%)$ who developed total atrioventricular block (AVB-III) requiring PPM implantation (at postoperative day 7, 10 $(2 x)$ and 100 , respectively). All of these patients had either a pre-existing $\operatorname{LBBB}(n=1)$ or new postoperative LBBB $(n=3)$. None of the patients without LBBB were implanted a postoperative PPM.

First-degree atrioventricular block (AVB-I) was pre-existing in 3 patients. In the remaining 28, there were 5 patients (17.9\%) who had a transient AVB-I and 8 patients (28.6\%) with persistent AVB-I (Table 2).

\section{Discussion}

This observational cohort study demonstrates that implantation of the Perceval S sutureless bioprosthesis is complicated by LBBB in $40 \%$ of patients. The conduction disorder was transient in one third of the cases. Secondly, 13\% of patients required implantation of a PPM and all of these patients had either pre-existing or new postoperative LBBB.

\section{Frequency and clinical relevance of new $\angle B B B$}

In the contemporary era, the frequency of new LBBB after conventional surgical AVR is as low as $6-7 \% .^{12,13}$ On the other hand, this frequency is considerably higher after TAVI with a range from $10-60 \%$ and is strongly dependent on the prosthesis used. ${ }^{5}$ To the best of our knowledge, there are no published data available on the frequency of postoperative new LBBB after SU AVR. With a new LBBB frequency of $40 \%$ and a persistence of $66.6 \%$ in the present study, the frequency seems comparable to that of TAVI, more specific of the MCS device. ${ }^{14,15}$ This is an important issue, as LBBB after aortic valve interventions is associated with higher risk for need of permanent pacemaker implantation, ${ }^{13,16}$ a decrease in left ventricular function ${ }^{16,17}$ and ultimately mortality. ${ }^{8}$ Our data suggest that SU AVR with the Perceval S prosthesis has the same disadvantages as TAVI with respect to the occurrence of conduction disorders. These disadvantages may neutralize the surgical/technical benefits of this prosthesis above conventional AVR.

\section{Incidence and clinical relevance of postoperative PPM}

In contrast to the occurrence of new $\mathrm{LBBB}$, more data is available on postoperative PPM implantation after conventional AVR, although reported frequency in larger 
study populations varies between $1 \%$ and $4 \% .^{13,18}$ For SU AVR, studies of small sample size suggest that the incidence of PPM implantation range between 7 and $19 \% 19,20$, although Flameng et al. reported only 1 implantation in 29 patients receiving the Perceval S bioprosthesis. ${ }^{21}$ In the present study, the PPM implantation rate was $13.3 \%$, which is in concordance with previous studies ${ }^{19,20}$. Noteworthy is that the majority of patients receiving a PPM first developed a new LBBB. This is in agreement with observations by van Mieghem et al. who previously reported that a postoperative new LBBB after SAVR is associated with an increased risk of postoperative PPM implantation. ${ }^{13}$ The effect of PPM implantation on long-term morbidity and mortality after aortic valve intervention is still unclear. Nevertheless, for patients receiving a PPM for sinus node dysfunction, the detrimental effects of chronic right ventricular pacing on left ventricular function are well known. ${ }^{22}$

Table 2. Comparison of electrocardiographic characteristics at baseline, within 24 hours after procedure, before discharge and at follow-up.*

\begin{tabular}{|c|c|c|c|c|}
\hline Characteristic & Baseline & $\begin{array}{l}\text { within } 24 \text { hour } \\
\text { after surgery }\end{array}$ & $\begin{array}{l}\text { before hospital } \\
\text { discharge }\end{array}$ & follow-up \\
\hline Time postprocedure - days (IQR) & - & $0(0-0)$ & $5(2-8)$ & $221(103-355)$ \\
\hline ECGs available - no. (\%) & $31(100 \%)$ & $31(100 \%)$ & $31(100 \%)$ & $28(90.3 \%)$ \\
\hline \multicolumn{5}{|l|}{ Rhythm - no. (\%) } \\
\hline Sinus rhythm & $30(96.8 \%)$ & $30(96.8 \%)$ & $24(77.4 \%)$ & 27 (96.4\%) \\
\hline Atrial fibrillation/flutter & $1(3.2 \%)$ & $0(0.0 \%)$ & $5(16.7 \%)$ & $1(3.6 \%)$ \\
\hline Ventricular pace & $0(0.0 \%)$ & $0(0.0 \%)$ & $1(3.3 \%)$ & $0(0.0 \%)$ \\
\hline Other & $0(0.0 \%)$ & $1(3.2 \%)$ & $1(3.3 \%)$ & $0(0.0 \%)$ \\
\hline PR-interval - msec & $178( \pm 41)$ & $188( \pm 31)$ & $200( \pm 49)$ & $184( \pm 38)$ \\
\hline QRS-duration - msec & $96( \pm 17)$ & $113( \pm 23)$ & $118( \pm 28)$ & $119( \pm 33)$ \\
\hline QRS-axis - degrees & $11( \pm 31)$ & $11( \pm 41)$ & $13( \pm 49)$ & $17( \pm 49)$ \\
\hline \multicolumn{5}{|l|}{ AV conduction disorders - no. (\%) } \\
\hline None & $28(90.3 \%)$ & $19(61.3 \%)$ & $17(56.7 \%)$ & $17(60.7 \%)$ \\
\hline First-degree AV block & $3(9.7 \%)$ & $11(35.4 \%)$ & $11(35.4 \%)$ & $11(39.3 \%)$ \\
\hline Second-degree AV block & $0(0.0 \%)$ & $0(0.0 \%)$ & $0(0.0 \%)$ & $0(0.0 \%)$ \\
\hline Third-degree AV block & $0(0.0 \%)$ & $2(6.5 \%)$ & $2(6.5 \%)$ & $1(3.6 \%)$ \\
\hline \multicolumn{5}{|l|}{ Bundle branch block - no. (\%) } \\
\hline None & $27(87.1 \%)$ & $18(58.1 \%)$ & $18(58.1 \%)$ & $17(60.7 \%)$ \\
\hline RBBB & $0(0.0 \%)$ & $0(0.0 \%)$ & $0(0.0 \%)$ & $0(0.0 \%)$ \\
\hline LAHB & $2(6.5 \%)$ & $1(3.2 \%)$ & $0(0.0 \%)$ & $0(0.0 \%)$ \\
\hline Incomplete LBBB & $0(0.0 \%)$ & $1(3.2 \%)$ & $1(3.3 \%)$ & $0(0.0 \%)$ \\
\hline LBBB & $2(6.5 \%)$ & $9(29.0 \%)$ & $9(30.0 \%)$ & $11(35.7 \%)$ \\
\hline Unspecified & $0(0.0 \%)$ & $2(6.5 \%)$ & $3(10.0 \%)$ & $1(3.6 \%)$ \\
\hline \multicolumn{5}{|c|}{ Change in conduction disorders - no. (\%) } \\
\hline New first-degree AV block & - & $8(25.8 \%)$ & $3(9.7 \%)$ & $2(7.1 \%)$ \\
\hline Resolution of first-degree AV & - & $0(0.0 \%)$ & $3(9.7 \%)$ & $2(7.1 \%)$ \\
\hline
\end{tabular}




\begin{tabular}{lllll}
\hline Characteristic & Baseline & \multicolumn{2}{c}{ within 24 hours before hospital } & follow-up \\
& & after surgery & discharge & \\
\hline block & - & $7(22.6 \%)$ & $3(9.7 \%)$ & $2(7.1 \%)$ \\
New LBBB & - & $0(0.0 \%)$ & $3(9.7 \%)$ & $1(3.6 \%)$ \\
Resolution of LBBB & - & & \\
\hline
\end{tabular}

* IQR denotes interquartile range, ECG electrocardiogram, AV atrioventricular, RBBB right bundle branch block, LAHB left anterior hemiblock, LBBB left bundle branch block.

\section{Mechanism of (atrio)ventricular conduction disorders}

The frequency of TAVI-induced LBBB is highly dependent on the prosthesis type being used with a higher frequency for the MCS (reported frequency 30-60\%) than for the Edwards SAPIEN (ES) device (reported frequency 6-12\%). 5,14,15,23 This difference is attributed to the different material properties and design of both valves. The ES valve consists of a balloon-expandable, cobalt-chrome frame with a height of approximately $15 \mathrm{~mm}$, while the MCS valve is mounted in a self-expanding, nitinol frame of approximately $55 \mathrm{~mm}$ in height. As the left bundle branch is in close proximity to the subaortic membranous septum, it assumed that the prosthesis causes damage to the conduction system by localized pressure of the frame. This is presumed to cause the high frequency of LBBB with the MCS valve, because the large stent lands deeper into the left ventricular outflow tract5,24 This effect is probably amplified by the presence of calcium from the native aortic valve leaflets that are compressed against the membranous septum. From this respect, it is interesting to note that the frequency of new LBBB with the Perceval S is comparable to the MCS prosthesis. In other words, the development of new LBBB couldn't be only attributed to the calcified annulus but possibly to valve design and other technical aspects as well. It is more plausible to presume, that any pressure at the level of the membranous septum damages the left bundle branch. For the Perceval S bioprosthesis, the large intra-annular sealing coil is probably responsible for the large frequency of new LBBB.

\section{Study limitations}

The number of patients in the present study is relatively small, so the findings should be cautiously interpreted. Electrocardiograms were collected retrospectively, however all baseline and procedural data were extracted from a prospective, local registry.

\section{Conclusions}

SU AVR with the Perceval S is frequently complicated by new-onset LBBB. Moreover, the incidence of postoperative need for PPM was relatively high. These findings need to be further investigated in larger studies. 


\section{References}

1. Leon MB, Smith CR, Mack M, Miller DC, Moses JW, Svensson LG, Tuzcu EM, Webb JG, Fontana GP, Makkar RR, Brown DL, Block PC, Guyton RA, Pichard AD, Bavaria JE, Herrmann HC, Douglas PS, Petersen JL, Akin JJ, Anderson WN, Wang D, Pocock S. Transcatheter aortic-valve implantation for aortic stenosis in patients who cannot undergo surgery. N Engl J Med 2010; 363: 1597-607.

2. Smith CR, Leon MB, Mack MJ, Miller DC, Moses JW, Svensson LG, Tuzcu EM, Webb JG, Fontana GP, Makkar RR, Williams M, Dewey T, Kapadia S, Babaliaros V, Thourani VH, Corso P, Pichard AD, Bavaria JE, Herrmann HC, Akin JJ, Anderson WN, Wang D, Pocock SJ. Transcatheter versus surgical aorticvalve replacement in high-risk patients. $N$ Engl J Med 2011; 364: 2187-98.

3. Makkar RR, Fontana GP, Jilaihawi H, Kapadia S, Pichard AD, Douglas PS, Thourani VH, Babaliaros VC, Webb JG, Herrmann HC, Bavaria JE, Kodali S, Brown DL, Bowers B, Dewey TM, Svensson LG, Tuzcu M, Moses JW, Williams MR, Siegel RJ, Akin JJ, Anderson WN, Pocock S, Smith CR, Leon MB. Transcatheter Aortic-Valve Replacement for Inoperable Severe Aortic Stenosis. N EnglJ Med 2012; 366: 16961704.

4. Généreux P, Head SJ, Van Mieghem NM, Kodali S, Kirtane AJ, Xu K, Smith C, Serruys PW, Kappetein AP, Leon MB. Clinical Outcomes After Transcatheter Aortic Valve Replacement Using Valve Academic Research Consortium Definitions. J Am Coll Cardiol 2012; 59: 2317-2326.

5. van der Boon RM, Nuis R-J, Van Mieghem NM, Jordaens L, Rodés-Cabau J, van Domburg RT, Serruys PW, Anderson RH, de Jaegere PPT. New conduction abnormalities after TAVI-frequency and causes. Nat Rev Cardiol 2012; 9: 1-10.

6. Jilaihawi H, Chin D, Vasa-Nicotera M, Jeilan M, Spyt T, Ng GA, Bence J, Logtens E, Kovac J. Predictors for permanent pacemaker requirement after transcatheter aortic valve implantation with the CoreValve bioprosthesis. Am Heart J 2009; 157: 860-866.

7. Shrestha M, Folliguet T, Meuris B, Dibie A, Bara C, Herregods M-C, Khaladj N, Hagl C, Flameng W, Laborde F, Haverich A. Sutureless Perceval S aortic valve replacement: a multicenter, prospective pilot trial. J Heart Valve Dis 2009; 18: 698-702.

8. Houthuizen P, Van Garsse LAFM, Poels TT, J, de Jaegere P, van der Boon R, Swinkels BM, ten Berg JM, van der Kley F, Schalij MJ, Cocchieri R, Brueren GRG, van Straten AHM, den Heijer P, Bentala M, van Ommen V, Kluin J, Stella PR, Prins MH, Maessen JG, Prinzen FW. Left bundle branch block induced by transcatheter aortic valve implantation increases risk of death. Circulation 2012; 126: 720-728.

9. Vahanian A, Baumgartner H, Bax J, Butchart E, Dion R, Filippatos G, Flachskampf F, Hall R, Iung B, Kasprzak J, Nataf P, Tornos P, Torracca L, Wenink A. Guidelines on the management of valvular heart disease: The Task Force on the Management of Valvular Heart Disease of the European Society of Cardiology. Eur Heart J 2007; 28: 230-268.

10. Vahanian A, Alfieri O, Andreotti F, Antunes MJ, Barón-Esquivias G, Baumgartner H, Borger MA, Carrel TP, Bonis M De, Evangelista A, Falk V, Iung B, Lancellotti P, Pierard L, Price S, Schäfers H-J, Schuler G, Stepinska J, Swedberg K, Takkenberg J, Oppell UO Von, Windecker S, Zamorano JL, Zembala M. Guidelines on the management of valvular heart disease (version 2012). Eur Heart J 2012; 33: 2451-2496.

11. Surawicz B, Childers R, Deal BJ, Gettes LS, Bailey JJ, Gorgels A, Hancock EW, Josephson M, Kligfield P, Kors J a, Macfarlane P, Mason JW, Mirvis DM, Okin P, Pahlm O, Rautaharju PM, Herpen G van, Wagner GS, Wellens H. AHA/ACCF/HRS recommendations for the standardization and interpretation of the electrocardiogram: part III: intraventricular conduction disturbances: a scientific statement from the American Heart Association Electrocardiography and Arrhythmias Committee. Circulation 2009; 119: e235-e240.

12. El-Khally Z, Thibault B, Staniloae C, Theroux P, Dubuc M, Roy D, Guerra P, Macle L, Talajic M. Prognostic significance of newly acquired bundle branch block after aortic valve replacement. Am J Cardiol 2004; 94: 1008-1011.

13. Van Mieghem NM, Head SJ, de Jong W, van Domburg RT, Serruys PW, de Jaegere PP, Jordaens L, Takkenberg JJM, Bogers AJJC, Kappetein A-P. Persistent annual permanent pacemaker implantation rate after surgical aortic valve replacement in patients with severe aortic stenosis. Ann Thorac Surg 2012; 94: 1143-1149. 
14. Bleiziffer S, Ruge H, Hörer J, Hutter A, Geisbüsch S, Brockmann G, Mazzitelli D, Bauernschmitt R, Lange R. Predictors for new-onset complete heart block after transcatheter aortic valve implantation. JACC Cardiovascular interventions 2010; 3: 524-530.

15. Roten L, Wenaweser P, Delacrétaz E, Hellige G, Stortecky S, Tanner H, Pilgrim T, Kadner A, Eberle B, Zwahlen M, Carrel T, Meier B, Windecker S. Incidence and predictors of atrioventricular conduction impairment after transcatheter aortic valve implantation. Am J Cardiol 2010; 106: 1473-1480.

16. Urena M, Mok M, Serra V, Dumont E, Nombela-Franco L, Delarochellière R, Doyle D, Igual A, Larose E, Amat-Santos I, Côté M, Cuéllar H, Pibarot P, de Jaegere P, Philippon F, Garcia Del Blanco B, RodésCabau J. Predictive factors and long-term clinical consequences of persistent left bundle branch block following transcatheter aortic valve implantation with a balloon-expandable valve. J Am Coll Cardiol 2012; 60: 1743-1752.

17. Hoffmann R, Herpertz R, Lotfipour S, Aktug O, Brehmer K, Lehmacher W, Autschbach R, Marx N, Lotfi S. Impact of a new conduction defect after transcatheter aortic valve implantation on left ventricular function. JACC Cardiovascular interventions 2012; 5: 1257-1263.

18. Merin O, Ilan M, Oren A, Fink D, Deeb M, Bitran D, Silberman S. Permanent pacemaker implantation following cardiac surgery: indications and long-term follow-up. Pacing Clin Electrophysiol 2009; 32: $7-12$.

19. Huynh H, Dalloul G, Ghanbari H, Burke P, David M, Daccarett M, Machado C, David S. Permanent pacemaker implantation following aortic valve replacement: current prevalence and clinical predictors. Pacing Clin Electrophysiol 2009; 32: 1520-1525.

20. Aymard T, Kadner A, Walpoth N, Göber V, Englberger L, Stalder M, Eckstein F, Zobrist C, Carrel T. Clinical experience with the second-generation 3f Enable sutureless aortic valve prosthesis. J Thor Cardiovasc Surg 2010; 140: 313-316.

21. Flameng W, Herregods M-C, Hermans H, Mieren G Van der, Vercalsteren M, Poortmans G, Hemelrijck J Van, Meuris B. Effect of sutureless implantation of the Perceval S aortic valve bioprosthesis on intraoperative and early postoperative outcomes. J Thor Cardiovasc Surg 2011;142: 1453-1457.

22. Sweeney MO, Hellkamp AS, Ellenbogen K, Greenspon AJ, Freedman R, Lee KL, Lamas G. Adverse effect of ventricular pacing on heart failure and atrial fibrillation among patients with normal baseline QRS duration in a clinical trial of pacemaker therapy for sinus node dysfunction. Circulation 2003; 107: 2932-2937.

23. Sinhal A, Altwegg L, Pasupati S, Humphries KH, Allard M, Martin P, Cheung A, Ye J, Kerr C, Lichtenstein $\mathrm{S}$ V, Webb JG. Atrioventricular block after transcatheter balloon expandable aortic valve implantation. JACC Cardiovascular interventions 2008; 1: 305-309.

24. Baan J, Yong ZY, Koch KT, Henriques JPS, Bouma BJ, Vis MM, Cocchieri R, Piek JJ, de Mol BAJM. Factors associated with cardiac conduction disorders and permanent pacemaker implantation after percutaneous aortic valve implantation with the CoreValve prosthesis. Am Heart J 2010; 159: 497-503. 

PART 2

Controversies in

Cardiac Resynchronization Therapy 



\section{CHAPTER 7}

\section{Atrioventricular and Interventricular Delay Optimization in Cardiac Resynchronization: Physiological Principles and Overview of Available Methods}

Patrick Houthuizen, Frank A.L.E. Bracke, Berry M. van Gelder Published in Heart Fail Rev 2011; 16: 263-276 


\begin{abstract}
In this review the physiological rationale for atrioventricular and interventricular delay optimization of cardiac resynchronization therapy is discussed including the influence of exercise and long-term cardiac resynchronization therapy. The broad spectrum of both invasive and non-invasive optimization methods are reviewed with critical appraisal of the literature. Although the spectrum of both invasive and noninvasive optimization methods is broad, no single method can be recommend for standard practice as large-scale studies using hard endpoints are lacking. Current efforts mainly investigate optimization during resting conditions, however, there is a need to develop automated algorithms to implement dynamic optimization in order to adapt to physiological alterations during exercise and after anatomical remodeling.
\end{abstract}




\section{Introduction}

In patients with symptomatic systolic heart failure and prolonged QRS duration, cardiac resynchronization therapy (CRT) has proven to be of additional value on top of recommended medical therapy.1,2 Nevertheless, there remain a considerable number of non-responders to CRT that can be as high as $30 \%{ }^{3}$ The non-response can be partly caused by inappropriate settings of atrioventricular (AV) and interventricular (VV) intervals leading to persistent atrioventricular, interventricular and intraventricular dyssynchrony. In this review we will discuss the physiological and pathophysiological rationale for $\mathrm{AV}$ and $\mathrm{VV}$ optimization followed by an overview of available optimization methods.

\section{Physiological electrical activation and mechanical contraction}

A coordinate contraction sequence of the heart chambers is facilitated by rapid activation via the specialized conduction system. The cardiac action potential originates in the sinus node and reaches the atrioventricular node (AV-node) within 100 milliseconds (msec). Slowing of conducting through the AV-node delays onset of ventricular activation with approximately $80 \mathrm{msec}$ to allow optimal atrial contribution to ventricular preload. Rapid conduction of the electrical impulse through the His bundle, bundle branches and the Purkinje system activates the whole left ventricle (LV) within 60-80 msec. Ventricular activation proceeds from subendocardially located breakthroughs of the bundle branches to the epicardium in a centrifugally and tangentially direction. ${ }^{4}$

Cardiac output is dependent on preload (Frank-Starling relation), afterload and myocardial contractility. The latter is not only influenced by neurohormones, but also dependent on heart rate (staircase phenomenon or Bowditch effect) and afterload (Anrep effect). Autonomic and neurohormonal regulatory mechanisms ensure adequate cardiac output under varying physiological conditions. Regulation and feedback is provided by pressure sensors in the venous and arterial vascular system. ${ }^{5}$

Sympathetic stimulation at increasing heart rate shortens AV delay and ventricular systole, thus preventing atrial systole to occur against a closed mitral valve during exercise. Shortening of ventricular systole also enables longer ventricular filling time. ${ }^{6}$ 


\section{Pathophysiological electrical activation and mechanical contraction}

Apart from decreased myocardial contractility, there are several other causes for decreased cardiac output in heart failure. First, in a subset of patients there is a disturbance in coordination of atrial and ventricular activation with suboptimal timing of atrial contraction (AV dyssynchrony).

The atrial contraction enhances ventricular preload by optimizing sarcomere length of ventricular myocytes prior to contraction which in turn increases LV stroke volume. This booster function generates an increase in LV enddiastolic pressure at a relatively low mean venous pressure, thus protecting the pulmonary system from edema. ${ }^{7}$ In case of a shortened or prolonged AV conduction this preload enhancement is diminished or even lost. As the atrial booster effect also contributes to timely closure of the atrioventricular valves, a prolonged AV delay can also lead to premature inversion of the atrioventricular pressure gradient resulting in diastolic mitral regurgitation. ${ }^{6,8}$

Secondly, a large number of heart failure patients have ventricular conduction disturbances, predominantly left bundle branch block (LBBB). Although the term "block" suggests an abrupt interruption of conduction, there is a spectrum of conduction abnormalities varying from a proximal barrier to a more diffuse slowing of conduction. As a consequence, the LV is electrically activated throughout myocardial tissue. ${ }^{9}$ Compared to the specialized conduction system, conduction velocity in myocardial tissue is slower and the activation front spreads preferably in a circumferential than a perpendicular direction. ${ }^{10}$ This can lead to mechanical interventricular (and intraventricular) dyssynchrony.

Because of their serial alignment and intimate anatomical relationship the mechanical properties of both ventricles are influenced by each other. This close interaction is further influenced by the interventricular septum and pericardium. Changes in preload or afterload of one ventricle alters the pressure in the other ventricle. ${ }^{11,12}$ Although this interaction is negligible in the healthy heart, both systolic and diastolic interaction is augmented in case of heart failure. ${ }^{13,14}$ Difference in activation timing with the right ventricle (RV) contracting earlier than the LV (as with LBBB), deteriorates LV function. ${ }^{15,16}$

Thirdly, asynchronous electrical activation of the LV in case of LBBB leads to an altered contraction pattern. Initially, the septum shortens during the isovolumic contraction time causing an early systolic stretching of the opposing, still non-activated posterolateral wall. Eventually, this posterolateral wall is activated late and exhibits a late systolic or even postsystolic shortening after the aforementioned early systolic stretching. This intraventricular dyssynchrony reduces the efficiency of the LV pumping function as part of the metabolic energy is wasted in intraventricular volume shifts rather than in ventricular ejection. ${ }^{17}$ 


\section{Atrioventricular and interventricular synchronization in CRT}

\section{Physiological rationale for optimization}

As outlined above, from a physiological point of view it seems reasonable to assume that correction of atrio-, inter- and intraventricular dyssynchrony improves cardiac function and efficiency. In the contemporary era of CRT this can be achieved by programming both AV and VV timing.

It should be stressed that intrinsic $A V$, programmed $A V$ and programmed VV delay can all influence ventricular activation and filling. Thus, depending on the device settings there can be up to three activation fronts that potentially determine the degree of intraventricular dyssynchrony: intrinsic right bundle branch activation, right and left ventricular pacing respectively (Fig. 1). ${ }^{16}$

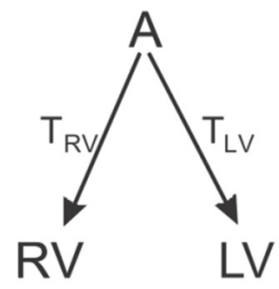

Normal conduction

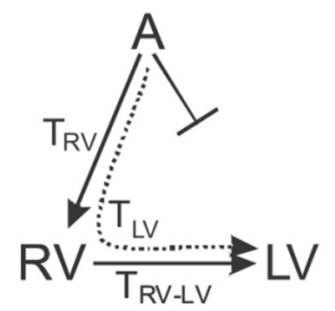

LBBB
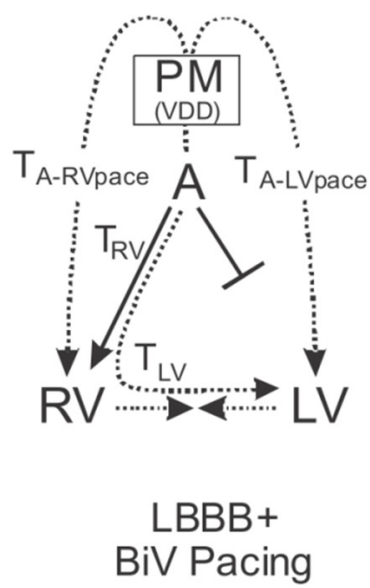

Figure 1

Schematic pathway of different ventricular activation fronts during normal conduction, LBBB and LBBB with biventricular pacing. During normal conduction (left), activation of right ventricle (RV) and left ventricle (LV) occurs through intrinsic activation and the time of activation (TRV and TLV) is similar. During LBBB (middle) activation to the LV lateral wall (TLV) is delayed because of slow myocardial conduction (TRV-LV). During biventricular pacing (right) RV and LV lateral wall can be activated by a pacing stimulus (TA-RVpace and TA-LVpace, respectively) if stimulation occurs before intrinsic activation. From Vernooy et al. Heart Rhythm 2007; 4: 76, with permission.

The interaction between these three activation fronts is illustrated in figure 2 showing a 12-lead electrocardiogram (ECG) recording during three different programmed AV delays in two patients with a CRT-device. In figure $2 \mathrm{~A}$ it can be appreciated that there is a progressive change in QRS-morphology between the AV delays. As the intrinsic PR-interval of this patient is $156 \mathrm{msec}$, the smallest QRS-complex is seen at a programmed AV delay of $170 \mathrm{msec}$ allowing maximal contribution of all three acti- 
vation fronts. In figure 2B on contrary, no change in QRS-morphology is noted between the AV delays. The intrinsic PR-interval of this patient is $289 \mathrm{msec}$ and therefore intrinsic conduction does not contribute to ventricular activation.
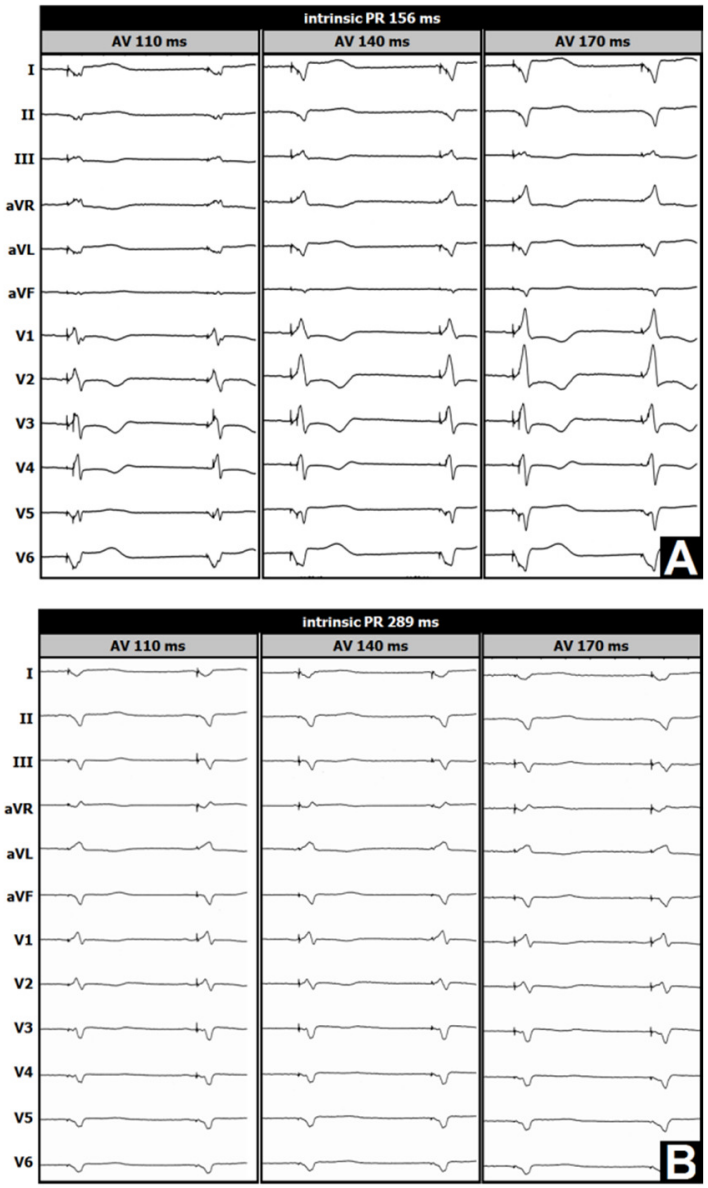

Figure 2.

Registration of 12-lead electrocardiogram in 2 patients with different intrinsic conduction during biventricular pacing with varying AV delays. Panel A: in this patient with an intrinsic PR- interval of $156 \mathrm{msec}$, there is progressive change in QRS-morphology between different AV delays. At an $\mathrm{AV}$ delay of $170 \mathrm{msec}$ there is maximal contribution of all 3 activation fronts resulting in the smallest QRS-complex. Panel $\mathrm{B}$ : in case of a very long intrinsic PR-interval of $289 \mathrm{msec}$, there is no change in QRScomplex at different AV delays as intrinsic conduction does not contribute to ventricular activation.

Most patients not only have variable intra-atrial, interventricular an intraventricular conduction delays, but also different positions of right atrial, RV and LV leads making it difficult to predict the optimal AV and VV timing. ${ }^{18}$ This supports the concept of an individualized and tailored optimization of AV en VV timings.

The importance of AV and VV optimization has already been shown in general pacing. RV single chamber pacing disturbs the temporal relation between atria en ventricles leading to decreased ventricular performance especially in case of compromised cardiac function. ${ }^{19,20}$ In the early nineties the use of DDD-pacing was proposed in patients with refractory terminal heart failure and a long atrioventricular delay. ${ }^{21}$ It was anticipated that improvement of the atrioventricular dyssynchrony by 
sequential atrioventricular pacing would lead to improved outcome. However, this potentially beneficial effect was hampered by the aggravated inter- en intraventricular dyssynchrony caused by RV pacing. ${ }^{22}$ These observations have set the base for the current therapy of biventricular pacing.

It has been demonstrated that diastolic mitral valve regurgitation (MR) can be reversed by AV sequential pacing with short AV intervals. ${ }^{23}$ The mechanism for improvement in functional systolic MR is more complex. It is caused by an imbalance between closing and tethering forces on the mitral valve leaflets. Due to LV and mitral valve annular dilation there is a restrictive leaflet motion requiring a higher (systolic) transmitral pressure gradient to close the valve. ${ }^{24}$ Moreover, LV dyssynchrony can lead to dyscoordinate contraction of both papillary muscles contributing to a synchronization of tethering forces. ${ }^{25}$ In contrast, closing forces are reduced as a consequence of decreased LV systolic function. CRT improves LV systolic function and can result in an immediate reduction of MR. ${ }^{24}$ In patients with late activation of the posterior papillary muscle an acute reduction can also be observed with CRT. Longterm resynchronization induces $\mathrm{LV}$ reverse remodeling with reduction in $\mathrm{LV}$ and mitral annular dimension resulting in further improvement of MR. ${ }^{26}$

\section{Evidence for atrioventricular optimization}

The beneficial effect of optimizing AV timing has been mainly investigated in patients with an indication for permanent dual-chamber (right atrial and RV) pacing. The majority of these small-scale, non-randomized studies focus on acute hemodynamic effects of atrioventricular optimization without evaluation of long-term morbidity and mortality. However, these results cannot be directly extrapolated to the CRT population. ${ }^{27}$

In a CRT population, the PAcing THerapies in Congestive Heart Failure (PATH$\mathrm{CHF}$ ) trial demonstrated a significant acute hemodynamic effect of varying the AV delay in both RV, LV and biventricular pacing. ${ }^{28,29}$ Interestingly, the optimal AV delay for left ventricular $\mathrm{dP} / \mathrm{dtmax}(\mathrm{LV} \mathrm{dP} / \mathrm{dtmax}$ ) was significantly shorter for $\mathrm{RV}$ and biventricular pacing compared to LV pacing in the group of responders. This variable acute hemodynamic response to different AV delays was also observed in the PATHCHF-II trial. ${ }^{30}$ This could be explained by the fact that during left ventricular pacing a left sided atrioventricular delay is set which should be longer to allow fusion with intrinsic conduction coming from the normal-conducting right bundle branch (Fig. 1).

An example of the effect of varying AV delay during left ventricular pacing is shown in figure 3. At an AV delay that is programmed $40 \mathrm{msec}$ shorter than the intrinsic PR-interval (indicated as "AV1" in figure 3) there is fusion with intrinsic right bundle branch conduction which can be appreciated from the surface ECG and RV electrogram. Fusion is lost with shorter AV delays (AV2, AV3 and AV4). ${ }^{31}$ 

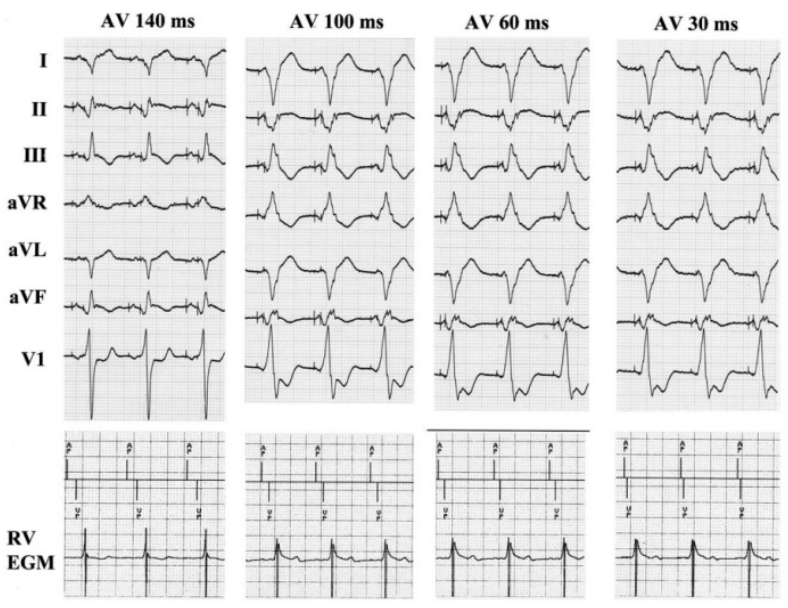

\section{Figure 3.}

During LV pacing there is fusion at AV interval 1 (AV1), however no fusion is observed at shorter AV intervals (AV2, AV3 and AV4), as can be appreciated from the 12-lead electrocardiogram. Notice the change in morphology of the RV electrogram (RV EGM) when there is no fusion with the intrinsic RBB. From van Gelder et al J Am Coll Cardiol 2005; 46: 2308, with permission.

Atrial sensing or atrial pacing will result in different optimal AV delays and has to be accounted for during optimization. Compared to atrial sensing, the optimal AV delay needs to be prolonged during atrial pacing in order to obtain similar synchronization. In practice, one could first optimize AV and VV delays during atrial pacing. To get the same resynchronization it suffices to adjust the AV delay during atrial sensing to match QRS morphology of the optimal AV delay obtained during atrial pacing (Fig. 4). ${ }^{32}$
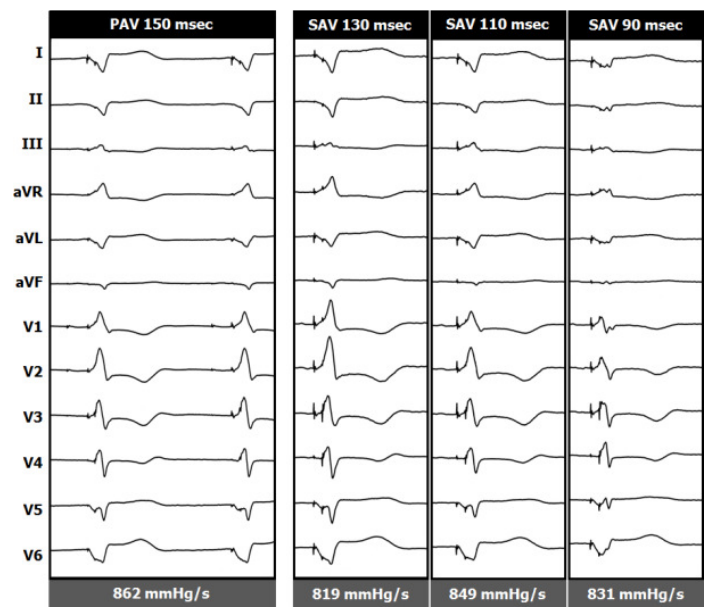

\section{Figure 4.}

Example of the difference in optimal paced AV (PAV) interval and optimal sensed AV (SAV) interval. In this patient, CRT was optimized during sequential AV pacing using LV dP/dtmax. The optimal PAV interval was 150 msec resulting in a $\mathrm{LV} \mathrm{dP/dtmax}$ of $862 \mathrm{mmHg} / \mathrm{s}$. To determine the optimal SAV interval the stimulation rate was reduced below the intrinsic sinus rate, and a 12-lead electrocardiogram was recorded during incremental shortening of the SAV interval. At a SAV interval of $110 \mathrm{msec}$, the QRS complex matches the QRS complex at the optimal PAV interval. Determination of optimal SAV interval is also confirmed by the LV dP/dtmax measurement. 
Only a small number of prospective and/or randomized clinical studies compare optimization of AV delay to an empirical AV delay. Although these studies are smallscale and use different optimization techniques, optimization of the AV delay shows a significant beneficial effect on acute hemodynamic response, New York Heart Association (NYHA) class, LV ejection fraction and brain natriuretic peptide level. ${ }^{33-35}$

So far there has been no large-scale, prospective and randomized trial evaluating the effect of AV optimization on morbidity and mortality. Nevertheless, most large CRT-trials applied some form of AV delay optimization. ${ }^{1-3,18}$ It is unknown if the beneficial effects of CRT in these trials would also be present without AV delay optimization. Based on the trials methodology and results, current guidelines of the European Society of Cardiology recommend to optimize the AV delay. ${ }^{36}$

\section{Evidence for interventricular optimization}

The relative position of right and left ventricular leads also influences timing of activation. As a consequence, VV optimization may compensate for suboptimal lead placement. ${ }^{37}$ However, even in case of optimal lead placement VV delay optimization can be of importance: some patients exhibit a significant delay between LV pacemaker stimulation and LV depolarization which can be counteracted by preexciting the LV pacing lead relative to the RV pacing lead (Fig. 5).

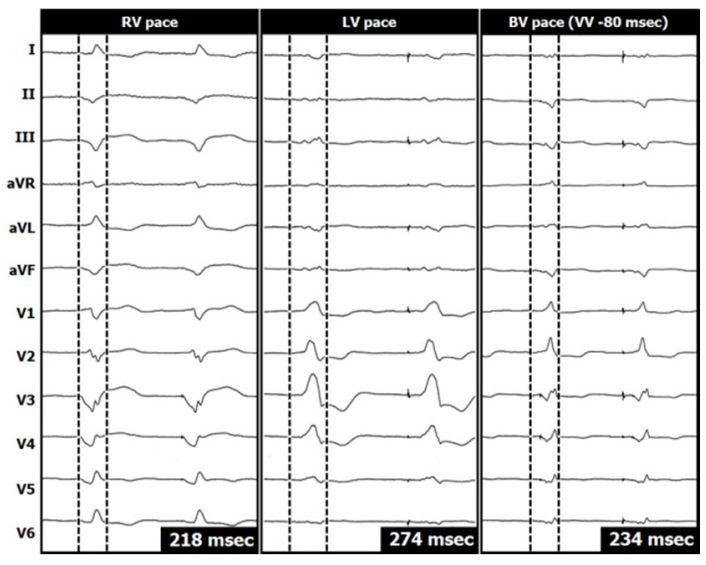

Figure 5 .

Twelve-lead electrocardiogram recording during RV pacing (left panel), LV pacing (middle panel) and biventricular (BV) pacing with VV delay of $80 \mathrm{msec}$ (right panel). The total activation time, defined as time from onset of pacing until the end of the QRS-complex, indicated between the two vertical dotted lines in each panel. During $\mathrm{RV}$ pacing the total activation time is 218 msec, however it is increased during $\mathrm{LV}$ pacing until 274 msec. During BV pacing this delayed activation can be compensated by pre-activating LV $80 \mathrm{msec}$ before RV.

None of the larger CRT-trials included VV optimization in their protocol, partly because this feature was not available at time of inclusion [38]. In smaller studies an improvement in acute hemodynamic response measured by $\operatorname{LV} \mathrm{dP} / \mathrm{dtmax}[39,40]$, exercise capacity [41] and echocardiographic left ventricular ejection fraction has been demonstrated [42, 43]. However, the larger, randomized "Device Evaluation of Contak Renewal 2 and Easytrak 2: Assesment of Safety and Effectiveness in Heart 
Failure" (DECREASE-HF) trial showed a trend towards greater reduction in left ventricular systolic diameter for the group with simultaneous biventricular pacing compared to sequential biventricular pacing44 and the single-blinded, randomized "Resynchronization for the Hemodynamic Treatment of Heart Failure Management II" (RHYTHM-II) trial did not find a benefit on functional endpoints of VV optimization compared to simultaneous biventricular pacing 45 The recent randomized, multi-center "Response of Cardiac Resynchronization Therapy Optimization With Ventricle to Ventricle Timing in Heart Failure Patients" (RESPONSE-HF) trial evaluated the effect of VV-optimization on top of AV-optimization. Patients who were non-responders after 3 months of CRT (with simultaneous biventricular pacing) were randomized to either sequential biventricular pacing with VV-optimization or simultaneous biventricular pacing. Non-response was defined on base of NYHA class and 6-minute hall walk distance. After 9 months of follow-up the response rate in the sequential group $(n=29)$ was $18.9 \%$ higher than the simultaneous group $(n=36) .{ }^{46}$

In all but one of these studies ${ }^{39} \mathrm{VV}$ delay optimization was performed on top of prior AV optimization. In the overall CRT population, the benefit of VV optimization compared to simultaneous biventricular pacing is relatively small: van Gelder et al. noted a mean increase in $\mathrm{LV} \mathrm{dP} / \mathrm{dtmax}$ of $66 \mathrm{mmHg} / \mathrm{s}(7 \%)$ on top of simultaneous biventricular pacing with optimized AV delay. ${ }^{40} \mathrm{VV}$-optimization may probably be more beneficial in a subset of patients who show no or little response to CRT. It can be concluded on base of current data that the role of VV optimization is still under

debate. This could partly be explained by the use of inaccurate optimization methods with high inter- and intraobserver variability.

There is no consensus in what order to optimize the AV and VV delay. However, in a small study the hemodynamic effect (measured by fingerphotoplethysmography) of simultaneously adjusting AV and VV delays were evaluated. There was a curvilinear effect with a clear optimal combination of AV and VV delay. VV optimization provided an additional, but smaller hemodynamic effect compared to AV optimization alone. ${ }^{47}$

\section{Intra-individual variation of optimal AV and VV delay}

The optimal AV and VV delays should not be regarded as static values, but may vary in time and in different circumstances. In general, optimization of AV and VV delays is performed during resting conditions in a supine or sitting position thus neglecting the effect of exercise. In the healthy heart, AV conduction time shortens during exercise as a result of increased sympathetic tone and inter- and intraventricular activation delays are virtually absent and not different from the resting condition. ${ }^{48}$ This is also the rationale for rate-adaptive atrial pacing with progressive shortening of the programmed AV delay during exercise. However, in the CRT population it is questionable whether rate-adaptive pacing is favourable, as the effect of exercise on atrial and ventricular conduction is more heterogeneous and complex. ${ }^{49}$ Several small studies investigating the effect of exercise on the optimal AV delay reported mixed 
results: some reported individual variation in optimal AV delay during exercise, ${ }^{50}$ others advise prolongation of the AV delay during exercise ${ }^{51}$ whilst others notice no change in optimal AV delay. ${ }^{52}$

VV optimization during exercise has been only sporadically investigated, using different optimization methods and including a limited number of patients. Lafitte et al. reported a change in interventricular dyssynchrony (defined as the interventricular mechanical delay) during bicycle exercise testing in $60 \%$ of 65 heart failure patients. ${ }^{48}$ In contrast, Valzania et al showed no significant change in interventricular mechanical delay during dobutamine stress testing. ${ }^{53}$ Two other small studies showed that the optimal VV delay changes during bicycle exercise testing in about $55 \%$ of patients. ${ }^{52,54}$ In one study in patients with atrial fibrillation and absent intrinsic AV conduction a decrease in optimal VV delay with increasing pacing rate was noted. 55

Besides the effect of exercise, optimal AV and VV delays may also change in time as a result of reverse remodeling. Also here, data regarding the effect of long-term CRT on optimal AV en VV delays are limited and contradicting. In one study there was a decrease in optimal AV delay and increase of LV preexcitation in VV setting after 6 months of CRT; 56 however another study showed an opposite effect after 9 months of CRT. ${ }^{57}$ Although patient population was comparable, both trials used different optimization methods.

The large prospective, randomized and multicenter "Frequent Optimization Study Using the QuickOpt method (FREEDOM)" trial compared frequent AV and VV optimization every 3 months using an algorithm based on the intracardiac electrogram to standard care with empiric programming or one-time optimization at the discretion of the investigator. A heart failure clinical composite score was used as primary endpoint after 12 months of follow-up. In 1525 patients analyzed, there was no significant difference in primary endpoint regardless of optimization. ${ }^{58}$

\section{Methods for optimization of AV and VV delay}

There are numerous invasive and non-invasive methods available to optimize both $\mathrm{AV}$ and VV delay. It seems reasonable to assume that optimal delays results in highest forward stroke volume. The ideal optimization method should therefore be able to measure left ventricular (forward) stroke volume or an equivalent in a preferably reproducible, easy-to-perform and non-invasive way.

\section{Invasive optimization methods}

\section{First derivate of left ventricular pressure pulse}

The ultimate way to determine contractile properties is measuring the force that is generated by a muscle, however it not possible to measure this in clinical practice. 
As an alternative, the rate of left ventricular pressure change ( $\mathrm{LV} \mathrm{dP} / \mathrm{dt}$ ) has been proposed. ${ }^{59,60}$ Pressure is defined as force per unit area and is thus related to wall force. The rate of pressure development is influenced by the contractile properties of the LV. Changes in contractility alter the slope of the pressure curve resulting in an increased or decreased peak rise in intraventricular pressure $\left(\mathrm{dP} / \mathrm{dt}_{\max }\right) \mathrm{during}$ isovolumetric contraction. ${ }^{61}$ However, $\mathrm{LV} \mathrm{dP} / \mathrm{dt}$ is a complex function which is not only dependent on contractility, but also on preload, afterload and heart rate. ${ }^{62,63}$ However, within physiological limits $\mathrm{LV} \mathrm{dP} / \mathrm{dt}_{\max }$ shows mainly dependence on contractility and preload. ${ }^{64}$ This properties make $\mathrm{LV} \mathrm{dP} / \mathrm{dt}_{\max }$ a useful instrument to evaluate the effect of both AV and VV delay on myocardial performance.

$\mathrm{LV} \mathrm{dP/dt}$ is optimally derived from a left ventricular pressure curve obtained by a micromanometer which is introduced endovascular into the LV.65 We have previously describe an alternative method using a 0.014" high-fidelity pressure wire (Radiwire, St. Jude Medical Inc., St. Paul, MN, USA) introduced either retrogradely or transseptally into the $L V .{ }^{40}$ In order to adequately determine the effect of different

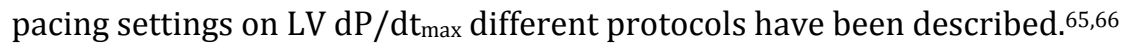

In order to overcome the influence of heart rate on $\mathrm{LV} \mathrm{dP} / \mathrm{dt}$, the atrium is paced at 5 to 10 beats above the intrinsic rate. In patients with atrial fibrillation, ventricular stimulation is performed above the intrinsic rate to ensure continuous capture. First, a baseline $\mathrm{LV} \mathrm{dP} / \mathrm{dt}_{\max }$ is measured and averaged out over several heart beats or seconds, excluding premature and post-extrasystolic beats from analysis. After baseline measurement, AV optimization is performed first during simultaneous biventricular

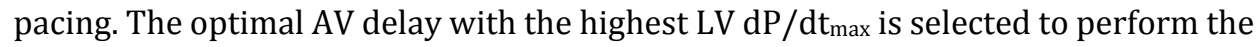
subsequent VV optimization. The optimization procedure should proceed under stable conditions to minimize any influence on $\mathrm{LV} \mathrm{dP} / \mathrm{dt}$ measurement.

This method has the advantage that it is easily implemented, even during the implantation procedure. Interpretation is not dependent on operator skills or technical limitations as with echocardiography. Also, it allows evaluation of multiple pacing sites in a short time frame. Due to these characteristics it is a suitable method to evaluate the acute hemodynamic effect of different pacing sites, either epicardially or even endocardially as has been demonstrated in a recent case report. ${ }^{67}$ As an example, we implanted a left endocardial lead in a patient who showed no clinical or echocardiographic response to standard CRT. The definite LV pacing site was determined

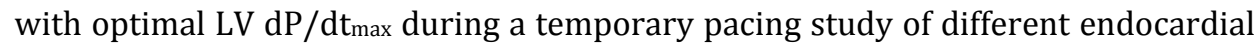
sites. At long-term follow-up there was both clinical and echocardiographic improvement.

A disadvantage of the $\mathrm{LV} \mathrm{dP} / \mathrm{dt}_{\max }$ optimization method is its invasive nature. However, as only a 4-French guiding is needed, no more complications than with standard angiography are to be expected. Nevertheless, in our opinion the advantages of this invasive technique outweigh the relatively low risk. Alternatively the pressure wire can be introduced via the radial artery or even via transseptal puncture. 
The use of continuous wave Doppler imaging of the mitral regurgitation signal is advocated as a non-invasive alternative to determine $\mathrm{LV} \mathrm{dP} / \mathrm{dt}_{\text {max. }}{ }^{68}$ Importantly, this method does not measure the true maximal $\mathrm{LV} \mathrm{dP} / \mathrm{dt}$, but an averaged slope of the left ventricular pressure curve between $4 \mathrm{mmHg}$ and $36 \mathrm{mmHg}$. This measure has not been validated in an experimental physiological set-up, as has been in case of invasively measured $\mathrm{LV} \mathrm{dP} / \mathrm{dt}_{\text {max. }}{ }^{61,63,64}$ Further, it requires the presence of a detectable mitral regurgitation signal which is not always present, ${ }^{69}$ has a lower temporal resolution than the invasive method and is more laborious to average over multiple heart beats.

Both PATH-CHF and PATH-CHF II trials used invasive $\mathrm{LV} \mathrm{dP} / \mathrm{dt}_{\max }$ to optimize the AV delay. ${ }^{30,65}$ So far, there are no randomized controlled trials evaluating the long-term outcome of CRT-optimization by $\mathrm{LV} \mathrm{dP} / \mathrm{dt}_{\max }$.

\section{Pressure-volume loops}

LV pressure-volume loops can be used to calculate stroke work defined as the integrated area within the pressure-volume loop (in $\mathrm{mmHg} \cdot \mathrm{mL}$ ). This index is mainly dependent on contractility and preload with little effect of changes in afterload. ${ }^{64}$

To acquire pressure-volume curves a 6-French or 7-French pressure-conductance catheter is inserted in the LV via the femoral artery. The signals are digitized and transformed to pressure-volume loops by dedicated software. 64,70

Except for its invasiveness, there are other disadvantages to the use of pressurevolume loops. Changes in LV volume are relatively inaccurate measured in dilated hearts and combined with a low signal-to-noise ratio, it might be difficult to acquire a reliable signal in heart failure patients. ${ }^{71}$ Also, the pressure-conductance catheter needs calibrating, has a larger size and is more expensive compared to the micromanometer used for left ventricular pressure measurements. ${ }^{72}$

In contrary to $\mathrm{LV} \mathrm{dP} / \mathrm{dt}_{\max }$ measurement, the pressure-volume loop covers both the systolic and the diastolic phase of the cardiac cycle and incorporates both pressure and volume changes. This makes stroke work more sensitive to measure CRTinduced volume changes caused by alteration in mitral regurgitation. Further, the internal flow fraction derived from the conductance signals can be used to quantify LV mechanical dyssynchrony [73]. In selected cases this dyssynchrony index could be used to support the indication for resynchronization therapy. ${ }^{74}$

Compared to $\mathrm{LV} \mathrm{dP} / \mathrm{dt}_{\max }$, pressure-volume loops have been used only limited in early cardiac resynchronization studies. ${ }^{71}$ Interestingly, when evaluating the acute hemodynamic response to CRT by both $\mathrm{LV} \mathrm{dP/dtmax} \mathrm{and} \mathrm{stroke} \mathrm{work,} \mathrm{both} \mathrm{measures}$ do not match in up to $50 \%$ of the cases when using a cut-off value of $10 \%$ change to define response to CRT. ${ }^{72}$ A sustained long-term hemodynamic response at six months has been demonstrated in a small-scale trial. ${ }^{70}$ 


\section{Automated algorithms}

Several manufacturers of CRT devices have implemented automated algorithms to adjust AV and/or VV delays. As the optimal delays may change in time as a consequence of reverse remodeling after CRT as well as during exercise, these algorithms may be of additional value. However, adaptation during exercise can only be achieved if optimization performed continuously in a closed loop configuration. Optimization for reverse remodeling could be performed intermittently with automated algorithms.

\section{Algorithms based on the intracardiac electrogram}

Quick0pt. The QuickOpt algorithm (St. Jude Medical, St. Paul, MN, USA) has been designed to optimize both AV and VV delays using intracardiac electrograms. It has been demonstrated that the optimal AV delay can be calculated by measuring the time difference between onset of right atrial activation and end of left atrial activation using the intracardiac electrogram. ${ }^{75}$ The QuickOpt algorithm uses the right intra-atrial electrogram to calculate the interatrial conduction delay. Depending on this delay an offset is added to determine the optimal AV delay. For VV delay optimization it is assumed that ventricular activation is optimal when the two depolarization wave fronts from right and left ventricular lead meet near the interventricular septum. The optimal VV delay is based on the conduction delay of both intrinsic rhythm and ventricular pacing. To measure this delay intracardiac electrograms of both right and left ventricular lead are used. The interval between intrinsic activation of RV and LV lead is defined $\delta$ and the difference between RV pacing to $L V$ sensing and LV pacing to RV sensing is defined $\varepsilon$. The optimal VV interval is then calculated using the formula 0.5 $\cdot(\delta+\varepsilon)$. Although, the algorithm shows a strong linear correlation with echocardiographic measurement of aortic velocity time integral, ${ }^{76}$ there is no correlation with the optimal VV-delay determined by $\mathrm{LV} \mathrm{dP} / \mathrm{dt}_{\text {max. }}{ }^{77}$ The correlation with the optimal $\mathrm{AV}$ and VV-delay measured by echocardiography (using the iterative method for AVoptimization and left ventricular outflow tract velocity time integral for VV-optimization) is also poor. ${ }^{78}$

The recent FREEDOM trial demonstrated that frequent optimization using Quick0pt did not significantly influence outcome as defined by the heart failure clinical composite score.58 However, these results may be due to inaccuracy of the QuickOpt algorithm.

SMART-AV. The "SmartDelay determined Atrioventricular Optimization" (SMART-AV) electrogram algorithm (Boston Scientific Corporation, St. Paul, MN, USA) is part of the Expert Ease for Heart Failure feature and has been developed from results of large clinical trials.3,30,79 Both sensed and paced AV delay are derived from the intracardiac electrogram and added to the QRS-duration on the surface electrocardiogram in either mode. A correction factor is used depending on left ventricular lead position. This algorithm has been compared to two echocardiographic optimi- 
zation methods (Ritter's and aortic velocity time integral method). In 28 patients examined, the electrogram optimization method correlated significantly better with LV $\mathrm{dP} / \mathrm{dt}_{\max }$ than the Ritter method. ${ }^{80}$ The on-going randomized, multicenter SMARTAV trial has been designed to compare the effect of different atrioventricular optimization methods on left ventricular remodeling. The electrogram optimization method will be compared to echocardiographic AV optimization (iterative method) and a fixed AV delay. ${ }^{81}$

\section{Peak endocardial acceleration}

During the isovolumetric contraction period the myocardium generates vibrations that are transmitted throughout the heart. The audible frequencies of these vibrations can be appreciated as the first (and second) heart sound. With a microaccelerometer (SonR, Sorin Biomedica, Saluggia, Italy) located on a lead inside the heart it is possible to record the full frequency spectrum and derive the peak endocardial acceleration (PEA). Early experimental research has shown that changes in PEA correlates well with changes in contractility induced by inotropic stimulation. ${ }^{82}$ The optimal AV delay determined by PEA correlates well with those obtained by echocardiography (Ritter's method).83-85 In CRT, PEA increases significantly during LV or biventricular pacing compared to RV pacing only. ${ }^{86}$

The randomized, multicenter Clinical Evaluation of Advanced Resynchronization (CLEAR) study compared AV- and VV-optimization by PEA to standard care for the composite endpoint of NYHA class, heart failure hospitalization and quality of life at 12 months in 186 patients. Patients optimized with PEA $(n=66)$ showed a significantly higher response rate. ${ }^{87}$

\section{Finger photoplethysmography}

The conventional pulse oximetry probe measures the arterial pulsations of the fingertip vascular bed using a photo detector. It is possible to measure systolic blood pressure, pulse pressure and mean arterial pressure. As aortic pulse pressure is influenced by stroke volume and thus left ventricular performance, finger photoplethysmography may be used to optimize atrioventricular and interventricular delay. It seems a promising tool in cardiac resynchronization optimization because of its non-invasive nature and high reproducibility. However, measurements are highly influenced by waveform reflections in the arterial system and autonomic effects on peripheral resistance.

To overcome these issues, measurements are only made a few beats after an atrioventricular delay change and an algorithm is used to correct for vasodilation and/or vasoconstriction. In patients who show a positive change in aortic pulse pressure during CRT (invasively measured), finger photoplethysmography (using the correction algorithm described) was able to predict the AV delay with the highest aortic pulse pressure change in up to $80 \%$ of the patients. ${ }^{88}$ 
Another technique uses a volume-clamp circuit around the finger that dynamically follows arterial pressure (Finapres Medical System, Amsterdam, the Netherlands). ${ }^{89}$ The use of systolic blood pressure change measured by this technique responds to changing AV intervals and is claimed to be highly reproducible. ${ }^{89,90}$ Alternatively, Nexfin (BMEYE B.V., Amsterdam, the Netherlands) combines the volumeclamp technique with a dedicated algorithm to calculate stroke volume. ${ }^{91}$ This method shows a good agreement with aortic valve velocity time integral to measure changes in stroke volume and to determine the optimal AV-delay. ${ }^{92}$

\section{Echocardiography}

Echocardiographic techniques for optimization of both AV and VV delays have been comprehensively described in recent review papers. ${ }^{27,93,94}$ In general, echocardiography is a widely available and noninvasive technique without significant burden for the patient. However, these optimization techniques are subject of higher intra- en interobserver variability than invasive measurements. Still, echocardiography remains a cornerstone in CRT because of its ability to evaluate response to CRT in terms of reverse remodeling and to identify other factors that might influence a nonresponse to CRT (e.g. RV failure, pulmonary hypertension, valvular disease).

\section{Evaluation of LV systolic function}

Pulsed wave left ventricular outflow tract velocity time integral (LVOTVTI). This parameter has been used to optimize both AV and VV delays. In a few small-scale, uncontrolled studies the optimal AV delay was defined as the delay with the highest stroke distance measured by LVOT-VTI but there is no correlation with outcome. ${ }^{35,51}$ In a post-hoc analysis, the InSync III study compared VV-optimization using LVOT stroke volume to simultaneous biventricular pacing. There was only a significant improvement in 6 minutes walking test (6MWT) compared to the control group; quality of life and NYHA class were not significantly different [95]. Also, the previously described RHYTHM II ICD trial used LVOT-VTI measurements for VV-optimization, but reported no benefit on functional endpoints. ${ }^{45}$ One small, non-randomized study used LVOT-VTI to optimize both AV and VV delays after 3 months of non-optimized CRT and concluded that the method was feasible, reproducible and able to improve response to CRT. ${ }^{96}$

Continuous wave aortic valve velocity time integral (AV-VTI). Sawhney et al. showed in a randomized, prospective trial in 40 patients that compared to an empirical AV delay of $120 \mathrm{msec}$, AV-optimization using AV-VTI yields a significant improvement in NYHA class, quality of life and 6MWT.33 Another prospective study in 40 patients compared AV-optimization by AV-VTI to the Ritter's method and concluded that the AV-VTI method resulted in greater systolic improvement. ${ }^{97}$ However, the methodology of both studies has been questioned. ${ }^{27}$ 
$\mathbf{L V ~ d P / d t . ~ E v e n ~ t h o u g h ~ p r o p o s e d ~ a s ~ a ~ s u r r o g a t e ~ f o r ~ i n v a s i v e ~} \mathrm{LV} \mathrm{dP} / \mathrm{dt}_{\max }$ measurement, ${ }^{68}$ this measurement is not recommended as optimization method as reproducibility has been reported as suboptimal. ${ }^{96}$

Tissue Doppler imaging (TDI). Although TDI has the potential to assess left ventricular dyssynchrony, it is subject to high inter- and intra-observer variability. ${ }^{96,98}$ TDI was used to optimize VV delay and was compared to empirical AV and VV delays by Vidal et al. in 100 patients ${ }^{99}$ The optimal VV delay was defined as the setting with the greatest superposition of TDI curves of opposing LV walls in 2-chamber and 4-chamber view. There was only a significant improvement in 6MWT in the optimized group. However, $25 \%$ of patients in the optimized group did not receive AV optimization because of atrial fibrillation and a power calculation justifying the included number of patients is lacking. Another study used TDI based on measurement of regional electromechanical delay of $18 \mathrm{LV}$ segments in the 3 apical views. The AV and VV delays were defined as optimal when the basal septal segment and the segments containing the right and left ventricular leads (as identified by computer tomography) were synchronized. Comparing a limited number of VV intervals, derived optimal VV delay coincided with the greatest cardiac output as measured by thermodilution. Although complex and time-consuming, this method is one of the few based on the underlying physiological concept of synchronizing the three activation fronts. ${ }^{100}$

\section{Evaluation of $L V$ diastolic function}

Iterative method. The AV delay is shortened by increments of $20 \mathrm{msec}$ until truncation of the A-wave on the pulsed Doppler transmitral flow pattern. Next, the AV delay is increased again by increments of $10 \mathrm{msec}$ until A-wave truncation disappears. The latter is defined as the optimal AV delay. The iterative method was used for AV optimization in the CARE-HF trial and the aforementioned study of Vidal et al. ${ }^{99,101}$

Ritter's formula. This method was originally proposed for patients with complete heart block. ${ }^{102}$ Even though, it has only been presented as an abstract and no further validation has been published, its use has been extrapolated to the CRT population without extensive validation. The formula defines the optimal AV delay as the $\mathrm{AV}$ interval that bridges the end of the A-wave with closure of the mitral valve or the onset of ventricular contraction. To do so, the time from onset of QRS-complex to time of termination of the A-wave (QA-interval) are measured at both a long (AVlong) and a short AV delay (AVshort). The optimal AV delay is calculated from following formula: AVopt = AVlong- (QAshort-QAlong). Ritter's formula has also been compared to the QuickOpt algorithm and AV-VTI for AV optimization using LV $\mathrm{dP} / \mathrm{dt}_{\max }$ as gold standard. This study showed that Ritter's formula was least accurate. ${ }^{80}$

Mitral inflow velocity time integral. On the pulsed Doppler transmitral flow pattern the VTI is calculated representing the stroke distance of mitral inflow as a surrogate of LV filling volume. The AV delay with the largest VTI is considered the 
optimal setting. The method showed a good correlation with optimization by LV $\mathrm{dP} / \mathrm{dt}_{\max }(\mathrm{r}=0.96)$ in a small study of 30 patients. ${ }^{103}$

Meluzin's method. A simplified method to merge the end of atrial contraction with mitral valve closure was proposed by Meluzin. ${ }^{104}$ A long AV delay is programmed and the pulsed Doppler transmitral inflow pattern is recorded. The time between end of the A-wave and onset of systolic mitral regurgitation is calculated. This time is subtracted from the programmed AV delay to determine the optimal AV interval. The method was only validated in a study of 18 patients which showed a significantly higher cardiac output measured by thermodilution when comparing the optimal AV delay to longer and shorter AV delays. ${ }^{104}$ Obviously, application of this method is dependent on a clear mitral regurgitation signal.

Evaluation of LV systolic and diastolic function.

Myocardial performance index (MPI). The MPI (or Tei index) is based on cardiac timing intervals and has been introduced as a measurement incorporating both LV systolic and diastolic function. The mitral-closure-to-opening (MCO) interval is measured on the pulsed Doppler transmitral flow signal and the ejection time (ET) is derived from the pulsed Doppler LVOT flow signal. As the total of the isovolumetric contraction and relaxation time (ICT and IRT) is obtained by subtracting ET from MCO, the index incorporates both systolic and diastolic indices. ${ }^{105}$ Two small studies used MPI to optimize AV delay ${ }^{106,107}$ and/or VV delay. ${ }^{106}$ Both studies lacked a control group and well-defined endpoints.

\section{Conclusion}

Experimental physiological and pathophysiological research support the rationale to optimize AV and VV delays in CRT. Although there is a spectrum of possible optimization methods, no evident golden standard has emerged, partly due to the lack of large-scale studies evaluating these methods to outcome. Thus at present no single method can be recommended for standard practice. Present studies support the physiological rationale for AV optimization, but data concerning VV optimization are still conflicting. As the incremental benefit of VV optimization is relatively small, the effect is probably more of importance in a subset of CRT patients (with special attention for non-responders). Although current efforts mainly investigate optimization during resting conditions, there is a need to develop automated algorithms to implement dynamic optimization in order to adapt to physiological alterations during exercise and after anatomical remodeling. 


\section{References}

1. Bristow MR, Saxon LA, Boehmer J, Krueger S, Kass DA, De Marco T, Carson P, DiCarlo L, DeMets D, White BG, DeVries DW, Feldman AM. Cardiac resynchronization therapy with or without an implantable defibrillator in advanced chronic heart failure. N Engl J Med 2004; 350: 2140-2150.

2. Cleland JG, Daubert JC, Erdmann E, Freemantle N, Gras D, Kappenberger L, Tavazzi L. The effect of cardiac resynchronization on morbidity and mortality in heart failure. N EnglJ Med 2005; 352: 15391549.

3. Abraham WT, Fisher WG, Smith AL, Delurgio DB, Leon AR, Loh E, Kocovic DZ, Packer M, Clavell AL, Hayes DL, Ellestad M, Trupp RJ, Underwood J, Pickering F, Truex C, McAtee P, Messenger J. Cardiac resynchronization in chronic heart failure. $N$ Engl J Med 2002; 346: 1845-1853.

4. Durrer D, van Dam RT, Freud GE, Janse MJ, Meijler FL, Arzbaecher RC. Total excitation of the isolated human heart. Circulation 1970; 41: 899-912.

5. Prinzen FW, Spinelli J, Auricchio A. Basic physiology and hemodynamics of cardiac pacing. In: Ellenbogen KA, Kay GN, Lau CP, Wilkoff B, eds. Clinical cardiac pacing, defibrillation, and resynchronization therapy. Philadelphia: Saunders Elsevier; 2007: 291-335.

6. Mitchell J, Gilmore J, Sarnoff S. The transport function of the atrium. Factors influencing the relation between mean left atrial pressure and left ventricular end diastolic pressure. Am J Cardiol 1962; 9: 237-247.

7. Burchell H. A clinical appraisal of atrial transport function. Lancet 1964; 1: 775-779.

8. Skinner N, Jr., Mitchell J, Wallace A, Sarnoff S. Hemodynamic effects of altering the timing of atrial systole. Am J Physiol 1963; 205: 499-503.

9. Fung JW, Yu CM, Yip G, Chan H, Kum CC, Sanderson JE. Variable left ventricular activation pattern in patients with heart failure and left bundle branch block. Heart 2004; 90: 17-19.

10. Frazier DW, Krassowska W, Chen PS, Wolf PD, Danieley ND, Smith WM, Ideker RE. Transmural activations and stimulus potentials in three-dimensional anisotropic canine myocardium. Circ Res 1988; 63: 135-146.

11. Weber KT, Janicki JS, Shroff S, Fishman AP. Contractile mechanics and interaction of the right and left ventricles. Am J Cardiol 1981; 47: 686-695.

12. Antoni H. Functional properties of the heart. In: Greger R, Windhorst U, eds. Comprehensive human physiology. From cellular mechanisms to integration. Vol 2. Berlin: Springer Verlag 1996: 18011824.

13. Farrar DJ, Woodard JC, Chow E. Pacing-induced dilated cardiomyopathy increases left-to-right ventricular systolic interaction. Circulation 1993; 88: 720-725.

14. Atherton JJ, Moore TD, Lele SS, Thomson HL, Galbraith AJ, Belenkie I, Tyberg JV, Frenneaux MP. Diastolic ventricular interaction in chronic heart failure. Lancet 1997; 349: 1720-1724.

15. Kosowsky BD, Scherlag BJ, Damato AN. Re-evaluation of the atrial contribution to ventricular function: study using His bundle pacing. Am J Cardiol 1968; 21: 518-524.

16. Vernooy K, Verbeek XA, Cornelussen RN, Dijkman B, Crijns HJ, Arts T, Prinzen FW. Calculation of effective $\mathrm{VV}$ interval facilitates optimization of $\mathrm{AV}$ delay and $\mathrm{VV}$ interval in cardiac resynchronization therapy. Heart Rhythm 2007; 4: 75-82.

17. Prinzen FW, Hunter WC, Wyman BT, McVeigh ER. Mapping of regional myocardial strain and work during ventricular pacing: experimental study using magnetic resonance imaging tagging. J Am Coll Cardiol 1999; 33: 1735-1742.

18. Cazeau S, Leclercq C, Lavergne T, Walker S, Varma C, Linde C, Garrigue S, Kappenberger L, Haywood GA, Santini M, Bailleul C, Daubert JC. Effects of multisite biventricular pacing in patients with heart failure and intraventricular conduction delay. N Engl J Med 2001; 344: 873-880.

19. Samet $P$, Castillo $C$, Bernsein WH. Hemodynamic consequences of sequential atrioventricular pacing. Subjects with normal hearts. Am J Cardiol 1968; 21: 207-212.

20. Wilkoff BL, Cook JR, Epstein AE, Greene HL, Hallstrom AP, Hsia H, Kutalek SP, Sharma A. Dual-chamber pacing or ventricular backup pacing in patients with an implantable defibrillator: the Dual Chamber and VVI Implantable Defibrillator (DAVID) Trial. JAMA 2002; 288: 3115-3123. 
21. Hochleitner M, Hortnagl H, Ng CK, Hortnagl H, Gschnitzer F, Zechmann W. Usefulness of physiologic dual-chamber pacing in drug-resistant idiopathic dilated cardiomyopathy. Am J Cardiol 1990; 66: 198-202.

22. Gold MR, Feliciano Z, Gottlieb SS, Fisher ML. Dual-chamber pacing with a short atrioventricular delay in congestive heart failure: a randomized study. J Am Coll Cardiol 1995; 26: 967-973.

23. Nishimura RA, Hayes DL, Holmes DR, Jr., Tajik AJ. Mechanism of hemodynamic improvement by dualchamber pacing for severe left ventricular dysfunction: an acute Doppler and catheterization hemodynamic study. J Am Coll Cardiol 1995; 25: 281-288.

24. Breithardt OA, Sinha AM, Schwammenthal E, et al. Acute effects of cardiac resynchronization therapy on functional mitral regurgitation in advanced systolic heart failure. J Am Coll Cardiol 2003; 41: 765770 .

25. Kanzaki H, Bazaz R, Schwartzman D, Dohi K, Sade LE, Gorcsan III J. A mechanism for immediate reduction in mitral regurgitation after cardiac resynchronization therapy: insights from mechanical activation strain mapping. J Am Coll Cardiol 2004; 44: 1619-1625.

26. Ypenburg C, Lancellotti P, Tops LF, Boersma E, Bleeker GB, Holman ER, Thomas JD, Schalij MJ, Piérard LA, Bax JJ. Mechanism of improvement in mitral regurgitation after cardiac resynchronization therapy. Eur Heart J 2008; 29: 757-765.

27. Stanton T, Hawkins NM, Hogg KJ, Goodfield NE, Petrie MC, McMurray JJ. How should we optimize cardiac resynchronization therapy?. Eur Heart J 2008; 29): 2458-2472.

28. Auricchio A, Stellbrink C, Block M, Sack S, Vogt J, Bakker P, Klein H, Kramer A, Ding J, Salo R, Tockman B, Pochet T, Spinelli J. Effect of pacing chamber and atrioventricular delay on acute systolic function of paced patients with congestive heart failure. The Pacing Therapies for Congestive Heart Failure Study Group. The Guidant Congestive Heart Failure Research Group. Circulation 1999; 99: 29933001.

29. Auricchio A, Ding J, Spinelli JC, Fleck E, Ding J, Yu Y, Huvelle E, Spinelli J. Cardiac resynchronization therapy restores optimal atrioventricular mechanical timing in heart failure patients with ventricular conduction delay. J Am Coll Cardiol 2002; 39: 1163-1169.

30. Butter C, Auricchio A, Stellbrink C, Fleck E, Ding J, Yu Y, Huvelle E, Spinelli J;. Effect of resynchronization therapy stimulation site on the systolic function of heart failure patients. Circulation 2001; 104: 3026-3029.

31. van Gelder BM, Bracke FA, Meijer A, Pijls NH. The hemodynamic effect of intrinsic conduction during left ventricular pacing as compared to biventricular pacing. J Am Coll Cardiol 2005; 46: 2305-2310.

32. Van Gelder BM, Bracke FA, van der Voort P, Meijer A. Optimal sensed atrio-ventricular interval determined by paced QRS morphology. Pacing Clin Electrophysiol 2007; 30: 476-481.

33. Sawhney NS, Waggoner AD, Garhwal S, Chawla MK, Osborn J, Faddis MN. Randomized prospective trial of atrioventricular delay programming for cardiac resynchronization therapy. Heart Rhythm 2004; 1: 562-567.

34. Morales MA, Startari U, Panchetti L, Rossi A, Piacenti M. Atrioventricular delay optimization by doppler-derived left ventricular $\mathrm{dP} / \mathrm{dt}$ improves 6-month outcome of resynchronized patients. Pacing Clin Electrophysiol 2006; 29: 564-568.

35. Hardt SE, Yazdi SH, Bauer A, Filusch A, Korosoglou G, Hansen A, Bekeredjian R, Ehlermann P, Remppis A, Katus HA, Kuecherer HF. Immediate and chronic effects of AV-delay optimization in patients with cardiac resynchronization therapy. Int J Cardiol 2007; 115: 318-325.

36. Vardas PE, Auricchio A, Blanc JJ, Daubert JC, Drexler H, Ector H, Gasparini M, Linde C, Morgado FB, Oto A, Sutton R, Trusz-Gluza M. Guidelines for cardiac pacing and cardiac resynchronization therapy: The Task Force for Cardiac Pacing and Cardiac Resynchronization Therapy of the European Society of Cardiology. Developed in collaboration with the European Heart Rhythm Association. Eur Heart J 2007; 28: 2256-2295.

37. Asirvatham SJ, Hayes DL. Optimization of biventricular devices. In: Hayes DL, Wang P, Sackner-Bernstein J, Asirvatham SJ, eds. Resynchronization and defibrillation for heart failure. A practical approach. Oxford: Blackwell Publishing; 2004:139-162. 
38. Mortensen PT, Sogaard P, Mansour H, Ponsonaille J, Gras D, Lazarus A, Reiser W, Alonso C, Linde CM, Lunati M, Kramm B, Harrison EM. Sequential biventricular pacing: evaluation of safety and efficacy. Pacing Clin Electrophysiol 2004; 27: 339-345.

39. Perego GB, Chianca R, Facchini M, Frattola A, Balla E, Zucchi S, Cavaglià S, Vicini I, Negretto M, Osculati G. Simultaneous vs. sequential biventricular pacing in dilated cardiomyopathy: an acute hemodynamic study. Eur J Heart Fail 2003; 5: 305-313.

40. van Gelder BM, Bracke FA, Meijer A, Lakerveld LJ, Pijls NH. Effect of optimizing the VV interval on left ventricular contractility in cardiac resynchronization therapy. Am J Cardiol 2004; 93: 1500-1503.

41. Leon AR, Abraham WT, Brozena S, Daubert JP, Fisher WG, Gurley JC, Liang CS, Wong G. Cardiac resynchronization with sequential biventricular pacing for the treatment of moderate-to-severe heart failure. J Am Coll Cardiol 2005; 46: 2298-2304.

42. Sogaard P, Egeblad H, Pedersen AK, Kim WY, Kristensen BO, Hansen PS, Mortensen PT. Sequential versus simultaneous biventricular resynchronization for severe heart failure: evaluation by tissue Doppler imaging. Circulation 2002; 106: 2078-2084.

43. Vanderheyden M, De Backer T, Rivero-Ayerza M, Geelen P, Bartunek J, Verstreken S, De Zutter M, Goethals M. Tailored echocardiographic interventricular delay programming further optimizes left ventricular performance after cardiac resynchronization therapy. Heart Rhythm 2005; 2: 1066-1072.

44. Rao RK, Kumar UN, Schafer J, Viloria E, De Lurgio D, Foster E. Reduced ventricular volumes and improved systolic function with cardiac resynchronization therapy: a randomized trial comparing simultaneous biventricular pacing, sequential biventricular pacing, and left ventricular pacing. Circulation 2007; 115: 2136-2144.

45. Boriani G, Muller CP, Seidl KH, Grove R, Vogt J, Danschel W, Schuchert A, Djiane P, Biffi M, Becker T, Bailleul C, Trappe HJ. Randomized comparison of simultaneous biventricular stimulation versus optimized interventricular delay in cardiac resynchronization therapy. The Resynchronization for the HemodYnamic Treatment for Heart Failure Management II implantable cardioverter. Am Heart J 2006; 151: 1050-1058.

46. Weiss R, Malik M, Dinerman J, Lee L, Petrutiu S, Khoo M. V-V optimization in cardiac resynchronization therapy non-responders: RESPONSE-HF trail results. Heart Rhythm 2010; 7: S26.

47. Whinnett ZI, Davies JE, Willson K, Manisty CH, Chow AW, Foale RA, Davies DW, Hughes AD, Mayet J, Francis DP. Haemodynamic effects of changes in atrioventricular and interventricular delay in cardiac resynchronisation therapy show a consistent pattern: analysis of shape, magnitude and relative importance of atrioventricular and interventricular delay. Heart 2006; 92: 1628-1634.

48. Lafitte S, Bordachar P, Lafitte M, Garrigue S, Reuter S, Reant P, Serri K, Lebouffos V, Berrhouet M, Jais P, Haissaguerre M, Clementy J, Roudaut R, DeMaria AN. Dynamic ventricular dyssynchrony: an exercise-echocardiography study. J Am Coll Cardiol 2006; 47: 2253-2259.

49. Bogaard MD, Kirkels JH, Hauer RN, Loh P, Doevendans PA, Meine M. Should We Optimize Cardiac Resynchronization Therapy During Exercise? J Cardiovasc Electrophysiol 2010; 21: 1307-1316.

50. Mokrani B, Lafitte S, Deplagne A, Ploux S, Laborderie J, Reant P, Dos Santos P, Roudaut R, Jais P, Haissaguerre M, Clementy J, Bordachar P. Echocardiographic study of the optimal atrioventricular delay at rest and during exercise in recipients of cardiac resynchronization therapy systems. Heart Rhythm 2009; 6: 972-977.

51. Scharf C, Li P, Muntwyler J, Chugh A, Oral H, Pelosi F, Morady F, Armstrong WF.. Rate-dependent AV delay optimization in cardiac resynchronization therapy. Pacing Clin Electrophysiol 2005; 28: 279284.

52. Valzania C, Eriksson MJ, Boriani G, Gadler F. Cardiac resynchronization therapy during rest and exercise: comparison of two optimization methods. Europace 2008; 10: 1161-1169.

53. Valzania C, Gadler F, Eriksson MJ, Olsson A, Boriani G, Braunschweig F. Electromechanical effects of cardiac resynchronization therapy during rest and stress in patients with heart failure. Eur J Heart Fail 2007; 9: 644-650.

54. Bordachar P, Lafitte S, Reuter S, et al. Echocardiographic assessment during exercise of heart failure patients with cardiac resynchronization therapy. Am J Cardiol 2006; 97: 1622-1625. 
55. van Gelder BM, Meijer A, Bracke FA. Stimulation rate and the optimal interventricular interval during cardiac resynchronization therapy in patients with chronic atrial fibrillation. Pacing Clin Electrophysiol 2008; 31: 569-574.

56. Porciani MC, Dondina C, Macioce R, et al. Temporal variation in optimal atrioventricular and interventricular delay during cardiac resynchronization therapy. J Card Fail 2006; 12: 715-719.

57. O'Donnell D, Nadurata V, Hamer A, Kertes P, Mohamed U. Long-term variations in optimal programming of cardiac resynchronization therapy devices. Pacing Clin Electrophysiol 2005; 28 Suppl 1: S24S26.

58. Abraham WT, Gras D, Yu CM, Guzzo L, Gupta MS. Results from the Freedom trial - assess the safety and efficacy of frequent optimization of cardiac resynchronization therapy. Heart Rhythm 2010; 7 Suppl 5: 2-3.

59. Mason DT, Braunwald E, Covell JW, Sonnenblick EH, Ross J, Jr. Assessment of cardiac contractility. The relation between the rate of pressure rise and ventricular pressure during isovolumic systole. Circulation 1971; 44: 47-58.

60. van den Bos GC. Indices of contractility in the intact heart. Proc R Soc Med 1972; 65: 545-547.

61. Reeves T, Hefner L, Jones W, Coghlan C, Prieto G, Carroll J. The hemodynamic determinants of the rate of change in pressure in the left ventricle during isometric contraction. Am Heart J 1960; 60: 745-761.

62. C.J. W. Some factors controlling the shape of the pressure curve in the right ventricle. Am J Physiol 1914; 33: 382-396.

63. Wallace A, Skinner N Jr, Mitchell J. Hemodynamic determinants of the maximal rate of rise of left ventricular pressure. Am J Physiol 1963; 205: 30-36.

64. Kass DA, Maughan WL, Guo ZM, Kono A, Sunagawa K, Sagawa K. Comparative influence of load versus inotropic states on indexes of ventricular contractility: experimental and theoretical analysis based on pressure-volume relationships. Circulation 1987; 76: 1422-1436.

65. Auricchio A, Stellbrink C, Sack S, Block M, Vogt J, Bakker P, Mortensen P, Klein H. The Pacing Therapies for Congestive Heart Failure (PATH-CHF) study: rationale, design, and endpoints of a prospective randomized multicenter study. Am J Cardiol 1999; 83: 130D-135D.

66. Jansen AH, van Gelder BM. Visual LV motion and invasive LVdP/dtmax for selection and optimisation of cardiac resynchronisation therapy. Neth Heart J 2008; 16 Suppl 1: S32-S35.

67. Bracke FA, Houthuizen P, Rahel BM, van Gelder BM. Left ventricular endocardial pacing improves the clinical efficacy in a non-responder to cardiac resynchronization therapy: role of acute haemodynamic testing. Europace 2010; 12: 1032-1034.

68. Bargiggia GS, Bertucci C, Recusani F, Raisaro A, de Servi S, Valdes-Cruz LM, Sahn DJ, Tronconi L. A new method for estimating left ventricular $\mathrm{dP} / \mathrm{dt}$ by continuous wave Doppler-echocardiography. Validation studies at cardiac catheterization. Circulation 1989; 80: 1287-1292.

69. Tournoux FB, Alabiad C, Fan D, Chen AA, Chaput M, Heist EK, Mela T, Mansour M, Reddy V, Ruskin JN, Picard MH, Singh JP. Echocardiographic measures of acute haemodynamic response after cardiac resynchronization therapy predict long-term clinical outcome. Eur Heart J 2007; 28: 1143-1148.

70. Steendijk P, Tulner SA, Bax JJ, Oemrawsingh PV, Bleeker GB, van Erven L, Putter H, Verwey HF, van der Wall EE, Schalij MJ. Hemodynamic effects of long-term cardiac resynchronization therapy: analysis by pressure-volume loops. Circulation 2006; 113: 1295-1304.

71. Kass DA, Chen CH, Curry C, Talbot M, Berger R, Fetics B, Nevo E. Improved left ventricular mechanics from acute VDD pacing in patients with dilated cardiomyopathy and ventricular conduction delay. Circulation 1999; 99: 1567-1573.

72. de Roest G, Knaapen P, Gotte M, Hendriks T, Allaart C, de Cock C, van Rossum A. Stroke work or systolic $\mathrm{dP} / \mathrm{dtmax}$ to evaluate acute response to cardiac resynchronization therapy: are they interchangeable? Eur J Heart Fail 2009; 11: 706-708.

73. Steendijk P, Tulner SA, Schreuder JJ, Bax JJ, van Erven L, van der Wall EE, Dion RA, Schalij MJ, Baan J. Quantification of left ventricular mechanical dyssynchrony by conductance catheter in heart failure patients. Am J Physiol Heart Circ Physiol 2004; 286: H723-H730. 
74. Penicka M, Kocka V, Herman D, Trakalova H, Herold M. Cardiac resynchronization therapy for the causal treatment of heart failure with preserved ejection fraction: insight from a pressure-volume loop analysis. Eur J Heart Fail 2010; 12: 634-636.

75. Worley SJ, Gohn C, Smith T. Optimization of cardiac resynchronization: left atrial electrograms measured at implant eliminates the need for echo and identifies patients where AV optimization is not possible. J Card Fail 2004; 10: S62.

76. Baker II J, McKenzie III J, Beau S, Greer GS, Porterfield J, Fedor M, Greenberg S, Daoud EG, Corbisiero R, Bailey JR, Porterfield L. Acute evaluation of programmer-guided AV/PV and VV delay optimization comparing an IEGM method and echocardiogram for cardiac resynchronization therapy in heart failure patients and dual-chamber ICD implants. J Cardiovasc Electrophysiol 2007; 18:185-191.

77. van Gelder BM, Meijer A, Bracke FA. The optimized V-V interval determined by interventricular conduction times versus invasive measurement by $\mathrm{LVdP} / \mathrm{dt}_{\max }$ J Cardiovasc Electrophysiol 2008; 19: 939-944.

78. Kamdar R, Frain E, Warburton F, Richmond L, Mullan V, Berriman T, Thomas G, Tenkorang J, Dhinoja M, Earley M, Sporton S, Schilling R. A prospective comparison of echocardiography and device algorithms for atrioventricular and interventricular interval optimization in cardiac resynchronization therapy. Europace 2010; 12: 84-91.

79. Auricchio A, Stellbrink C, Sack S, Block M, Vogt J, Bakker P, Huth C, Schöndube F, Wolfhard U, Böcker D, Krahnefeld O, Kirkels H. Long-term clinical effect of hemodynamically optimized cardiac resynchronization therapy in patients with heart failure and ventricular conduction delay. J Am Coll Cardiol 2002; 39: 2026-2033.

80. Gold MR, Niazi I, Giudici M, Leman RB, Sturdivant JL, Kim MH, Yu Y, Ding J, Waggoner AD. A prospective comparison of AV delay programming methods for hemodynamic optimization during cardiac resynchronization therapy. J Cardiovasc Electrophysiol 2007; 18: 490-496.

81. Corporation BS. Comparison of AV optimization methods used in cardiac resynchronization therapy (CRT) (SMART-AV). http://www.clinicaltrials.gov/ct2/show/NCT00677014. 2008.

82. Rickards AF, Bombardini T, Corbucci G, Plicchi G. An implantable intracardiac accelerometer for monitoring myocardial contractility. The Multicenter PEA Study Group. Pacing Clin Electrophysiol 1996; 19: 2066-2071.

83. Ritter P, Padeletti L, Gillio-Meina L, Gaggini G. Determination of the optimal atrioventricular delay in DDD pacing. Comparison between echo and peak endocardial acceleration measurements. Europace 1999; 1: 126-130.

84. Leung SK, Lau CP, Lam CT, Ho S, Tse HF, Yu CM, Lee K, Tang MO, To KM, Renesto F. Automatic optimization of resting and exercise atrioventricular interval using a peak endocardial acceleration sensor: validation with Doppler echocardiography and direct cardiac output measurements. Pacing Clin Electrophysiol 2000; 23: 1762-1766.

85. Dupuis JM, Kobeissi A, Vitali L, Gaggini G, Merheb M, Rouleau F, Leftheriotis G, Ritter P, Victor J. Programming optimal atrioventricular delay in dual chamber pacing using peak endocardial acceleration: comparison with a standard echocardiographic procedure. Pacing Clin Electrophysiol 2003; 26: 210-213.

86. Bordachar P, Garrigue S, Reuter S, Hocini M, Kobeissi A, Gaggini G, Jaïs P, Haïssaguerre M, Clementy J. Hemodynamic assessment of right, left, and biventricular pacing by peak endocardial acceleration and echocardiography in patients with end-stage heart failure. Pacing Clin Electrophysiol 2000; 23: 1726-1730.

87. Ritter P, Nagele H, Lunati M, Silvestre J, Padeletti L, Borri A, Delnoy P. Clinical benefit of cardiac resynchronization therapy patients optimized by SonR or standard methods: final results from the CLEAR study. Europace 2010; 12 Suppl 1: i50.

88. Butter C, Stellbrink C, Belalcazar A, Villalta D, Schlegl M, Sinha A, Cuesta F, Reister C. Cardiac resynchronization therapy optimization by finger plethysmography. Heart Rhythm 2004; 1: 568-575.

89. Whinnett ZI, Davies JE, Willson K, Chow AW, Foale RA, Davies DW, Hughes AD, Francis DP, Mayet J. Determination of optimal atrioventricular delay for cardiac resynchronization therapy using acute non-invasive blood pressure. Europace 2006; 8: 358-366. 
90. Whinnett ZI, Davies JE, Nott G, Willson K, Manisty CH, Peters NS, Kanagaratnam P, Davies DW, Hughes $\mathrm{AD}$, Mayet J. Efficiency, reproducibility and agreement of five different hemodynamic measures for optimization of cardiac resynchronization therapy. Int J Cardiol 2008; 129: 216-226.

91. Eeftinck Schattenkerk D, van Lieshout J, van den Meiracker A, et al. Nexfin noninvasive continuous blood pressure validation against Riva-Rocci/Korotkoff. Am J Hypertens 2009; 22: 378-383.

92. van Geldorp IE, Delhaas T, Hermans B, Vernooy K, Broers B, Klimusina J, Regoli F, Faletra FF, Moccetti T, Gerritse B, Cornelussen R, Settels JJ, Crijns HJ, Auricchio A, Prinzen FW. Comparison of a non-invasive arterial pulse contour technique and echo Doppler aorta velocity-time integral on stroke volume changes in optimization of cardiac resynchronization therapy. Europace 2010; 13: 87-95.

93. Bhan A, Kapetanakis S, Monaghan MJ. Optimization of cardiac resynchronization therapy. Echocardiography 2008; 25: 1031-1039.

94. Bertini M, Delgado V, Bax JJ, Van de VeN. Why, how and when do we need to optimize the setting of cardiac resynchronization therapy? Europace 2009; 11 Suppl 5: v46-v57.

95. Leon AR, Abraham WT, Curtis AB, Daubert JP, Fisher WG, Gurley J, Hayes DL, Lieberman R, PetersenStejskal S, Wheelan K. Safety of transvenous cardiac resynchronization system implantation in patients with chronic heart failure: combined results of over 2,000 patients from a multicenter study program. J Am Coll Cardiol 2005; 46: 2348-2356.

96. Thomas DE, Yousef ZR, Fraser AG. A critical comparison of echocardiographic measurements used for optimizing cardiac resynchronization therapy: stroke distance is best. Eur J Heart Fail 2009; 11: 779-788.

97. Kerlan JE, Sawhney NS, Waggoner AD, Chawla MK, Garhwal S, Osborn JL, Faddis MN. Prospective comparison of echocardiographic atrioventricular delay optimization methods for cardiac resynchronization therapy. Heart Rhythm 2006; 3: 148-154.

98. Chung ES, Leon AR, Tavazzi L, Sun JP, Nihoyannopoulos P, Merlino J, Abraham WT, Ghio S, Leclercq C, Bax JJ, Yu CM, Gorcsan J 3rd, St John Sutton M, De Sutter J, Murillo J. Results of the Predictors of Response to CRT (PROSPECT) trial. Circulation 2008; 117: 2608-2616.

99. Vidal B, Sitges M, Marigliano A, Delgado V, Díaz-Infante E, Azqueta M, Tamborero D, Tolosana JM, Berruezo A, Pérez-Villa F, Paré C, Mont L, Brugada J.. Optimizing the programation of cardiac resynchronization therapy devices in patients with heart failure and left bundle branch block. Am J Cardiol 2007; 100: 1002-1006.

100. Novak M, Lipoldova J, Meluzin J, Krejcí J, Hude P, Feitová V, Dusek L, Kamarýt P, Vítovec J.. Contribution to the V-V interval optimization in patients with cardiac resynchronization therapy. Physiol Res 2008; 57: 693-700.

101. Cleland JG, Daubert JC, Erdmann E, Freemantle N, Gras D, Kappenberger L, Klein W, Tavazzi L. The CARE-HF study (CArdiac REsynchronisation in Heart Failure study): rationale, design and endpoints. Eur J Heart Fail 2001; 3: 481-489.

102. Ritter P, Lelieve T, Lavergne T. Quick determination of the optimal AV delay at rest in patients paced in DDD mode for complete AV block. Eur J Cardiac Pacing Electrophysiol 1994; 4: A163.

103. Jansen AH, Bracke FA, van Dantzig JM, Meijer A, van der Voort PH, Aarnoudse W, van Gelder BM, Peels KH. Correlation of echo-Doppler optimization of atrioventricular delay in cardiac resynchronization therapy with invasive hemodynamics in patients with heart failure secondary to ischemic or idiopathic dilated cardiomyopathy. Am J Cardiol 2006; 97: 552-557.

104. Meluzin J, Novak M, Mullerova J, Krejcí J, Hude P, Eisenberger M, Dusek L, Dvorák I, Spinarová L. A fast and simple echocardiographic method of determination of the optimal atrioventricular delay in patients after biventricular stimulation. Pacing Clin Electrophysiol 2004; 27: 58-64.

105. Tei C, Ling LH, Hodge DO, Bailey KR, Oh JK, Rodeheffer RJ, Tajik AJ, Seward JB. New index of combined systolic and diastolic myocardial performance: a simple and reproducible measure of cardiac function - a study in normals and dilated cardiomyopathy. J Cardiol 1995; 26: 357-366.

106. Porciani MC, Dondina C, Macioce R, Demarchi G, Pieragnoli P, Musilli N, Colella A, Ricciardi G, Michelucci A, Padeletti L. Echocardiographic examination of atrioventricular and interventricular delay optimization in cardiac resynchronization therapy. Am J Cardiol 2005; 95: 1108-1110. 
107. Stockburger M, Fateh-Moghadam S, Nitardy A, Langreck H, Haverkamp W, Dietz R. Optimization of cardiac resynchronization guided by Doppler echocardiography: haemodynamic improvement and intraindividual variability with different pacing configurations and atrioventricular delays. Europace 2006; 8: 881-886. 



\section{CHAPTER 8}

\section{Baseline Left Ventricular $\mathbf{d P} / \mathbf{d t}_{\max }$ rather than the Acute Improvement in $\mathbf{d P} / \mathbf{d t}_{\max }$ Predicts Clinical Outcome in Patients with Cardiac Resynchronization Therapy}

Margot D. Bogaard, Patrick Houthuizen, Frank A Bracke, Pieter A. Doevendans, Frits W. Prinzen, Mathias Meine, Berry M. van Gelder

Published in Eur J Heart Fail 2011; 13 : 1126-32 


\section{Abstract}

\section{Background}

The maximum rate of left ventricular (LV) pressure rise $\left(\mathrm{dP} / \mathrm{dt}_{\max }\right)$ has been used to assess the acute hemodynamic effect of cardiac resynchronization therapy (CRT). We tested the hypothesis that $\mathrm{LV} \mathrm{dP} / \mathrm{dt}_{\max }$ predicts long-term clinical outcome after initiation of CRT.

\section{Methods and Results}

This was a retrospective observational multicenter study in 285 patients in whom $\mathrm{dP} / \mathrm{dt}_{\max }$ was measured invasively following implantation of a CRT device. The minimum required follow-up was 1 year. We analyzed the relationship between $\mathrm{dP} / \mathrm{dt}_{\max }$ and time to the composite endpoint, consisting of all-cause mortality, heart transplantation (HTX) or LV assist device (LVAD) implantation within the first year of CRT.

Thirty-four events occurred after a mean follow-up of 160 days (range 21-359). Patients with event had lower $\mathrm{dP} / \mathrm{dt}_{\max }$ than patients without event both at baseline $(705 \pm 194 \mathrm{mmHg} / \mathrm{s}$ versus $800 \pm 222 \mathrm{mmHg} / \mathrm{s}, \mathrm{P}=0.018)$ and during CRT $(894 \pm 224$ $\mathrm{mmHg} / \mathrm{s}$ versus $985 \pm 244 \mathrm{mmHg} / \mathrm{s}, \mathrm{P}=0.033$ ), but the acute increase in $\mathrm{dP} / \mathrm{dt}_{\max }$ was similar in patients with and without event $(190 \pm 133 \mathrm{mmHg} / \mathrm{s}$ versus $185 \pm 115$ $\mathrm{mmHg} / \mathrm{s}, \mathrm{P}=\mathrm{NS}$ ). $\mathrm{LV} \mathrm{dP} / \mathrm{dt}_{\max }-$ level at baseline and during CRT both predicted the clinical outcome after adjustment for gender, etiology and New York Heart Association (NYHA) class: hazard ratio (HR) 0.791 (95\% confidence interval [95\% CI] $0.658-$ 0.950, $\mathrm{P}=0.012$ ) and HR 0.846 (95\% CI 0.723-0.991, $\mathrm{P}=0.038)$, respectively.

\section{Conclusion}

$\mathrm{LV} \mathrm{dP} / \mathrm{dt}_{\max }$ measured at baseline and during CRT are predictors of 1-year survival free from all-cause mortality, HTX or LVAD implantation, but the acute improvement in $\mathrm{dP} / \mathrm{dt}_{\max }$ is not correlated to clinical outcome. 


\section{Introduction}

Cardiac resynchronization therapy (CRT) improves morbidity and mortality in patients with symptomatic heart failure, poor left ventricular (LV) function and prolonged QRS duration. ${ }^{1,2}$ One of the ways to assess the acute hemodynamic effect of CRT is by measuring the maximum first time derivative of the LV pressure curve $\left(\mathrm{dP} / \mathrm{dt}_{\max }\right) . \mathrm{LV} \mathrm{dP} / \mathrm{dt}_{\max }$ occurs during the isovolumetric contraction period of the cardiac cycle and is regarded as a good surrogate for $\mathrm{LV}$ contractility and function. ${ }^{3,4}$ Also, $\mathrm{dP} / \mathrm{dt}_{\max }$ is known to be sensitive for asynchrony. ${ }^{5}$ Therefore it has been suggested that $\mathrm{LV} \mathrm{dP} / \mathrm{dt}_{\max }$ can aid in guiding the $\mathrm{LV}$ lead to an optimal position ${ }^{6-8}$ and optimizing the atrioventricular (AV) and interventricular (VV) delay. ${ }^{7-11}$ Whether this translates into better prognosis after CRT is unknown. Although many of the landmark CRT trials performed AV delay optimization in all patients, 1,2,12-14 a longterm beneficial effect has not been proven yet and the recently updated guidelines on device therapy in heart failure ${ }^{15}$ do not mention a statement about whether or not to perform individual optimization of CRT.

We hypothesized that the $\mathrm{LV} \mathrm{dP} / \mathrm{dt}_{\max }$ level during CRT and the acute change in $\mathrm{dP} / \mathrm{dt}_{\max }$ correlate to long-term clinical outcome after CRT and assessed whether these parameters predict 1-year risk of mortality, heart transplantation (HTX) or LV assist device (LVAD) implantation.

\section{Methods}

\section{Study design}

All patients from the University Medical Center Utrecht (UMCU) and the Catharina Hospital Eindhoven (CHE) in whom $\mathrm{LV} \mathrm{dP/dtmax} \mathrm{was} \mathrm{measured} \mathrm{for} \mathrm{AV}$ and $\mathrm{VV}$ delay optimization were included in this retrospective observational study. Patients with atrial fibrillation or AV block were also included. The composite endpoint consisted of all-cause mortality, LVAD implantation or HTX in the first year after CRT implantation. Information was collected at regular outpatient visits in the implanting hospitals, from hospital records of referring hospitals or from phone contact with patient's general practitioners. Unless an event had occurred within 1 year after CRT device implantation, patients were excluded from this analysis if follow-up data were not available up to 1 year. The UMCU is an academic hospital with facilities for LVAD implantation and HTX and CHE is a general tertiary care center. Implantations were performed between January 2002 and February 2009. All subjects gave informed consent. 


\section{Implantation}

Implantation of the CRT device was performed under local anesthesia and all leads were implanted via the cephalic and/or subclavian vein. The LV lead was aimed at a tributary of the coronary sinus overlying the LV free wall. For $\mathrm{LV} \mathrm{dP/dt}$ max measurement, a pressure wire (PressureWire ${ }^{\circledR}$ 5, St.-Jude Medical, Inc., St. Paul, MN, USA) was introduced into the LV via the femoral artery as described previously. ${ }^{8,11}$ Measurements were performed immediately following the implantation procedure or within $24 \mathrm{~h}$ after implantation. If optimization was performed after implantation, no pressure wire was placed during implantation. Patients were excluded from invasive measurement of $\mathrm{dP} / \mathrm{dt}_{\max }$ if they had a mechanical aortic valve replacement, severe aortic valve stenosis, LV thrombus, or inability to access both femoral arteries or due to logistic reasons.

\section{Left ventricular $d P / d t_{\max }$ measurement}

After a baseline measurement of $\mathrm{dP} / \mathrm{dt}_{\max }$, the acute effect of CRT on $\mathrm{dP} / \mathrm{dt}_{\max }$ was assessed. $\mathrm{LV} \mathrm{dP} / \mathrm{dt}_{\max }$ was automatically derived from continuous invasive pressure measurements digitized at $100 \mathrm{~Hz}$ (Radi Analyzer Physio Monitor v1.0 beta4, St. Jude Medical, Inc., St. Paul, MN, USA). Measurements were averaged over a 10-30 seconds (sec) period for each setting and premature ventricular beats and the first post-extrasystolic beat were manually excluded from analysis. The baseline $\mathrm{dP} / \mathrm{dt}_{\max }$ was determined during atrial pacing (in patients with sinus rhythm) or right ventricular pacing (in patients with atrial fibrillation or third degree AV block). Lower rate limit was programmed 5-10 bpm above intrinsic heart rate throughout the optimization procedure to eliminate variation in heart rate as a possible cause of $\mathrm{dP} / \mathrm{dt}_{\max }$ changes. In each patient, first the AV delay (if applicable) and then the VV delay were consecutively optimized during atrio-biventricular pacing to maximize the increase in $\mathrm{dP} / \mathrm{dt}_{\max }$ compared with baseline. The AV delay was optimized during simultaneous biventricular pacing and the VV delay was optimized at the optimal AV delay. LV $\mathrm{dP} / \mathrm{dt}_{\max }$ during active CRT (CRT $\mathrm{dP} / \mathrm{dt}_{\max }$ ) was determined during atrio-biventricular pacing with optimal AV delay (if applicable) and optimal VV delay.

\section{Statistical analysis}

Four $\mathrm{LV} \mathrm{dP} / \mathrm{dt}_{\max }$ indices were evaluated for their ability to predict clinical outcome: baseline $\mathrm{LV} \mathrm{dP} / \mathrm{dt}_{\max }$ without CRT (baseline $\mathrm{dP} / \mathrm{dt}_{\max }$ ), $\mathrm{LV} \mathrm{dP} / \mathrm{dt}_{\max } d$ uring active CRT (CRT dP/dt $\mathrm{dax}_{\text {ax }}$ ), and absolute and relative increase in $\mathrm{LV} \mathrm{dP} / \mathrm{dt}_{\max }$ achieved by CRT. $\mathrm{LV} \mathrm{dP} / \mathrm{dt}_{\max }$ was analyzed primarily as a continuous variable; for exploratory categorical analyses baseline and $\mathrm{CRT} \mathrm{dP} / \mathrm{dt}_{\max }$ were also dichotomized. Survival curves were determined according to the Kaplan-Meier method, and cumulative event rates compared by log-rank test. A separate Cox proportional hazards model was created for each $\mathrm{dP} / \mathrm{dt}_{\max }$ variable together with three other variables: ischemic etiology 
(yes/no), gender, and New York Heart Association (NYHA) functional class (IV). These variables were chosen based on previous literature. ${ }^{16,17}$ The number of variables was kept limited to assure a sufficient number of events for each independent variable. A $\log (-\log )$ plot was used for the survival analysis to validate the proportionality assumption. Hazard ratios (HR) and 95\% confidence intervals (95\% CI) are reported. Hazard ratios for $\mathrm{dP} / \mathrm{dt}_{\max }$ as continuous variable are based on incremental steps of $100 \mathrm{mmHg} / \mathrm{s}$. For exploratory purposes, additional separate analyses of the Cox proportional hazards models were performed for patients with and without atrial fibrillation.

One-year event rates were determined by dividing the number of events by the sum of all included patients. Continuous variables were expressed as mean \pm SD unless stated otherwise, and compared by independent $t$-test as appropriate. The degree of correlation between two continuous variables was assessed by Pearson's correlation coefficient. Categorical variables were summarized as frequencies and percentages and compared by two-sided Pearson $\chi^{2}$ test. Correlations of $\mathrm{dP} / \mathrm{dt}_{\max }$ values to the following variables were tested: heart failure etiology, QRS width, NYHA class, and gender. A p-value of $<0.05$ was considered significant. Data analysis was performed with SPSS 17.0 (SPSS Inc, Chicago, IL, USA).

\section{Results}

\section{Study population}

Of 411 patients who received a CRT device during the study period, $\mathrm{LV} \mathrm{dP} / \mathrm{dt}_{\max }$ was measured in 285 patients. The clinical characteristics are outlined in Table 1. Mean age was $67 \pm 10$ years, $72 \%$ of the population was male, mean QRS duration was $169 \pm 27 \mathrm{~ms}$ and $56 \%$ had heart failure of ischemic etiology. Mean $\mathrm{dP} / \mathrm{dt}_{\max }$ at baseline was $789 \pm 221 \mathrm{mmHg} / \mathrm{s}$. The activation of CRT increased $\mathrm{dP} / \mathrm{dt}_{\max }$ by $186 \pm 117$ $\mathrm{mmHg} / \mathrm{s}(26 \pm 18 \%)$.

\section{Correlates of left ventricular $d P / d t_{\max }$}

Significant correlations existed between baseline and CRT dP/dtmax (Pearson's R 0.877, $\mathrm{P}<0.001)$, baseline and relative increase in $\mathrm{dP} / \mathrm{dt}_{\max }(\mathrm{R}-0.435, \mathrm{P}<0.001)$, CRT $\mathrm{dP} / \mathrm{dt}_{\max }$ and absolute increase in $\mathrm{dP} / \mathrm{dt}_{\max }(\mathrm{R} 0.423, \mathrm{P}<0.001)$ and absolute and relative increase in $\mathrm{dP} / \mathrm{dt}_{\max }(\mathrm{R} 0.875, \mathrm{P}<0.001)$.

Patients with QRS width $\geq 150 \mathrm{~ms}$ had lower baseline $\mathrm{dP} / \mathrm{dt}_{\max }$ and showed a significantly larger absolute and relative increase in $\mathrm{dP} / \mathrm{dt}_{\max }$ (Table 2). During active CRT there was no difference in $\mathrm{dP} / \mathrm{dt}_{\max }$ between the two QRS groups. The prevalence of left bundle branch block morphology was the same in patients with QRS width $\geq 150 \mathrm{~ms}$ versus $<150 \mathrm{~ms}$ ( $77 \%$ versus $79 \%$ ). Baseline and $\mathrm{CRT} \mathrm{dP} / \mathrm{dt}_{\max }$ were 
lower in patients with non-ischemic etiology. None of the four $\mathrm{dP} / \mathrm{dt}_{\max }$ variables (baseline, during CRT, relative and absolute increase in $\mathrm{dP} / \mathrm{dt}_{\max }$ ) was significantly different between patients with NYHA class IV vs. below IV or between male versus female patients (Table 2).

Patients with an event had a significantly lower baseline $\mathrm{dP} / \mathrm{dt}_{\max }$ and CRT $\mathrm{dP} / \mathrm{dt}_{\max }$ compared with patients without event (Table 1). There was no difference in absolute or relative increase in $\mathrm{dP} / \mathrm{dt}_{\max }$ between patients with or without event. Patients with event were more often male, had a worse functional class (NYHA class IV), more often had atrial fibrillation and tended to have an ischemic etiology of heart failure more often (Table 1).

\section{Follow-up}

By design of the study, no patients were lost to follow-up in the first year after implantation. Within the first year, 34 events occurred after a mean follow-up of 160 days (range 21-359). Events represented 29 deaths, 4 HTX and 1 LVAD implantation. The principal cause of death was cardiac in 15, non-cardiac in 4, and unknown in 10. The overall one-year event rate was $11.9 \%$ and did not differ between patients with CRT-defibrillator compared with patients with CRT-pacemaker (Table 1).

\section{Predictive value of left ventricular $d P / d t_{\max }$}

In univariable analysis, baseline and $\mathrm{CRT} \mathrm{dP} / \mathrm{dt}_{\max }$ emerged as predictors of the composite endpoint with a hazard ratio of 0.812 and 0.855 , respectively, for every 100 $\mathrm{mmHg} / \mathrm{s}$ increase (Table 3). Based on the $\log (-\log )$ plot, there was no evidence that the proportional hazards assumption was violated by etiology, gender, NYHA class, or $\mathrm{dP} / \mathrm{dt}_{\text {max. }}$. In a multivariable analysis, baseline and CRT $\mathrm{dP} / \mathrm{dt}_{\max }$ also predicted the endpoint independent of heart failure etiology, gender, and NYHA class with a hazard ratio (HR) of 0.791 and 0.846 , respectively (Table 3). The absolute and relative increases in $\mathrm{dP} / \mathrm{dt}_{\max }$ achieved by CRT were not predictive of clinical outcome (unadjusted HR 1.041 and 1.011, respectively; Table 3).

Exploratory multivariable analysis of baseline and CRT $\mathrm{dP} / \mathrm{dt}_{\max }$ as a dichotomous variable revealed that patients with a baseline $\mathrm{dP} / \mathrm{dt}_{\max }<650 \mathrm{mmHg} / \mathrm{s}$ or CRT $\mathrm{dP} / \mathrm{dt}_{\max }<900 \mathrm{mmHg} / \mathrm{s}$ had lower survival rates free from the composite endpoint (HR, 3.229; 95\% confidence interval [CI], 1.604-6.498 and HR, 2.515; 95\% CI, 1.2455.078), respectively; Figure 1 and Table 3).

The prognostic value of $\mathrm{dP} / \mathrm{dt}_{\max }$ was analyzed separately for patients with atrial fibrillation ( $n=62,12$ events) and patients without atrial fibrillation (n=223, 22 events). For baseline $\mathrm{dP} / \mathrm{dt}_{\max }$ as a continuous variable the hazard ratio was similar, and for baseline $\mathrm{dP} / \mathrm{dt}_{\max }$ as a dichotomous variable the hazard ratio was higher in patients without atrial fibrillation (Table 4). The hazard ratio's for CRT $\mathrm{dP} / \mathrm{dt}_{\mathrm{max}}$, both as continuous and dichotomous variable, were closer to 1 for patients with atrial fibrillation compared to patients without atrial fibrillation (Table 4). 
Table 1. Clinical characteristics.

\begin{tabular}{llllll}
\hline & $\mathrm{n}$ & Total & $\begin{array}{l}\text { No event } \\
(\mathrm{n}=251)\end{array}$ & $\begin{array}{l}\text { Event } \\
(\mathrm{n}=34)\end{array}$ & $\mathrm{p}$ \\
\hline Age (years) & 285 & $67.1 \pm 10.1$ & $67.0 \pm 10.0$ & $68.3 \pm 11.0$ & 0.468 \\
Male (\%) & 285 & 72.3 & 70.1 & 88.2 & 0.027 \\
QRS duration (ms) & 282 & $169 \pm 27$ & $169 \pm 27$ & $170 \pm 25$ & 0.863 \\
PR duration (ms) & 192 & $195 \pm 45$ & $195 \pm 46$ & $200 \pm 40$ & 0.645 \\
LBBB / RBBB / RVP / nQRS (n) & 285 & $219 / 10 / 49 / 7$ & $190 / 10 / 45 / 6$ & $29 / 0 / 4 / 1$ & $0.213 *$ \\
Rhythm SR / AF / RVP / AP (n) † & 285 & $195 / 62 / 49 / 9$ & $175 / 50 / 45 / 7$ & $20 / 12 / 4 / 2$ & $0.041 \neq$ \\
NYHA class I / II / III / IV (n) & 284 & $8 / 17 / 209 / 50$ & $8 / 16 / 191 / 35$ & $0 / 1 / 18 / 15$ & $<0.001 \S$ \\
LVEF (\%) & 215 & $21.9 \pm 7.2$ & $22.1 \pm 7.3$ & $20.2 \pm 6.6$ & 0.213 \\
Ischemic etiology (\%) & 284 & 56.0 & 54.0 & 70.6 & 0.068 \\
LV lead position AL / L / PL / P (n) & 281 & $8 / 71 / 125 / 77$ & $7 / 60 / 113 / 68$ & $1 / 11 / 12 / 9$ & 0.737 \\
Baseline dP/dtmax (mmHg/s) & 285 & $789 \pm 221$ & $800 \pm 222$ & $705 \pm 194$ & 0.018 \\
CRT dP/dtmax (mmHg/s) & 285 & $975 \pm 243$ & $985 \pm 244$ & $894 \pm 224$ & 0.033 \\
$\Delta$ dP/dtmax (mmHg/s) & 285 & $186 \pm 117$ & $185 \pm 115$ & $190 \pm 133$ & 0.835 \\
$\Delta$ dP/dtmax (\%) & 285 & $26 \pm 18$ & $25 \pm 18$ & $29 \pm 21$ & 0.251 \\
CRT-D (\%) & 285 & 74.7 & 74.9 & 73.5 & 0.863 \\
\hline
\end{tabular}

* Proportion of patients with LBBB compared to no LBBB. $†$ The number of patients exceeds the total number of included patients due to overlap between categories. ‡ Proportion of patients with AF compared to no AF. § Proportion of patients with NYHA class IV compared to other classes. A, anterior; AF, atrial fibrillation; AL, anterolateral; AP, atrial pacing dependent; CRT-D, CRT-defibrillator; L, lateral; LVEF, LV ejection fraction; $\mathrm{nQRS}$, narrow $\mathrm{QRS}<120 \mathrm{~ms}$; $\mathrm{P}$, posterior; $\mathrm{PL}$, posterolateral; RVP, right ventricular pacing dependent; SR, sinus rhythm.

Table 2. Correlations between LV dP/dtmax and other clinical characteristics.

\begin{tabular}{|c|c|c|c|c|}
\hline & $\begin{array}{l}\text { Baseline } \mathrm{dP} / \mathrm{dt}_{\max } \\
(\mathrm{mmHg} / \mathrm{s})\end{array}$ & $\begin{array}{l}\mathrm{CRT} \mathrm{dP} / \mathrm{dt}_{\max } \\
(\mathrm{mmHg} / \mathrm{s})\end{array}$ & $\begin{array}{l}\Delta \mathrm{dP} / \mathrm{dt}_{\max } \\
(\mathrm{mmHg} / \mathrm{s})\end{array}$ & $\begin{array}{l}\Delta \mathrm{dP} / \mathrm{dt}_{\text {ma }} \\
(\%)\end{array}$ \\
\hline \multicolumn{5}{|l|}{ QRS width } \\
\hline$\geq 150 \mathrm{~ms}$ & $769 \pm 211^{*}$ & $969 \pm 241$ & $200 \pm 119 \dagger$ & $28 \pm 19 \dagger$ \\
\hline$<150 \mathrm{~ms}$ & $867 \pm 227$ & $999 \pm 235$ & $132 \pm 95$ & $16 \pm 13$ \\
\hline \multicolumn{5}{|l|}{ HF etiology } \\
\hline Ischemic & $818 \pm 224 \neq$ & $1007 \pm 249 \neq$ & $189 \pm 122$ & $25 \pm 18$ \\
\hline Non-ischemic & $752 \pm 213$ & $933 \pm 232$ & $181 \pm 111$ & $26 \pm 18$ \\
\hline \multicolumn{5}{|l|}{ NYHA class } \\
\hline 4 & $766 \pm 220$ & $960 \pm 263$ & $194 \pm 127$ & $27 \pm 19$ \\
\hline$<4$ & $791 \pm 219$ & $976 \pm 239$ & $184 \pm 115$ & $26 \pm 18$ \\
\hline \multicolumn{5}{|l|}{ Gender } \\
\hline Male & $781 \pm 222$ & $966 \pm 247$ & $185 \pm 120$ & $26 \pm 19$ \\
\hline Female & $811 \pm 220$ & $998 \pm 235$ & $187 \pm 108$ & $25 \pm 16$ \\
\hline
\end{tabular}

P-values are based on a comparison of $\mathrm{dP} / \mathrm{dt}_{\max }$ between patients classified by dichotomous clinical char-

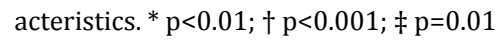


Table 3. Cox proportional hazard ratio's ( $95 \%$ confidence interval) for $\mathrm{LV} \mathrm{dP} / \mathrm{dt}_{\max }$ variables.

\begin{tabular}{|c|c|c|c|c|c|}
\hline & & Unadjusted & $\mathrm{p}$ & Adjusted* & $\mathrm{p}$ \\
\hline \multirow[t]{2}{*}{ Baseline $\mathrm{dP} / \mathrm{dt}_{\max }$} & $\begin{array}{l}\text { Continuous } \\
(100 \mathrm{mmHg} / \mathrm{s})\end{array}$ & $\begin{array}{l}0.812 \\
(0.683-0.965)\end{array}$ & 0.018 & $\begin{array}{l}0.791 \\
(0.658-0.950)\end{array}$ & 0.012 \\
\hline & $\begin{array}{l}\text { Dichotomous } \\
<650 \mathrm{mmHg} / \mathrm{s}\end{array}$ & $\begin{array}{l}3.044 \\
(1.552-5.971)\end{array}$ & 0.001 & $\begin{array}{l}3.229 \\
(1.604-6.498)\end{array}$ & 0.001 \\
\hline \multirow[t]{2}{*}{$\mathrm{CRT} \mathrm{dP} / \mathrm{dt}_{\max }$} & $\begin{array}{l}\text { Continuous } \\
(100 \mathrm{mmHg} / \mathrm{s})\end{array}$ & $\begin{array}{l}0.855 \\
(0.735-0.995)\end{array}$ & 0.043 & $\begin{array}{l}0.846 \\
(0.723-0.991)\end{array}$ & 0.038 \\
\hline & $\begin{array}{l}\text { Dichotomous } \\
<900 \mathrm{mmHg} / \mathrm{s}\end{array}$ & $\begin{array}{l}2.442 \\
(1.233-4.834)\end{array}$ & 0.010 & $\begin{array}{l}2.515 \\
(1.245-5.078)\end{array}$ & 0.010 \\
\hline$\Delta \mathrm{dP} / \mathrm{dt}_{\max }$, relative & $\begin{array}{l}\text { Continuous } \\
\text { (1 percentage point) }\end{array}$ & $\begin{array}{l}1.011 \\
(0.994-1.028)\end{array}$ & 0.218 & - & - \\
\hline$\Delta \mathrm{dP} / \mathrm{dt}_{\max }$, absolute & $\begin{array}{l}\text { Continuous } \\
(100 \mathrm{mmHg} / \mathrm{s})\end{array}$ & $\begin{array}{l}1.041 \\
(0.782-1.387)\end{array}$ & 0.782 & - & - \\
\hline
\end{tabular}

*Adjusted for: etiology, gender, NYHA class.

Table 4. Adjusted* Cox proportional hazard ratio's (95\% confidence interval) for $\mathrm{LV} \mathrm{dP}^{\mathrm{dt}} \mathrm{dt}_{\max } \mathrm{var}$ iables for patients with atrial fibrillation and patients without atrial fibrillation.

\begin{tabular}{|c|c|c|c|c|c|}
\hline & & $\begin{array}{l}\text { No atrial fibrillation } \\
\text { (n=223, } 22 \text { events) }\end{array}$ & $\mathrm{p}$ & $\begin{array}{l}\text { Atrial } \\
\text { fibrillation } \\
(n=62,12 \text { events })\end{array}$ & $\mathrm{p}$ \\
\hline \multirow[t]{2}{*}{ Baseline $\mathrm{LV} \mathrm{dP} / \mathrm{dt}_{\max }$} & $\begin{array}{l}\text { Continuous } \\
(100 \mathrm{mmHg} / \mathrm{s})\end{array}$ & $\begin{array}{l}0.772 \\
(0.614-0.971)\end{array}$ & 0.027 & $\begin{array}{l}0.779 \\
(0.532-1.140)\end{array}$ & 0.199 \\
\hline & $\begin{array}{l}\text { Dichotomous } \\
<650 \mathrm{mmHg} / \mathrm{s}\end{array}$ & $\begin{array}{l}4.730 \\
(1.860-12.033)\end{array}$ & 0.001 & $\begin{array}{l}2.264 \\
(0.664-7.718)\end{array}$ & 0.192 \\
\hline \multirow[t]{2}{*}{ CRT LV dP/dtmax } & $\begin{array}{l}\text { Continuous } \\
(100 \mathrm{mmHg} / \mathrm{s})\end{array}$ & $\begin{array}{l}0.803 \\
(0.659-0.978)\end{array}$ & 0.029 & $\begin{array}{l}0.904 \\
(0.652-1.253)\end{array}$ & 0.544 \\
\hline & $\begin{array}{l}\text { Dichotomous } \\
<900 \mathrm{mmHg} / \mathrm{s}\end{array}$ & $\begin{array}{l}3.639 \\
(1.425-9.290)\end{array}$ & 0.007 & $\begin{array}{l}1.852 \\
(0.575-5.969)\end{array}$ & 0.302 \\
\hline
\end{tabular}

*Adjusted for: etiology, gender, NYHA class.

\section{Discussion}

Our data suggest that $\mathrm{LV} \mathrm{dP} / \mathrm{dt}_{\max }$ is not only a parameter of acute hemodynamic condition, but is also related to long-term clinical outcome in CRT patients. Unlike baseline $\mathrm{dP} / \mathrm{dt}_{\max }$ or $\mathrm{dP} / \mathrm{dt}_{\max }$ during active CRT, the change in $\mathrm{dP} / \mathrm{dt}_{\max }$ (absolute or relative) achieved by initiation of CRT was not predictive of clinical outcome in the first year after CRT implantation. 

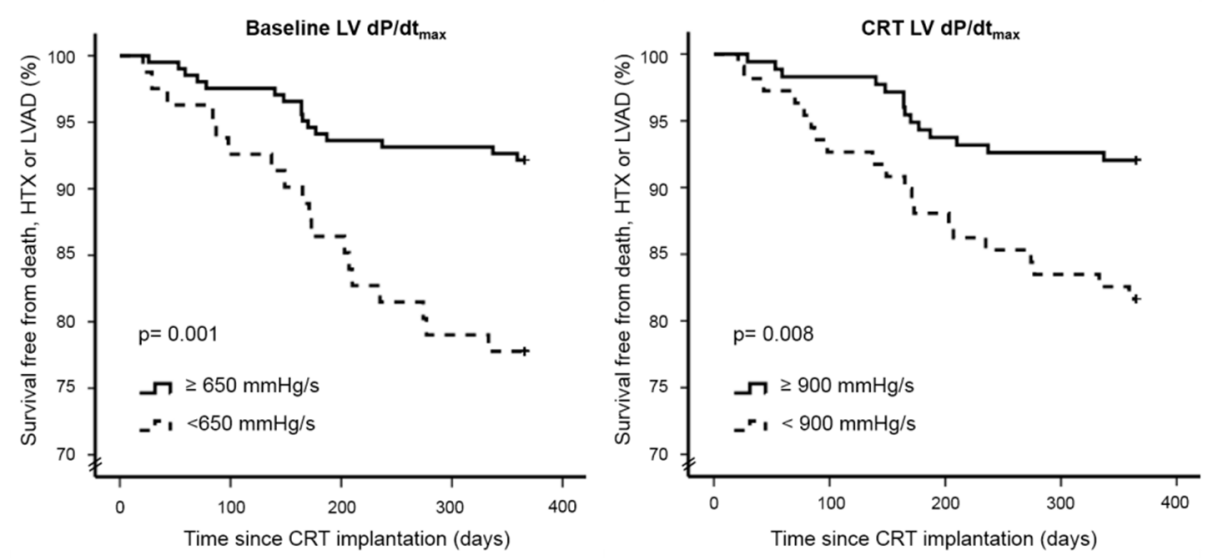

\section{Figure 1.}

Cumulative survival free from all-cause mortality, heart transplantation (HTX) or left ventricular assist device (LVAD) implantation, categorized by $\mathrm{dP} / \mathrm{dt}_{\max }$-levels at baseline and during cardiac resynchronization therapy (CRT)

Several factors may explain the lack of a correlation between acute hemodynamic improvement and long-term outcome after CRT. First of all, the total range of baseline $\mathrm{dP} / \mathrm{dt}_{\text {max }}$-levels $(95 \% \mathrm{CI}, 435-1328 \mathrm{mmHg} / \mathrm{s}$ ) is much larger than that of delta $\mathrm{dP} / \mathrm{dt}_{\max }(95 \% \mathrm{CI},-28-471 \mathrm{mmHg} / \mathrm{s})$. Therefore, a patient starting at the lower end of the spectrum will not likely be able to make it to the upper end, however good CRT is. In the absence of a matched control group in whom CRT was turned off after implantation, we cannot pass judgment on the benefit of a large systolic improvement for the prognosis of the individual patient (in other words, the CRT response). Secondly, measurement of $\mathrm{LV} \mathrm{dP} / \mathrm{dt}_{\max }$ only during resting conditions may not represent the full picture of daily life after CRT implantation. $\mathrm{LV} \mathrm{dP} / \mathrm{dt}_{\max }$ is not a fixed value that remains the same during the day and it will be influenced by changes in for example sympathetic tone and heart rate. Previously the value of measuring LV contractile reserve during exercise was emphasized ${ }^{18,19}$ and chronotropic incompetence was suggested to be a critical determinant of response to CRT. ${ }^{20}$ Therefore, additive predictive information may be gained by a combined assessment of resting and exercise $\mathrm{dP} / \mathrm{dt}_{\max }$.

In addition, the acute increase in $\mathrm{dP} / \mathrm{dt}_{\max }$ may be rather a measure of response to CRT than of prognosis per se. This corresponds to the observation that the increase in $\mathrm{dP} / \mathrm{dt}_{\max }$ was significantly higher in patients with $\mathrm{QRS}$ width $\geq 150 \mathrm{~ms}$, a patient group that is known to respond better to CRT.1,21 Previously however, CRT response as assessed by echocardiographic reverse remodeling was linked to long term outcome. ${ }^{22,23} \mathrm{~A}$ disagreement between acute hemodynamic response and reverse remodeling was observed by Mullens et al., ${ }^{24}$ who showed that in a subset of patients deleterious cardiac enlargement may occur despite a beneficial hemodynamic effect of CRT. Acute hemodynamic improvement may reflect a fundamentally 
different effect of CRT (response) than reverse remodeling. This may also be due to different timing of assessing response: while reverse remodeling is typically assessed 3-12 months after CRT, the hemodynamic response is assessed acutely after initiation of CRT and therefore does not include information on spontaneous disease progression.

Consistent with our findings, Suzuki et al. ${ }^{25}$ recently found that invasively measured $\mathrm{dP} / \mathrm{dt}_{\max }$ during CRT was a predictor of cardiac mortality and morbidity, whereas relative change in $\mathrm{dP} / \mathrm{dt}_{\max }$ was not. This study had a lower statistical power due to a smaller sample size $(n=68)$ and a low number of events $(n=14)$. Furthermore, in their study only a low proportion of patients had ischemic heart disease $(10 \%)$, and no information was given on baseline $\mathrm{dP} / \mathrm{dt}_{\max }$ values and their correlation with $\mathrm{CRT} \mathrm{dP} / \mathrm{dt}_{\max }$ and other clinical characteristics. ${ }^{25}$

In our study, analyses including $\mathrm{dP} / \mathrm{dt}_{\max }$ as a categorical variable revealed that patients with baseline $\mathrm{dP} / \mathrm{dt}_{\max } \geq 650 \mathrm{mmHg} / \mathrm{s}$ or CRT $\mathrm{dP} / \mathrm{dt}_{\max } \geq 900 \mathrm{mmHg} / \mathrm{s}$ had a significantly better clinical outcome. Previously, a binary discrimination by baseline $\mathrm{dP} / \mathrm{dt}_{\max }>700 \mathrm{mmHg} / \mathrm{s}$ was suggested to predict the acute hemodynamic response to $\mathrm{CRT},{ }^{3}$ and a threshold of $>750 \mathrm{mmHg} / \mathrm{s}$ for CRT $\mathrm{dP} / \mathrm{dt}_{\max }$ discriminated patients with higher chance of survival from cardiac death and heart failure hospitalization. ${ }^{25}$ Although the use of cut-off points may be appealing for usage in daily clinical practice, it is important to stress that $\mathrm{dP} / \mathrm{dt}_{\max }$ is fundamentally a continuous variable and these exploratory categorical analyses should be interpreted with care. Furthermore the cut-off values were based on measurements during continuous atrial pacing and may be different during intrinsic sinus rhythm.

The predictive value of $\mathrm{dP} / \mathrm{dt}_{\max }$ seemed smaller and was not statistically significant in patients with atrial fibrillation. The HRs may however have been depressed by the small number of events in a limited number of patients with atrial fibrillation.

\section{We should not yet discard left ventricular $d P / d t_{\max }$ as an optimization parameter}

This study was not designed to assess the value of $\mathrm{LV} \mathrm{dP} / \mathrm{dt}_{\max }$ as a parameter for $\mathrm{AV}$ and/or VV delay optimization and a definite answer cannot be given. However, the versatility of $\mathrm{dP} / \mathrm{dt}_{\max }$ as a parameter of $\mathrm{LV}$ function was shown in this study by its correlation to QRS width, heart failure etiology and clinical outcome after CRT. Since long, $\mathrm{dP} / \mathrm{dt}_{\max }$ has been considered a fair surrogate for contractility, although it is also influenced by altered loading conditions. ${ }^{4,26,27}$ Stroke work derived from combined measurement of LV pressure and volume (pressure-volume loops) may be considered physiologically preferable to $\mathrm{dP} / \mathrm{dt}_{\max }$ since it incorporates the $\mathrm{LV}$ function during the entire cardiac cycle ${ }^{28}$ while $\mathrm{dP} / \mathrm{dt}_{\max }$ is achieved during the isovolumetric phase of contraction. However, $\mathrm{LV} \mathrm{dP} / \mathrm{dt}_{\max }$ as a measure for the acute response to CRT has several practical advantages. It is easy to acquire using a regular pressure wire which is flexible, has a small diameter of 1 French and requires little calibration; and unlike most echocardiographic parameters, it does not require extensive training to collect and interpret $\mathrm{dP} / \mathrm{dt}$-data and the method is objective, 
avoiding observer variability. Acute increase in $\mathrm{dP} / \mathrm{dt}_{\max }$ has been frequently used as a reference to evaluate new optimization methods or to assess acute response to CRT, ${ }^{29-31}$ but a gold standard optimization parameter cannot be advised with our current knowledge.

The reasons for the lack of relation between acute $\mathrm{dP} / \mathrm{dt}_{\max }$ increase and clinical outcome in CRT patients (see above) may also apply to other hemodynamic indices. This observation does not mean that we cannot rely on $\mathrm{dP} / \mathrm{dt}_{\max }$ as a parameter for optimization of, for example, the AV delay, VV delay or LV lead position. The acute increase in $\mathrm{dP} / \mathrm{dt}_{\max }$ achieved by CRT reflects at least one aspect of CRT response, i.e. the extent of resynchronization, as has been shown in animal experiments. ${ }^{32}$

The invasive nature of $\mathrm{LV}$ pressure measurement limits its use in current daily practices. The incidence of local vascular complications at the site of puncture was not prospectively recorded in this study and was therefore not available. Local vascular complication rates of using a pressure wire in CRT patients have not been published, but will likely not exceed the complication rate of $1.6 \%$ observed after diagnostic cardiac catheterization. ${ }^{33}$ To overcome the invasive nature, it has been proposed to determine $\mathrm{dP} / \mathrm{dt}$ by echocardiography from the slope of the continuouswave Doppler signal of the mitral regurgitation jet. ${ }^{34}$ However, for this measurement, sufficient mitral regurgitation is necessary which is not the case in up to $45 \%$ of patients eligible for CRT. ${ }^{35}$ Moreover, echocardiographic $\mathrm{dP} / \mathrm{dt}$ does not represent the true peak $\mathrm{dP} / \mathrm{dt}\left(\mathrm{dP} / \mathrm{dt}_{\max }\right)$ and its timing during the cardiac cycle is different from $\mathrm{dP} / \mathrm{dt}_{\max }$.

\section{Limitations}

This study was a non-randomized retrospective observational study with concurrent limitations. Due to the absence of a control group not receiving CRT it was not possible to determine the relationship between acute increase in systolic LV function and CRT response. A prospective randomized controlled study will be needed to confirm

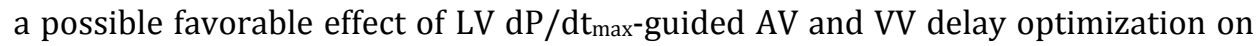
prognosis and functional status after CRT. This study only reported clinical outcome defined by mortality, HTX and LVAD implantation rate; data on reverse remodeling, major adverse cardiac events or hospitalization due to worsening heart failure were not consistently available. Whether $\mathrm{dP} / \mathrm{dt}_{\max }$ and the acute increase in $\mathrm{dP} / \mathrm{dt}_{\max }$ correlate to morbidity after CRT implantation therefore still needs to be determined. Due to the retrospective design of the study, some baseline characteristics were not available in all patients, as was shown in Table 1.

The study population was a selected group, since not all implanted patients underwent $\mathrm{AV}$ and $\mathrm{VV}$ delay optimization by $\mathrm{dP} / \mathrm{dt}_{\max }$ and were therefore not included. Reasons not to measure $\mathrm{dP} / \mathrm{dt}_{\max }$ were not prospectively collected. However, characteristics of the studied population were similar to those presented in previous CRT trials regarding distribution of age, sex and heart failure etiology. ${ }^{1,2}$ The number of 
patients with NYHA class I or II was limited. Seven patients had narrow QRS and received CRT because of the presence of echocardiographic dyssynchrony. The oneyear mortality rate after initiation of CRT in this study was $10.2 \%$, which is comparable with results of the CARE-HF (Cardiac Resynchronization in Heart Failure) trial (9.7\%) and the Comparison of Medical Therapy, Pacing and Defibrillation in Heart Failure (COMPANION) trial (12\% for CRT-defibrillator, 15\% for CRT-pacemaker). ${ }^{1,2}$

Possible variation in $\mathrm{LV} \mathrm{dP} / \mathrm{dt}_{\max }$ due to breathing pattern and varying venous return was kept limited by averaging $\mathrm{dP} / \mathrm{dt}_{\max }$ over $10-30 \mathrm{sec}$ for each pacing setting. Baseline and CRT $\mathrm{dP} / \mathrm{dt}_{\max }$ were measured once during the optimization procedure. Depending on the duration of the optimization procedure, it may be recommendable to repeat $\mathrm{dP} / \mathrm{dt}_{\max }$ measurements several times and measure the effect of different pacing settings in randomized order. To the knowledge of the authors, the variability and reproducibility of $\mathrm{dP} / \mathrm{dt}_{\max }$ have not been published yet.

\section{Conclusions}

Left ventricular $\mathrm{dP} / \mathrm{dt}_{\max }$ is an objective and versatile determinant of $\mathrm{LV}$ function and the $\mathrm{dP} / \mathrm{dt}_{\max }$-level measured at baseline or during CRT predicts 1-year survival free from all-cause mortality, HTX or LVAD implantation. The acute increase in $\mathrm{dP} / \mathrm{dt}_{\max }$ is not correlated to clinical outcome. Whether $\mathrm{dP} / \mathrm{dt}_{\max }$-guided CRT optimization improves individual outcome remains to be determined. 


\section{References}

1. Bristow MR, Saxon LA, Boehmer J, Krueger S, Kass DA, De Marco T, Carson P, DiCarlo L, DeMets D, White BG, DeVries DW, Feldman AM. Cardiac-Resynchronization Therapy with or without an Implantable Defibrillator in Advanced Chronic Heart Failure. N Engl J Med 2004; 350: 2140-2150.

2. Cleland JGF, Daubert JC, Erdmann E Freemantle N, Gras D, Kappenberger L, Tavazzi L. The Effect of Cardiac Resynchronization on Morbidity and Mortality in Heart Failure. N Engl J Med 2005; 352: 1539-1549.

3. Nelson GS, Curry CW, Wyman BT, Kramer A, Declerck J, Talbot M, Douglas MR, Berger RD, McVeigh ER, Kass DA. Predictors of Systolic Augmentation From Left Ventricular Preexcitation in Patients With Dilated Cardiomyopathy and Intraventricular Conduction Delay. Circulation 2000;101: 27032709.

4. Mason DT. Usefulness and limitations of the rate of rise of intraventricular pressure (dp-dt) in the evaluation of myocardial contractility in man. Am J Cardiol 1969;23:516-527.

5. Verbeek XA, Vernooy K, Peschar M, van der Nagel T, van Hunnik A, Prinzen FW. Quantification of interventricular asynchrony during LBBB and ventricular pacing. Am J Physiol Heart Circ Physiol 2002; 283: H1370-H1378.

6. Gold MR, Auricchio A, Hummel JD, Giudici MC, Ding J, Tockman B, Spinelli J. Comparison of stimulation sites within left ventricular veins on the acute hemodynamic effects of cardiac resynchronization therapy. Heart Rhythm 2005; 2: 376-381.

7. Butter C, Auricchio A, Stellbrink C, Fleck E, Ding J, Yu Y, Huvelle E, Spinelli J. Effect of resynchronization therapy stimulation site on the systolic function of heart failure patients. Circulation 2001; 104: 3026-3029.

8. Bogaard MD, Doevendans PA, Leenders GE, Loh P, Hauer RN, van Wessel H, Meine M. Can optimization of pacing settings compensate for a non-optimal left ventricular pacing site? Europace 2010; 12: 1262-1269.

9. Auricchio A, Stellbrink C, Block M Sack S, Vogt J, Bakker P, Klein H, Kramer A, Ding J, Salo R, Tockman B, Pochet T, Spinelli J. Effect of pacing chamber and atrioventricular delay on acute systolic function of paced patients with congestive heart failure. The Pacing Therapies for Congestive Heart Failure Study Group. The Guidant Congestive Heart Failure Research Group. Circulation 1999; 99: 29933001.

10. Auricchio A, Stellbrink C, Sack S, Block M, Vogt J, Bakker P, Huth C, Schöndube F, Wolfhard U, Böcker D, Krahnefeld O, Kirkels H. Long-term clinical effect of hemodynamically optimized cardiac resynchronization therapy in patients with heart failure and ventricular conduction delay. J Am Coll Cardiol 202; 39: 2026-2033.

11. van Gelder BM, Bracke FA, Meijer A, Lakerveld LJM, Pijls NHJ. Effect of optimizing the VV interval on left ventricular contractility in cardiac resynchronization therapy. Am J Cardiol 2004; 93: 1500-1503.

12. Abraham WT, Fisher WG, Smith AL, Delurgio DB, Leon AR, Loh E, Kocovic DZ, Packer M, Clavell AL, Hayes DL, Ellestad M, Trupp RJ, Underwood J, Pickering F, Truex C, McAtee P, Messenger J. Cardiac Resynchronization in Chronic Heart Failure. N Engl J Med 2002; 346: 1845-1853.

13. Auricchio A, Ding J, Spinelli JC, Kramer AP, Salo RW, Hoersch W, KenKnight BH, Klein HU. Cardiac resynchronization therapy restores optimal atrioventricular mechanical timing in heart failure patients with ventricular conduction delay. J Am Coll Cardiol 2002; 39: 1163-1169.

14. Cazeau S, Leclercq C, Lavergne T, Walker S, Varma C, Linde C, Garrigue S, Kappenberger L, Haywood GA, Santini M, Bailleul C, Daubert JC. Effects of Multisite Biventricular Pacing in Patients with Heart Failure and Intraventricular Conduction Delay. N Engl J Med. 2001;344:873-880.

15. Dickstein K, Vardas PE, Auricchio A, Daubert JC, Linde C, McMurray J, Ponikowski P, Priori SG, Sutton R, van Veldhuisen DJ. 2010 focused update of ESC Guidelines on device therapy in heart failure: an update of the 2008 ESC Guidelines for the diagnosis and treatment of acute and chronic heart failure and the 2007 ESC Guidelines for cardiac and resynchronization therapy. Developed with the special contribution of the Heart Failure Association and the European Heart Rhythm Association. Eur J Heart Fail 2010; 12: 1143-1153. 
16. Cleland J, Freemantle N, Ghio S, Fruhwald F, Shankar A, Marijanowski M, Verboven Y, Tavazzi L. Predicting the long-term effects of cardiac resynchronization therapy on mortality from baseline variables and the early response. A report from the CARE-HF (Cardiac Resynchronization in Heart Failure) Trial. J Am Coll Cardiol 2008; 52: 438-445.

17. Saxon LA, Bristow MR, Boehmer J, Krueger S, Kass DA, De Marco T, Carson P, DiCarlo L, Feldman AM, Galle E, Ecklund F. Predictors of sudden cardiac death and appropriate shock in the Comparison of Medical Therapy, Pacing, and Defibrillation in Heart Failure (COMPANION) Trial. Circulation 2006; 114: 2766-2772.

18. Valzania C, Gadler F, Boriani G, Eriksson MJ. Effects of cardiac resynchronization therapy on myocardial contractile reserve during exercise. Eur J Heart Fail 2011; 13: 406-411.

19. Muto C, Gasparini M, Neja CP, Iacopino S, Davinelli M, Zanon F, Dicandia C, Distefano G, Donati R, Calvi V, Denaro A, Tuccillo B. Presence of left ventricular contractile reserve predicts midterm response to cardiac resynchronization therapy--results from the LOw dose DObutamine stress-echo test in Cardiac Resynchronization Therapy (LODO-CRT) trial. Heart Rhythm 2010; 7: 1600-1605.

20. Maass AH, Buck S, Nieuwland W, Brugemann J, Van Veldhuisen DJ, Van Gelder I. Importance of heart rate during exercise for response to cardiac resynchronization therapy. J Cardiovasc Electrophysiol 2009; 20: 773-780.

21. Moss AJ, Hall WJ, Cannom DS, Klein H, Brown MW, Daubert JP, Estes NA 3rd, Foster E, Greenberg H, Higgins SL, Pfeffer MA, Solomon SD, Wilber D, Zareba W. Cardiac-Resynchronization Therapy for the Prevention of Heart-Failure Events. N Engl J Med 2009; 361: 1329-1338.

22. Foley PW, Chalil S, Khadjooi K, Irwin N, Smith RE, Levya F. Left ventricular reverse remodeling, longterm clinical outcome, and mode of death after cardiac resynchronization therapy. Eur J Heart Fail 2011; 13: 43-51.

23. Yu CM, Bleeker GB, Fung JW-H, Schalij MJ, Zhang Q, van der Wall EE, Chan YS, Kong SL, Bax JJ. Left Ventricular Reverse Remodeling but Not Clinical Improvement Predicts Long-Term Survival After Cardiac Resynchronization Therapy. Circulation 2005; 112: 1580-1586.

24. Mullens W, Verga T, Grimm RA, Starling RC, Wilkoff BL, Tang WH. Persistent hemodynamic benefits of cardiac resynchronization therapy with disease progression in advanced heart failure. J Am Coll Cardiol 2009; 53: 600-607.

25. Suzuki H, Shimano M, Yoshida Y, Inden Y, Muramatsu T, Tsuji Y, Tsuboi N, Hirayama H, Shibata R, Murohara. Maximum derivative of left ventricular pressure predicts cardiac mortality after cardiac resynchronization therapy. Clin Cardiol 2010; 33: E18-E23.

26. Kass DA, Maughan WL, Guo ZM, Kono A, Sunagawa K, Sagawa K. Comparative influence of load versus inotropic states on indexes of ventricular contractility: experimental and theoretical analysis based on pressure-volume relationships. Circulation 1987; 76: 1422-1436.

27. Carabello BA. Evolution of the study of left ventricular function: everything old is new again. Circulation 2002; 105: 2701-2703.

28. de Roest G, Knaapen P, Gotte M, Hendriks T, Allaart C, de Cock C, van Rossum A. Stroke work or systolic $\mathrm{dP} / \mathrm{dtmax}$ to evaluate acute response to cardiac resynchronization therapy: are they interchangeable? Eur J Heart Fail 2009; 11: 706-708.

29. Bordachar P, Labrousse L, Ploux S, Thambo JB, Lafitte S, Reant P, Jais P, Haissaguerre M, Clementy J, Dos Santos P. Validation of a New Noninvasive Device for the Monitoring of Peak Endocardial Acceleration in Pigs: Implications for Optimization of Pacing Site and Configuration. J Cardiovasc Electrophysiol 2008; 19: 725-729.

30. Jansen AH, Bracke FA, van Dantzig JM, Meijer A, van der Voort PH, Aarnoudse W, van Gelder BM, Peels KH. Correlation of echo-Doppler optimization of atrioventricular delay in cardiac resynchronization therapy with invasive hemodynamics in patients with heart failure secondary to ischemic or idiopathic dilated cardiomyopathy. Am J Cardiol 2006; 97: 552-557.

31. van Dijk J, Knaapen P, Russel IK, Hendriks T, Allaart CP, de Cock CC, Kamp O. Mechanical dyssynchrony by 3D echo correlates with acute haemodynamic response to biventricular pacing in heart failure patients. Europace 2008; 10: 63-68. 
32. Verbeek XAAM, Vernooy K, Peschar M, Cornelussen RNM, Prinzen FW. Intra-ventricular resynchronization for optimal left ventricular function during pacing in experimental left bundle branch block. J Am Coll Cardiol 2003; 42: 558-567.

33. Wyman RM, Safian RD, Portway V, Skillman JJ, McKay RG, Baim DS. Current complications of diagnostic and therapeutic cardiac catheterization. J Am Coll Cardiol 1988; 12: 1400-1406.

34. Bargiggia GS, Bertucci C, Recusani F, Raisaro A, de Servi S, Valdes-Cruz LM, Sahn DJ, Tronconi. A new method for estimating left ventricular $\mathrm{dP} / \mathrm{dt}$ by continuous wave Doppler-echocardiography. Validation studies at cardiac catheterization. Circulation 1989; 80: 1287-1292.

35. Tournoux FB, Alabiad C, Fan D, Chen AA, Chaput M, Heist EK, Mela T, Mansour M, Reddy V, Ruskin JN, Picard MH, Singh JP. Echocardiographic measures of acute haemodynamic response after cardiac resynchronization therapy predict long-term clinical outcome. Eur Heart J 2007; 28: 1143-1148. 



\section{CHAPTER 9}

\section{General Discussion}





\section{Introduction}

This thesis deals with the effect of left bundle branch block (LBBB) that develops during or after aortic valve interventions. The main findings of present thesis are:

- LBBB induced by transcatheter aortic valve implantation (TAVI) is an independent predictor of all-cause mortality and might neutralize the beneficial effect of valve repair.

- TAVI-induced LBBB occurs in up to $40 \%$ of the patients and develops almost always before hospital discharge. The conduction disorder is persistent in two thirds of the patients. Both LBBB before discharge and persistent LBBB are associated with an increase in mortality.

- New-onset LBBB is an infrequent complication of surgical aortic valve replacement (SAVR) occurring in less than $5 \%$ of the patients.

- Sutureless aortic valve replacement (SU AVR) is frequently complicated by new LBBB, which is persistent in the majority of patients.

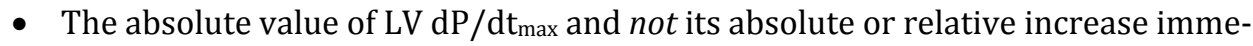
diately after onset of cardiac resynchronization therapy (CRT) predicts long-term clinical outcome.

\section{Clinical significance of transcatheter aortic valve induced left bundle branch block}

In chapter 2 we found that TAVI-induced LBBB is an independent predictor of allcause mortality after adjustment for possible confounders. In this retrospective cohort, the excess in mortality was mainly related to cardiac causes. We furthermore demonstrated that TAVI-induced LBBB which persists during follow-up (persistent LBBB) is associated with an increased mortality in univariate analysis (chapter 3). It is therefore conceivable that TAVI-induced LBBB may antagonize the survival benefit after TAVI as demonstrated in the Placement of Aortic Transcatheter Valves (PARTNER) study in which an overall reduction in mortality of $38 \%$ reduction was found in comparison to medical therapy.

Others have reported a decline in left ventricular ejection fraction (LVEF) in patients with TAVI-induced LBBB..$^{1-3}$ These observations fit with the pathophysiological concept that LBBB induces electrical (and mechanical) dyssynchrony resulting in impaired left ventricular (LV) function. Some case reports have described the occurrence of heart failure after development of TAVI-induced LBBB in patients with severely reduced LVEF. 4,5 These data are in line with the known adverse effects of LBBB in the general population or patients with cardiac disease ${ }^{6}$ and with the benefit of cardiac resynchronization therapy (CRT), indicating that LBBB is often cause and not consequence of heart failure. ${ }^{7-10}$ Since the time at which LBBB occurs is usually not known, the TAVI population may help to better understand the pathophysiological 
and prognostic effects of new LBBB in patients with normal and impaired cardiac performance, acknowledging that TAVI patients are in general older and have longlasting increased afterload exposure.

\section{Controversies about the prognostic value of TAVI-induced LBBB}

The prognostic significance of TAVI-induced LBBB is subject of debate, as our findings were not confirmed in other studies. On one hand, our findings are supported by a recent publication of Meguro et al. who demonstrated that the discharge QRSduration after TAVI was the strongest independent predictor of all-cause mortality and/or heart failure admission during follow-up. ${ }^{11}$

Urena et $a .^{2}$, on the other hand, did not find an increased mortality in patients with LBBB at hospital discharge in a study population of 202 patients receiving the Edwards SAPIEN (ES) valve. The number of patients with persistent LBBB was however low $(n=25)$ and the study was neither designed nor powered to conduct a mortality analysis. Compared to other reports, ${ }^{12}$ the rate of new LBBB was high $(30 \%)$ considering the ES device that had been used in this study. We found that the ES valve induces left anterior hemiblock (LAHB) more frequently than LBBB (chapter 3). It is therefore conceivable that in Urena's study some patients with LAHB have been categorized as LBBB. The diagnosis of LBBB can be challenging, especially in TAVI-patients with left ventricular hypertrophy, since both LAHB and LBBB lead to postoperative QRS-prolongation (chapter 3).

In another paper, Testa et al. $^{13}$ reported that LBBB was not associated with higher all-cause mortality in a population of 1,060 patients treated with the Medtronic CoreValve System (MCS) valve. Whether this is a true phenomenon or due to observational bias cannot be excluded. For instance, no information is provided on the methodology of ECG analysis. Also, the Kaplan-Meier survival curves suggest that follow-up was performed at fixed time intervals, instead of continuous monitoring. In addition, the mean QRS duration in the LBBB group was relatively low, indicating that patients without LBBB may have been included in the LBBB group. Also, the Italian registry consisted of more comorbid patients, as can be appreciated from the EUROscore, indicating that other prognostic factors may have played a more dominant role in patient's outcome. Finally, although not mentioned in the paper, a previous report from the same authors, suggest that the vendor was involved in database design and data collection. ${ }^{14}$

\section{Future research}

Available data on the prognostic impact of TAVI-induced LBBB are conflicting, urging the need for a prospective, international cohort study. This will overcome the flaws of retrospective and/or registry-based data and will provide standardized ECG analysis by a core lab. In such a study, the performance of different ECG criteria for LBBB (table 1 of chapter 1 ) can be assessed as well. 


\section{Device therapy after transcatheter aortic valve implantation}

\section{Cardiac resynchronization therapy}

According to current guidelines, cardiac resynchronization therapy (CRT) is indicated in patients with symptomatic heart failure despite optimal medical therapy, LVEF $\leq 35 \%$ and preferably LBBB. ${ }^{15}$ Still, TAVI-induced LBBB resolves in up to one third of patients after hospital discharge (chapter 3). CRT implantation in the early postoperative phase should therefore be discouraged in order to avoid unnecessary device implantation.

The majority of patients with TAVI-induced LBBB have LVEF $>35 \%$ and do not qualify for CRT implantation. Nevertheless, based on various experimental and clinical studies, the benefit of CRT does not depend on LVEF.16-18 Given the effects of TAVIinduced LBBB on left ventricular function ${ }^{1-3}$ and mortality (chapter 2 and 3), clinical and echocardiographic follow-up of these patients is warranted. In case heart failure with left ventricular dysfunction develops in presence of persistent LBBB, CRT implantation may be considered irrespective of LVEF. Some case reports have shown that TAVI-induced LBBB is an excellent substrate for CRT. 4,5

\section{Permanent pacemaker implantation}

TAVI-induced LBBB has been identified as a risk factor for high degree atrioventricular (AV)-block and postprocedural PPM implantation. ${ }^{2}$ In chapter 3 we concluded that patients receiving a PPM post-TAVI have an early mortality benefit compared to LBBB patients. This suggests that patients with TAVI-induced LBBB and PPM are protected against brady-arrhythmic death explaining the favourable early survival. However, this does not justify early PPM implantation, as some studies indicate that half of the patients who received a PPM after TAVI are not pacemaker dependent at long-term follow-up. ${ }^{19,20}$

Moreover, as has been apparent from both the Mode Selection Trial (MOST) and the Dual Chamber and VVI Implantable Defibrillator (DAVID) trial, ${ }^{21,22}$ chronic right ventricular (RV) pacing is associated with an increased risk of heart failure and cardiovascular death. This implies that TAVI-patients who are pacemaker dependent, are potentially at an increased risk. This was not confirmed by Buellesfeld et al. In a population of 353 patients receiving either the MCS or ES prosthesis, he found no difference in all-cause 1-year mortality between patients with and without postoperative PPM. ${ }^{23}$ Yet, as outlined above, up to $50 \%$ of patients are not pacemaker-dependent at follow-up. Also, almost three quarters of implants occurred within 3 days after TAVI indicating liberal or low threshold criteria for PPM indication. Moreover, the low number of patients may preclude the detection of a difference in mortality. ${ }^{24}$ The decision to implant a PPM in TAVI-patients should be based on current guidelines. ${ }^{15}$ However, in patients with reduced LVEF, the choice for a CRT-device could 
be considered given the recent insights from the randomized Biventricular versus Right Ventricular Pacing in Heart Failure Patients with Atrioventricular Block (BLOCK-HF) trial. This study demonstrated that biventricular pacing is superior to right ventricular pacing in patient with AV block, heart failure New York Heart Association (NYHA) class I to III and LVEF $\leq 50 \% .{ }^{18}$ These conditions apply for many TAVIpatients who develop a LBBB.

\section{Future research}

The cause of death in patients with TAVI-induced LBBB needs to be elucidated. In particular, a distinction between the occurrence of brady-arrhythmias and dyssynchrony-induced heart failure can help to propose recommendations whether to implant a PPM- or CRT-device. To do so, an implantable loop recorder could be used to compare the incidence of AV conduction disorders between patients with and without TAVI-induced LBBB. Echocardiography using an ultrasound contrast agent and speckle tracking analysis will allow follow-up of LV function and dyssynchrony.

\section{Frequency of TAVI-induced LBBB and timing of diagnosis}

Already with the introduction of TAVI, it was appreciated that a large amount of patients develop LBBB during or after the procedure. ${ }^{12}$ Most of the studies used the ECG at hospital discharge for the diagnosis of LBBB, thereby neglecting the possible transient character of the conduction disorder. ${ }^{12}$ In chapter 3 we confirmed that TAVIinduced LBBB is a frequent conduction disorder. Yet, we found that it has a transient character in more than one third of patients. In patients receiving the MCS, TAVIinduced LBBB had a lower tendency to resolve compared to patients with the ES valve. Also, recovery of new LBBB was seen in almost $20 \%$ of patients with new LBBB before hospital discharge. These observations might, at least partly, explain the differences in frequency of TAVI-induced LBBB between different studies since the timing of the diagnosis of LBBB is important.

\section{Mechanism and cause of transcatheter aortic valve implantation induced left bundle branch block}

\section{Interaction between patient- and device-related factors}

The pathophysiology of TAVI-induced LBBB has not been subject of our research, but several findings may help to understand the mechanism of development of LBBB. It is presumed that pressure of the lower end of the prosthesis on the left ventricular 
outflow tract (LVOT) is a causative factor. ${ }^{12,25}$ Post-mortem investigation has described microscopic injury at the site of the basal interventricular septum in patients dying from high-degree $\mathrm{AV}$-block. ${ }^{26,27}$ This concept is supported by the observation that the self-expanding MCS prosthesis results in significantly more LBBB than the ES valve (chapter 2 and 3). Also, the self-expandable Perceval S prosthesis (Sorin Biomedica Cardio Srl, Sallugia, Italy) is associated with a similar risk of LBBB induction in comparison to MCS. It is conceivable that this is because of the large cushion protruding into the LVOT, despite removal of the native valve and calcium. It suggests that valve properties rather than patient characteristics (i.e. valve calcification) play a more important and potentially causative role in the development of LBBB. Yet, other procedural factors are also involved in the mechanism of LBBB, as Nuis et al. reported that LBBB develops before the actual valve implantation in up to $50 \%$ of the patients. ${ }^{28}$ Also, the size of the valve might be important, as LBBB is proportional to the size of the ES valve (Figure 1).

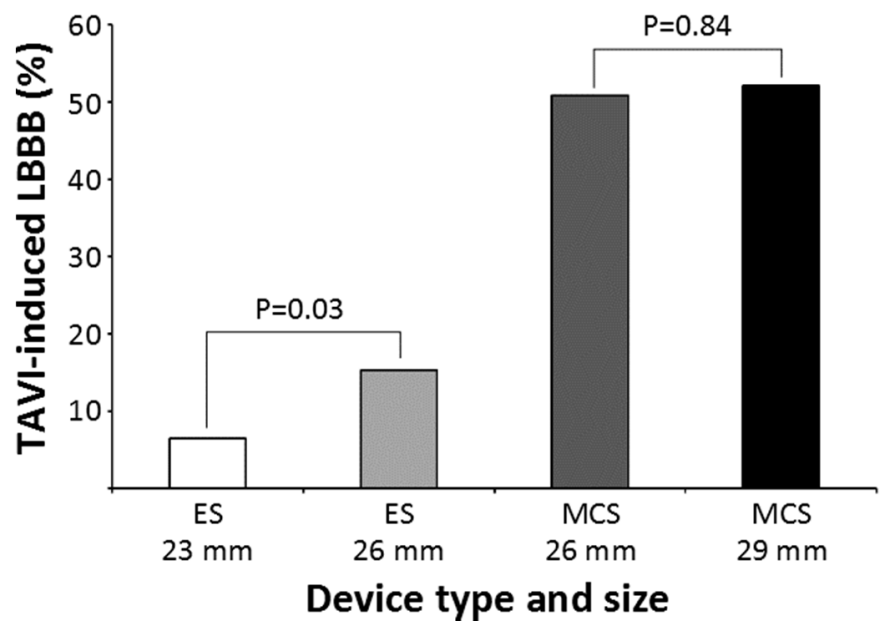

Figure 1.

Frequency of TAVI-induced LBBB comparing device type and size. ES denotes Edwards SAPIEN, MCS Medtronic CoreValve System.

\section{Experience and learning curve}

Experience and newer implantation techniques (i.e. depth of implantation ${ }^{13,29,30}$ ) may play a role in the development of LBBB, as we have described a difference in frequency of LBBB when comparing procedures before and after June 2010 in chapter 3 (Figure 2). For the MCS valve in particular, the incidence of TAVI-induced LBBB decreases over time due to less occurrence of LBBB (chapter 4), presumably due to a combination of increased experience, insight in the development of TAVI-induced conduction disorders and improved delivery systems. 


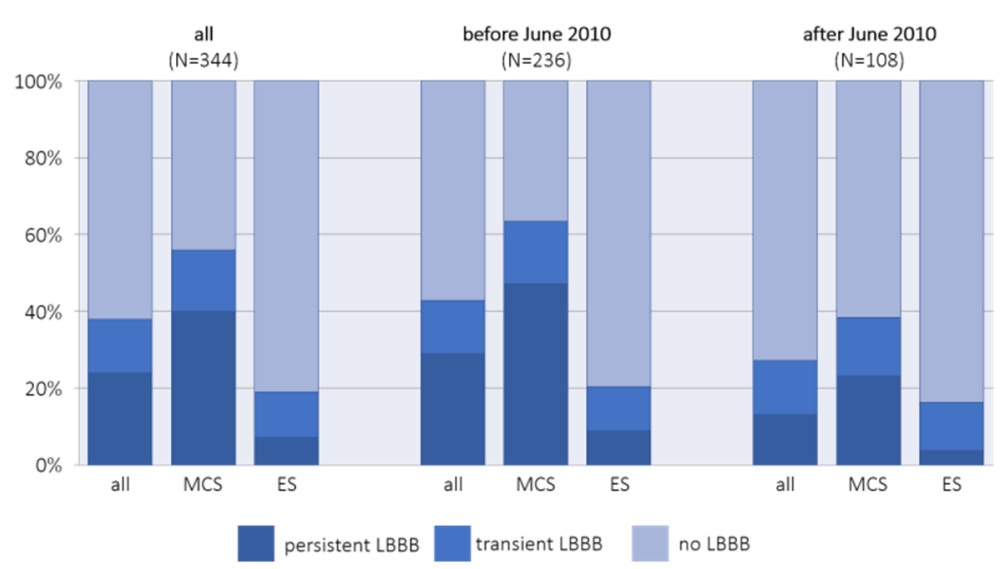

Figure 2.

Frequency of TAVI-induced LBBB comparing experience and devices. In the left pane, the frequency of left bundle branch block (LBBB) is viewed depending on the device used (MCS Medtronic CoreValve System, ES Edwards SAPIEN). The middle and right pane show the effect of experience by comparing interventions before June 2010 with those after June 2010.

\section{Surgical aortic valve implantation and left bundle branch block}

In chapter 5 we demonstrated that new LBBB after surgical aortic valve replacement (SAVR) is infrequent and not associated with an increase in all-cause mortality. However, the latter should be interpreted with caution. Indeed, the number of patients who developed LBBB was low. Moreover, the impact of LBBB on patients who underwent SAVR may be less profound, because they are younger and have less comorbidities.

As opposed to the low incidence of SAVR-induced LBBB, our early experience with the Perceval S prosthesis suggest that new LBBB occurs frequently with this device (chapter 6). In the light of the aforementioned adverse effects of TAVI-induced LBBB, larger studies with the Perceval device are needed to investigate the incidence of LBBB and its possible impact on clinical outcome.

\section{Response and long-term outcome after cardiac resynchronization therapy}

Although CRT has an established role in the treatment of heart failure, the issue of non-response remains subject of debate and controversy. It is increasingly being recognized that non-response is a sliding scale rather than a binary phenomenon with 
multiple factors being involved. CRT should be custom-made and tailored to the individual patient. ${ }^{31}$

After CRT-implantation the atrioventricular (AV) and ventriculo-ventricular (VV) interval can also be programmed to the individual patient's need. We have discussed that there is a physiological rationale to optimize the AV/VV interval, however in the broad spectrum of available optimization methods no single method can be recommended, as large-scale and randomized studies are limited (chapter 7). For automated algorithms, there are some randomized studies available, but results are variable. ${ }^{32-34}$ The conflicting evidence for $\mathrm{AV} / \mathrm{VV}$ optimization in general, might be explained by the fact that measurements are prone to a low signal-to-noise ratio. To overcome this issue, measures should be repeated, averaged and fitted to a curve in order to determine to optimal setting. ${ }^{35}$ Also, all methods lack the possibility to dynamically adjust the intervals to altering physiological circumstances, for example exercise.

The electrocardiogram is a key element for the adequate selection of patients who are potential candidates for CRT. During implantation, hemodynamic measures may, at first sight, also aid in predicting long-term response to CRT. Indeed, the acute hemodynamic response to CRT as measured by the maximum rate of rise in LV pressure ( $\left.\mathrm{LV} \mathrm{dP} / \mathrm{dt}_{\mathrm{max}}\right)$, occurs immediately and lasts as long as the therapy is delivered. ${ }^{36}$ Although it is presumed that a positive acute response translates into favourable long-term outcome, we were not able to find a relation between the acute increase in $\mathrm{LV} \mathrm{dP} / \mathrm{dt}_{\max }$ and all-cause mortality (chapter 8 ). These findings are in line with other reports, indicating that the acute, relative increase is not associated with a reduction in LV end-systolic volume (LVESV), heart failure hospitalizations and/or cardiac mortality. ${ }^{37,38}$ In contrast, Duckett et al. found that a the relative increase in LV $\mathrm{dP} / \mathrm{dt}_{\max }$ was a predictor of chronic volumetric response (as defined by a $\geq 15 \%$ increase in LVESV). ${ }^{39}$ The sample size was however small $(\mathrm{N}=32)$ and the study focussed on the predictive value of $\mathrm{LV} \mathrm{dP} / \mathrm{dt}_{\max }$ as a dichotomous variable, whereas the correlation between acute hemodynamic and long-term response was modest $(\mathrm{R}=0.6){ }^{40}$ More recently, de Roest et al. added to this controversy by their finding that the acute increase in stroke work (SW; as measured by pressure-volume loops) and not the increase in $\mathrm{LV} \mathrm{dP} / \mathrm{dt}_{\max }$ predicted long-term (volumetric) response. ${ }^{41}$ Given the accumulating evidence against $\mathrm{LV} \mathrm{dP} / \mathrm{dt}_{\max }$, this suggests that $\mathrm{SW}$ might be a better alternative to measure the acute hemodynamic response. Theoretically, this could be explained by the fact that $\mathrm{LV} \mathrm{dP} / \mathrm{dt}_{\max }$ focalizes on the isovolumetric contraction phase of systole, while SW incorporates the full cardiac cycle. Still, recording of pressure-volume loops is technically challenging and, more important, it is unclear what is being measured in dilated and dyssynchronous hearts. Indeed, pressure-volume loops measurements in these hearts result in obstinate artifacts of the signal. ${ }^{42}$ 


\section{Future perspectives}

\section{Choice of aortic valve intervention and device}

In recent years, treatment possibilities of patients with aortic valve stenosis have expanded tremendously. Beside SAVR with its inherent (peri)operative risks though excellent long-term results, alternative and less invasive therapies have become available, including the sutureless aortic valve replacement and TAVI.

The minimally invasive character and favourable results of both PARTNER trials, ${ }^{43-}$ ${ }^{46}$ have resulted in an exponential growth in the number of TAVI procedures worldwide. Although still reserved for patients who are considered too high risk for SAVR, TAVI will expand towards younger and less sick patients. Despite the apparent success, TAVI is often complicated by a number of clinical and technical complications such as paravalvular regurgitation, $\mathrm{LBBB}, \mathrm{AV}$ conduction disorders and/or stroke that all affect outcome. 45

The sutureless Perceval S aortic valve replacement is supposed to fill the gap between SAVR and TAVI by combining the advantages of native valve removal with shorter clamping time and easier implantation. ${ }^{47}$ Still, early experience demonstrates a high rate of PPM implantation and $\mathrm{LBBB}^{48,49}$ and most patients undergo full sternotomy with a cardiopulmonary bypass (chapter $\mathbf{6}$ ). This questions whether the advantages still outweigh the possible disadvantages of SAVR.

The choice for a specific operative technique and/or device should be tailored to the individual patient. SAVR remains the first choice for patients with symptomatic aortic valve stenosis due to its low complication rate. However, in eldery patients with comorbidities and/or very high operative risk, TAVI is an attractive and even preferable treatment. Given the issue of new conduction abnormalities discussed in this thesis, we believe that the choice of the prosthesis should depend on the baseline characteristics of the patient. Patients with severely reduced LV function are more vulnerable to the deleterious effects of LBBB-induced heart failure. Therefore, the use of devices and/or valve sizes with high risk of developing LBBB are to be avoided in such patients. Similarly, patients with bi- or trifascicular block at baseline are at risk for postoperative PPM implantation. ${ }^{50-52}$ A prosthesis with a low postoperative PPM implantation rate is therefore preferable.

For a surgical procedure, limited data suggest that the frequency of new LBBB (and PPM) after implantation of the Perceval S prosthesis is high. Future research has to elucidate whether this device is an alternative to classical SAVR.

\section{Device development}

Currently, a large number of new TAVI devices are entering the market. The risk of new LBBB after these prostheses are at present unknown. This thesis emphasises that recording this adverse event is of importance. 


\section{Cardiac resynchronization therapy and optimization}

Despite the apparent gap between acute hemodynamic response and long-term clinical outcome, measurement techniques like $\mathrm{LV} \mathrm{dP} / \mathrm{dt}_{\max }$ are still of clinical value. After all, the response to CRT is complex and not merely an acute phenomenon. On the long run, a reverse remodeling process is initiated that induces molecular changes. Measurement of $\mathrm{LV} \mathrm{dP} / \mathrm{dt}_{\max }$ is relatively easy, reproducible and has the advantages to guide lead implantation and/or AV and ventriculo-ventricular (VV) delay optimization. Incorporation of $\mathrm{LV} \mathrm{dP} / \mathrm{dt}_{\max }$ measurement in future devices create possibilities to dynamically adjust $\mathrm{AV}$ and $\mathrm{VV}$ delays depending on altering physiological conditions (like improvement of LV function and exercise). ${ }^{53}$ 


\section{References}

1. Tzikas A, Dalen BM van, Mieghem NM Van, Gutierrez-Chico J-L, Nuis R-J, Kauer F, Schultz C, Serruys PW, Jaegere PPT de, Geleijnse ML. Frequency of conduction abnormalities after transcatheter aortic valve implantation with the Medtronic-CoreValve and the effect on left ventricular ejection fraction. Am J Cardiol 2011; 107: 285-289.

2. Urena M, Mok M, Serra V, Dumont E, Nombela-Franco L, Delarochellière R, Doyle D, Igual A, Larose E, Amat-Santos I, Côté M, Cuéllar H, Pibarot P, Jaegere P de, Philippon F, Garcia Del Blanco B, RodésCabau J. Predictive factors and long-term clinical consequences of persistent left bundle branch block following transcatheter aortic valve implantation with a balloon-expandable valve. J Am Coll Cardiol 2012; 60: 1743-1752.

3. Hoffmann R, Herpertz R, Lotfipour S, Aktug O, Brehmer K, Lehmacher W, Autschbach R, Marx N, Lotfi S. Impact of a new conduction defect after transcatheter aortic valve implantation on left ventricular function. JACC Cardiovasc Interv 2012; 5: 1257-1263.

4. Osmancik P, Stros P, Herman D, Kocka V, Paskova E. Cardiac resynchronization therapy implantation following transcatheter aortic valve implantation. Europace 2011; 13: 290-291.

5. Meguro K, Lellouche N, Teiger E. Cardiac resynchronization therapy improved heart failure after left bundle branch block during transcatheter aortic valve implantation. J Invas Cardiol 2012; 24: 132133.

6. Zannad F, Huvelle E, Dickstein K, van Veldhuisen DJ, Stellbrink C, Køber L, Cazeau S, Ritter P, Maggioni A Pietro, Ferrari R, Lechat P. Left bundle branch block as a risk factor for progression to heart failure. Eur J Heart Fail 2007; 9: 7-14.

7. Auricchio A, Stellbrink C, Block M, Sack S, Vogt J, Bakker P, Klein H, Kramer A, Ding J, Salo R, Tockman $B$, Pochet $T$, Spinelli J. Effect of pacing chamber and atrioventricular delay on acute systolic function of paced patients with congestive heart failure. Circulation 1999; 99: 2993-3001.

8. Bristow MR, Saxon LA, Boehmer J, Krueger S, Kass DA, De Marco T, Carson P, DiCarlo L, DeMets D, White BG, DeVries DW, Feldman AM. Cardiac-resynchronization therapy with or without an implantable defibrillator in advanced chronic heart failure. $N$ Engl J Med 2004; 350: 2140-2150.

9. Abraham WT, Young JB, León AR, Adler S, Bank AJ, Hall SA, Lieberman R, Liem LB, O'Connell JB, Schroeder JS, Wheelan KR. Effects of cardiac resynchronization on disease progression in patients with left ventricular systolic dysfunction, an indication for an implantable cardioverter-defibrillator, and mildly symptomatic chronic heart failure. Circulation 2004; 110: 2864-2868.

10. Cleland JGF, Daubert J-C, Erdmann E, Freemantle N, Gras D, Kappenberger L, Tavazzi L. The effect of cardiac resynchronization on morbidity and mortality in heart failure. N Engl J Med 2005; 352: 15391549.

11. Meguro K, Lellouche N, Yamamoto M, Fougeres E, Monin J-L, Lim P, Mouillet G, Dubois-Rande J-L, Teiger E. Prognostic Value of QRS Duration After Transcatheter Aortic Valve Implantation for Aortic Stenosis Using the CoreValve. Am J Cardiol 2013; 111: 1778-1783.

12. van der Boon RM, Nuis R-J, Van Mieghem NM, Jordaens L, Rodés-Cabau J, van Domburg RT, Serruys PW, Anderson RH, de Jaegere PPT. New conduction abnormalities after TAVI-frequency and causes. Nat Rev Cardiol 2012; 9: 1-10.

13. Testa L, Agnifili M, Bedogni F, Brambilla NE, Colombo A, De Marco F, De Servi S, Ettori F, Klugmann S, Lanotte S, Latini R, Laudisa ML, Napodano M, Petronio AS, Pizzocri S, Poli A, Ramondo A, Tamburino C. Clinical impact of persistent left bundle branch block after CoreValve Revalving System implantation. Insight from a multicenter Italian registry. JACC Cardiovasc Interv 2012; 60: 2013.

14. Tamburino C, Capodanno D, Ramondo A, Petronio AS, Ettori F, Santoro G, Klugmann S, Bedogni F, Maisano F, Marzocchi A, Poli A, Antoniucci D, Napodano M, De Carlo M, Fiorina C, Ussia GP. Incidence and predictors of early and late mortality after transcatheter aortic valve implantation in 663 patients with severe aortic stenosis. Circulation 2011; 123: 299-308. 
15. Brignole M, Auricchio A, Baron-Esquivias G, Bordachar P, Boriani G, Breithardt OA, Cleland J, Deharo JC, Delgado V, Elliott PM, Gorenek B, Israel CW, Leclercq C, Linde C, Mont L, Padeletti L, Sutton R, Vardas PE; ESC Committee for Practice Guidelines (CPG), Zamorano JL, Achenbach S, Baumgartner H, Bax JJ, Bueno H, Dean V, Deaton C, Erol C, Fagard R, Ferrari R, Hasdai D, Hoes AW, Kirchhof P, Knuuti J, Kolh P, Lancellotti P, Linhart A, Nihoyannopoulos P, Piepoli MF, Ponikowski P, Sirnes PA, Tamargo JL, Tendera M, Torbicki A, Wijns W, Windecker S; Document Reviewers, Kirchhof P, Blomstrom-Lundqvist C, Badano LP, Aliyev F, Bänsch D, Baumgartner H, Bsata W, Buser P, Charron P, Daubert JC, Dobreanu D, Faerestrand S, Hasdai D, Hoes AW, Le Heuzey JY, Mavrakis H, McDonagh T, Merino JL, Nawar MM, Nielsen JC, Pieske B, Poposka L, Ruschitzka F, Tendera M, Van Gelder IC, Wilson CM. 2013 ESC Guidelines on cardiac pacing and cardiac resynchronization therapy: The Task Force on cardiac pacing and resynchronization therapy of the European Society of Cardiology (ESC). Developed in collaboration with the European Heart Rhythm Association. Eur Heart J 2013; 34: 2281-2329.

16. Vernooy K, Cornelussen RNM, Verbeek XAAM, Vanagt WYR, van Hunnik A, Kuiper M, Arts T, Crijns HJGM, Prinzen FW. Cardiac resynchronization therapy cures dyssynchronopathy in canine left bundle-branch block hearts. Eur Heart J 2007; 28: 2148-2155.

17. van Geldorp IE, Vernooy K, Delhaas T, Prins MH, Crijns HJ, Prinzen FW, Dijkman B. Beneficial effects of biventricular pacing in chronically right ventricular paced patients with mild cardiomyopathy. Europace $2010 ; 12: 223-229$.

18. Curtis AB, Worley SJ, Adamson PB, Chung ES, Niazi I, Sherfesee L, Shinn T, Sutton MSJ. Biventricular pacing for atrioventricular block and systolic dysfunction. N Engl J Med 2013; 368: 1585-1593.

19. Jilaihawi H, Chin D, Vasa-Nicotera M, Jeilan M, Spyt T, Ng GA, Bence J, Logtens E, Kovac J. Predictors for permanent pacemaker requirement after transcatheter aortic valve implantation with the CoreValve bioprosthesis. Am Heart J 2009; 157: 860-866.

20. Boon RM a van der, Mieghem NM Van, Theuns DA, Nuis R-J, Nauta ST, Serruys PW, Jordaens L, Domburg RT van, Jaegere PPT de. Pacemaker dependency after transcatheter aortic valve implantation with the self-expanding Medtronic CoreValve System. Int J Cardiol 2013; 168: 1269-1273.

21. Wilkoff BL, Cook JR, Epstein AE, Greene HL, Hallstrom AP, Hsia H, Kutalek SP, Sharma A. Dual-chamber pacing or ventricular backup pacing in patients with an implantable defibrillator: the Dual Chamber and VVI Implantable Defibrillator (DAVID) Trial. JAMA 2002; 288: 3115-3123.

22. Sweeney MO, Hellkamp AS, Ellenbogen K, Greenspon AJ, Freedman R, Lee KL, Lamas G. Adverse effect of ventricular pacing on heart failure and atrial fibrillation among patients with normal baseline QRS duration in a clinical trial of pacemaker therapy for sinus node dysfunction. Circulation 2003; 107: 2932-2937.

23. Buellesfeld L, Stortecky S, Heg D, Hausen S, Mueller R, Wenaweser P, Pilgrim T, Gloekler S, Khattab A a., Huber C, Carrel T, Eberle B, Meier B, Boekstegers P, Jüni P, Gerckens U, Grube E, Windecker S. Impact of Permanent Pacemaker Implantation on Clinical Outcome Among Patients Undergoing Transcatheter Aortic Valve Implantation. J Am Coll Cardiol 2012; 60: 493-501.

24. Houthuizen P, van Boon RM, Van Garsse LAFM, Prinzen FW, de Jaegere P. Why permanent pacemaker implantation after transcatheter aortic valve implantation does not affect long-term clinical outcome. J Am Coll Cardiol 2012; 60: 2339-2340; author reply 2340-2341.

25. Khawaja M, Rajani R, Cook A, Khavandi A, Moynagh A, Chowdhary S, Spence MS, Brown S, Khan SQ, Walker N, Trivedi U, Hutchinson N, Belder a J De, Moat N, Blackman DJ, Levy RD, Manoharan G, Roberts D, Khogali SS, Crean P, Brecker SJ, Baumbach A, Mullen M, Laborde J-C, Hildick-Smith D. Permanent pacemaker insertion after CoreValve transcatheter aortic valve implantation: incidence and contributing factors (the UK CoreValve Collaborative). Circulation 2011; 123: 951-960.

26. Sinhal A, Altwegg L, Pasupati S, Humphries KH, Allard M, Martin P, Cheung A, Ye J, Kerr C, Lichtenstein $\mathrm{S}$ V, Webb JG. Atrioventricular block after transcatheter balloon expandable aortic valve implantation. JACC Cardiovasc Interv 2008; 1: 305-309.

27. Nietlispach F, Webb JG, Ye J, Cheung A, Lichtenstein S V, Carere RG, Gurvitch R, Thompson CR, Ostry AJ, Matzke L, Allard MF. Pathology of transcatheter valve therapy. JACC Cardiovasc Interv 2012; 5: 582-590. 
28. Nuis R-J, Van Mieghem NM, Schultz CJ, Tzikas A, van der Boon RM, Maugenest A-M, Cheng J, Piazza N, van Domburg RT, Serruys PW, de Jaegere PP. Timing and potential mechanisms of new conduction abnormalities during the implantation of the Medtronic CoreValve System in patients with aortic stenosis. Eur Heart J 2011; 32: 2067-2074.

29. Piazza N, Onuma Y, Jesserun E, Kint PP, Maugenest A-M, Anderson RH, de Jaegere PPT, Serruys PW. Early and persistent intraventricular conduction abnormalities and requirements for pacemaking after percutaneous replacement of the aortic valve. JACC Cardiovasc Interv 2008; 1: 310-316.

30. Baan J, Yong ZY, Koch KT, Henriques JPS, Bouma BJ, Vis MM, Cocchieri R, Piek JJ, de Mol BAJM. Factors associated with cardiac conduction disorders and permanent pacemaker implantation after percutaneous aortic valve implantation with the CoreValve prosthesis. Am Heart J 2010; 159: 497-503.

31. Prinzen FW, Vernooy K, Auricchio A. Cardiac resynchronization therapy - state-of-the-art of current applications, guidelines, ongoing trials and areas of controversy. Circulation 2013; 128: 2407-2418.

32. Abraham WT, Gras D, Yu CM, Guzzo L, Gupta MS. Results from the Freedom trial - assess the safety and efficacy of frequent optimization of cardiac resynchronization therapy. Heart Rhythm 2010; 7 Suppl 5: 2-3.

33. Ritter P1, Delnoy PP, Padeletti L, Lunati M, Naegele H, Borri-Brunetto A, Silvestre J. A randomized pilot study of optimization of cardiac resynchronization therapy in sinus rhythm patients using a peak endocardial acceleration sensor versus standard methods. Europace 2012; 14: 1324-1333.

34. Ellenbogen KA, Gold MR, Meyer TE, Fernndez Lozano I, Mittal S, Waggoner AD, Lemke B, Singh JP, Spinale FG, Van Eyk JE, Whitehill J, Weiner S, Bedi M, Rapkin J, Stein KM. Primary results from the SmartDelay determined AV optimization: a comparison to other AV delay methods used in cardiac resynchronization therapy (SMART-AV) trial: a randomized trial comparing empirical, echocardiography-guided, and algorithmic atrioventricular delay programming in cardiac resynchronization therapy. Circulation 2010; 122: 2660-2668.

35. Pabari PA, Willson K, Stegemann B, van Geldorp IE, Kyriacou A, Moraldo M, Mayet J, Hughes AD, Francis DP. When is an optimization not an optimization? Evaluation of clinical implications of information content (signal-to-noise ratio) in optimization of cardiac resynchronization therapy, and how to measure and maximize it. Heart Fail Rev 2011; 16: 277-290.

36. Prinzen FW, Auricchio A. The "missing" link between acute hemodynamic effect and clinical response. J Cardiovasc Trans Res 2012; 5: 188-195.

37. Stellbrink C, Breithardt O-A, Franke A, Sack S, Bakker P, Auricchio A, Pochet T, Salo R, Kramer A, Spinelli J. Impact of cardiac resynchronization therapy using hemodynamically optimized pacing on left ventricular remodeling in patients with congestive heart failure and ventricular conduction disturbances. J Am Coll Cardiol 2001; 38: 1957-1965.

38. Suzuki H, Shimano M, Yoshida Y, Inden Y, Muramatsu T, Tsuji Y, Tsuboi N, Hirayama H, Shibata R, Murohara T. Maximum derivative of left ventricular pressure predicts cardiac mortality after cardiac resynchronization therapy. Clin Cardiol 2010; 33: E18-E23.

39. Duckett SG, Ginks M, Shetty AK, Bostock J, Gill JS, Hamid S, Kapetanakis S, Cunliffe E, Razavi R, CarrWhite G, Rinaldi CA. Invasive acute hemodynamic response to guide left ventricular lead implantation predicts chronic remodeling in patients undergoing cardiac resynchronization therapy.JAm Coll Cardiol 2011; 58: 1128-1136.

40. Prinzen FW, Houthuizen P, Bogaard MD, van Gelder B, Bracke F, Cramer MJM, Leenders GE, Meine M. Is acute hemodynamic response a predictor of long-term outcome in cardiac resynchronization therapy? J Am Coll Cardiol 2012; 59: 1198; author reply 1198-9.

41. de Roest GJ, Allaart CP, Kleijn SA, Delnoy PPHM, Wu L, Hendriks ML, Bronzwaer JGF, van Rossum AC, de Cock CC. Prediction of long-term outcome of cardiac resynchronization therapy by acute pressure-volume loop measurements. Eur J Heart Fail 2013; 15: 299-307.

42. Mafi Rad M, Blaauw Y, Prinzen FW, Vernooy K. The role of acute invasive haemodynamic measurements in cardiac resynchronization therapy: looping towards prediction of long-term response and therapy optimization. Eur J Heart Fail 2013; 15: 247-249. 
43. Leon MB, Smith CR, Mack M, Miller DC, Moses JW, Svensson LG, Tuzcu EM, Webb JG, Fontana GP, Makkar RR, Brown DL, Block PC, Guyton RA, Pichard AD, Bavaria JE, Herrmann HC, Douglas PS, Petersen JL, Akin JJ, Anderson WN, Wang D, Pocock S. Transcatheter aortic-valve implantation for aortic stenosis in patients who cannot undergo surgery. N Engl J Med 2010; 363: 1597-1607.

44. Smith CR, Leon MB, Mack MJ, Miller DC, Moses JW, Svensson LG, Tuzcu EM, Webb JG, Fontana GP, Makkar RR, Williams M, Dewey T, Kapadia S, Babaliaros V, Thourani VH, Corso P, Pichard AD, Bavaria JE, Herrmann HC, Akin JJ, Anderson WN, Wang D, Pocock SJ. Transcatheter versus surgical aorticvalve replacement in high-risk patients. $N$ Engl J Med 2011; 364: 2187-2198.

45. Kodali SK, Williams MR, Smith CR, Svensson LG, Webb JG, Makkar RR, Fontana GP, Dewey TM, Thourani VH, Pichard AD, Fischbein M, Szeto WY, Lim S, Greason KL, Teirstein PS, Malaisrie SC, Douglas PS, Hahn RT, Whisenant B, Zajarias A, Wang D, Akin JJ, Anderson WN, Leon MB. Two-Year Outcomes after Transcatheter or Surgical Aortic-Valve Replacement. N Engl J Med 2012; 366: 16861695.

46. Makkar RR, Fontana GP, Jilaihawi H, Kapadia S, Pichard AD, Douglas PS, Thourani VH, Babaliaros VC, Webb JG, Herrmann HC, Bavaria JE, Kodali S, Brown DL, Bowers B, Dewey TM, Svensson LG, Tuzcu M, Moses JW, Williams MR, Siegel RJ, Akin JJ, Anderson WN, Pocock S, Smith CR, Leon MB. Transcatheter Aortic-Valve Replacement for Inoperable Severe Aortic Stenosis. N Engl J Med 2012; 366: 16961704.

47. D’Onofrio A, Messina A, Lorusso R, Alfieri OR, Fusari M, Rubino P, Rinaldi M, Bartolomeo R Di, Glauber $M$, Troise G, Gerosa G. Sutureless aortic valve replacement as an alternative treatment for patients belonging to the "gray zone" between transcatheter aortic valve implantation and conventional surgery: A propensity-matched, multicenter analysis. J Thor Cardiovasc Surg 2012; 144: 1010-1018.

48. Huynh H, Dalloul G, Ghanbari H, Burke P, David M, Daccarett M, Machado C, David S. Permanent pacemaker implantation following aortic valve replacement: current prevalence and clinical predictors. Pacing Clin Electrophysiol 2009; 32: 1520-1525.

49. Aymard T, Kadner A, Walpoth N, Göber V, Englberger L, Stalder M, Eckstein F, Zobrist C, Carrel T. Clinical experience with the second-generation $3 \mathrm{f}$ Enable sutureless aortic valve prosthesis. J Thor Cardiovasc Surg 2010; 140: 313-316.

50. Erkapic D, Kim WK, Weber M, Möllmann H, Berkowitsch A, Zaltsberg S, Pajitnev DJ, Rixe J, Neumann T, Kuniss M, Sperzel J, Hamm CW, Pitschner HF. Electrocardiographic and further predictors for permanent pacemaker requirement after transcatheter aortic valve implantation. Europace 2010; 12: 1188-1190.

51. Ferreira ND, Caeiro D, Adão L, Oliveira M, Gonçalves H, Ribeiro J, Teixeira M, Albuquerque A, Primo J, Braga P, Simões L, Ribeiro VG. Incidence and predictors of permanent pacemaker requirement after transcatheter aortic valve implantation with a self-expanding bioprosthesis. Pacing Clin Electrophysiol 2010; 33: 1364-1372.

52. Roten L, Wenaweser P, Delacrétaz E, Hellige G, Stortecky S, Tanner H, Pilgrim T, Kadner A, Eberle B, Zwahlen M, Carrel T, Meier B, Windecker S. Incidence and predictors of atrioventricular conduction impairment after transcatheter aortic valve implantation. Am J Cardiol 2010; 106: 1473-1480.

53. Houthuizen P, Bracke FALE, van Gelder BM. Atrioventricular and interventricular delay optimization in cardiac resynchronization therapy: physiological principles and overview of available methods. Heart Fail Rev 2011; 16: 263-276. 

Addendum 



\section{The transcatheter valve revolution: time for a compensatory pause.}

Welt FGP, Davidson MJ, Eisenhauer AC. Circulation 2012; 126: 674-676.

\section{Editorial to}

Houthuizen P, Van Garsse LAFM, Poels TT, de Jaegere P, van der Boon RM, Swinkels $\mathrm{BM}$, ten Berg JM, van der Kley F, Schalij MJ, Cocchieri R, Brueren BRG, van Straten AHM, den Heijer P, Bentala M, van Ommen V, Kluin J, Stella PR, Prins MH, Maessen JG, Prinzen FW. Left bundle-branch block induced by transcatheter aortic valve implantation increases risk of death. Circulation 2012; 126: 720-708.

The last 2 years have seen a torrent of information regarding transcatheter aortic valve replacement (TAVR), and it is no exaggeration to say that this compelling technology has revolutionized our approach to treatment of valvular aortic stenosis. High-risk and inoperable patients heretofore relegated to minimally effective medical therapies have been offered a return to activity and, in some cases, a longer life.1,2

Yet, not all the news is good. Although the rate of vascular complications has subsided with lower profile tools and increased experience, the incidents of such complications remain vexingly high. Similarly, stroke rates hover around 5\%, with some data suggesting they are higher than the risk associated with conventional surgery. ${ }^{3}$ Earlier this year, data emerged that even mild paravalvular leak (a common occurrence postimplantation) was associated with considerably worse outcome. ${ }^{4}$ Finally, the durability of these valves remains undetermined.

All of these issues gain additional import when seen in the context of the explosive growth of this procedure. An estimated 40,000 to 50,000 cases have been performed worldwide, with the majority being in Europe. In Germany, where the most enthusiastic adoption has taken place, reports are that $\approx 30 \%$ of valves implanted are via a transcatheter route. In the United States, we have just seen the approval of the device for commercial use in inoperable patients. Adoption is much more conservative at present, but growing.

In addition to the complications noted above, and germane to this editorial, there has been a well-recognized incidence of conduction system disturbance in patients post-TAVR. Although it has been assumed by many that this is a nuisance phenomena simply requiring the insertion of a permanent pacemaker in those with high-degree AV block, evidence presented by Prinzen and colleagues 5 in this issue of Circulation shows that new left bundle-branch block (LBBB) induced by TAVR is associated with 
increased mortality with a hazard ratio of 1.54 and an absolute increase in mortality of $13.8 \%$ at 450 days. Although this has prognostic significance, this finding also raises several fundamental questions about this specific condition and about the field in general that can only be answered by further investigation.

\section{Mechanistic questions}

That LBBB should be associated with higher mortality should be of little surprise to the clinician because there is abundant evidence that in a wide variety of clinical scenarios, including asymptomatic patients without known cardiovascular disease, LBBB is consistently found to be a potent risk factor for death. ${ }^{6}$ Whether this is simply a marker for increased risk or causative cannot be answered definitively by the current study. However, the authors found that the increased mortality is cardiac in nature and not sudden, suggesting that a possible mechanism is dyssynchronyinduced left ventricular dysfunction. A correlation between higher rate of LBBB after TAVR and of need for permanent pacemaker implantation has been documented in prior registries, ${ }^{7}$ but a specific connection with mortality in this group has not been previously identified. Presumably, impingement of the prosthesis on the conduction system is the specific causative event.

Mechanistic insight is more than an academic question both in terms of the importance for patients currently being treated and the ramifications for device development moving forward. If bradyarrhythmias are the culprit for associated mortality, then it would be reasonable to assume that pacemaker therapy would be the solution. However, if cardiac dyssynchrony is responsible, it is much more problematic to assume that cardiac resynchronization therapy would restore longevity. Current guidelines suggest that the greatest benefit of cardiac resynchronization therapy is in patients with advanced heart failure, reduced $(<35 \%)$ left ventricular ejection fraction, and LBBB with a prolonged QRS (>120 ms). ${ }^{8}$ Recent meta-analysis suggests that real benefit is restricted to those patients with a QRS $150 \mathrm{~ms} .{ }^{9}$ The baseline ejection fraction of the population studied in the report of Prinzen and colleagues ${ }^{5}$ was less than $50 \%$ in only $\sim 29 \%$ of patients developing new LBBB and the QRS length in those patients ranged from 140-162 msec suggesting that the vast majority of patients with new LBBB would not fall into a previously identified subgroup that would reasonably expect symptomatic or mortality benefit. Although case reports have suggested clinical improvement after cardiac resynchronization therapy for LBBB postTAVR, ${ }^{10}$ this benefit cannot yet be generalized to this population. In addition, there are issues of both cost and incremental risk that would need to be taken into consideration for patients requiring an additional invasive procedure.

\section{Device comparisons}

Undoubtedly, what will receive the most interest is the fact that there was a much higher incidence of induced LBBB among patients treated with the Medtronic 
CoreValve device compared with the Edwards Sapien device. We do not have the benefit of head-to-head randomized trials to understand the relative strengths and weaknesses of the devices as they now exist. A recent meta-analysis of 3,519 patients from 16 studies using both the Edwards and Medtronic devices found rates of permanent pacemaker implantation of $4.9 \%$ versus $28.9 \%$, respectively, which was a statistically significant finding. ${ }^{11}$ The generally accepted reason for a higher rate of conduction system disorders with the Medtronic device is that it often extends deeper within the outflow tract and applies constant outward radial pressure as a result of its self-expanding platform.

The most obvious conclusion, but potentially incorrect, is to assume that this represents a sign of superiority of one device over the other. This study cannot answer that question. Rather, we suggest that the study illustrates that there are likely significant differences in clinical performance of the valves that follow from their different materials, design, and methods of insertion. Furthermore, the authors illustrate a phenomenon of a learning curve with the Medtronic CoreValve device in which the incidence of LBBB falls with increased experience. This observation, coupled with previous data showing that many patients develop LBBB before actual insertion of the valve, ${ }^{12}$ suggests that the valve itself may not be the predominant cause of conduction system defects but rather the method of insertion. It is certainly possible that there are other substantive differences in clinical performance between the 2 valves that would favor one over the other in certain clinical circumstances. An obvious comparison can be made with the decision regarding the selection of surgical aortic valve replacement between bioprosthetic and mechanical valves. Although one of the few trials showed a long-term survival advantage of mechanical valves (resulting from earlier valve failure of bioprostheses), this came at a cost of a higher rate of bleeding. ${ }^{13}$ Thus, for older patients who have shorter expected survival and higher risks of bleeding, bioprosthetic valves, despite their lesser durability, are more commonly implanted.

\section{Lessons from the surgical experience}

There are few data in the surgical literature to shed light on the particular question of procedure-induced LBBB. Early experience with surgical valve replacement suggested that LBBB was a relatively frequent complication of surgery, with an incidence as high as $32 \%,{ }^{14}$ whereas a more recent study by El-Khally et al ${ }^{15}$ demonstrated a much lower rate at $\sim 6 \%$. This single-center experience suggested that new LBBB after surgical AVR was associated with a high adverse event rate postoperatively. Although a higher incidence of death has been associated with new LBBB, most of the reported deaths were sudden and presumed to be associated with a high-degree AV block. 14 Only one study has compared new conduction delay rates after transcatheter versus surgical AVR. Although limited by its nonrandomized design and small sample size, this report suggested that new and persistent conduction delay rates are lower (12\% versus $28 \%$ ) in surgical versus transcatheter patients. ${ }^{16}$ 
There is more to be learned from the surgical experience when the field is examined from a broader perspective. Prospective randomized trials of surgical valves are relatively few in number. In the early days of surgical valve replacement, it was assumed to be essentially unethical to randomize patients with severe AS to medical therapy given the dismal natural history of untreated critical AS. Accordingly, the mortality advantage conferred by surgical valve replacement has been studied only in nonrandomized and retrospective studies. Even the randomized trials of mechanical versus bioprosthetic valves have been greeted by many with suspicion. A rather remarkable discussion documented in the "Sounding Board" of the New England Journal of Medicine in 1979 suggested that randomized trials were of limited value in the realm of surgical procedures and that "the referring physician is ... the surgeon's Food and Drug Administration," as poor results would be greeted by fewer referrals. ${ }^{17}$ In the same piece and speaking of the Veterans Administration randomized study comparing the efficacy of different prosthetic valves, it was said that "one might question a plan to offer different prostheses to randomized patients who might best be served by a particular prosthesis," suggesting what could be called a proceduralist knows best policy. One could hardly imagine such a conversation in today's highly regulated environment, where we are increasingly being confronted with randomized data questioning the relative lack of benefit of many of the invasive procedures that have become so common in cardiology and cardiac surgery.

\section{The way forward}

So how should we react to the finding that acquired LBBB during TAVR is frequent and associated with worse mortality? What are we to make of this finding, how should it inform our current practice, and what is needed to resolve uncertainty moving forward? The prognostic importance of a factor that is induced by the procedure is of inherently little value in patient selection unless there are other predictive features that can be identified and, unfortunately, none are suggested in this report. However, this study should spur further investigation into the patient characteristics that predict this outcome, to therapies that can mitigate the increased mortality, and to device design modifications that cause fewer conduction system disorders.

These issues are increasingly important in the era of commercialization and rapid increased use of this technology. The danger, of course, is that the spectacular results of the tightly controlled early randomized trials will fail to be reproduced when applied to a broader uncontrolled population. Findings such as those reported by Prinzen and colleagues ${ }^{5}$ are a constant reminder of the knowledge gaps present in this relatively nascent technology now being applied to an increasingly sick and complex patient population. This and other issues are unlikely to be resolved without eventually conducting further investigations including randomized, head-to-head trials of devices. 


\section{References}

1. Leon MB, Smith CR, Mack M, Miller DC, Moses JW, Svensson LG, Tuzcu EM, Webb JG, Fontana GP, Makkar RR, Brown DL, Block PC, Guyton RA, Pichard AD, Bavaria JE, Herrmann HC, Douglas PS, Petersen JL, Akin JJ, Anderson WN, Wang D, Pocock S, PARTNER Trial Investigators. Transcatheter aortic-valve implantation for aortic stenosis in patients who cannot undergo surgery. N Engl J Med 2010; 363: 1597-1607.

2. Smith CR, Leon MB, Mack MJ, Miller DC, Moses JW, Svensson LG,Tuzcu EM, Webb JG, Fontana GP, Makkar RR, Williams M, Dewey T, Kapadia S, Babaliaros V, Thourani VH, Corso P, Pichard AD, Bavaria JE, Herrmann HC, Akin JJ, Anderson WN, Wang D, Pocock SJ, PARTNER Trial Investigators. Transcatheter versus surgical aortic-valve replacement in high-risk patients. N Engl J Med 2011; 364: 21872198.

3. Miller DC, Blackstone EH, Mack MJ, Svensson LG, Kodali SK, Kapadia S, Rajeswaran J, Anderson WN, Moses JW, Tuzcu EM, Webb JG, Leon MB, Smith CR, PARTNER Trial Investigators and Patients, PARTNER Stroke Substudy Writing Group and Executive Committee. Transcatheter (TAVR) versus surgical (AVR) aortic valve replacement: occurrence, hazard, risk factors, and consequences of neurologic events in the PARTNER trial. J Thorac Cardiovasc Surg 2012; 143: 832-843.

4. Kodali SK, Williams MR, Smith CR, Svensson LG, Webb JG, Makkar RR, Fontana GP, Dewey TM, Thourani VH, Pichard AD, Fischbein M, Szeto WY, Lim S, Greason KL, Teirstein PS, Malaisrie SC, Douglas PS, Hahn RT, Whisenant B, Zajarias A, Wang D, Akin JJ, Anderson WN, Leon MB, PARTNER Trial Investigators. Two-year outcomes after transcatheter or surgical aortic-valve replacement. $N$ Engl J Med 2012; 366: 1686-1695.

5. Houthuizen P, Van Garsse LAFM, Poels TT, de Jaegere P, van der Boon RMA, Swinkels BM, ten Berg JM, van der Kley F, Schalij MJ, Baan J, Cocchieri R, Brueren GRG, van Straten AHM, den Heijer P, Bentala M, van Ommen V, Kluin J, Stella PR, Prins MH, Maessen JG, Prinzen FW. Left bundle-branch block induced by transcatheter aortic valve implantation increases risk of death. Circulation 2012; 126: 720-728.

6. Miller WL, Ballman KV, Hodge DO, Rodeheffer RJ, Hammill SC. Risk factor implications of incidentally discovered uncomplicated bundle branch block. Mayo Clin Proc 2005; 80: 1585-1590.

7. Aktug O, Dohmen G, Brehmer K, Koos R, Altiok E, Deserno V, Herpertz R, Autschbach R, Marx N, Hoffmann R. Incidence and predictors of left bundle branch block after transcatheter aortic valve implantation. Int J Cardiol 2011; 160: 26-30.

8. Epstein AE, Dimarco JP, Ellenbogen KA, Estes NA, III, Freedman RA, Gettes LS, Gillinov AM, Gregoratos G, Hammill SC, Hayes DL, Hlatky MA, Newby LK, Page RL, Schoenfeld MH, Silka MJ, Stevenson LW, Sweeney MO, American College of Cardiology/American Heart Association Task Force on Practice, American Association for Thoracic Surgery, Society of Thoracic Surgeons. ACC/AHA/HRS 2008 guidelines for device-based therapy of cardiac rhythm abnormalities: executive summary. Heart Rhythm 2008; 5: 934-955.

9. Sipahi I, Chou JC, Hyden M, Rowland DY, Simon DI, Fang JC. Effect of QRS morphology on clinical event reduction with cardiac resynchronization therapy: meta-analysis of randomized controlled trials. Am Heart J 2012; 163: 260-267.

10. 10. Meguro K, Lellouche N, Teiger E. Cardiac resynchronization therapy improved heart failure after left bundle branch block during transcatheter aortic valve implantation. J Invasive Cardiol. 2012;24:132-133.

11. Genereux P, Head SJ, Van Mieghem NM, Kodali S, Kirtane AJ, Xu K, Smith C, Serruys PW, Kappetein AP, Leon MB. Clinical outcomes after transcatheter aortic valve replacement using valve academic research consortium definitions: a weighted meta-analysis of 3,519 patients from 16 studies. $\mathrm{J} \mathrm{Am}$ Coll Cardiol 2012; 59: 2317-2326.

12. Nuis RJ, Van Mieghem NM, Schultz CJ, Tzikas A, van der Boon RM, Maugenest AM, Cheng J, Piazza N, van Domburg RT, Serruys PW, de Jaegere PP. Timing and potential mechanisms of new conduction abnormalities during the implantation of the Medtronic CoreValve System in patients with aortic stenosis. Eur Heart J 2011; 32: 2067-2074. 


\section{ADDENDUM}

13. 13. Hammermeister K, Sethi GK, Henderson WG, Grover FL, Oprian C, Rahimtoola SH. Outcomes 15 years after valve replacement with a mechanical versus a bioprosthetic valve: final report of the Veterans Affairs randomized trial. J Am Coll Cardiol 2000; 36: 1152-1158.

14. Thomas JL, Dickstein RA, Parker FB Jr, Potts JL, Poirier RA, Fruehan CT, Eich RH. Prognostic significance of the development of left bundle conduction defects following aortic valve replacement. $J$ Thorac Cardiovasc Surg 1982; 84: 382-386.

15. El-Khally Z, Thibault B, Staniloae C, Theroux P, Dubuc M, Roy D, Guerra P, Macle L, Talajic M. Prognostic significance of newly acquired bundle branch block after aortic valve replacement. Am J Cardiol 2004; 94: 1008-1011.

16. Roten L, Stortecky S, Scarcia F, Kadner A, Tanner H, Delacretaz E, Meier B, Windecker S, Carrel T, Wenaweser P. Atrioventricular conduction after transcatheter aortic valve implantation and surgical aortic valve replacement. J Cardiovasc Electrophysiol 2012; 23: 1115-1122.

17. Bonchek LI. Sounding board. Are randomized trials appropriate for evaluating new operations? $N$ Engl J Med 1979; 301: 44-45. 


\section{Cardiac conduction disturbances after transcatheter aortic valve replacement: much remains to be learned.}

Nazif T, Kodali SK. EuroIntervention 2014; 9: 1136-1138.

\section{Editorial to}

Houthuizen P, van der Boon RMA, Urena M, Van Mieghem M, Brueren BRG, Poels TT, Van Garsse LAFM, Rodés-Cabau J, Prinzen FW, de Jaegere P. Occurrence, fate and consequences of ventricular conduction abnormalities after transcatheter aortic valve implantation. EuroIntervention 2014; 9: 1142-1150.

Over the past decade, transcatheter aortic valve replacement (TAVR) has emerged as a less invasive alternative to surgical aortic valve replacement (SAVR) for high-risk surgical candidates and the treatment of choice for inoperable patients with symptomatic, severe aortic stenosis (AS). Recently, there has been explosive growth in the clinical adoption of TAVR worldwide. With this increasing role, intense research efforts have focused on understanding and reducing procedural complications of TAVR, the most common of which are cardiac conduction disturbances.

Two reports in the current issue of EuroIntervention, by Houthuizen et al and Lange et al, focus on cardiac conduction disturbances after TAVR. The study by Houthuizen et al elaborates on the incidence, fate, and clinical impact of left bundle branch block (LBBB), the most frequent conduction disturbance after TAVR. ${ }^{1}$ The report of Lange et al, on the other hand, explores the impact of balloon aortic valvuloplasty (BAV) balloon sizing on the occurrence of the most threatening conduction disturbance after TAVR, complete atrioventricular block requiring permanent pacemaker implantation (PPI). ${ }^{2}$ These complications occur with varying frequency after TAVR, and it is of critical importance to understand their aetiologies, clinical implications, and possible means of prevention.

New-onset LBBB is the most frequent conduction disturbance to complicate both SAVR and TAVR. The incidence of new LBBB after SAVR has been reported to range from 6 to $20 \% .^{3,4}$ Following TAVR, the exact frequency varies with the transcatheter heart valve (THV) system used and the elapsed time from the procedure. The rate of new LBBB with the Edwards SAPIEN valve (ESV; Edwards Lifesciences, Irvine, CA, USA) is similar to SAVR, with recent large series reporting rates ranging from 10 to $30 \% .^{5-7}$ The incidence of new LBBB with the Medtronic CoreValve (MCV; Medtronic, 
Minneapolis, MN, USA) is substantially higher, ranging from approximately 40 to $55 \%$ in large series. ${ }^{5,8,9}$ While the wide range of rates across studies may reflect differences in populations, it may also be due to differences in definition, intensity of surveillance, and time of assessment of LBBB after TAVR.

In the current study, Houthuizen et al analysed the occurrence of LBBB after TAVR in 476 patients (223 MCV, 253 ESV) without pre-existing LBBB or pacemaker. The overall rate of new LBBB was similar to previously published reports: approximately $37 \%$ overall, $54 \%$ after MCV, and 22\% after ESV. However, this study makes an important contribution in its close examination of the time course of development and resolution of new LBBB. It is notable that the vast majority of new LBBB developed within 24 hours of the procedure $(86 \%)$ or during the index hospitalisation (98\%). In agreement with prior studies, the authors also found that a significant proportion of new LBBB after TAVR resolve over time. ${ }^{6-8}$ Importantly, the degree of resolution of new LBBB was significantly less with MCV than ESV (28\% vs. 56\%). The fact that new LBBB is both substantially more frequent and also less likely to resolve with MCV may have important implications for the choice of THV in certain patients, such as those with reduced left ventricular function in whom dyssynchrony may lead to worsening cardiac function and clinical heart failure.

Importantly, the authors also propose a new classification scheme for the time course of new LBBB after TAVR, in which LBBB is defined as acute, subacute, or chronic based on occurrence within 24 hours, from 24 hours to discharge, and after discharge, respectively. LBBB is further classified as transient or persistent based on whether or not it remains at one year. Of note, this definition of "persistent" differs from prior studies, which have used the term to refer to LBBB persisting at hospital discharge.6,7 Furthermore, in our recent analysis from the PARTNER trial, we demonstrated that the vast majority of LBBB resolution occurred by 30 days, which may also be a candidate time point for defining "persistent". The Valve Academic Research Consortium (VARC), which standardised definitions for many TAVR endpoints, has recommended systematic reporting of data on conduction disturbances, but has stopped short of proposing specific definitions. ${ }^{10}$ It may, therefore, be hoped that the new classification scheme proposed by Houthuizen et al will be a first step in clarifying the vague, often confusing terminology that currently exists in the literature regarding LBBB after TAVR.

The clinical impact of new-onset LBBB after TAVR received substantial attention after a study in 2012 by Houthuizen et al reported higher one-year mortality in patients with new LBBB after TAVR with either ESV or MCV. ${ }^{5}$ However, multiple subsequent publications, including large cohorts of patients treated with both ESV and $\mathrm{MCV}$, have failed to substantiate this finding.6-8 In contrast to these studies, Houthuizen et al once again report an association of new-onset LBBB with mortality, this time with a median follow-up of 915 days. However, this finding must be interpreted with caution given the likely overlap of the current patient population with the previously published cohort and the failure of other groups to replicate the findings in 
independent populations. Although there may be differences in definitions and patient characteristics that explain the discrepancy with other studies, it is also possible that the association of new LBBB with mortality is due to unidentified confounders. Furthermore, given the known incomplete pacemaker dependency of patients who undergo PPI after TAVR, it is not clear that PPI within 30 days should be an exclusion criterion when analysing the clinical impact of new LBBB. The ongoing debate regarding the impact of new LBBB on mortality does not, however, imply that it is benign, given its association with PPI and impaired recovery of left ventricular function..$^{6-8}$ Unfortunately, analyses of these additional endpoints was not possible in the current study.

The other important conduction disturbance after TAVR is complete atrioventricular block and related conduction abnormalities requiring PPI. Contemporary studies have reported PPI rates ranging from 3 to 7\% after isolated SAVR for AS.11,12 Recent, large-scale meta-analyses have shown similar average PPI rates after TAVR with ESV (5.9 to 6.5\%). ${ }^{13-15}$ However, PPI rates with MCV are reported to be significantly higher (24.5-25.8\%). ${ }^{13-15}$ Multiple studies have examined predictors of PPI after TAVR and have clearly established the use of MCV and pre-existing RBBB as the most reliable and potent predictors of PPI. ${ }^{13,16}$ More limited studies have identified an array of other electrocardiographic, anatomic, and procedural risk factors for PPI. Important among these are modifiable, procedural risk factors, such as depth of THV implantation. ${ }^{9,17}$

More recently, BAV has been identified as another potentially modifiable, procedural risk factor for conduction disturbances after TAVR. ${ }^{18,19}$ While the incidence of PPI after isolated BAV is less than 1.5\%, studies have shown that up to half of all conduction disturbances during TAVR occur prior to valve deployment, most often during BAV.20-22 As postulated by Lange et al, this suggests a "two-hit model", in which an initial conduction system injury during BAV is exacerbated and becomes permanent due to a second injury from THV deployment. It is therefore rational that avoidance of BAV during TAVR may minimise conduction disturbances, including PPI. Several small pilot studies have now shown that TAVR with both MCV and ESV may be feasible without BAV and that this strategy may minimise conduction disturbances. ${ }^{18,23}$

A prior, small study of patients treated with MCV showed that the ratio of the BAV balloon diameter, but not the THV prosthesis, to the aortic valve annulus was associated with conduction disturbances. ${ }^{22}$ The current study by Lange et al extends this work by analysing the impact of BAV balloon size on PPI in a larger cohort of 237 patients without prior pacemaker who underwent TAVR with MCV. In this analysis, the overall incidence of PPI was $21.1 \%$, but was significantly higher when a $25 \mathrm{~mm}$ balloon was used (27.1\%) than when a $23 \mathrm{~mm}$ or smaller balloon was used $(15.4 \%)$ for the BAV. Furthermore, when stratified by THV size (26 or $29 \mathrm{~mm}$ ), there was a step-wise increase in PPI rate with each increase in balloon size. The association of balloon size with PPI remained significant after multivariable adjustment for differ- 
ences in baseline patient characteristics. Overall, these results suggest that pacemaker rates after TAVR may be safely decreased by using the smallest possible BAV balloon.

There are several limitations of this analysis that should be considered. First, the rationale for choosing different balloon sizes in individual cases was not discussed. It remains possible that smaller balloons were utilised in patients in whom conduction disturbances or other complications were feared and that unidentified confounders, such as the burden of calcification, affected the result. The indications for PPI were also not provided, although the authors state that pacemakers were only placed at their institution for complete atrioventricular block or symptomatic bradycardia. Finally, the potential impact of BAV size on THV valve areas and rates of paravalvular regurgitation were not investigated. Additional, prospective studiesare necessary to understand better the impact on clinical outcomes of minimising the balloon size or deferring BAV altogether.

Cardiac conduction disturbances, including LBBB and complete atrioventricular block or other abnormalities requiring PPI, are the most frequent complication of TAVR. The studies in this issue of EuroIntervention contribute to our understanding of the aetiology, time course, and clinical impact of conduction disturbances. Future studies should aim to further this understanding with a particular focus on clinical implications and modifiable risk factors. 


\section{References}

1. Houthuizen P, van der Boon RM, Urena M, van Mieghem N, Brueren GB, Poels TT, Van Garsse LA, Rodés-Cabau J, Prinzen FW, de Jaegere P. Occurrence, fate and consequences of ventricular conduction abnormalities after transcatheter aortic valve implantation. EuroIntervention 2014; 9: 11421150.

2. Lange P, Greif M, Vogel A, Thaumann A, Helbig S, Schwarz F, Schmitz C, Becker C, D’Anastasi M, Boekstegers P, Pohl T, Laubender RP, Steinbeck G, Kupatt C. Reduction of pacemaker implantation rates after CoreValve implantation by moderate pre-dilatation. EuroIntervention 2014; 9: 1151-1157.

3. Thomas JL, Dickstein RA, Parker FB Jr, Potts JL, Poirier RA, Fruehan CT, Eich RH. Prognostic significance of the development of left bundle conduction defects following aortic valve replacement.J Thorac Cardiovasc Surg 1982; 84: 382-386.

4. Van Mieghem NM, Head SJ, de Jong W, van Domburg RT, Serruys PW, de Jaegere PP, Jordaens L, Takkenberg JJ, Bogers AJ, Kappetein AP. Persistent annual permanent pacemaker implantation rate after surgical aortic valve replacement in patients with severe aortic stenosis. Ann Thorac Surg 2012; 94: 1143-1149.

5. Houthuizen P, Van Garsse LA, Poels TT, de Jaegere P, van der Boon RM, Swinkels BM, Ten Berg JM, van der Kley F, Schalij MJ, Baan J Jr, Cocchieri R, Brueren GR, van Straten AH, den Heijer P, Bentala M, van Ommen V, Kluin J, Stella PR, Prins MH, Maessen JG, Prinzen FW. Left bundle-branch block induced by transcatheter aortic valve implantation increases risk of death. Circulation 2012; 126: 720-728.

6. Urena M, Mok M, Serra V, Dumont E, Nombela-Franco L, DeLarochellière R, Doyle D, Igual A, Larose E, Amat-Santos I, Côté M, Cuéllar H, Pibarot P, de Jaegere P, Philippon F, Garcia del Blanco B, RodésCabau J. Predictive factors and long-term clinical consequences of persistent left bundle branch block following transcatheter aortic valve implantation with a balloon-expandable valve. J Am Coll Cardiol 2012; 60: 1743-1752.

7. Nazif TM, Williams MR, Hahn RT, Kapadia S, Babaliaros V, Rodés-Cabau J, Szeto WY, Jilaihawi H, Fearon WF, Dvir D, Dewey TM, Makkar RR, Xu K, Dizon JM, Smith CR, Leon MB, Kodali SK. Clinical implications of new-onset left bundle branch block after transcatheter aortic valve replacement: analysis of the PARTNER experience. Eur Heart J 2013; in press.

8. Testa L, Latib A, De Marco F, De Carlo M, Agnifili M, Latini RA, Petronio AS, Ettori F, Poli A, De Servi S, Ramondo A, Napodano M, Klugmann S, Ussia GP, Tamburino C, Brambilla N, Colombo A, Bedogni F. Clinical impact of persistent left bundle branch block after transcatheter aortic valve implantation with CoreValve Revalving System. Circulation 2013; 127: 1300-1307.

9. De Carlo M, Giannini C, Bedogni F, Klugmann S, Brambilla N, De Marco F, Zucchelli G, Testa L, Oreglia J, Petronio AS. Safety of a conservative strategy of permanent pacemaker implantation after transcatheter aortic CoreValve implantation. Am Heart J 2012; 163: 492-499.

10. Kappetein AP, Head SJ, Généreux P, Piazza N, van Mieghem NM, Blackstone EH, Brott TG, Cohen DJ, Cutlip DE, van Es GA, Hahn RT, Kirtane AJ, Krucoff MW, Kodali S, Mack MJ, Mehran R, Rodés-Cabau J, Vranckx P, Webb JG, Windecker S, Serruys PW, Leon MB; Valve Academic Research Consortium-2. Updated standardized endpoint definitions for transcatheter aortic valve implantation: the Valve Academic Research Consortium-2 consensus document. EuroIntervention 2012; 8: 782-795.

11. Bagur R, Manazzoni JM, Dumont E, Doyle D, Perron J, Dagenais F, Mathieu P, Baillot R, Charbonneau É, Metrás J, Mohammadi S, Côté M, Philippon F, Voisine P, Rodés-Cabau J. Permanent pacemaker implantation following isolated aortic valve replacement in a large cohort of elderly patients with severe aortic stenosis. Heart 2011; 97: 1687-1694.

12. Dawkins S, Hobson AR, Kalra PR, Tang AT, Monro JL, Dawkins KD. Permanent pacemaker implantation after isolated aortic valve replacement: incidence, indications, and predictors. Ann Thorac Surg 2008; 85: 108-112.

13. Erkapic D, De Rosa S, Kelava A, Lehmann R, Fichtlscherer S, Hohnloser SH. Risk for permanent pacemaker after transcatheter aortic valve implantation: a comprehensive analysis of the literature. $J$ Cardiovasc Electrophysiol 2012; 23: 391-397. 


\section{ADDENDUM}

14. Khatri PJ, Webb JG, Rodés-Cabau J, Fremes SE, Ruel M, Lau K, Guo H, Wijeysundera HC, Ko DT. Adverse effects associated with transcatheter aortic valve implantation: a meta-analysis of contemporary studies. Ann Intern Med 2013; 158: 35-46.

15. Jilaihawi H, Chakravarty T, Weiss RE, Fontana GP, Forrester J, Makkar RR. Meta-analysis of complications in aortic valve replacement: comparison of Medtronic-Corevalve, Edwards-Sapien and surgical aortic valve replacement in 8,536 patients. Catheter Cardiovasc Interv 2012; 80: 128-138.

16. Fraccaro C, Napodano M, Tarantini G. Conduction disorders in the setting of transcatheter aortic valve implantation: a clinical perspective. Catheter Cardiovasc Interv 2013; 81: 1217-1223.

17. Binder RK, Webb JG, Toggweiler S, Freeman M, Barbanti M, Willson AB, Alhassan D, Hague CJ, Wood DA, Leipsic J. Impact of post-implant SAPIEN XT geometry and position on conduction disturbances, hemodynamic performance, and paravalvular regurgitation. JACC Cardiovasc Interv 2013; 6: 462468.

18. Grube E, Naber C, Abizaid A, Sousa E, Mendiz O, Lemos P, Kalil Filho R, Mangione J, Buellesfeld L. Feasibility of transcatheter aortic valve implantation without balloon pre-dilation: a pilot study. JACC Cardiovasc Interv 2011; 4: 751-757.

19. Khawaja MZ, Rajani R, Cook A, Khavandi A, Moynagh A, Chowdhary S, Spence MS, Brown S, Khan SQ, Walker N, Trivedi U, Hutchinson N, De Belder AJ, Moat N, Blackman DJ, Levy RD, Manoharan G, Roberts D, Khogali SS, Crean P, Brecker SJ, Baumbach A, Mullen M, Laborde JC, Hildick-Smith D. Permanent pacemaker insertion after CoreValve transcatheter aortic valve implantation: incidence and contributing factors (the UK CoreValve Collaborative). Circulation 2011; 123: 951-960.

20. Laynez A, Ben-Dor I, Hauville C, Xue Z, Satler LF, Kent KM, Pichard AD, Lindsay J, Waksman R. Frequency of cardiac conduction disturbances after balloon aortic valvuloplasty. Am J Cardiol 2011; 108: 1311-1315.

21. Ben-Dor I, Pichard AD, Satler LF, Goldstein SA, Syed AI, Gaglia MA Jr, Weissman G, Maluenda G, Gonzalez MA, Wakabayashi K, Collins SD, Torguson R, Okubagzi P, Xue Z, Kent KM, Lindsay J, Waksman R. Complications and outcome of balloon aortic valvuloplasty in high-risk or inoperable patients. JACC Cardiovasc Interv 2010; 3: 1150-1156.

22. Nuis RJ, Van Mieghem NM, Schultz CJ, Tzikas A, van der Boon RM, Maugenest AM, Cheng J, Piazza N, van Domburg RT, Serruys PW, de Jaegere PP. Timing and potential mechanisms of new conduction abnormalities during the implantation of the Medtronic CoreValve System in patients with aortic stenosis. Eur Heart J 2011; 32: 2067-2074.

23. García E, Martín P, Hernández R, Rodríguez V, Fernández A, Gama V, Almería C, Macaya C. Feasibility and safety of transfemoral implantation of Edwards SAPIEN XT prosthesis without balloon valvuloplasty in severe stenosis of native aortic valve. Catheter Cardiovasc Interv 2013; in press. 
Summary 



\section{Summary}

Left bundle branch block (LBBB) causes a delayed activation of the left ventricle (LV) which results in an uncoordinated LV contraction (interventricular dyssynchrony). This in turn induces immediate and persistent inhomogeneities in local myocardial strain and blood flow of both the septal and lateral wall, leading to a reduction in stroke work with subsequent progressive dilation and decrease in LV ejection fraction (LVEF). Epidemiological studies have shown that LBBB is associated with an increased cardiovascular morbidity and mortality in varying patient populations. Although most of these studies were not able to demonstrate that LBBB is cause and not consequence of heart failure, insight from cardiac resynchronization therapy (CRT) has shown that reversal of LBBB-induced dyssynchrony restores LV function and reduces morbidity and mortality.

Transcatheter aortic valve implantation (TAVI) has rapidly emerged as a valuable and evidence-based alternative to surgical aortic valve replacement (SAVR) in patients who do not qualify for surgery. Still, TAVI is associated with specific complications, such as amongst others, stroke, atrioventricular conduction disorders and LBBB. Given its effect on ventricular contraction, it is important to know the frequency of LBBB, its nature (persistent or transient) and its effects on mortality.

In chapter 1 of this thesis, we outline the historical perspective of LBBB together with a description of its functional anatomy and pathophysiology in order to understand why LBBB is a causative factor in the development of heart failure. We focus on the historical and contemporary controversies regarding the diagnosis of LBBB, followed by revision of studies investigating its clinical significance. The available data on the frequency of LBBB after aortic valve interventions, including TAVI and SAVR is presented together with the presumed mechanism of TAVI-induced LBBB. Finally, attention is paid to CRT, that is aimed at the correction or restoration of LBBB-induced dyssynchrony. While generally successful, the benefit for the individual patient varies considerably. We pay specific attention to the role of measuring the maximum rate of rise in $\mathrm{LV}$ pressure $\left(\mathrm{LV} \mathrm{dP} / \mathrm{dt}_{\max }\right)$ to determine the acute hemodynamic response to CRT and effect on long-term outcome.

The results of our study investigating the impact of TAVI-induced LBBB on mortality are presented in chapter 2. In this multicentre registry of 679 TAVI patients, we demonstrated that TAVI-induced LBBB is a frequent postoperative conduction disorder occurring in more than one third of the patients. TAVI-induced LBBB occurred about four times more frequently with implantation of the Medtronic CoreValve System (MCS) than with the Edwards SAPIEN (ES) device $(51.1 \%$ and $12.0 \%$, respectively). During a median follow-up of 15 months, TAVI-induced LBBB was an significant and independent predictor of all-cause mortality irrespective of the device being used (hazard ratio, HR, 1.54). 
This first study focussed on the development of TAVI-induced LBBB within 7 days after implantation, and did not address its resolution or occurrence over time. This was investigated in a subsequent observational multicentre international study encompassing $476 \mathrm{TAVI}$ patients and is presented in chapter 3 . We confirmed that TAVI-induced LBBB occurs in more than one third of the patients of which almost all developed before hospital discharge. At 1 year post-implantation, the conduction disorder was persistent in $63.4 \%(\mathrm{n}=111)$ of patients who developed LBBB. As demonstrated earlier, implantation of the MCS was associated with 2.5 times more LBBB than the ES device and also showed four times less recovery during follow-up. Persistent LBBB was associated with a significant increase in all-cause mortality compared to patients with no LBBB or temporary LBBB $(\mathrm{HR}, 1.49)$.

Our observation in chapter 2 indicating that the frequency of TAVI-induced LBBB after MCS implantation decreased with increasing entry time into the TAVI programme, led us to the study described in chapter 4 . The previously described study population of 476 TAVI patients was divided into three equally distributed cohorts of consecutive patients ranked in chronological order of implantation. For the three cohorts, we observed a significant decrease of any TAVI-induced LBBB over time (47.2\%, 34.6\% and 28.5\%, respectively). Development of TAVI-induced LBBB was dependent on the device type and the decrease between the consecutive cohorts was only significant after MCS implantation. Parallel with this observation, was the finding that there was a significant decrease in median depth of implantation, in particular after MCS valve implantation from the first to the latest cohort. The findings indicate that experience as well as improved implantation techniques are responsible for the reduction in new LBBB.

Given the impact of TAVI-induced LBBB on mortality, we questioned the clinical significance of this conduction disorder after surgical aortic valve replacement (SAVR). This was subject of investigation of chapter 5, in which we retrospectively analysed pre- and postprocedural electrocardiograms (ECGs) of 1,764 patients who underwent SAVR in the Catharina hospital (Eindhoven, the Netherlands). SAVR-induced LBBB occurred in less than $5 \%$ of the patients $(n=71)$ and resolved in almost $60 \%$ of patients at follow-up. This persistent SAVR-induced LBBB was not identified as a predictor of all-cause mortality, partly due to the low number of this conduction abnormality. This study shows that TAVI is currently inferior to SAVR with respect to the induction of conduction abnormalities.

In chapter 6, we report the first series of 31 patients who underwent implantation of the self-expandable stent-mounted Perceval $S$ bioprosthesis. In this early report, we found that new LBBB occurred in $40 \%$ of the patients with persistence in two-thirds of these patients. Although these results may, at least partly, be influenced by a learning curve, they indicate that the frequency of LBBB after implantation of the Perceval S prostheses is considerably larger than after SAVR. Notably, the Perceval S device has a similar design as the MCS device (self-expanding, nitinol frame). Despite removal of the native valve and its calcium, the Perceval S still induces new 
LBBB. This suggest that trauma inflicted by the valve itself on the left ventricular outflow tract (LVOT) is a causative factor in the development of conduction disorders.

In chapter 7 we review a controversial topic in the area of cardiac resynchronization therapy (CRT), namely optimization of the atrioventricular (AV) and ventriculo-ventricular (VV) interval. We discuss the physiological rationale for optimization and present available invasive and non-invasive methods and their limitations.

With the development of (CRT), the maximum rate of rise in LV pressure (LV $\mathrm{dP} / \mathrm{dt}_{\max }$ ) was reintroduced as a surrogate for measuring contractility to determine the acute hemodynamic response to CRT. In chapter 8 , we present the results of retrospective observational study in 285 patients from the Catharina hospital (Eindhoven) and University Medical Center Utrecht, who underwent CRT implantation with subsequent optimization of the $\mathrm{AV} / \mathrm{VV}$ interval using $\mathrm{LV} \mathrm{dP} / \mathrm{dt}_{\max }$. Neither the acute, nor the relative increase in $\mathrm{LV} \mathrm{dP} / \mathrm{dt}_{\max }$ was associated with a decrease in mortality. The opposite was true for the absolute values of both $\mathrm{LV} \mathrm{dP} / \mathrm{dt}_{\max }$ at baseline and after CRT optimization: a lower $\mathrm{LV} \mathrm{dP} / \mathrm{dt}_{\max }$ value was a strong predictor of poor survival.

Chapter 9 recapitulates the main findings of present thesis and provides future perspectives. Controversies regarding the prognostic value of TAVI-induced LBBB are highlighted and causes for these discrepancies are discussed. We conclude that TAVI-induced LBBB does impact patient's outcome and may prevented by increased experience and novel delivery systems enhancing more appropriate valve positioning and release. For patients who develop LBBB, we propose to withhold PPM or CRT implantation in the early postoperative phase given the often transient character of the conduction disorder.

From the data presented in present thesis, our main conclusion is that LBBB induced by aortic valve interventions is a serious adverse event that impacts patient's outcome. The occurrence of LBBB is dependent on the intervention technique (TAVI versus SAVR), device (MCS and Perceval S versus ES), experience and/or improved implantation techniques. This insight may be taken into account during patient selection and type of aortic valve intervention and in particular when choosing TAVI. 

Samenvatting 



\section{Samenvatting}

Het linker bundeltak blok (LBTB) kenmerkt zich door een vertraagde activatie van de linker hartkamer. Als gevolg van deze vertraging, verloopt de samentrekking (contractie) van de hartspier ongecoördineerd (dyssynchronie). Er treden veranderingen op in het contractiepatroon van verschillende delen van de hartspierwand, met name tussen het kamertussenschot (septum) en de zijwand (laterale wand). Door de inefficiënte samenwerking tussen de verschillende delen van de hartspier, treedt progressieve verwijding op van de linker hartkamer en gaat de pompfunctie achteruit. Epidemiologische studies hebben laten zien dat LBTB vaak gepaard gaat met een hogere sterftekans in verschillende patiëntengroepen. Deze studies zijn meestal niet in staat een onderscheid te maken tussen "de kip en het ei"; het is niet duidelijk is of LBTB oorzaak dan wel gevolg is. Sinds deze eeuw bestaat er echter een behandeling die in staat is om het effect van LBTB te verminderen met een specifiek type pacemaker (cardiale resynchronisatietherapie, kortweg CRT). Deze therapie herstelt de pompfunctie van het hart en leidt tot een vermindering van de sterftekans. Dit is een indirect bewijs dat LBTB inderdaad minstens een deel van de oorzaak van hartfalen is.

Onafhankelijk van bovenstaande ontwikkelingen, is er in de afgelopen jaren een nieuwe behandeling gekomen voor patiënten met een ernstige vernauwing van een hartklep, meer bepaald de aortaklep. De transcatheter aortaklep implantatie (TAVI) maakt het mogelijk om een nieuwe hartklep te plaatsen zonder dat open-hart chirurgie noodzakelijk is. TAVI is een waardevol alternatief voor de klassieke hartoperatie bij mensen die daar niet voor in aanmerking komen (door bijvoorbeeld een te hoog risico). Toch is TAVI gekenmerkt door verschillende complicaties, zoals bijvoorbeeld beroerte en stoornissen in de impulsgeleiding waaronder LBTB. Gezien bovengenoemde kennis over LBTB in andere patiëntengroepen, vonden wij het belangrijk om meer te weten over de frequentie, aard en risico's van het door TAVI veroorzaakte LBTB.

In hoofdstuk 1 van dit proefschrift, blikken we terug op de wetenschappelijke geschiedenis van het LBTB waarbij we ook diens anatomie en gevolgen beschrijven om zo beter te begrijpen waarom LBTB een belangrijke oorzaak is in de ontwikkeling van hartfalen. We stippen de historische en actuele tegenstrijdigheden in de literatuur aan samen met een overzicht van relevante studies. De actuele kennis over het voorkomen van LBTB na ingrepen aan de aortaklep wordt besproken waarbij dieper ingegaan wordt op het vermoedelijke ontstaansmechanisme van het door TAVI veroorzaakte LBTB. In het laatste deel ligt de focus op CRT als behandeling van LBTB. In het algemeen is dit een succesvolle therapie, maar het effect varieert sterk van patient tot patiënt. De mogelijkheid bestaat om tijdens implantatie van CRT het effect op de bloeddruk te meten. Hiertoe wordt de maximale waarde van de afgeleide van de 
linker kamer drukcurve $\left(L V d P / d t_{\max }\right)$ gebruikt. Alhoewel dit een goede maat is van het acute effect van CRT, is het niet duidelijk of deze maat ook een voorspelling tot over de langetermijnprognose van de patiënt.

Hoofdstuk 2 vermeldt de resultaten van onze studie naar het gevolg van door TAVI veroorzaakte LBTB op de overlevingskansen van patiënten. In een bestand van 679 TAVI patiënten uit acht centra in Nederland, toonden we dat het door TAVI veroorzaakte LBTB een frequent voorkomende complicatie is en voorkomt in $34 \%$ van de patiënten. Het optreden wordt sterk bepaald door de gebruikte hartklepprothese want het komt vier keer meer voor na implantatie van de Medtronic CoreValve System (MCS) dan na implantatie van de Edwards SAPIEN (ES) hartklep (51,1\% en $12,0 \%$, respectievelijk). Na een mediane duur van 15 maanden, bleek het door TAVI veroorzaakte LBTB een belangrijke voorspeller voor sterfte, en dit onafhankelijk van andere factoren die de sterftekans verhogen: patiënten met een door TAVI veroorzaakt LBTB hadden 55\% meer kans om te sterven in vergelijking met patiënten zonder de geleidingsstoornis. De sterftekans veroorzaakt door LBTB was niet afhankelijk van de gebruikte hartklepprothese (MCS of ES), anders gezegd het optreden van LBTB was in beide gevallen even slecht.

In deze eerste studie onderzochten wij het optreden van LBTB binnen 7 dagen na implantatie van de hartklepprothese en hebben we geen aandacht besteed aan het eventueel verdwijnen hiervan. In hoofdstuk 3 beschrijven we een vervolgonderzoek in 476 TAVI patiënten uit centra in Nederland en Canada. We bevestigden in deze studie dat het door TAVI veroorzaakte LBTB optreedt in meer dan een derde van de patiënten. Het LBTB manifesteerde zich bijna altijd voor ontslag uit het ziekenhuis. Eén jaar na de aortaklepbehandeling was het LBTB nog aanwezig in 63.4\% van de patiënten die eerder het LBTB ontwikkelden. Ook in deze studie zagen we dat implantatie van de MCS prothese tot 2,5 maal meer LBTB leidde dan implantatie van de ES hartklep. Bovendien bleef het LBTB veroorzaakt door de MCS prothese vaker bestaan. Indien het door TAVI veroorzaakte LBTB persisteerde na een jaar, was er een hogere sterftekans voor deze patiënten in vergelijking met patiënten zonder LBTB of met een voorbijgaand LBTB.

In hoofdstuk 2 zagen we reeds dat het optreden van LBTB na implantatie van de MCS prothese afnam naarmate de ervaring met deze klepimplantatie steeg. Dit was reden tot de studie beschreven in hoofdstuk 4. De eerder beschreven groep van 476 patiënten werd verdeeld in 3 gelijke cohorten na chronologische rangschikking in volgorde van implantatie. In deze 3 cohorten zagen we dat het optreden van LBTB daalde in de tijd (van 47,2\% naar 34,6\% naar 28,5\%, respectievelijk). Daarnaast bleek opnieuw dat het optreden van door TAVI veroorzaakte LBTB afhankelijk was van de gebruikte hartklepprothese waarbij de afname van LBTB in de tijd alleen werd gezien bij de MCS prothese. Bij meer recentere implantaties, werden de hartkleppen ook minder diep in de linker hartkamer geplaatst; dit zou er op kunnen wijzen dat ervaring en verbeterde implantatietechnieken mede verantwoordelijk zijn voor het verminderd optreden van LBTB. 
Gezien het door ons vastgestelde effect van het door TAVI veroorzaakte LBTB op het sterfterisico, stelden we ons de vraag hoe vaak LBTB ontstaat na de klassieke aortaklepvervanging zoals deze wordt uitgevoerd door de hartchirurg. Ook wilden we weten of dit type LBTB een vergelijkbaar nadelig effect heeft op de sterftekans. Dit was onderwerp van het onderzoek in hoofdstuk 5. We vergeleken het hartfilmpje (electrocardiogram, kortweg ECG) voor en na een aortaklepoperatie in 1.764 patiënten die geopereerd waren in het Catharina ziekenhuis te Eindhoven. Een nieuw LBTB trad op in minder dan $5 \%$ van de patiënten $(n=71)$ en verdween bovendien in bijna $60 \%$ van de gevallen. Ook hier stelden we vast dat de sterfte zo'n $40 \%$ hoger was in de groep met een nieuw LBTB, maar deze groep was te klein om hier betrouwbare uitspraken over te doen. Belangrijker was dat LBTB een zeer zeldzame complicatie van klassieke aortaklepvervanging was. Onze studie toont daarom aan dat TAVI ondergeschikt is aan de klassieke aortaklepoperatie voor wat betreft het ontstaan van geleidingsstoornissen zoals LBTB.

In hoofdstuk 6 rapporteren we de eerste resultaten van een nieuwe hartklepprothese, namelijk de Perceval S hartklepprothese. De Perceval S is, net als de MCS, gemonteerd in een geraamte van een geheugenmetaal (nitinol) en oefent dus continue druk uit op het omliggende weefsel. Een belangrijk verschil is dat bij implantatie van de Perceval S, de zieke en verkalkte hartklep van de patiënt zelf integraal wordt verwijderd; desondanks treedt LBTB nog steeds frequent op. In de eerste serie van 31 patiënten stelden we vast dat een nieuw LBTB optrad in $40 \%$ van de patiënten waarbij de geleidingsstoornis bleef bestaan in twee derde van de gevallen. Alhoewel deze resultaten beïnvloed kunnen zijn door het effect van training (leercurve), suggereert dit dat het optreden van LBTB bij de Perceval S veel frequenter is dan met de klassieke hartklepprothesen. Een en ander doet vermoeden dat kleppen zoals Perceval S en MCS lokale beschadiging veroorzaken in de buurt van de linker bundeltak.

De negatieve effecten het LBTB op de pompfunctie van het hart, kunnen grotendeels opgeheven worden door het toepassen van CRT. Eén van de problemen bij deze behandeling is dat ongeveer een derde van de patiënten geen verbetering laat zien in pompfunctie. Meer en meer is men tot het besef gekomen dat CRT dan ook "maatwerk" is, aangepast aan de individuele patiënt. Een deel van deze behandeling op maat bestaat in het optimaliseren van de pacemakerfunctie waarbij geprogrammeerd wordt wanneer de beide hartkamers dienen samen te trekken. In hoofdstuk 7 beschrijven we dat deze optimalisatie nodig is om een zo natuurlijk mogelijk werking van het hart te garanderen. We laten echter ook zien, dat er tot op heden geen goede manier beschikbaar is om de pacemaker op een effectieve manier te programmeren.

Zoals eerder beschreven, beleefde meting van $\mathrm{LV} \mathrm{dP/dt}$ max een herintroductie met de ontwikkeling van CRT en dan met name als surrogaat om de contractiliteit van de linker hartkamer te bepalen als maat voor het acute effect van CRT. In hoofdstuk 8 beschrijven we een studie in 285 patiënten die CRT implantatie onderging in het Universitair Medisch Centrum Utrecht of het Catharina ziekenhuis in Eindhoven. We stelden vast dat noch de absolute noch de procentuele toename in $\mathrm{LV} \mathrm{dP} / \mathrm{dt}_{\max }$ 
door CRT een voorspeller was voor de sterftekans op langere termijn. De absolute waarde van $\mathrm{LV} \mathrm{dP/dt}$ max voor en na CRT implantatie was dit echter wel: hoe lager LV $\mathrm{dP} / \mathrm{dt}_{\max }$ hoe slechter de overlevingskans van de patiënt. Met andere woorden, de uitgangspositie van de patiënt is bepalend voor zijn of haar prognose waarbij patienten met een slechtere pompfunctie van het hart (uitgedrukt in $\mathrm{LV} \mathrm{dP} / \mathrm{dt}_{\max }$ ) een lagere overlevingskans hebben. Het acute effect van CRT gemeten door middel van $\mathrm{LV} \mathrm{dP} / \mathrm{dt}_{\max }$ is weliswaar niet voorspellend voor de overleving, maar hierbij dient opgemerkt dat er tussen dit acute effect en het lange termijn effect vele andere factoren van invloed kunnen zijn op de prognose.

Hoofdstuk 9 vat de belangrijkste bevindingen van dit proefschrift samen en plaatst deze in een toekomstperspectief. Het effect van door TAVI veroorzaakte LBTB op de sterftekans blijkt een controversieel onderwerp te zijn, daarom proberen we een verklaring te geven voor de tegenstrijdige bevindingen op dit gebied in de wetenschappelijke literatuur. In veel studies werden patiënten die na TAVI een pacemakerimplantatie niet uitgesloten van statistische analyse; het is juist het beschermend effect van de pacemaker op plotseling overlijden dat het effect van LBTB op de sterftekans beïnvloedt. Ook is de diagnose van LBTB niet eenvoudig waardoor patiënten ten onrechte als LBTB geclassificeerd kunnen worden. Onze conclusie is dat het door TAVI veroorzaakte LBTB een invloed heeft op de prognose van de patiënt, waarbij het optreden van LBTB voorkomen kan worden door training en verbeterde implantatietechnieken die leiden tot een betere positionering van de prothese. CRT is in staat om het effect van LBTB grotendeels te reduceren waarbij de prognose van de patiënt verbetert. Er zijn ook in de wetenschappelijke literatuur enkele gevallen beschreven waarbij CRT een gunstig effect had bij patiënten die hartfalen ontwikkelden onder invloed van een door TAVI veroorzaakt LBTB. Als een patiënt daarom een LBTB ontwikkelt dat niet verdwijnt in de tijd, lijkt het raadzaam om implantatie van CRT te overwegen.

Onze belangrijkste conclusie gebaseerd op de gegevens in het huidige proefschrift luidt: LBTB dat ontstaat tijdens een behandeling van de aortaklep is een ernstige complicatie en beïnvloedt de prognose van de patiënt. Het optreden van LBTB is sterk afhankelijk van de techniek (TAVI of klassieke aortaklepvervanging), de hartklepprothese (MCS en Perceval S in vergelijking met ES) en/of verbeterde implantatietechnieken. Deze bevindingen zouden mede bepalend kunnen zijn bij de keuze van het type aortaklepbehandeling voor de individuele patiënt en dan met name bij de keuze voor TAVI. 


\section{Dankwoord}





\section{Dankwoord}

Serendipiteit is het sleutelwoord voor het onderzoekstraject dat aan dit proefschrift voorafgegaan is. Niemand had tevoren geanticipeerd dat de nadruk uiteindelijk op aortaklepinterventies en bijhorende complicaties zou komen te liggen. In de aanloop zijn er dan ook vele andere projecten geweest waarbij een groot aantal personen hebben bijgedragen aan mijn klinische en wetenschappelijke vorming. Ik zou dan ook graag iedereen willen bedanken die op directe of indirecte wijze hebben meegewerkt aan de totstandkoming van het huidige manuscript.

Naast serendipiteit speelden ook toevalligheden een belangrijke rol. Alhoewel geboren in Maastricht, dacht ik na het afronden van mijn middelbare schoolperiode nooit meer terug te keren naar Zuid-Limburg. Uitgeloot voor de studie geneeskunde, dwaalde ik in de zomer van 1994 rond in Utrecht zoekende naar een kamer als aanstaand student biologie. Mijn ouders wisten mij evenwel te overtuigen om in België de opleiding geneeskunde aan te vangen. In 2008 leidde een ontmoeting tussen twee bekende onbekenden op een luchthaven in de Verenigde Staten tot het begin van mijn huidige onderzoekstraject en keerde ik geheel onverwacht terug naar Maastricht. Een door linker bundeltak blok gebiologeerde fysioloog (nota bene afgestudeerd in Utrecht...) en een interventiecardioloog uit België met een voorliefde voor artikelen in een korte, mannelijke en sexy stijl, werden de sturende kracht achter het huidige eindresultaat.

En dan, aan het eind van de werkdag, is het altijd weer gezellig samen zijn met mijn vier lieve vrouwen in ons fijne huisje. Het bewijst voor mij dat geluk immaterieel is. Gelukkig maar... 



\section{Curriculum Vitae}





\title{
Curriculum Vitae
}

\section{Persoonlijke gegevens}

\author{
Voornaam Patrick \\ Naam Houthuizen \\ Geboortedatum 14 maart 1976 \\ Geboorteplaats Maastricht
}

\section{Opleiding en werkervaring}

1988-1994 Voorbereidend Wetenschappelijk Onderwijs met Latijn

Scholengemeenschap Sint-Michiel, Geleen, Nederland

1994-2001 Geneeskunde

Katholieke Universiteit, Leuven, België

2002-2003 Geneesheerspecialist in opleiding specialisatie inwendige geneeskunde

Jan Palfijn ziekenhuis, Merksem, België

2002-2003 Assistent-geneeskundige in opleiding specialisatie longziekten

Catharina ziekenhuis, Eindhoven, Nederland

2003-2005 Vooropleiding interne geneeskunde Catharina ziekenhuis, Eindhoven, Nederland

2005-2009 Assistent-geneeskundige in opleiding specialisatie cardiologie

Catharina ziekenhuis, Eindhoven, Nederland

2009-2013 Arts-onderzoeker

Afdeling fysiologie, Universiteit Maastricht, Nederland

2009-2013 Waarnemend cardioloog

TweeSteden ziekenhuis, Tilburg, Nederland

2009-heden Cardioloog-onderzoeker

Catharina ziekenhuis, Eindhoven, Nederland 



\section{List of Publications}





\section{List of publications}

Houthuizen P, Polak PE, Edelbroek MA, Peels CH. Giant cell arteritis as a cardiovascular entity. Neth Heart J 2009; 17 (7-8): 281-283.

Bracke FA, Houthuizen P, Rahel BM, van Gelder BM. Left ventricular endocardial pacing improves the clinical efficacy in a non-responder to cardiac resynchronization therapy: role of acute hemodynamic testing. Europace 2010; 12 (7): 1032-1034.

Houthuizen P, Bracke FA, van Gelder BM. Atrioventricular and interventricular delay optimization in cardiac resynchronization therapy: physiological principles and overview of available methods. Heart Fail Rev 2011; 16 (3): 263-276.

Prinzen FW, Houthuizen P. The CRT Monopoly game. Circ J 2011: 75 (5): 1053-1054.

van Gelder BM, Houthuizen P, Bracke FA. Transseptal left ventricular endocardial pacing: preliminary experience from a femoral approach with subclavian pullthrough. Europace 2011; 13 (10): 1126-1132.

Bogaard MD, Houthuizen P, Bracke FA, Doevendans PA, Prinzen FW, Meine M, van Gelder BM. Baseline left ventricular $\mathrm{dP} / \mathrm{dtmax}$ rather than the acute improvement in $\mathrm{dP} / \mathrm{dtmax}$ predicts clinical outcome in patients with cardiac resynchronization therapy. Eur J Heart Fail 2011; 13 (10): 1126-1132.

Bracke FA, van Gelder BM, Dekker LR, Houthuizen P, ter Woorst JF, Tejink JA. Left ventricular endocardial pacing in cardiac resynchronization therapy: Moving from bench to bedside. Neth Heart J 2012; 20 (3): 118-124.

Mischi M, Kaklidou F, Houthuizen P, Aben JP, Prinzen FW, Bracke F, van den Bosch $\mathrm{H}$, Korsten $\mathrm{HH}$. Three-dimensional quantification of regional left-ventricular dyssynchrony by magnetic resonance imaging. Conf Proc IEEE Eng Med Biol Soc 2011; 2011: 2646-2649.

Prinzen FW, Houthuizen P, Bogaard MD, van Gelder B, Bracke F, Cramer MJ, Leenders GE, Meine M. Is acute hemodynamic response a predictor of long-term outcome in cardiac resynchronization therapy? J Am Coll Cardiol 2012; 59 (13): 1198; author reply 1198-1199.

Houthuizen P, Van Garsse LA, Poels TT, de Jaegere P, van der Boon RM, Swinkels BM, Ten Berg JM, van der Kley F, Schalij MJ, Baan J Jr, Cocchieri R, Brueren GR, van Straten 
AH, den Heijer P, Bentala M, van Ommen V, Kluin J, Stella PR, Prins MH, Maessen JG, Prinzen FW. Left bundle branch block induced by transcatheter aortic valve implantation increases risk of death. Circulation 2012; 126 (6): 720-728.

Houthuizen P, van der Boon RM, Van Garsse LA, Prinzen FW, de Jaegere P. Why permanent pacemaker implantation after transcatheter aortic valve implantation does not affect long-term clinical outcome. J Am Coll Cardiol 2012; 60 (22): 2339-2340.

Seehase M, Houthuizen P, Jellema RK, Collins JJ, Bekers O, Breuer J, Kramer BW. Propofol administration to the fetal-maternal unit reduces cardiac injury in late-preterm lambs subjected to severe prenatal asphyxia and cardiac arrest. Pediatr Res 2013; 73 (4 Pt 1): 427-434.

Strik M, van Middendorp LB, Houthuizen P, Ploux S, van Hunnik A, Kuiper M, Auricchio A, Prinzen FW. Interplay of electrical wavefronts as determinant of the response to cardiac resynchronization therapy in dyssynchronous canine hearts. Circ Arrhythm Electrophysiol 2013; 6 (5): 924-931.

van Middendorp LB, Strik M, Houthuizen P, Kuiper M, Maessen JG, Auricchio A, Prinzen FW. Electrophysiological and hemodynamic effects of vernakalant and flecainide during cardiac resynchronization in dyssynchronous canine hearts. J Cardiovasc Pharmacol 2014; 63 (1): 25-32.

Herold IH, Russo G, Mischi M, Houthuizen P, Saidov T, van Het Veer M, van Assen HC, Korsten HH. Volume quantification by contrast-enhanced ultrasound: an in-vitro comparison with true volumes and thermodilution. Cardiovasc Ultrasound 2010; 11 : 36.

Houthuizen P, de Jaegere P, Prinzen FW. Letter by Houthuizen et al regarding article, "Clinical impact of persistent left bundle-branch block after transcatheter aortic valve implantation with CoreValve revalving system". Circulation 2013; 128 (22): e443.

van der Boon RM, Houthuizen P, Nuis RJ, van Mieghem NM, Prinzen F, de Jaegere PP. Clinical implications of conduction abnormalities and arrhythmias after transcatheter aortic valve implantation. Curr Cardiol Rep 2014; 16 (1): 429.

Houthuizen P, van der Boon RM, Urena M, van Mieghem N, Brueren GB, Poels TT, Van Garsse LA, Rodés-Cabau J, Prinzen FW, de Jaegere P. Occurrence, fate and consequences of ventricular conduction abnormalities after transcatheter aortic valve implantation. EuroIntervention 2014; 9 (10): 1142-1150. 


\section{Abbrevations}





\section{Abbrevations}

\begin{tabular}{|c|c|}
\hline 6MWT & six-minutes walking test \\
\hline AHA & American Heart Association \\
\hline AL & anterolateral \\
\hline AMI & acute myocardial infarction \\
\hline ANOVA & analysis of variance \\
\hline AP & atrial pacing \\
\hline AV & atrioventricular \\
\hline AVR & aortic valve replacement \\
\hline BL & baseline \\
\hline BLOCK-HF & $\begin{array}{l}\text { Biventricular versus Right Ventricular Pacing in Heart Failure } \\
\text { Patients with Atrioventricular Block }\end{array}$ \\
\hline bpm & beats per minute \\
\hline CABG & coronary artery bypass grafting \\
\hline CARE-HF & Cardiac Resynchronization in Heart Failure \\
\hline CASS & Coronary Artery Surgery Study \\
\hline CCF & Cleveland Clinic Foundation \\
\hline CHE & Catharina Hospital Eindhoven \\
\hline $\mathrm{CHF}$ & chronic heart failure \\
\hline CI & confidence interval \\
\hline CLEAR & Clinical Evaluation of Advanced Resynchronization \\
\hline COMPANION & $\begin{array}{l}\text { Comparison of Medical Therapy, Pacing and Defibrillation in } \\
\text { Heart Failure }\end{array}$ \\
\hline COPD & chronic obstructive lung disease \\
\hline CRT & cardiac resynchronization therapy \\
\hline CRT-D & cardiac resynchronization therapy with defibrillator \\
\hline CRT-P & cardiac resynchronization therapy with pacemaker \\
\hline CVA & cerebrovascular accident \\
\hline DAVID & Dual Chamber and VVI Implatable Defibrillator \\
\hline DECREASE-HF & $\begin{array}{l}\text { Device Evaluation of Contak Renewal } 2 \text { and Easytrak 2: Asses- } \\
\text { ment of Safety and Effectiveness in Heart Failure }\end{array}$ \\
\hline ECC & extracorporeal circulation \\
\hline ECG & electrocardiogram \\
\hline EGM & electrogram \\
\hline ES & Edwards SAPIEN \\
\hline ESC & European Society of Cardiology \\
\hline ET & ejection time \\
\hline $\begin{array}{l}\text { EuroSCORE } \\
\text { F }\end{array}$ & $\begin{array}{l}\text { European System for Cardiac Operative Risk Evaluation } \\
\text { female }\end{array}$ \\
\hline
\end{tabular}


FREEDOM Frequent Optimization Study Using the QuickOpt method

HERO-2

$\mathrm{HF}$

Hirulog and Early Reperfusion or Occlusion-2

HTX

heart failure

IABP

ICD

heart transplantation

ICT

intra-aortic balloon pump

IHA

intracardiac defibrillator

isovolumetric contraction time

IHF

IQR

IRT

IVCD

Icelandic Heart Association

JPEG

Irish Heart Foundation

$\mathrm{L}$

LAHB

Lat

LBBB

LBTB

interquartile range

isovolumetric relaxation time

intraventricular conduction delay

Joint Photographics Expert Group

LIFE

LPHB

lateral

left anterior hemiblock

lateral

left bundle branch block

LV

linker bundeltak blok

$\mathrm{LV} \mathrm{dP} / \mathrm{dt}_{\max }$ maximum rate of rise in left ventricular pressure

LVAD

LVEF

Losartan Intervention for Endpoint Reduction in Hypertension

left posterior hemiblock

LVESV

left ventricular assist device

left ventricular ejection fraction

LVOT

$\mathrm{M}$

left ventricular endsystolic volume

left ventricular outflow tract

male

MADIT

MCO

Multicenter Automatic Defibrillation Implantation Trial

MCS

MI

mitral closure to opening

Medtronic CoreValve System

MOST

myocardial infarction

Mode Selection Trial

MPI

myocardial performance index

msec

millisecond

no.

number

nQRS

narrow QRS

NS

non-significant

NYHA New York Heart Association Class

OR odds ratio

P posterior

PAD peripheral artery disease

PAMI Primary Angioplasty in Myocardial Infarction

PARTNER Placement of Aortic Transcatheter Valve 


$\begin{array}{ll}\text { PATH-CHF } & \text { Pacing Therapies for Congestive Heart Failure } \\ \text { PAV } & \text { paced atrioventricular } \\ \text { PCI } & \text { percutaneous coronary intervention } \\ \text { PDF } & \text { Portable Document File } \\ \text { PEA } & \text { peak endocardial acceleration } \\ \text { PL } & \text { posterolateral } \\ \text { PPM } & \text { permanent pacemaker } \\ \text { PRAGMATIC } & \text { Pooled Rotterdam-Milano-Toulouse In Collaboration } \\ \text { RBBB } & \text { right bundle branch block } \\ \text { RESPONSE-HF } & \text { Response of Cardiac Resynchronization Therapy Optimization } \\ & \text { With Ventricle to Ventricle Timing in Heart Failure Patients } \\ \text { RHYTHM-II } & \text { Resynchronization for the Hemodynamic Treatment of Heart } \\ & \text { Failure Management II } \\ \text { RIKS-HIA } & \text { Register of Information and Knowledge about Swedish Inten- } \\ & \text { sive Care Admissions } \\ \text { RR } & \text { relative risk } \\ \text { RV } & \text { right ventricle } \\ \text { RVP } & \text { right ventricular pacing } \\ \text { SAV } & \text { sensed atrioventricular } \\ \text { SAVR } & \text { surgical aortic valve replacement } \\ \text { SD } & \text { standard deviation } \\ \text { SD } & \text { standard deviation } \\ \text { Sep } & \text { septal } \\ \text { SMART-AV } & \text { SmartDelay determined Atrioventricular Optimization } \\ \text { SPSS } & \text { Statistical Package for Social Sciences } \\ \text { SPWMD } & \text { septal to posterior wall motion delay } \\ \text { SU AVR } & \text { sutureless aortic valve replacement } \\ \text { SW } & \text { stroke work } \\ \text { TAVI } & \text { transcatheter aortic valve implantation } \\ \text { TDI } & \text { tissue Doppler imaging } \\ \text { THV } & \text { transcatheter heart valve } \\ \text { UK } & \text { United Kingdom } \\ \text { UMCU } & \text { University Medical Center Utrecht } \\ \text { US } & \text { United States } \\ \text { VARC } & \text { Valve Academic Research Consortium } \\ \text { VTI } & \text { velocity time integral } \\ \text { VV } & \text { ventriculo-ventricular } \\ \text { WWII } & \text { World War II } \\ & \end{array}$

